\title{
SUPPLEMENTATION IN THE COLUMBIA BASIN SUMMARY REPORT SERIES
}

\author{
FINAL REPORT
}

Prepared for:

U.S. Department of Energy

Bonneville Power Administration

Division of Fish and Wildlife

P.O. Box 3621

Portland. OR 97283-3621

Project Number 85-62

Contract Number DE-AC06-75RL01830

DECEMBER 1992 


\section{RASP CONTRIBUTORS}

Scientists with expertise and interest in supplementation have contributed to this report, among them are: Tom Backman, Ed Bowles, Craig Busack, Rich Carmichael, Duane Fickeisen, Larry Lestelle, Jim Lichatowich, Rich Lincoln, Lars Mobrand, Willa Nehlsen, Rich Turner, Tom Vogel, Harry Wagner, and Bruce Watson. Numerous constructive and insightful comments to previous drafts were also received from the Scientific Review Group. 


\section{PAR T I}

BACKGROUND, DESCRIPTION, PERFORMANCE MEASURES, UNCERTAINTY AND THEORY

\section{PART II}

SUPPLEMENTATION THEORY

\section{PART III}

PLANNING GUIDELINES

\section{PART IV}

DESCRIPTION OF A SUPPLEMENTATION MODEL AND REGIONAL COORDINATION OF RESEARCH AND MONITORING

\section{PART V}

APPENDICES 


\section{RASP SUMMARY REPORT SERIES PART I}

BACKGROUND, DESCRIPTION, PERFORMANCE MEASURES, UNCERTAINTY AND THEORY

December, 1992 


\section{TABLE OF CONTENTS}

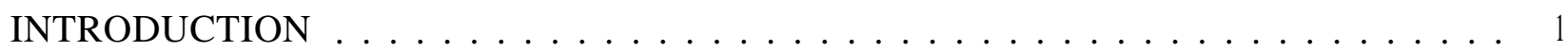

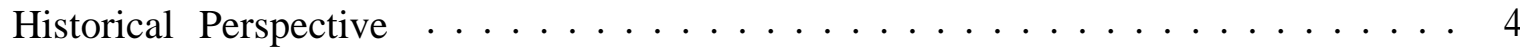

Review of Recent Work ...................... 5

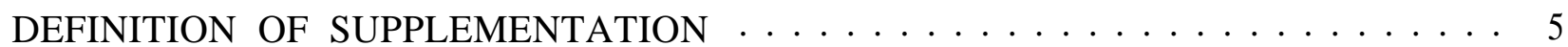

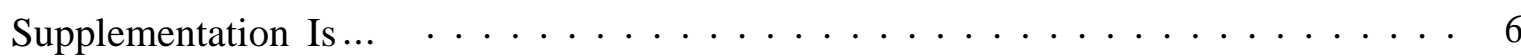

Supplementation Is Not. ..................... 7

DESCRIPTION OF SUPPLEMENTATION PROJECTS $\ldots \ldots \ldots \ldots \ldots \ldots$

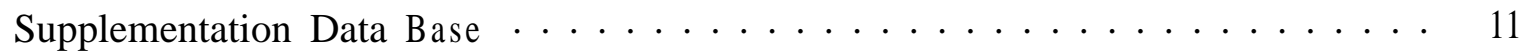

OBJECTIVES AND PERFORMANCE STANDARDS .............. 11

Post-Release Survival . . . . . . . . . . . . . . . . . . . . 19

Reproductive Success . . . . . . . . . . . . . . . . . . . 19

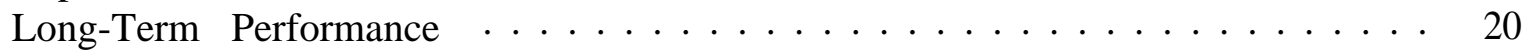

Ecological Interactions . . . . . . . . . . . . . . . 20

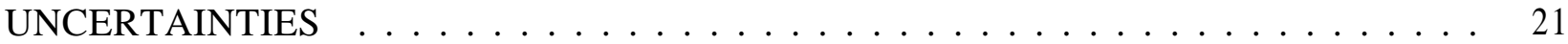

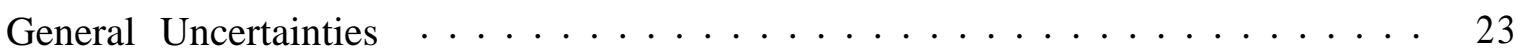

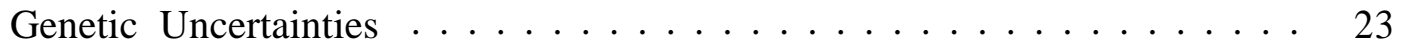

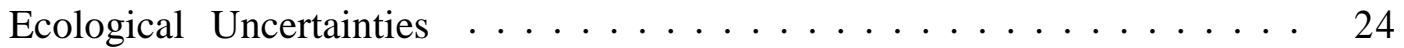

Identifying Supplementation Uncertainties . . . . . . . . . . . 25

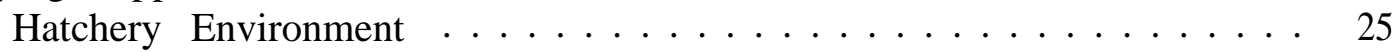

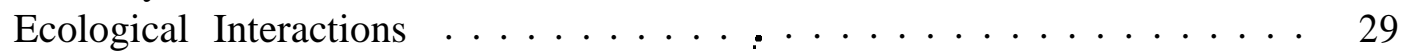

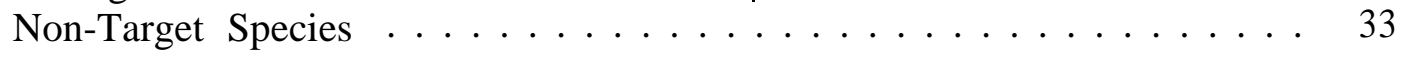

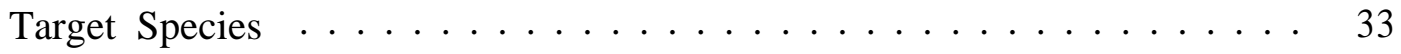

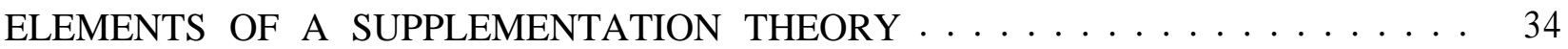

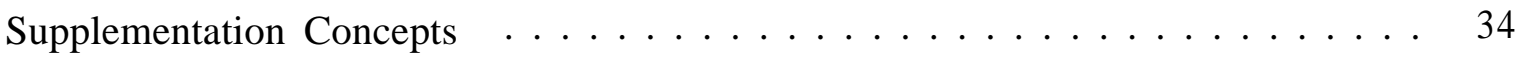

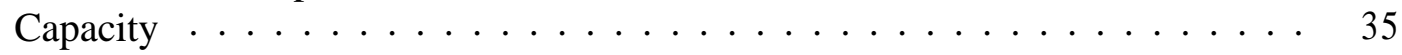

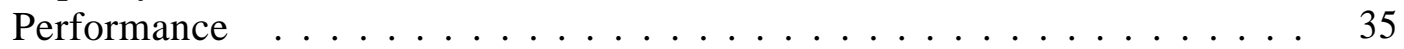

Stock-Recruit Relationship . . . . . . . . . . . . . 35

Stock-Recruitment Models . . . . . . . . . . . . . . . . . . 36

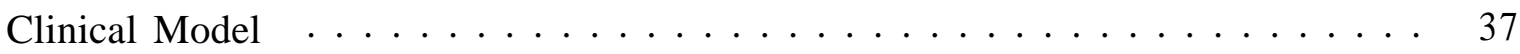

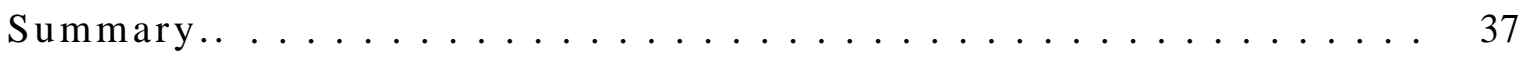

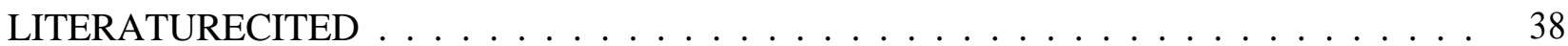

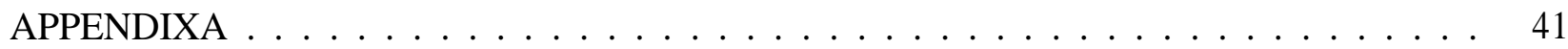




\title{
RASP SUMMARY REPORT SERIES: PART I.
}

\section{BACKGROUND, DESCRIPTION, PERFORMANCE MEASURES, UNCERTAINTY AND THEORY}

\author{
INTRODUCTION
}

This progress report broadly defines the scope of supplementation plans and activities in the Columbia Basin. It provides the foundation for more detailed analysis of supplementation in subsequent reports in this series. Topics included in this report are: definition of supplementation, project diversity, objectives and performance standards, uncertainties and theory. Since this is a progress report, the content is subject to modification with new information. The supplementation theory will continue to evolve throughout the duration of RASP and beyond. The other topics in this report are essentially complete and are not expected to change significantly.

This is the first of a series of four reports which will summarize information contained in the larger, RASP progress and completion reports. Our goal is to make the findings of RASP more accessible by grouping related topics into smaller but complete narratives on important aspects of supplementation. We are planning to publish the following reports under the general title Supplementation in the Columbia River Basin: Part 1, Background, Description, Performance Measures, Uncertainty and Theory; Part 2, Theoretical Framework and Models; Part 3, Planning Guidelines; and Part 4, Regional Coordination of Research and Monitoring.

Supplementation is expected to be a major contributor to the planned increase in salmon and steelhead production in the Columbia Basin. The Fish and Wildlife Program of the Northwest Power Planning Council (NPPC) uses three approaches to protect and enhance salmon and steelhead in the Columbia Basin: 1) enhance fish production; 2) improve passage in the mainstem rivers; and 3) revise harvest management to support the rebuilding of fish runs (NPPC 1987). The fish production segment calls for a three-part approach focused on natural production, hatchery production, and supplementation. Supplementation is planned to provide over half of the total production increases. (Table 1). 
Table 1. Percent of production increases attributable to supplementation' in System Planning. Computed from System Planning Model output (data supplied by Duane Anderson, NPPC).

\begin{tabular}{|c|c|c|c|c|c|}
\hline \multirow[b]{2}{*}{ Species/Stock } & \multicolumn{5}{|c|}{ Columbia River Region } \\
\hline & Lower & Mid & Snake & Upper & All \\
\hline Late Coho & $97.7 \%$ & - & - & - & $97.7 \%$ \\
\hline Early Coho & $100.0 \%$ & $100.0 \%$ & b & - & $100.0 \%$ \\
\hline Fall Chinook & $0.0 \%$ & $37.4 \%$ & $51.2 \%$ & $0.0 \%$ & $8.6 \%$ \\
\hline Spring Chinook & $88.4 \%$ & $64.0 \%$ & $74.3 \%$ & $34.7 \%$ & $65.4 \%$ \\
\hline Summer Chinook & & $6.3 \%$ & $66.9 \%$ & $38.4 \%$ & $43.5 \%$ \\
\hline Summer Steelhead A & $100.0 \%$ & $25.6 \%$ & $95.5 \%$ & $73.9 \%$ & $71.8 \%$ \\
\hline Summer Steelhead B & & & $72.0 \%$ & - & $72.0 \%$ \\
\hline Winter $S$ teelhead & $48.0 \%$ & $100.0 \%$ & - & & $60.2 \%$ \\
\hline All & $45.4 \%$ & $47.5 \%$ & $78.2 \%$ & $34.5 \%$ & $52.4 \%$ \\
\hline
\end{tabular}

The Regional Assessment of Supplementation Project (RASP) was initiated as a result of a request by NPPC to address long-standing concerns about the need to coordinate supplementation research, monitoring and evaluation. Such coordination was also recommended by the Supplementation Technical Work Group.

In August 1990, the NPPC gave conditional approval to proceed with the final design of the Yakima Production Project. The Council called on the Bonneville Power Administration (BPA) to "fund immediately a supplementation assessment to reevaluate, prioritize and coordinate all existing and planned supplementation monitoring and evaluation activities in the basin.. . Provid[ing] for the participation of the fishery agencies and tribes and others having expertise in this area.

'Supplementaion projects in System Planning do not necessarily meet the RASP definition.

RASP Summary Report Series, Part I: Background, Description, Performance Measures, Uncertainty, Theory December, 1992 i Page 2 
RASP addresses four principal objectives:

- $\quad$ provide an overview of ongoing and planned supplementation activities and identify critical uncertainties associated with supplementation,

- $\quad$ construct a conceptual framework and model which estimates the potential benefits and risks of supplementation and prioritizes uncertainties,

- $\quad$ provide guidelines for the development of supplementation projects,

- $\quad$ develop a plan for regional coordination of research and monitoring.

These objectives, once attained, will provide the technical tools fishery managers need to carry out the Council's direction to protect and enhance salmon and steelhead.

RASP has further divided the four broad objectives into 12 technical topics:

- definition of supplementation

- description of the diversity of supplementation projects

- $\quad$ objectives and performance standards

- $\quad$ identification of uncertainties

- $\quad$ supplementation theory

- development of a conceptual model of supplemented populations

- development of spreadsheet model of risks and benefits of supplementation

- $\quad$ classification of stocks, streams, and supplementation strategies

- $\quad$ regional design of supplementation evaluation and monitoring

- $\quad$ guidelines for planning supplementation projects

- $\quad$ application of the spreadsheet model to supplementation planning

- $\quad$ experimental design and decision making with uncertainty

RASP Summary Report Series, Part I: Background, Description, Performance Measures, Uncertainty, Theory December, 1992 / Page 3 
Progress in each topic area-is presented in regular progress reports which are available from the Bonneville Power Administration.

\section{Historical Perspective}

Recent supplementation initiatives in the Columbia River Basin are embedded in a larger historical context and a changing management paradigm. Policies that will guide the Council's program to rebuild salmon and steelhead populations in the Columbia Basin reflect evolving management standards. Those policies express concern over the conservation of genetic resources, the need to integrate natural and artificial propagation in the basin, a recognition of the need to address mainstem survival and harvest management, and the need to approach restoration with an integrated, system wide program within the framework of an adaptive management policy (NPPC 1987). Emphasis on conservation of genetic resources is consistent with the results of a Council-sponsored workshop which concluded that salmon production goals for the basin can only be achieved and sustained if the genetic resources of the basin's remaining salmon stocks are maintained (Riggs 1990). Developing and implementing production initiatives consistent with the Council's policies, in particular genetic conservation, clearly calls for new thinking, new approaches and new performance measures in the basin's salmon and steelhead restoration programs.

Salmonids have been artificially propagated in the Columbia Basin for over 100 years. Throughout that period hatcheries were the major tool of managers who used them to supply the fishing industry with commodity and replace production lost through habitat destruction. The early research focused on hatchery practices and the production of a healthy smolt in the hatchery. The interaction between hatchery programs and wild stock conservation was not given careful consideration.

The recent emphasis on supplementation to revitalize natural production in the basin (Table 1), the precarious status of several stocks of salmon and steelhead (Nehlsen et al. 1991), and the commitment to double total production in the basin (NPPC 1987), has reaffirmed the importance of hatcheries in the Columbia's salmon production system. Hatcheries will remain important in their traditional roles and supplementation will give them new roles. Hatchery programs, especially supplementation, will be evaluated by new performance standards which will include ecological as well as genetic criteria. For examples of these changes, see the supplementation section of the Integrated System Plan (CBFWA 1991); Oregon's Natural Production and Wild Fish Management Rules (Oregon Administrative Rules 635-07-501 through 529 and 635-07-800 through 815) and Idaho's Anadromous Fishery Management Plan (Idaho Department of fish and Game 199 1).

The hatchery program is facing its greatest challenge since the 1940's when it became generally accepted procedure to rear salmon to full term smolts to achieve the highest 
survival. The transition from making fry or sac fry releases to rearing full term smolts required better understanding of nutritional requirements of salmon and disease control, prevention, and treatment. In addition, many of the early hatcheries were designed for fry release and did not have the year-round water supplies needed for smolt production (Oregon Fish Commission 1955).

The manager's new challenge is to learn how to integrate the artificial and natural salmon production systems in the Columbia Basin to produce sustainable increases in total production. This will call for new ideas in the physical design and operation of hatcheries as well as a better technical understanding of genetics, behavior, competition, and predation fields that were not strongly emphasized in the domain of artificial propagation until recently.

These fundamental changes in management strategies are not easy to accommodate. Managers are faced with major new challenges while at the same time the conventional wisdom they relied on is challenged and weakened.

\section{Review of Recent Work}

The emphasis on supplementation as a tool to restore natural production and concern about the erosion of genetic resources has produced a rapidly growing literature. RASP has summarized selected publications using a format that makes the information relevant to supplementation readily available to the manager. The summaries give each paper's contribution to eight areas of importance to supplementation: definition of supplementation, description of project diversity, planning recommendations, performance standards, genetic uncertainties, physiological and behavioral uncertainties, research and monitoring, and recommendations (see Appendix A).

\section{DEFINITION OF SUPPLEMENTATION}

The Scientific Review Group (SRG) ${ }^{2}$ recognized the need for a clear definition and agreement on what is meant by supplementation (SRG 1990). Current definitions of supplementation vary and are not sufficiently specific to be helpful to the development of performance standards and the design of evaluation studies. RASP agreed with the findings of the SRG and recognized the need for a clear working definition of supplementation.

$\mathbf{2}$ The Scientific Review Group is a panel of senior-level scientists that provides scientific and technical advice and recommendations to BPA and the Policy Review Group on implementation of the Fish and Wildlife Program.

RASP Summary Report Series, Part I: Background, Description, Performance Measures, Uncertainty, Theory December, 1992 / Page 5 
RASP developed the following definition of supplementation:

\section{"Supplementation is the use of artificial propagation in the attempt to maintain or increase natural production while maintaining the long term fitness of the target population, and keeping the ecological and genetic impacts on non-target populations within specified biological limits."}

Recent publications have used other definitions, which are presented for comparison:

- "The release of fish from hatcheries at locations away from the hatchery to increase natural production in streams determined to be seeded or used at less than 'optimal levels'." (Smith et al. 1985)

- "Planting all life stages of hatchery fish to enhance wild/natural stocks of anadromous salmonids." (Miller et al. 1990)

- $\quad$ "Supplementation is usually undertaken to provide harvestable surpluses of fish from stocks that may not otherwise naturally produce sufficient fish to meet the demand from fishermen. Management opportunities range from rebuilding threatened or endangered wild stocks to bolstering already self sufficient natural runs. Hatchery fish used to supplement wild stocks of salmonids are stocked at egg, fry fingerling, smolt and adult life stages." (Steward and Bjomn 1990)

In its definition, RASP limited the scope of supplementation to those activities carried out with the explicit intention of maintaining or increasing natural production by means of artificial propagation. Excluded from the RASP definition is the unplanned addition of hatchery-reared fish to natural populations.

\section{Supplementation Is.. .}

Supplementation refers to strategies for increasing natural production by taking fish into a protected artificial environment for a portion of their life cycle and then releasing them, or their progeny, into streams where they are later expected to reproduce naturally.

Supplementation encompasses a wide range of management characterized by four general objectives (SRG 1990):

- Restoration: the restoration of a native species to habitats where it has been extirpated. 
- Introduction: planting a species into habitat where it was not native.

- $\quad$ Rearing Augmentation: planting fish in habitat that is under utilized.

- Harvest Augmentation: planting fish for the purpose of increasing harvest.

Within the context of those broad objectives supplementation attempts to provide a net survival benefit to the target stock. To provide that benefit, supplementation must circumvent part of the early natural mortality while preserving the natural processes that maintain long term performance of the stock and sustainability of natural production.

What distinguishes supplementation from other management activities is the assumption that artificial propagation can be used to improve the production of naturally-spawning populations without adverse genetic or ecological effects. At a minimum, supplementation programs are designed to conserve the genetic identity and variability of the target population and to hold the competitive and predatory impacts on other populations within prescribed limits. Supplementation may employ one or more of many different strategies and life stages.

\section{Supplementation Is Not.. .}

Supplementation and conventional hatchery programs differ in the goals they set for the use of returning adults. The typical goal of the conventional hatchery is to maximize adult production for harvest while assuring the collection of adequate broodstock. In the past, there has been no acceptable limitation of the impacts of hatchery programs on natural production.

Supplementation is differentiated from other artificial attempts to increase natural production by the required elements of artificial spawning or rearing. We have defined "artificial" as "the substitution of human activity occurring in a man-made environment for voluntary behavior by fish in a natural stream. "

\section{DESCRIPTION OF SUPPLEMENTATION PROJECTS}

A number of ongoing and planned supplementation projects in Washington, Idaho and Oregon which are called supplementation are summarized in Table 2. All the stocks/streams listed in Table 2 will be supplemented, however, in many of the supplementation projects, the associated evaluation includes unsupplemented control streams. Those streams are not included in the table, but they are included in the supplementation data base compiled by RASP. 
able 2.

Ongoing and planned_supplementation_projects

\begin{tabular}{|c|c|c|c|c|}
\hline & Stream & species & Project/Agency & Status \\
\hline $\mathbf{1}$ & upper Yaloima River & Spring Chinook & Yakima/Kickital Fisheries Project & Planned \\
\hline 2 & NachesRiver & Spring Chinook & Yalima/Klickitat Fisheries Project & Planned \\
\hline 3 & $\begin{array}{l}\text { salmon River, } \\
\text { Alturas Lake Creek; } \\
\text { Firt Generation }\end{array}$ & SpringChinook & Idaho Supplementation Studiea & Planned \\
\hline 4 & $\begin{array}{l}\text { Eaxt Fork Salmon River; } \\
\text { Firc Generation }\end{array}$ & Spring Chinook & Idah@upplementatiosstudies & Planned \\
\hline 5 & $\begin{array}{l}\text { Salmon River, } \\
\text { Alturas Lake Creek; } \\
\text { Second Generation }\end{array}$ & Spring Chinook & IdahoSupplementationStudies & Planned \\
\hline 6 & $\begin{array}{l}\text { Eact Fork Salmon River; } \\
\text { Second Generation }\end{array}$ & Spring Chinook & Idaho SupplementationStudies & Planned \\
\hline 7 & $\begin{array}{l}\text { West Fork Yankee Fork: } \\
\text { First Generation }\end{array}$ & Spring Chinook & Idaho Supplementation Studiea & Planned \\
\hline 8 & $\begin{array}{l}\text { Weat Fork Yankee Fork; } \\
\text { SecondGeneration }\end{array}$ & Spring Ckinook & Idaho Supplementation Studies & Planned \\
\hline 9 & Clear Creek & Spring Chinook & IdahoSupplementationStudies & Planned \\
\hline 10 & $\begin{array}{l}\text { Red River; } \\
\text { First Generation }\end{array}$ & Spring Chinook & IdahoSupplementationStudies & Planned \\
\hline 11 & $\begin{array}{l}\text { Red River; } \\
\text { Second Generation }\end{array}$ & Spring Chinook & IdahoSupplementation Studies & Planned \\
\hline 12 & American River & Spring Chinook & IdahoSupplementationStudies & Planned \\
\hline 13 & $\begin{array}{l}\text { Crooked River; } \\
\text { First Generation }\end{array}$ & Spring Chinook & Idaho Supplementation Studies & Planned \\
\hline 14 & $\begin{array}{l}\text { Crooked River; } \\
\text { Second Generation }\end{array}$ & Spring Chinook & IdahoSupplementationStudies & Planned \\
\hline 15 & Papoose Creek & Spring Chinook & Idaho Supplementation Studies & Planned \\
\hline 16 & Pete King Creek & Spring Chinook & Idaho Supplementation Studies & Planned \\
\hline 17 & SquewCreek & Spring Chinook & IdahoSupplementationStudie & Planned \\
\hline 18 & White Sand Creek & Spring Chinook & IdahoSupplementationStudies & Planned \\
\hline 19 & Big Flat Creek & Spring Chinook & IdahoSupplementation Studies & Planned \\
\hline 20 & Crooked Fork Creek & Spring Chinook & IdahoSupplementationStudies & Planned \\
\hline 21 & $\begin{array}{l}\text { LemhiRiver; } \\
\text { Smolt Rd - Only }\end{array}$ & Spring Chinook & Idaho Supplementation Studied & Planned \\
\hline 22 & $\begin{array}{l}\text { Lemhi River; } \\
\text { ParrReleasea; } \\
\text { Fii Generation }\end{array}$ & SpringChinook & Idaho Supplementation Studia & Plonned \\
\hline 23 & $\begin{array}{l}\text { Lemhi R.; } \\
\text { Smolt: When Used With } \\
\text { Parr; } \\
\text { Fii Generation }\end{array}$ & Spring Chinook & IdahoSupplementationStudie & Planned \\
\hline 24 & Hood River & Spring Ckinook & Hood River Spring Chinook Project & Ongoing \\
\hline $\mathbf{2 5}$ & UmatillaRiver & Spring Ckinook & Umatilla Spring Chinook Project & Ongoing \\
\hline 26 & Catherine Cr. & Spring Ckinook & Catherine Cr. Spring Chinook Project & Planned \\
\hline
\end{tabular}




\begin{tabular}{|c|c|c|c|c|}
\hline & Stream & Species & Project/Agency & Status \\
\hline$: 7$ & Lookinglaes Cr. & Spring Chinook & $\begin{array}{l}\text { Lookinglas Cr. Spring Chinook } \\
\text { ReintroductionProject }\end{array}$ & Planned \\
\hline 18 & Lostine River & Spring Chinook & Lodine River Spring Chinook Project & Planned \\
\hline 49 & Klichitat River & Spring Chinook & Yakima/Klickitat Fisheriea Project & Planned \\
\hline 30 & Chiwawa River & Spring Chinook & Eastbank; Chelan Co. PUD & Ongoing \\
\hline 31 & TwispRiver & Spring Chinook & Methoa Hatchery; Douglas Co. PUD & Planned \\
\hline 32 & Chewack River & SpringChinook & Methow Hatchery, Douglas Co. PUD & Planned \\
\hline 33 & Methoa River & Spring Chinook & Methow Hatchery; Douglas Co. PUD. & Planned \\
\hline 34 & Tucannon River & Spring Chinook & Tucannon; Lower Snake River Comp. Plan & Ongoing \\
\hline 35 & Slate Creek & Spring Chinook & Nez Perce Tribal Hatchery Supplmentation Project & Planned \\
\hline 36 & Meadow Cr./Selway River & Spring Chinook & Nez Perce Tribal Fatchery Supplmentation Project & Planned \\
\hline 37 & $\begin{array}{l}\text { Meadow Cr./S.F. } \\
\text { ClearwaterRiver }\end{array}$ & Spring Chinook & Nez Perce Tribal Hatchery Supplmentation Project & Planned \\
\hline 38 & $\begin{array}{l}\text { Newsome Creek/S.F. } \\
\text { ClearwaterRiver }\end{array}$ & Spring Chinook & Nez Perce Tribal Hatchery Supplmentation Project & Planned \\
\hline 39 & Mill Creek & Spring Chinook & Nez Perce Tribel Hatchery Supplmentation Project & Planned \\
\hline 40 & Slate Creek & Spring Chinook & Nez Perce Tribal Fatchery Supplmentation Project & Planned \\
\hline 41 & Lolo Creek & Spring Chinook & Nez Perce Tribal Hatchery Supplmentation Project & Planned \\
\hline 42 & ImnahaRiver & $\begin{array}{l}\text { Summer } \\
\text { Chinook }\end{array}$ & Imnaha Spring Chinook Supplementation Project & Ongoing \\
\hline 43 & $\begin{array}{l}\text { Upper S.F.Salmon R.; } \\
\text { First Generation }\end{array}$ & $\begin{array}{l}\text { Summer } \\
\text { Chinook }\end{array}$ & IdahoSupplementaionStudies & Planned \\
\hline 44 & $\begin{array}{l}\text { Upper s.F. Salmon R.; } \\
\text { Second Generation }\end{array}$ & $\begin{array}{l}\text { Summer } \\
\text { Chinook }\end{array}$ & IdahoSupplementationStudie: & Planned \\
\hline 45 & $\begin{array}{l}\text { PahnimeroiRiver; } \\
\text { Fird Generation }\end{array}$ & $\begin{array}{l}\text { Summer } \\
\text { Chinook }\end{array}$ & Idaho Supplementation Studies & Planned \\
\hline 46 & $\begin{array}{l}\text { PahsimeroiRiver; } \\
\text { Second Generation }\end{array}$ & $\begin{array}{l}\text { Summer } \\
\text { Chinook }\end{array}$ & IdahoSupplementation Studies & Plonned \\
\hline 47 & WenatcheeRiver & $\begin{array}{l}\text { Summer } \\
\text { Chinook }\end{array}$ & Eastbank; Chelan Co. Pud & Ongoing \\
\hline 48 & MethowRiver & $\begin{array}{l}\text { Summer } \\
\text { Chinook }\end{array}$ & Eastbank, Chelan Co. Pud. & Ongoing \\
\hline 49 & OknnoganRiver & $\begin{array}{l}\text { Summer } \\
\text { Chinook }\end{array}$ & Fastbank, Chelan Co. Pud. & Ongoing \\
\hline $\mathbf{5 0}$ & $\begin{array}{l}\text { Lower Naches R. \& } \\
\text { Middle Yalimn R. }\end{array}$ & $\begin{array}{l}\text { Summer } \\
\text { Chinook }\end{array}$ & Yakima/Kickitat Production Project & Planned \\
\hline 51 & Meadow Cr./Selway River & $\begin{array}{l}\text { Surnmer } \\
\text { Chinook }\end{array}$ & Nea Pem Tribal Hatchery' Supplmentation Project & Plonned \\
\hline 52 & UmatilloRiver & Fell Chinook & UmatillaFallChinookSupplementation Program & Ongoing \\
\hline $\mathbf{5 3}$ & $\begin{array}{l}\text { Lower Mainatem Yakima } \\
\text { River }\end{array}$ & Fell Chinook & Yakima/Kickitat Fisheries Project & Planned \\
\hline 54 & $\begin{array}{l}\text { Upper Maindem Yalrima } \\
\text { River }\end{array}$ & Fall Chinook & Yalima/Kickitat Fisheries Project & Plonned \\
\hline
\end{tabular}




\begin{tabular}{|c|c|c|c|c|}
\hline & Stream & species & Project/Agency & Status \\
\hline 55 & $\begin{array}{l}\text { S.F.ClearwaterRiver } \\
\text { at Luke'» Gulch }\end{array}$ & Fall Chinook & Nea Perce Tribal Hetchery Supplmentation Project & Planned \\
\hline 56 & $\begin{array}{l}\text { Selway River at USFS } \\
\text { Fenn Ranger Station }\end{array}$ & Fall Chinook & NezPerce Tribal Hatchery Supplmentulion Project & Planned \\
\hline 57 & $\begin{array}{l}\text { Lapwai Creek at } \\
\text { Confluesce With } \\
\text { Clearwater River }\end{array}$ & FallChinook & Nez Perce Tribal Hatchery Supplmentation Project & Planned \\
\hline 58 & $\begin{array}{l}\text { Lolo Creek at Confluence } \\
\text { with Clearwater River }\end{array}$ & Fall Chinook & Nex Perce Tribal Hatchery Supplmentation Project & Planned \\
\hline 59 & Upper Yakime River & $\begin{array}{l}\text { Summer } \\
\text { Steelhead A-run }\end{array}$ & Yakima/Klickitat Fisheries Project & Plonned \\
\hline 60 & ToppeninhCreek & $\begin{array}{l}\text { Summer } \\
\text { Steelhead A-run }\end{array}$ & Yakima/Klickitat Fieheries Project & Planned \\
\hline 61 & NachesRiver & $\begin{array}{l}\text { Summer } \\
\text { Steelhead A-run }\end{array}$ & Yakima/Klickitat Fisheries Project & Plonned \\
\hline 62 & Hood River & $\begin{array}{l}\text { Summer } \\
\text { Steelhead A-run }\end{array}$ & $\begin{array}{l}\text { Hood River Summer St\&end Supplementation } \\
\text { Project }\end{array}$ & Ongoing \\
\hline 63 & UmatilleRiver & $\begin{array}{l}\text { Summer } \\
\text { Steelhead A-run }\end{array}$ & Umatilla Summer Steelhead Supplementation Project & Ongoing \\
\hline 64 & Little Sheep Creek & $\begin{array}{l}\text { Summer } \\
\text { Steelhead A-run }\end{array}$ & $\begin{array}{l}\text { Imnaha River Summer Steelhead Supplementation } \\
\text { Project }\end{array}$ & Ongoing \\
\hline 65 & Catherine Creek & $\begin{array}{l}\text { Summer } \\
\text { Steelhead A-run }\end{array}$ & NE Oregon Steelhead Supplementation Project & Planned \\
\hline 66 & Deer Creek & $\begin{array}{l}\text { Summer } \\
\text { Steelhead A-run }\end{array}$ & NE Oregon Steelhead Supplementation Project & Planned \\
\hline 67 & Fly Creek & $\begin{array}{l}\text { Summer } \\
\text { Steelhead A-run }\end{array}$ & NE Oregon Steelhead Supplementation Project & Ongoing \\
\hline 68 & IndianCreek & $\begin{array}{l}\text { summer } \\
\text { Steelhead A-run }\end{array}$ & NE Oregon Steelhead Supplementation Project & Ongoing \\
\hline 69 & $\begin{array}{l}\text { Klickitat Mainstem \& } \\
\text { Tributaries }\end{array}$ & $\begin{array}{l}\text { Summer } \\
\text { Steellhead A-run }\end{array}$ & Yakima/Klickitat Fisheries Project & Planned \\
\hline 70 & Hood River & $\begin{array}{l}\text { Winter } \\
\text { Steelhead }\end{array}$ & $\begin{array}{l}\text { Hood River Winter Steelhead Supplementation } \\
\text { Program }\end{array}$ & Planned \\
\hline 71 & Lake Wenatchee & Sockeye & Eactbank, Chelen Co. Pud. & Ongoing \\
\hline 72 & $\begin{array}{l}\text { Naches River \& } \\
\text { Tributaries }\end{array}$ & Coho & Yakima/Kliclitat Fisheries Project & Planned \\
\hline 73 & $\begin{array}{l}\text { Middle Maindem, } \\
\text { Yakima River }\end{array}$ & Cobo & Yalima/Xicloitat Fisheriea Project & Planned \\
\hline
\end{tabular}


A number of ongoing outplanting programs were excluded from Table 2 because they are intended primarily to augment harvest, not natural production. Some harvest augmentation programs will be replaced with "true" supplementation projects; in those instances, only the planned project was included.

\section{Supplementation Data Base}

A computer program ("SUPQUEST") was developed to gather data on stocks, streams and strategies for existing and planned supplementation projects. Copies of the program were distributed to project leaders for data collection. A disk containing the actual computerized questionnaire and the data base generated from it can be obtained from the Bonneville Power Administration. In addition to the questionnaire, data collected in the System Planning Process was incorporated into the supplementation data base.

Information collected to date shows that the purpose of most of the projects is to supplement spring, fall and summer chinook and summer steelhead (Figure 1). To provide a broad picture of supplementation in the basin, we have arranged the information from the questionnaire into three major categories: description of stocks to be supplemented, description of the stream and the supplementation strategies to be employed. Figures $2-7$ display part of the information from the data base.

\section{OBJECTIVES AND PERFORMANCE STANDARDS}

This section describes the objectives of supplementation and how progress toward the objectives will be measured. Supplementation planning must produce objectives that are socially useful and technically sound, and they must be stated in a way that permits measurement of performance and progress. Performance standards should provide insight into the mechanisms that determine success or failure. Performance standards therefore must reflect biological or ecological significance as well as economic and social benefit.

Supplementation is relatively new. It is a largely untested means of integrating natural and artificial production to achieve sustainable increases in productivity (CBFWA 1991). Since fishery managers do not have extensive experience in the implementation and evaluation of supplementation, project planning, in particular the development of objectives and performance standards, assumes increased importance.

The four general objectives of supplementation (restoration, introduction, rearing augmentation, and harvest augmentation) are useful in discriminating projects at a gross 


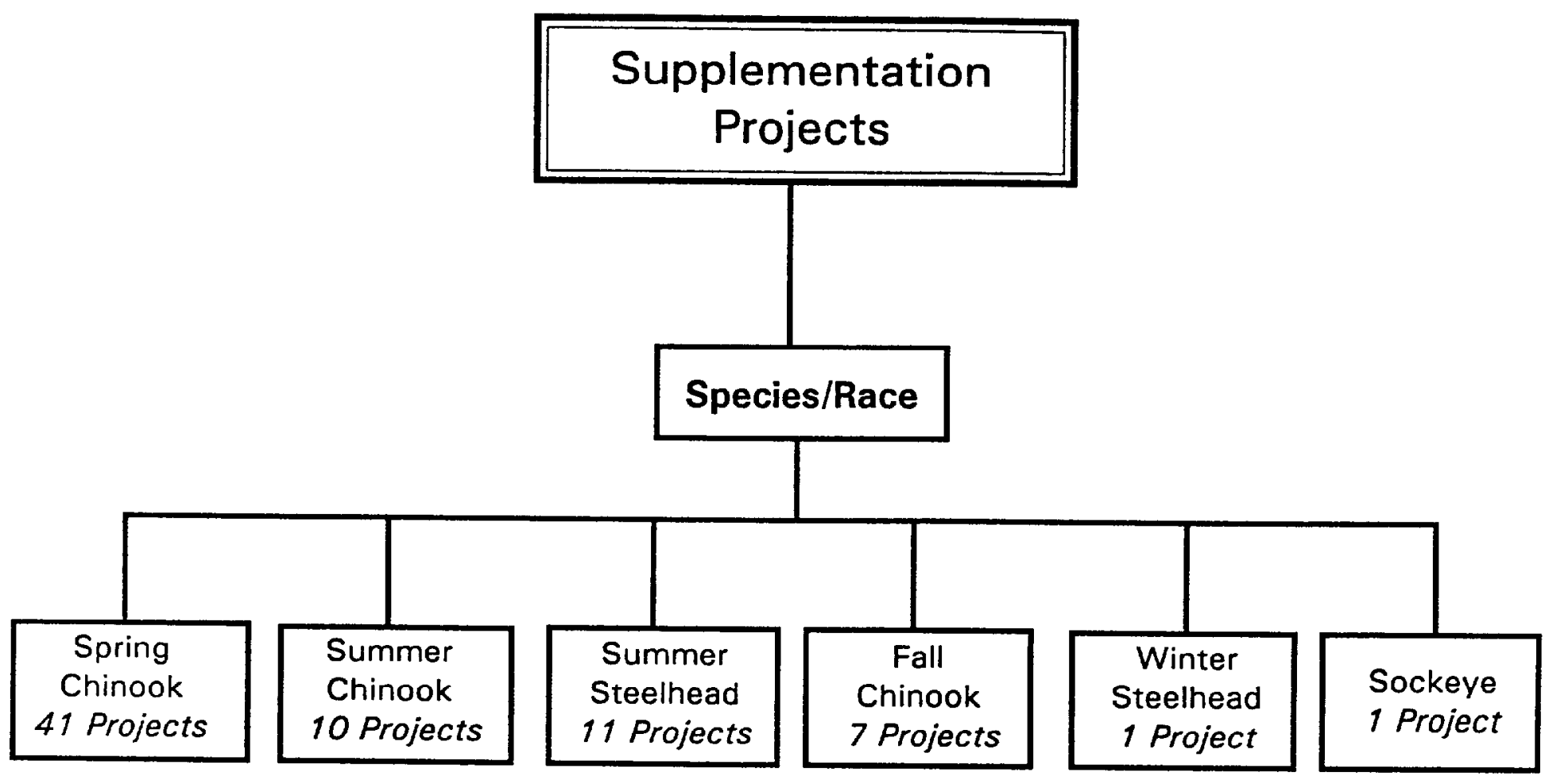

Figure 1. Distribution of supplementation projects among the species and races of salmon and steelhead. 


\section{Spring Chinook}

41 Projects

\begin{tabular}{|c|c|}
\hline Char & $\begin{array}{l}\text { Stock } \\
\text { acteristic }\end{array}$ \\
\hline $\begin{array}{l}\text { Population } \\
\text { Trend } \\
\text { Declining } \\
\text { Stable } \\
\text { Increasing } \\
\text { Extinct or } \\
\text { marainal } \\
\end{array}$ & $\begin{array}{l}\text { Trend } \\
\begin{array}{|c|}\text { No. Stocks } \\
27 \\
4 \\
0 \\
10 \\
\end{array}\end{array}$ \\
\hline \multicolumn{2}{|l|}{ Stock Status } \\
\hline \multicolumn{2}{|c|}{$\begin{array}{l}\text { Current prod. } \\
\text { as \% of carryl No. } \\
\text { ing capacity } \\
\text { intocks }\end{array}$} \\
\hline $\begin{array}{l}<20 \% \\
20-50 \% \\
>50 \% \\
\text { Extinct or } \\
\text { marginal }\end{array}$ & $\begin{array}{r}29 \\
4 \\
2 \\
6 \\
\end{array}$ \\
\hline \multicolumn{2}{|c|}{$\begin{array}{l}\text { Smolt Survival from } \\
\text { Release to Below } \\
\text { Bonneville Dam }\end{array}$} \\
\hline Survival & No. Stocks \\
\hline $\begin{array}{l}10-15 \% \\
15-20 \% \\
20-25 \% \\
2530 \% \\
30-35 \% \\
4550 \% \\
8690 \%\end{array}$ & $\begin{array}{r}26 \\
5 \\
1 \\
4 \\
2 \\
1 \\
2\end{array}$ \\
\hline \multicolumn{2}{|c|}{$\begin{array}{l}\text { Mean Fecundity per } \\
\text { Adult }\end{array}$} \\
\hline $\begin{array}{c}\text { Eggs } \\
1900-2100 \\
2100-2300 \\
2300-2500 \\
2500-2700 \\
2700-2900 \\
2900-3100 \\
3800-3900\end{array}$ & \begin{tabular}{|c|c|} 
No.Stocks \\
& 21 \\
& 9 \\
0 & 5 \\
0 & 1 \\
0 & 3 \\
0 & 1 \\
0 & 1
\end{tabular} \\
\hline \multicolumn{2}{|c|}{ Stock History } \\
\hline Status & No. Stocks \\
\hline $\begin{array}{l}\text { Native } \\
\text { Nat./Hatch } \\
\text { Introduced } \\
\text { Extinct or } \\
\text { marginal }\end{array}$ & $\begin{array}{c}8 \\
12 \\
15 \\
\\
6 \\
\end{array}$ \\
\hline
\end{tabular}

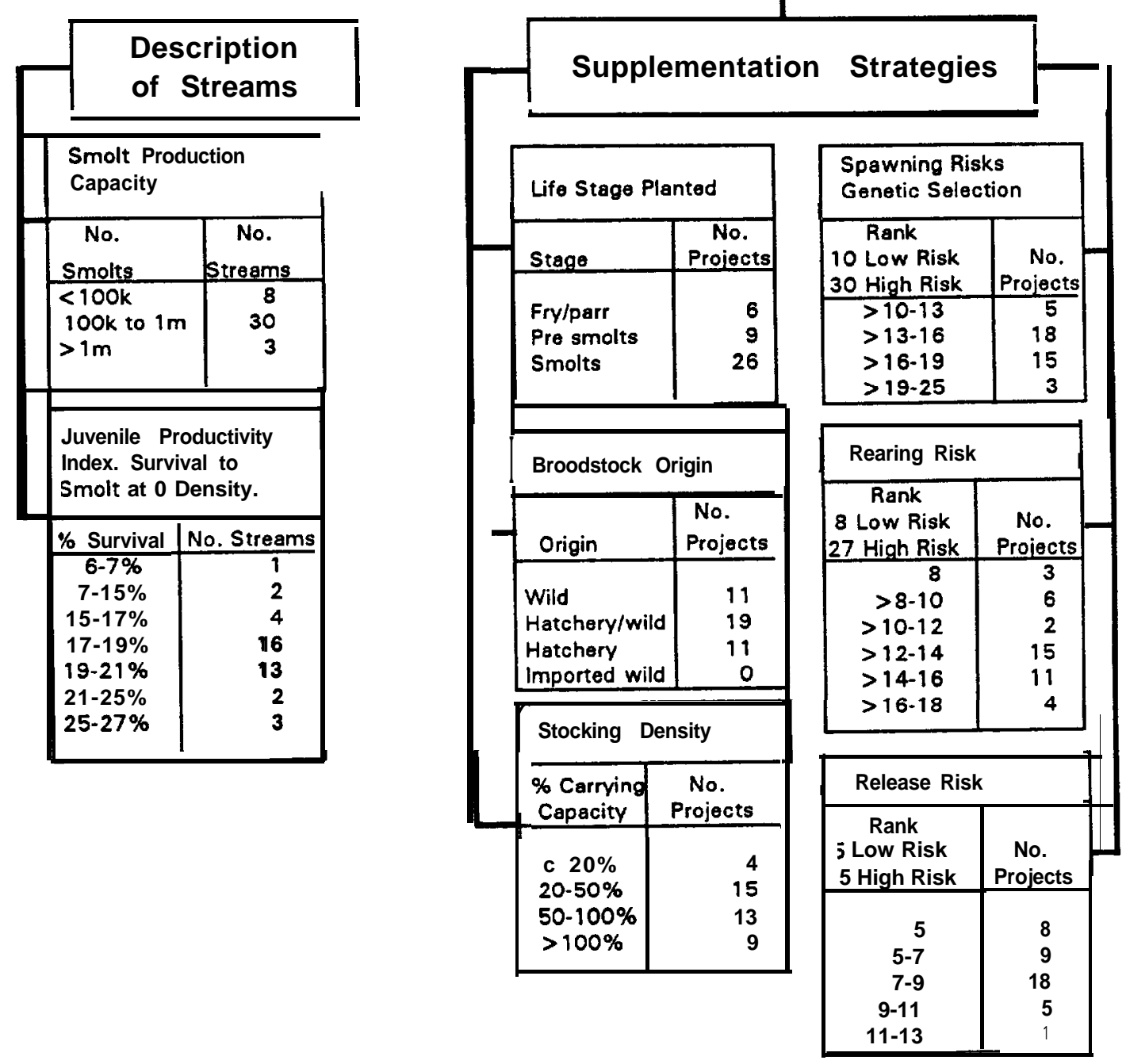

Figure 2. Stock and stream characteristics and strategies for 41 planned and ongoing spring chinoook supplementation projects. 


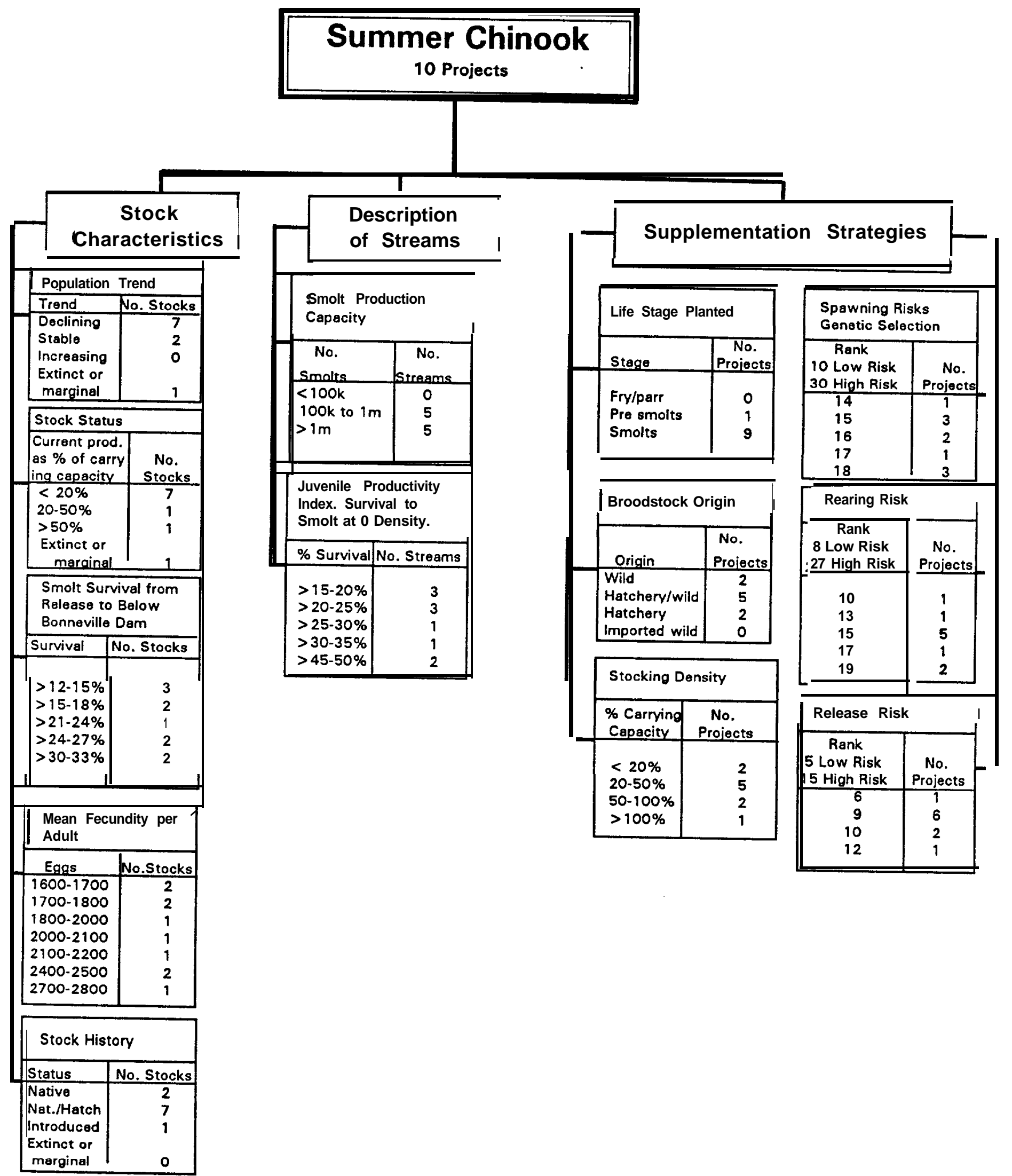

Figure 3. Stock and stream characteristics and strategies for 10 planned and ongoing summer chinook supplementation projects. 


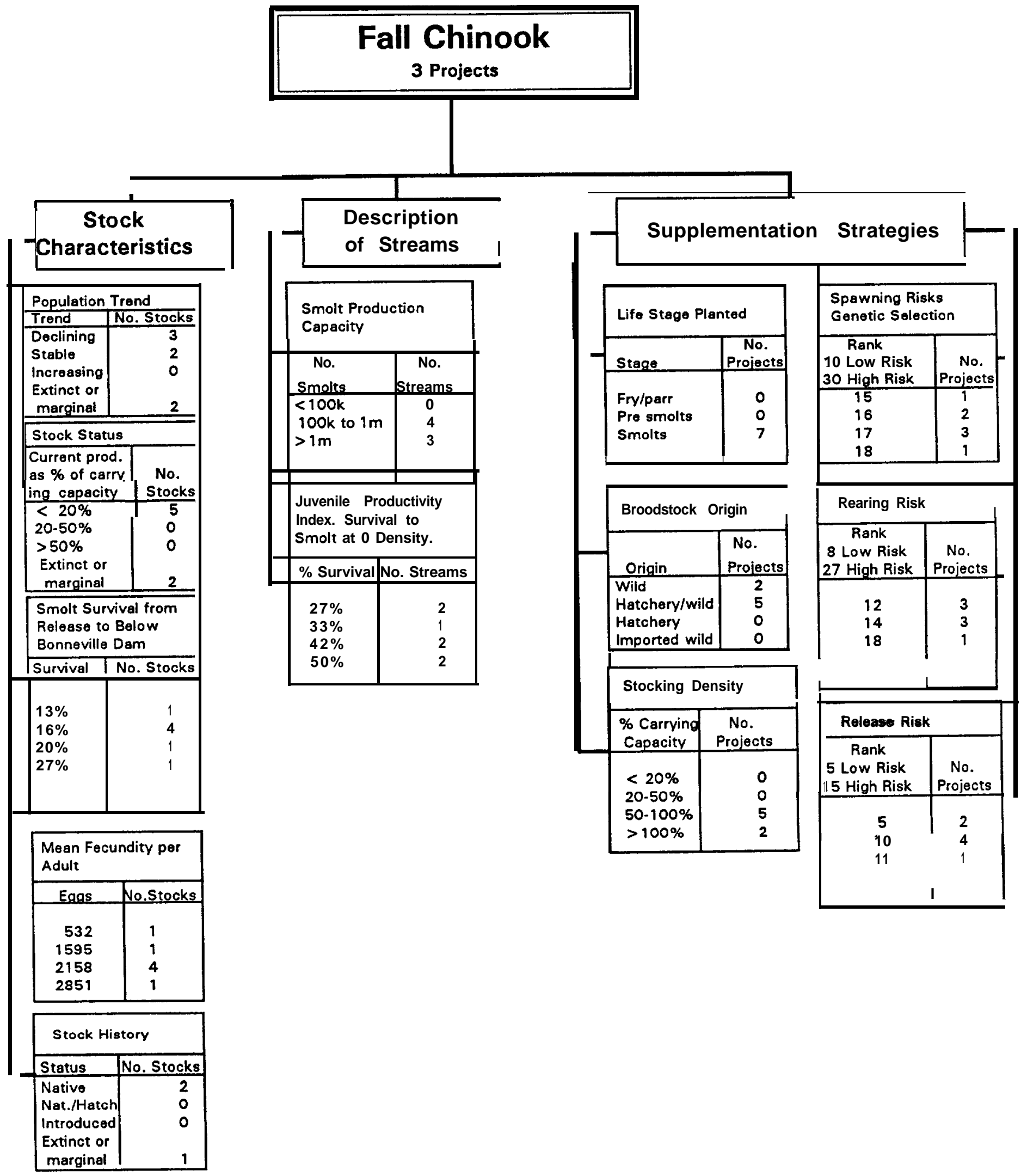

Figure 4. Stock and stream characteristics and strategies for 7 planned and ongoing fall chinook supplementation projects. 


\section{Summer Steelhead}

11 Projects

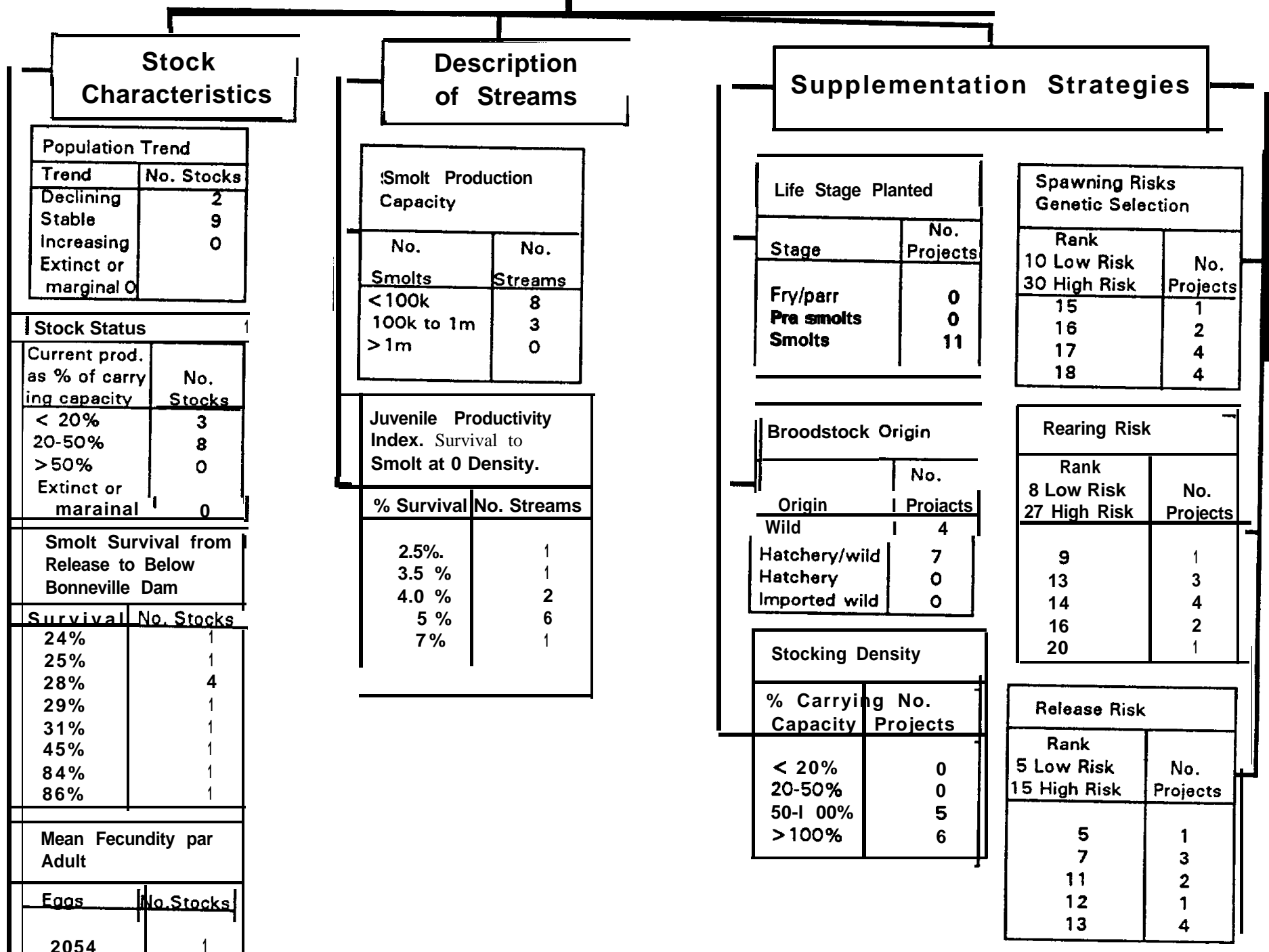

Figure 5. Stock and stream characteristics and strategies for 11 planned and ongoing summer steelhead supplementation projects. 


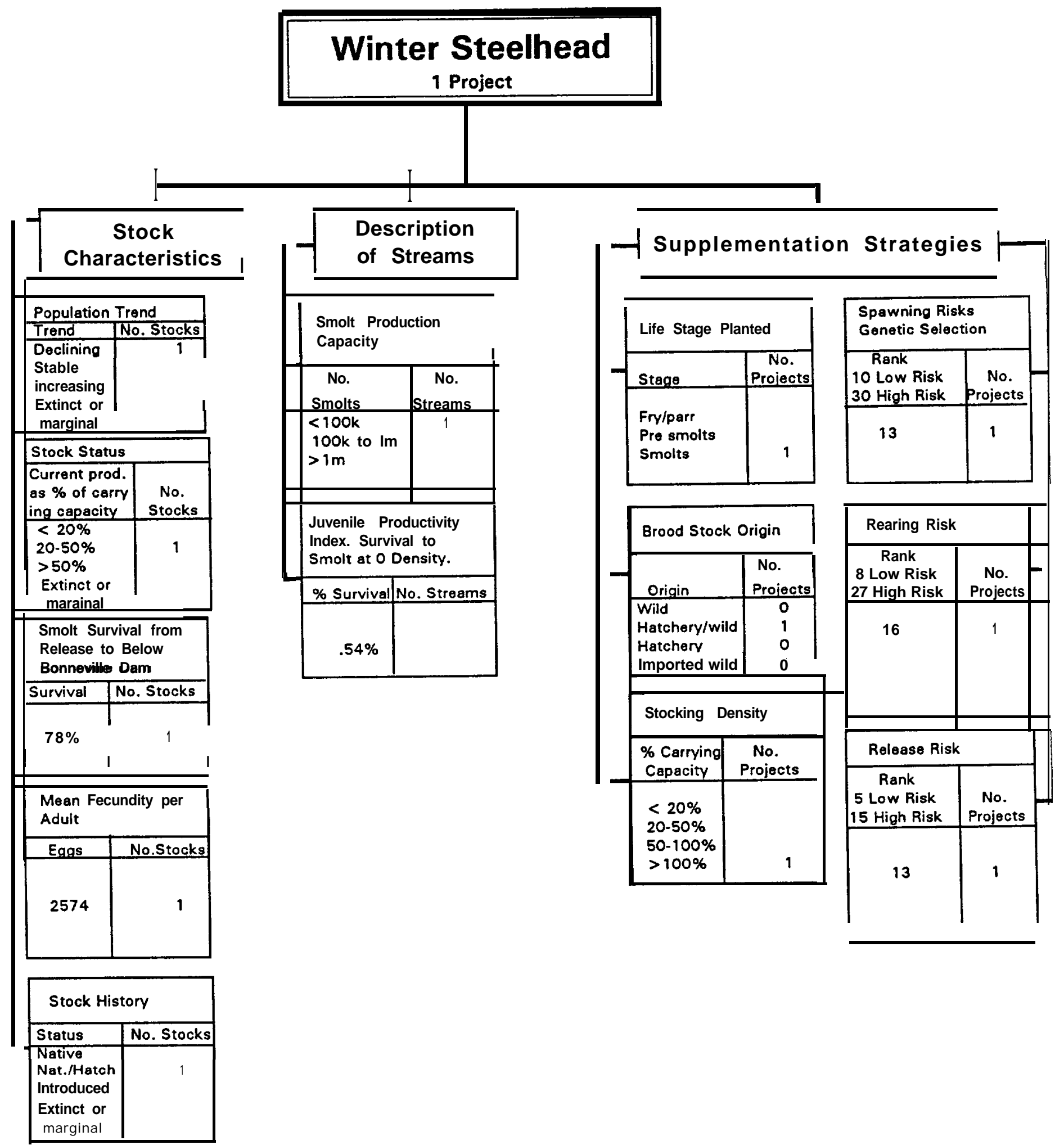

Figure 6. Stock and stream characteristics and strategies for 1 planned winter steelhead supplementation .project. 


\section{Sockeye}

1 Project

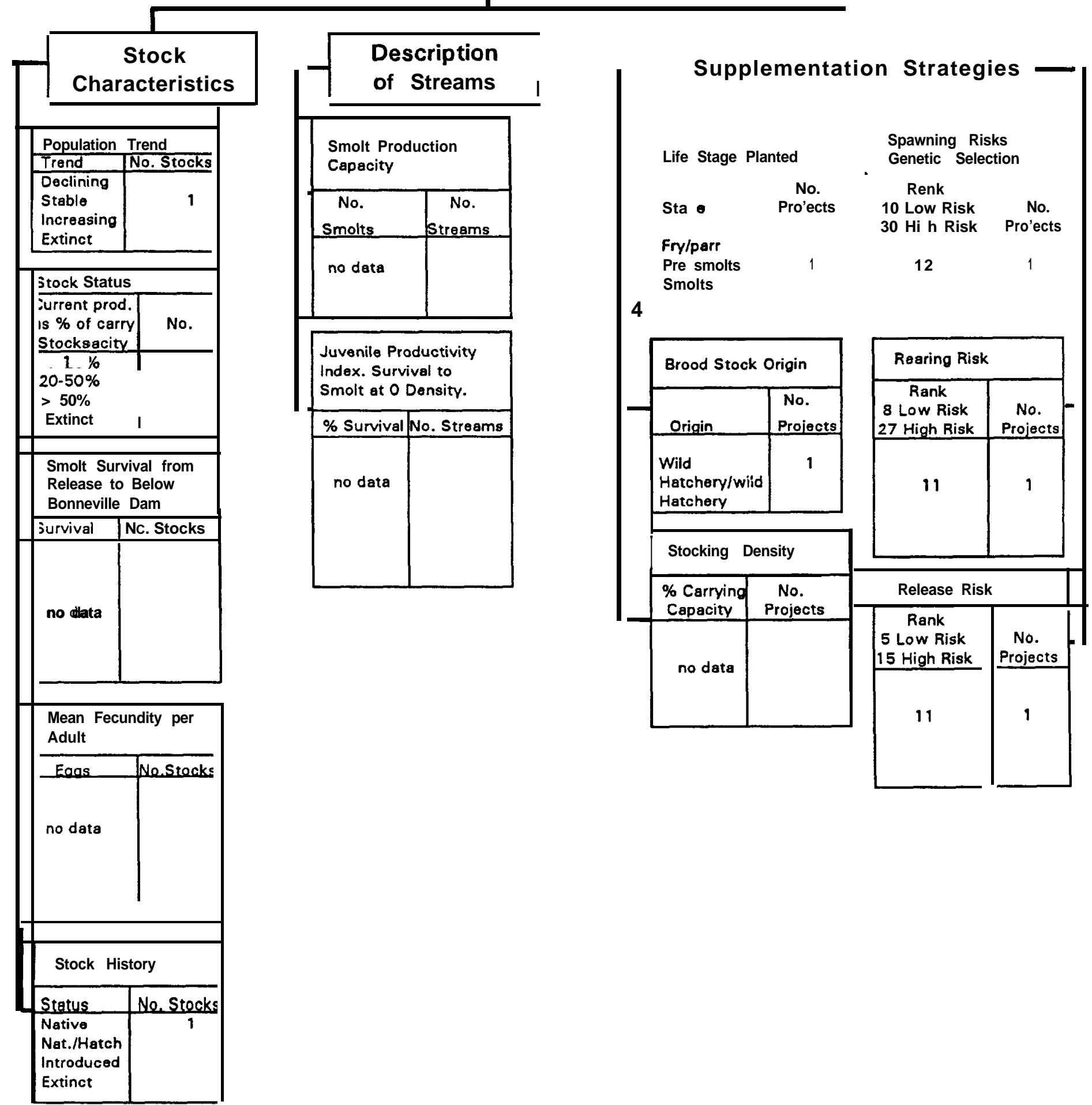

Figure 7. Stock and stream characteristics and strategies for 1 planned sockeye supplementation project. 
level, for example, in an overall survey of the types of supplementation projects in the basin. Objectives have another more important function: to define specific targets against which performance of the program can be measured. Objectives of hatchery programs have traditionally been limited to production targets - pounds of fish reared and released, contribution to fisheries, etc. Those targets are important, but the definition of supplementation adopted by RASP implies that other measures of performance must also be included in the objectives. RASP has proposed the routine addition of four new performance standards in all supplementation projects: post-release survival, reproductive success, longterm reproductive performance, and ecological interactions.

\section{Post-Release Survival}

Post-release survival is measured from the time of release to the time adults return to the subbasin or are harvested in a fishery. The system planning model discounts the contribution of hatchery fish by $50 \%$ to account for differential survival between wild and hatchery smolts (Monitoring and Evaluation Group 1989). Given the magnitude of the discount applied to hatchery fish, improving post-release performance can make a large contribution to the success of a supplementation project. To improve post-release survival, evaluation projects should focus on learned behavior in the hatchery, physiological state of the hatchery fish, ecological factors such as predation and competition, and environmental factors such as flow and temperature patterns.

\section{Reproductive Success}

Reproductive success measures how well supplemented fish reproduce in the natural environment. It is limited to those changes in the natural reproductive process induced by the hatchery experience but that do not persist into the next generation. Reproductive success is broadly defined as the number of offspring produced per spawner and it is influenced by:

- $\quad$ changes in average fecundity of the stock

- $\quad$ pre-spawning mortality

- $\quad$ large- and small-scale spawning distribution (homing to appropriate drainage or selection of quality spawning bed)

- $\quad$ spawning effectiveness (mate acquisition, redd digging capability, spawning timing, and egg retention) 
- $\quad$ survival of progeny of hatchery-reared fish across significant life history stages (egg-to-fry, fry-to-presmolt, and presmolt-to-smolt survival and recruit per spawner ratios).

\section{Long-Term Performance}

Long-term performance is defined as the capacity of a population to persist in the face of environmental variability while undergoing natural genetic change. Ultimately, long-term performance is demonstrated by the simple fact that a population has maintained its productivity over a long period of time. Long-term performance of a stock might be indexed by changes in the ratio of recruits to spawners, overall egg to adult survival and survival between life history stages, gene frequencies as measured by electrophoresis, by changes in life history patterns. Long-term performance is a relatively new approach to the evaluation of artificial propagation, hence new tools and methodologies are needed. Standards designed to measure long-term performance must consider the four genetic risks associated with supplementation: extinction, loss of within-population variability, loss of between-population variability and domestication (Busack 1990).

\section{Ecological Interactions}

Hatchery fish released into the natural stream immediately become a part of the ecological matrix comprised of the physical habitat and its biota, including predators and competitors. Hatchery-reared fish both affect and are affected by the ecological matrix of the stream. For example, one of the most controversial biotic effects is the impact of a successful supplementation program on non-target species or races. The inter- and intra-specific tradeoffs implicit in any supplementation program and the performance standards used to measure those trade-offs must be made explicit. Performance standards designed to measure the interaction between ecological factors and supplementation may be derived from:

- factors limiting production, including identification of critical or unique seasonal patterns of habitat use by specific life history stages

- $\quad$ species-specific carrying capacities in mainstem reaches and tributaries;

- $\quad$ changes in critical habitat parameters (e.g., adult passage at dams and other obstructions; effectiveness of screening and bypass systems for irrigation diversions; adequate in-stream flows for spawning, rearing, and outmigration; and water quality, especially as impacted by such human activities as logging and grazing

RASP Summary Report Series, Part I: Background. Description, Performance Measures, Uncertainty, Theory December, 1992 /Page 20 
- $\quad$ competitive and genetic interactions between resident @e-existing) and anadromous trout (supplemented)

- $\quad$ interactions between pre-existing resident trout and other anadromous species

- $\quad$ interactions among supplemented and natural anadromous salmonids themselves (e.g., competition, predation, "pied piper" effects, and residualism)

- $\quad$ specific times and places associated with large losses of outplanted fish and development of compensatory release strategies

- $\quad$ multiple stability regions caused by depensatory mortality and development of plans intended to move the population into the higher stability region

\section{UNCERTAINTIES}

This section describes uncertainties associated with supplementation. In supplementation planning, as in other activities where a biological resource is to be manipulated, what we don't know is at least as important in shaping the program as what we do know and can control. This is because our ignorance often outweighs our knowledge about ecological systems.

The uncertainties associated with a supplementation project result from a combination of three factors: the productive processes in the stream ecosystem, or our perception of them; the supplementation strategies; and the objectives (performance targets) of the project (Figure 8).

Management decisions, whether to initiate programs or to take no actions, are often made with uncertainty. The presence of uncertainty automatically presents the manager with risk risk of failure, risk of unintended impacts (genetic or ecological), and risk of future surprise outcomes. Uncertainty and risk are inseparable elements in fisheries programs: where you find one you will always find the other.

Risk can be estimated and assessed through models that substitute assumptions for the critical uncertainties. The accuracy of risk measured in this way depends on the accuracy of assumptions. Lesser uncertainties are usually ignored in the models. Risks can also be assessed by listing and reviewing of critical uncertainties. The nature of those uncertainties and the potential importance of their effect can be estimated qualitatively through experience

RASP Summary Report Series, Part I: Background, Description, Performance Measures, Uncertainty, Theory December, 1992 / Page 21 


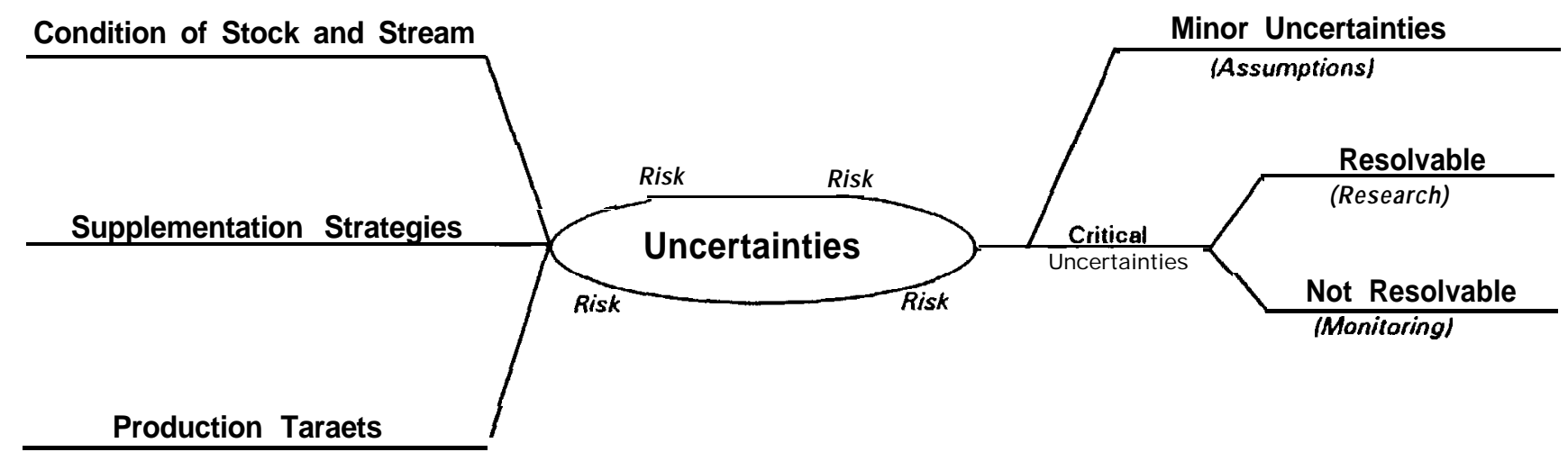

Figure 8. Schematic representation of the origin and treatment of supplementation uncertainties. 
and a review of the literature. This method cannot deal effectively with cumulative or synergistic interactions among uncertainties, but models can be designed to handle those kinds of interactions.

Uncertainties also play an important role in the design of monitoring and evaluation programs. One way to reduce risk to acceptable levels is to monitor the appropriate parameters in a way that gives early warning of a problem. RASP calls this "risk containment monitoring. "

Since uncertainties are the product of factors that will vary from project to project, they must be evaluated on a case-by-case basis. However there is utility in displaying uncertainties that are generally applicable to supplementation. A general list of uncertainties and matrices that can be used to generate potential uncertainties are presented in the next two sections.

\section{General Uncertainties}

The SRG (1990) identified the central uncertainty or question regarding supplementation as:

" Under what set of conditions will supplementation of natural and wild production with hatchery production add to the total production of salmon, steelhead or other targeted fishes over the long term?" All of the more specific uncertainties are related to that question. One source of the more specific uncertainties is the literature review by Steward and Bjomn (1990). The list presented below is our interpretation of the major uncertainties contained in that report. An exhaustive review is not intended: the original document should be consulted for details.

\section{$\underline{\text { Genetic Uncertainties }}$}

1) Biochemical techniques for stock separation are not always conclusive and the genetic basis for the observed variability in stocks of Pacific salmon is not well documented.

2) It is not known whether some species or races of salmon or life histories within species are better suited to supplementation than others.

3) It is not known whether domestication and loss of performance in the wild is an inevitable consequence of artificial propagation. The kinds of hatchery environments and practices that preserve natural adaptations in hatchery-reared fish are unknown.

4) The impact of the use of foreign or distant broodstock on smolt-to-adult survival and fitness is unknown. A closely related uncertainty is the magnitude of outbreeding depression and the consequences of losing co-adapted gene complexes in wild stocks when exogenous stocks are used.

RASP Summary Report Series, Part I: Background, Description, Performance Measures, Uncertainty, Theory December, 1992 / Page 23 
5) The amount of information on genetics, life history, ecological characteristics and interactions of hatchery and wild stocks necessary to employ artificial selection safely and beneficially in supplementation is unknown. Put another way, can "remedial selection" in a hatchery ever be safely employed on stocks that have already lost genetic variability or are poorly adapted to a modem environment?

6) The rate at which hatchery-reared fish adapt to natural environments is unknown. A related uncertainty with major implications for supplementation is the number of natural generations required before offspring of hatchery-reared parents achieve the fitness of the wild stock.

7) The conditions under which beneficial gene flow from hatchery to wild stocks occurs are unknown.

8) The maximum ratio of hatchery to wild spawners to ensure minimal deleterious genetic impacts is unknown. The minimum effective population size for hatchery breeding and natural spawning is unknown.

9) The environmental conditions (dam mortality, habitat degradation, etc.) under which supplementation will fail to achieve its goals - even when hatchery fish are genetically equivalent to wild fish - are unknown.

\section{Ecological Uncertainties}

10) The effects of hatchery practices on survival and production are unknown. For example, the combinations of release size, time, and density which stimulate natural production without displacing wild fish are unknown; the life stage and season of stocking that minimize hatchery-induced impairment of predator avoidance and feeding efficiency are unknown; the degree to which behavior learned in the hatchery predisposes hatchery fish to higher rates of predation, lower feeding efficiency, or suboptimal habitat use is not known; and the degree to which improved hatchery practices (size and time of release, disease prophylaxis, and reduced rearing density, etc.) can improve early marine survival is unknown.

11) It is not known whether interspecific competition or predation can prevent a depressed target population from responding to supplementation. A related uncertainty concerns the impacts of multiple stability regions. Assuming that multiple stock-recruitment stability regions exist, and that some populations are "trapped" in a lower region because of interspecific competition or predation, what combinations of hatchery release numbers and reductions of competitor or predator populations will allow the target population to regain its higher equilibrium level?

RASP Summary Report Series, Part I: Background, Description, Performance Measures, Uncertainty, Theory December, 1992 / Page 24 
12) It is not known whether the magnitude or strategies employed by particular supplementation projects could attract predators and exacerbate predatory losses of wild fish.

13) The incidence of vertical transmission of disease from hatchery to wild fish is unknown, as is the impact such transmission has on wild stocks.

14) The conditions under which successful supplementation might selectively increase harvest of wild fish in a mixed population have not been determined.

\section{Identifying Supplementation Uncertainties}

This section describes potential sources of uncertainties related to supplementation. These are intended to provide guidance for identification of relevant uncertainties for specific supplementation projects. The section considers sources in the hatchery environment and from ecological interactions.

\section{$\underline{\text { Hatchery Environment }}$}

The survival of first generation hatchery fish is influenced by the culture practices, the environmental conditions in the hatchery, the compatibility of the stock, and the size and time of release to the natural environment. Certain behavioral and physiological characteristics of fish, and in some cases genetically related traits, are apparently altered within the first generation of hatchery experience. Such changes explain why hatchery fish produced from wild parents exhibit significantly lower survival than natural fish in the same river system for the same life history phases. These changes in a fish's condition or characteristics, referred to here as its attributes, apparently cause the poor performance within the natural environment.

RASP identified 19 attributes of salmonids potentially altered by hatchery practices within the first generation of hatchery experience (Table 3). Each attribute can affect survival and therefore contribute to the differential in performance of hatchery and wild fish. RASP also developed a schematic model to illustrate the link between an attribute and survival during a particular life stage (Figure 9).

Figure 9 lists six potential fates, of hatchery produced fish that die before spawning. Clearly, death may be caused by several of these modes, acting in concert. For example, starvation, stress, and disease could all be contributors to a fish's demise. However, for descriptive purposes, it is useful to link attributes and fates as though they act independently (Table 4). 
Table 3. Survival-related attributes of salmonids potentially altered by hatchery practices within the first generation of hatchery experience.

\begin{tabular}{|c|c|}
\hline Attribute & Description \\
\hline Aggressiveness & Extent of inter- or intra-specific aggressive behavior within the natural environment. \\
\hline Dispersiveness & Extent and rate of dispersal within the natural environment. \\
\hline Downstream emigmtion pattern & Timing and rate of travel of seaward migration. \\
\hline Upstream immigration pattern & Timing and mte of travel of the upstream spawning migration. \\
\hline Amount of body fat & Quantity of body fat related to nutrition and exercise. \\
\hline Feeding behavior & Use of foraging areas, prey selection, and associated energetics of feeding. \\
\hline Habitat selection & Use of habitats by season, including depth, velocity, substrate type, and shelter. \\
\hline Health & Overall health related to history of nutrition, exposure to pathogens and stressors, and exercise. \\
\hline Homing/straying & Degree of homing to the home spawning stream (or stream of release). \\
\hline Disease resistance & Immunity to disease, either due to immunogenetic resistance or antibodies from prior exposure. \\
\hline Matumtion & Age at sexual maturity, or relative timing of sexual maturity within a particular season. \\
\hline Predator recognition & Ability to detect both presence and associated danger of predators. \\
\hline Prey recognition & Ability to locate suitable prey items. \\
\hline s i i & Length and associated condition factor of fish at time or age. \\
\hline Smoltitication & Timing and degree of physiological tmnsformation in preparation for seaward migration/entry. \\
\hline Saltwater transfer efficiency & Effectiveness of successfully making transition from fresh to saltwater. \\
\hline Swimming ability & Burst speed, maneuverability, and stamina associated with swimming. \\
\hline Social interaction & Set of behaviors associated with dispersal, territoriality, hiemmhial associations, and schooling. \\
\hline Catchability & Effectiveness, or lack thereof, at avoiding capture by a fishery. \\
\hline
\end{tabular}


Table 4. Potential fates, or modes of death, of hatchery produced sahnonids unsuccessful at surviving to spawn and attributes which can contribution to a particular fate.

\begin{tabular}{|c|c|c|c|c|c|}
\hline Predation & Starvation & Disease & $\begin{array}{l}\text { Environmental } \\
\text { Impacts }\end{array}$ & Fishery & Stress \\
\hline predator recognition & health & health & habitat selection & dispersiveness & health \\
\hline swimming ability & feeding behavior & disease resistance & swimming ability & emigration pattern & amount of body fat \\
\hline size & dispersiveness & smoltification & emigration pattern & immigmtion pattern & srnoltification \\
\hline dispersiveness & emigration pattern & emigration pattern & immigmtion pattern & hominglstmying & aggressiveness \\
\hline feeding behavior & social intemction & immigmtion pattern & hominglstmying & smoltitication & dispersiveness \\
\hline emigration pattern & prey recognition & aggressiveness & smoltification & size & social interaction \\
\hline habitat selection & amount of body fat & dispersiveness & size & aggressiveness & habitat selection \\
\hline \multirow[t]{4}{*}{ smoltification } & aggressiveness & social intemction & & prey recognition & \\
\hline & smoltification & amount of body fat & & catchability & \\
\hline & $\begin{array}{l}\text { saltwater tmnsfer } \\
\text { efficiency }\end{array}$ & $\begin{array}{l}\text { saltwater tmnsfer } \\
\text { efficiency }\end{array}$ & & maturation & \\
\hline & & & & feeding behavior & \\
\hline
\end{tabular}



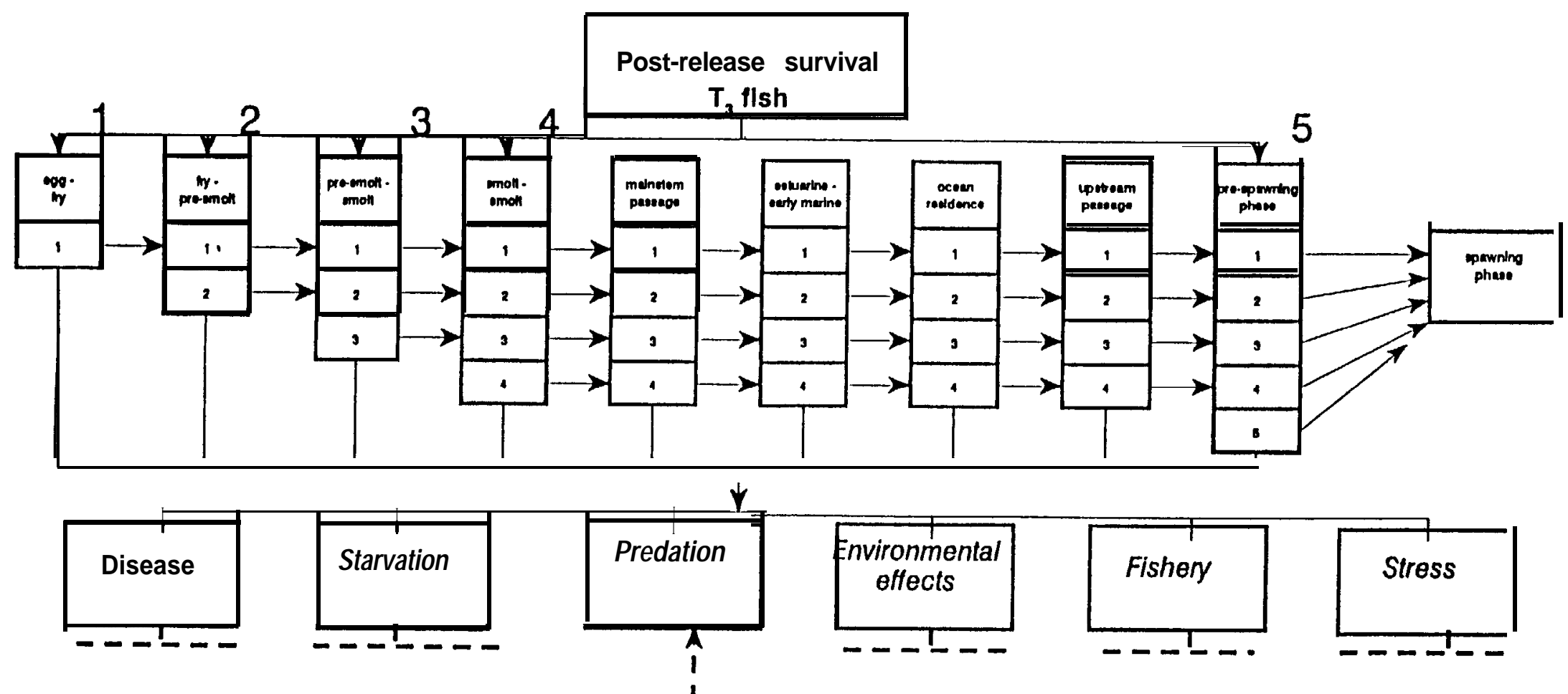

Loss

Lie Stage
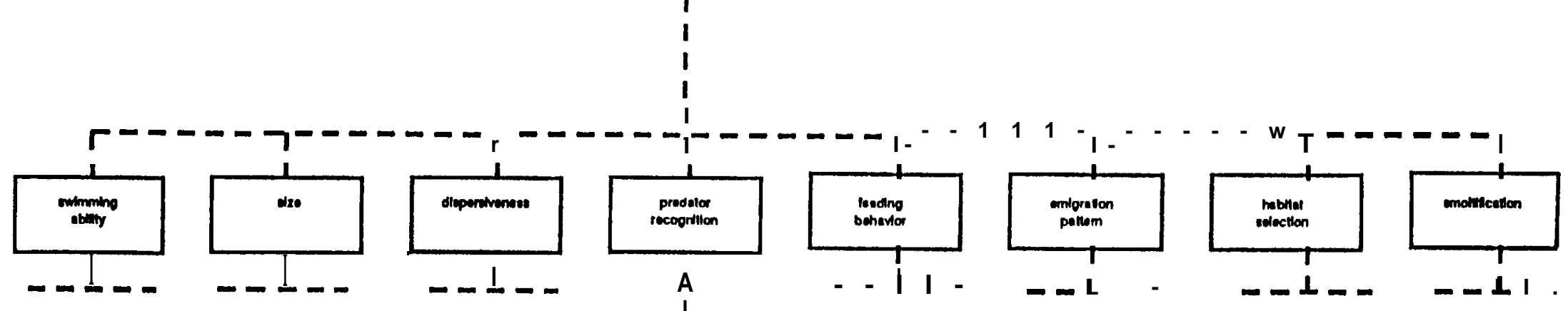

Contrlbuting Attribute<smiles>C=CC1CCC1C</smiles><smiles>C1CC1</smiles>

- I I. $-\mathbf{L}$

$-1-1$

$--11$

Fate

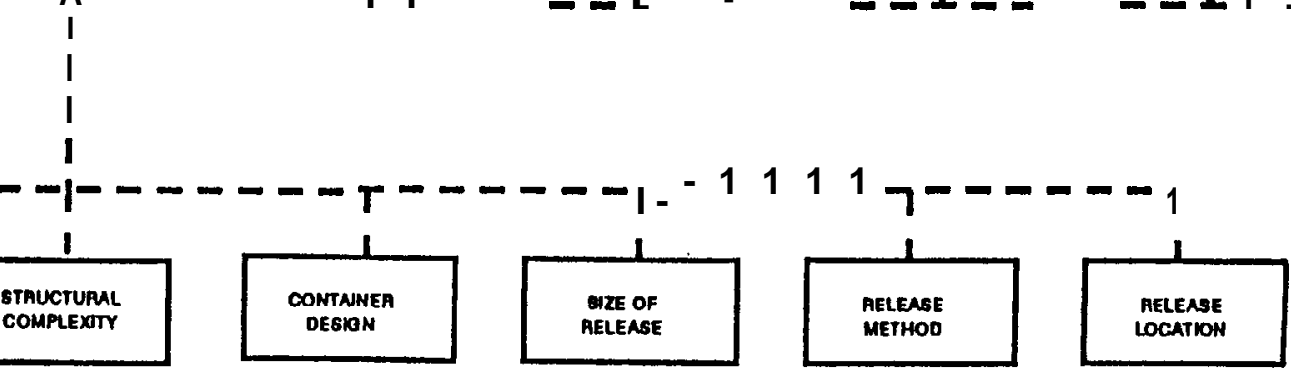

Figure 9. Schematic of effects of hatchery treatment on survival related attributes of first generation hatchery fiih outplanted at different life stages. 
Figure 9 also illustrates that the life stage being supplemented is an important factor. The relative influence of a particular attribute on survival of hatchery produced fish differs between fish released as fry and fish released as smolts. Sorting out these life history effects will increase the complexity of the task significantly.

Numerous hatchery practices or treatments can potentially alter survival-related attributes. We focused our attention on 22 treatments considered of greatest importance (Table 5). This list will be modified as RASP continues its assessment. A very brief description of each treatment is provided in Table 5.

Many of the same hatchery practices that create the first generation effects identified in Tables 3-5 can also cause changes in the diversity or distribution of genetic information in the population and thus cause changes in the long-term performance. For example, all the attributes listed in Table 3 probably have a genetic, as well as an environmental component. The genetic component can be altered through selection exerted by hatchery treatments shown in Table 5.

Busack (1990) identified four types of genetic risk associated with supplementation projects. His risks included: extinction, loss of within-population variability, loss of betweenpopulation variability, and domestication. Table 6 displays the hatchery practices that can contribute to uncertainties associated with each type of genetic risk.

\section{Ecological Interactions}

Juvenile salmon and steelhead released into a stream as part of a supplementation project are expected to return to the stream, to spawn, and to contribute to natural production unless they are harvested. The rate at which they return (survive) is determined largely by their physiological state, their behavior (especially maladaptive behavior learned in the hatchery environment), their genetic fitness, the mainstem passage mortality and the ecological interactions between them and the physical and biological habitat. The last category is probably the one about which we know the least. Many of the first generation effects and genetic changes are expressed as reduced survival; however, the proximate cause of mortality in many of these cases is probably some type of "ecological interaction".

Ecological interactions are partitioned into three general types: interaction between salmonids and their habitat, biotic interactions that impact target species, and biotic interactions that impact non-target species/races (Table 7).

Habitat. Production may be severely limited by a suite of factors in the target stream which act at one or two specific life stages (production "bottlenecks"). Such production bottlenecks and mainstem passage mortality may have to be substantially reduced before the supplementation objectives can be met. For example, streams with headwater impoundments

RASP Summary Report Series, Part I: Background, Description, Performance Measures, Uncertainty, Theory December, 1992 / Page 29 
Table 5. List of hatchery treatments potentially affecting survival-related attributes of salmonids within the first generation of hatchery experience.

\begin{tabular}{|c|c|}
\hline Hatchery treatment & Component of treatment of potential concern \\
\hline Broodstock origin & Indigenous natural stock or imported stock (hatchery or natural and source) \\
\hline Broodstock capture/holding methods & Representiveness of timing and ages obtained by capture/holding methods \\
\hline Mating practices & Random vs. non-random, representation by age classes, male-per-female ratio, etc. \\
\hline Incubator type and substrate & Degree of interaction between substrate and alevin; emergence or removal \\
\hline Diet & Type of food: dry vs. wet, buoyant vs. sinking, natural vs. manufactured \\
\hline Growth schedule & Rate of desired growth and size projected; ration adjusted to meet schedule \\
\hline Feeding method & Automatic feeders, demand feeders, broadcasting by humans, etc. \\
\hline Density & Rearing density \\
\hline Grading & Consolidation of sizes in rearing with or without culling of undesirable fish \\
\hline Predation exposure & Extent of experience with natural predators: birds, otters, fish \\
\hline Structural complexity & Exposure to variable habitat structure: overhanging cover, visual separators, etc. \\
\hline Container design & Size, shape and depth of tearing unit: raceway vs. pond, meander vs. straight \\
\hline Flow & Quantity and velocity of flow through rearing unit \\
\hline Water temperature & Range of temperatures during either incubation or rearing compared to nature \\
\hline Disease control & Extent of exposure to pathogens and treatments applied \\
\hline Hygiene & Rearing vessel cleaning practices (frequency and methods) \\
\hline Size of release & Number of fish released \\
\hline Release method & Volitional vs. forced, degree of acclimation, mode of transportation \\
\hline Release location & Distance from hatchery, ringle point release vs. multiple release sites, etc. \\
\hline Release timing & Means of selecting date for release; relationship to natural timing \\
\hline
\end{tabular}


Table 6. Hatchery treatment and critical uncertainties associated with four genetic risks.'

\begin{tabular}{|c|c|}
\hline Genetic Risk & Hatchery Treatment/Uncertainty \\
\hline Extinction & $\begin{array}{l}\text { Donor population reduced below MVP by removal of hatchery broodstock } \\
\text { Supplemented population has different genetic makeup, life history or rearing environment than the hatchery } \\
\text { stock } \\
\text { Hatchery stock strays into non-target spawning areas } \\
\text { Mixed stock fisheries reduce target or non-target population below MVP }\end{array}$ \\
\hline $\begin{array}{l}\text { Loss of Within-Population } \\
\text { Variability }\end{array}$ & $\begin{array}{l}\left.\text { Hatchery broodstock less than the minimum effective population size } \mathbf{N}_{\mathrm{e}}\right) \\
\text { Mating design and fertilization protocol reduces N. below minimum } \\
\text { Hatchery practices increase natural variation in family size } \\
\text { Non-random selection of brood fish from the donor population } \\
\text { Mixed-stock fisheries reduces non-target population below } \mathrm{N} \text {, } \\
\text { Failure to recognize and compensate (during brood selection) for the impact of a selective fishery }\end{array}$ \\
\hline $\begin{array}{l}\text { Loss of Between-Population } \\
\text { Variability }\end{array}$ & $\begin{array}{l}\text { Occurrence and magnitude of outbreeding depression } \\
\text { Hatchery broodstock is taken from a genetically distant donor stock } \\
\text { Scale of the supplementation program causes excessive strays into non-target streams } \\
\text { Hatchery practices cause abnormal rates of straying into non-target streams } \\
\text { - }\end{array}$ \\
\hline Domestication & $\begin{array}{l}\text { Hatchery brood stock not collected from all portions of the run } \\
\text { Grading, ponding, outplanting or other hatchery practice causes non-random mortality } \\
\text { Broodstock not selected randomly among age classes and life histories } \\
\text { Rearing and release strategy is not consistent with natural life history pattern }\end{array}$ \\
\hline
\end{tabular}

‘Adopted from Kapuscinski, A. R., C. R. Steward, M. L. Goodman, C.C. Krueger, J. Holt Williamson, E. Bowles and R. Carmichael (1991). 
Table 7. Interaction uncertainties partitioned by habitat, target species, and nontarget species.

\begin{tabular}{|c|c|}
\hline Interaction Category & Uncertainty \\
\hline Habitat & $\begin{array}{l}\text { Habitat bottleneck limits natural production: } \\
\text { - Access to spawning area blocked } \\
\text { - Summer rearing limited } \\
\text { - Winter rearing limited } \\
\text { - Juvenile outmigration impeded } \\
\text { Flows and/or temperatures not compatible with life } \\
\text { history ('juvenile and adult) } \\
\text { Mainstem passage mortality } \\
\text { Altered habitat better suited to non-target species }\end{array}$ \\
\hline Target Population & $\begin{array}{l}\text { Habitat previously used by target species colonized } \\
\text { by non-target species/race which: } \\
\text { - Preys on target species } \\
\text { - Competes with target species } \\
\text { - Forces target population into a lower } \\
\text { stability region } \\
\text { Supplementation strategy attracts predators }\end{array}$ \\
\hline Non-Target Population & $\begin{array}{l}\text { Successful supplementation displaces non-target } \\
\text { species or race of economic or recreational value } \\
\text { Resident, non-target species or race vulnerable to } \\
\text { predators attracted by supplementation strategy }\end{array}$ \\
\hline
\end{tabular}


and regulated flows may have a seasonal hydrograph and temperature regime that severely compromises the performance of a targeted species. If the timing of life history events is entrained to natural rhythms of flow or temperature, critical events such as emergence, outmigration, and spawning will be disrupted and production will be reduced dramatically.

Non-Target Species. One cannot assume that a stream with a depleted salmon population has vacant habitat equivalent to the difference between the past and present population sizes. Depletion of an abundant and productive salmon population generally doesn't create production vacuums. In oligotrophic waters, the loss of salmon carcasses might result in a reduced productivity and production of potential prey. In more productive waters, vacant habitat will, in many cases, be colonized by another species/race. Consequently successful supplementation may displace a population of another species or a resident population of the same species (e.g. steelhead may displace resident rainbow trout). The displacement can have biological, economic and political consequences.

Target Species. The effect of ecological interactions on target species can be expressed by several uncertainties. For example, one set of uncertainties arise from the existence of multiple stability points in the stock-recruitment relationship. Managers proposing supplementation should be especially concerned when colonizing species compete with and/or prey on the supplemented species with sufficient intensity to lock the latter in a lower stability region. Peterman (1977) worked out the theoretical basis for multiple stability regions in salmon production functions and McIntyre et al. (1988) observed empirical support for the theory in the sockeye population of Karluk Lake, Alaska.

Shifts in dominance following the collapse of a dominate species have also been observed in marine populations. For example, the northern anchovy became dominant after the collapse of California sardine populations and Atlantic herring dominated after the collapse of the Atlantic mackerel (Skud 1982). Regarding the marine species, Skud (1982) quoted N. Daan's estimate that it would require a $50 \%$ reduction in the dominant species and a corresponding $50 \%$ increase in the depleted species maintained for several years to reestablish dominance.

McIntyre et al. (1988) concluded that a lower exploitation rate of $30 \%$ to $35 \%$ on Karluk Lake sockeye would have maintained the population in a higher stability region. These observations have important implications for supplementation planning. The concept of multiple stability regions is an important uncertainty that has generally been overlooked by managers.

RASP summary Report Series, Part I: Background, Description, Performance Measures, Uncertainty, Theory December, 1992 / Page 33 


\section{ELEMENTS OF A SUPPLEMENTATION THEORY}

The expectation that we can increase total production by adding artificially propagated fish to natural habitats, is based on our understanding of the artificial and natural production systems. Realizing the expected increases in production depends on how well the two systems are integrated. Supplementation theory is an attempt to generalize our understanding of natural and artificial production and to establish guidelines for integrating the two. Theory gives managers the tools needed to build conceptual models of supplemented stream/stock systems. The models permit managers to deduce hypotheses about the expectations (benefits and risks) of supplementation. The hypotheses are also the basis for performance evaluation and subsequent refmement of both theory and supplementation strategies (adaptive management).

A supplementation theory should describe the basis for assessing potential benefits, risks, applications and uncertainties of supplementation. Developing a supplementation theory is important to: narrow the range of potential risks, applications and uncertainties; track the rational for assessment of those parameters; and provide common ground from which discussions of supplementation can take place.

Consistent with the overall purpose of this report - to provide a general introduction to supplementation in the Columbia Basin and broadly describe the scope of the program - the purpose of this discussion of supplementation theory is limited to general concepts. More detailed development of theory and examples of its use will be discussed in later reports in this series.

\section{Supplementation Concepts}

Supplementation theory rests on three concepts:

- $\quad$ capacity: each stream/stock system has a capacity to produce salmon and steelhead determined by the interaction of abiotic and biotic factors operating through the stock's life history

- $\quad$ performance: performance of a stream/stock is that part of the capacity realized in any given time interval

- $\quad$ stock-recruit relationship: there is a relationship between the quality and quantity of a spawning population and recruitment of the adult progeny. 


\section{$\underline{\text { Capacity }}$}

The geomorphic setting, vegetation, climate and stock life histories determine the capacity of the system to produce salmon. Capacity is the product of the interaction of the biotic and abiotic factors and the stock life histories, therefore, it can rarely be measured directly as a fixed quantity. Capacity of a stock/stream system is not necessarily determined in the spawning or freshwater rearing habitats because capacity incorporates all life stages and associated habitats. For example, the ability of a stream system to produce emigrants may never be realized because of factors limiting capacity during the smolt to adult stage.

Supplementation introduces another determinate of capacity -- the physical size and operational practices of the hatchery. Hatcheries have a physical capacity to produce juvenile salmon. Because hatcheries circumvent much of the freshwater incubation and rearing mortality, they may be considered analogous to a super tributary from the standpoint of smolt production. Hatchery practices that alter long term fitness or life histories will change the interaction between the stock and its habitat and therefore influence capacity.

\section{Performance}

That part of a stream's capacity realized over a specified period is its performance and it is usually measured as the production of target species and races. Production is comprised of measures of abundance, post-release survival, reproductive success, long-term performance, and ecological interactions. Following supplementation, the performance of a stream /stock system is determined by the fitness of the supplemented stock and the density-dependent regulation of the combined natural/artificial population. Factors outside the subbasin such as mainstem passage mortality also influence performance. The goal of supplementation is to improve performance and increase natural production, but before supplementation can be considered an appropriate management strategy, the manager must conclude that the capacity of the system is greater than its current performance. However, a difference between capacity and performance does not automatically lead to supplementation. For example, if the difference between capacity and production is due to degradation of spawning, rearing and migrational habitat, supplementation may not improve performance without concurrent habitat improvement.

\section{$\underline{\text { Stock-Recruit Relationshin }}$}

Salmon mangers generally accept the existence of a relationship between the quantity and quality of spawners and recruitment in the next generation. In addition to biotic and abiotic components of the habitat and life history of the native stock, the performance of a stream/stock system is influenced by density-dependent population regulation. The stockrecruit model has served for 40 years as the primary tool for evaluating the nature of the density-dependent influence of stock size on subsequent recruitment and production. Various 
types of stock-production models have been proposed for salmon, including the Ricker (1954) and Beverton and Holt (1957) models and the more complex forms proposed by Paulik (1973). Families of stock-recruitment curves may be used to show the range of performance levels of a stock/stream system.

In addition, salmon and steelhead typically exhibit discrete life history stages (egg to fry, fry to emigrant, emigrant to smolt, and smolt to adult). Specific productivity curves illustrating the performance relationship within each life history can be useful in evaluating the overall stock-recruitment relationship.

\section{Stock-Recruitment Models}

Stock-recruitment models of salmon populations have received extensive treatment since Ricker's (1954) treatise on the subject. However, the debate, refinement and use of the stock-recruitment models have focused on questions related to harvest management. Among the exceptions are Junge's (1970) use of stock-production models to determine the relative impact of smolt, adult and racial mortalities in freshwater on overall production. Ginzburg (1990) used a stock-recruit model to assess the effect of density-dependence on the risks of extinction. Reisenbichler and McIntyre (1977) illustrated the impact on production of interbreeding between hatchery and wild steelhead through hypothetical stock-recruit models. Reisenbichler (1984) used the stock-recruit model to show the theoretical response of a wild population to supplementation and the loss of fitness through the introduction of a maladapted allele.

In the development of a supplementation theory, we will assume that the shape of the stockproduction curve describes the density-dependent regulation of numbers, that this regulation takes place predominately in freshwater, and therefore it reflects important constraints on production which supplementation must address. A criticism of the use of stock-production models to characterize salmonid populations is that they contain little or no allowance for evolutionary or other complex biological mechanisms (Slobodkin 1973). Also, changes in habitat can alter the relationship between stock size and subsequent production (Moussalli and Hilbom 1986). Some of these concerns can be addressed through modifications of the basic model.

Paulik (1973) and Peterman (1977) illustrated how stock-production relationships can have multiple stability regions. Paulik (1973) and Moussalli (1984) described ways of partitioning a stock-production relationship into life stages to address some of the complexities that arise in models based on full generations. The potential for multiple stability regions has important implications to the scale of supplementation projects. Use of multiple life stages can permit greater diversity of experimental approaches and designs. 


\section{Clinical Model}

For descriptive purposes, the concepts of capacity and performance are embedded in a broader clinical model of the target stream and stock. The basic elements of the clinical model $^{3}$ are: Template, the healthy stream/stock system; patient, the current condition of the stream/stock in need of restoration; diagnosis, the comparison of template and patient that leads to identification of limiting factors; and treatment, the specific strategies to remove or circumvent the limiting factors.

A description' of the stream/stock's capacity is a template against which proposed future states of system habitat and stock life histories are compared. The template is a historical reconstruction of the habitat and life histories in the healthy system. Because it is a historical reconstruction, the template analysis will often employ indirect evidence or findings from other streams reported in the literature. The template serves as a guide, a model or a pattern, to assist in planning the reconstruction of a degraded stream/stock system.

The current performance of the stream/stock system is analogous to a patient in the clinical model. In many cases only fragments of the template will remain in the patient stream/stock. Life histories and their associated habitats may be missing entirely or severely degraded. A comparison of the template with the patient leads to a diagnosis of not only the proximate causes of observed performance, but it suggests potential treatments that are likely to increase performance. The comparison of template and patient will also identify treatments that might decrease performance, for example, selection of a stock for supplementation that exhibits maladapted life histories for the target habitat.

When constructing the template and patient descriptions, it is important to include all life history stages including those that take place outside of the spawning and juvenile rearing habitats. This is particularly important where the patient's condition is primarily determined outside the subbasin where spawning takes place.

\section{Summary}

The stock-recruit model and the concepts of capacity and performance are the basis for a supplementation theory. Those concepts employed in a clinical model result in a description of the production process in a stream/stock system in a way that permits rational development of biologically appropriate treatments and the formulation of hypotheses that permit critical evaluation and adaptive management of the supplementation program.

${ }^{3}$ The clinical model is described in greater detail in the third report in this series dealing with planning guidelines

RASP Summary Report Series, Part I: Background, Description, Performance Measures, Uncertainty, Theory December, 1992 / Page 37 


\section{LITERATURE CITED}

Busack, C. 1990. Yakima/Klickitat production project genetic risk assessment. Manuscript.

Genetics Unit, Washington Department of Fisheries, Olympia, WA. 21 p.

Columbia Basin Fish and Wildlife Authority. 1991. Integrated system plan. Portland, OR. $527 \mathrm{p}$.

Currens, K. P., C. A. Busack, G. K. Meffee, D. P. Phillip, E. P. Pister, F. M. Utter, and S. Youndt. 1991. A hierarchical approach to conservation genetics and production of anadromous salmonids in the Columbia River Basin. Draft report from the Sustainability Workshop, January 24-26, 1991. Northwest Power Planning Council. Portland, OR. 30 p.

Junge, Charles 0. 1970. The effect of superimposed mortalities on reproduction curves.

Research Reports of the Fish Commission of Oregon, 2: 1 56-63.

Idaho Department of Fish and Game. 1991. Idaho's anadromous fishery management plan. Boise, ID.

Kapuscinski, A. R., C. R. Steward, M. L. Goodman, C. C. Krueger, J. H. Williamson, E. Bowles and R. Carmichael. 1991. Genetic conservation guidelines for salmon and steelhead conservation. Draft report from the Sustainability Workshop, January 24-26, 1991. Northwest Power Planning Council. Portland, OR. 51 p.

McIntyre, J.D., R.R. Reisenbichler, J.M. Emlin and R.L. Wilmont. 1988. Predation of Karluk River sockeye salmon by coho salmon and char. Fishery Bulletin Vol. 36: 611-616.

Miller, W.H., T.C. Coley, H.L. Burge and T. T. Kisanuki. 1990. Analysis of salmon and steelhead supplementation: Emphasis on unpublished reports and present programs. U. S. Department of Energy Bonneville Power Administration project No. 88-100.

Moussalli, E.I. and R. Hilbom. 1986. Optimal stock size and harvest rate in multistage life history models. Can. J. Fish. Aquat. Sci. 43: 135-141.

Nehlsen, W., J.E. Williams and J. Lichatowich. 1991. Pacific salmon at the crossroads: stocks at risk from California, Oregon, Idaho and Washington. Fisheries 16: 4-21.

RASP Summary Report Series, Part I: Background, Description, Performance Measures, Uncertainty, Theory December, 1992 / Page 38 
Northwest Power Planning Council. 1987. Columbia River Basin Fish and Wildife Program (Amended). Portland, OR.

Oregon Fish Commission. 1955. Biennial report of the Fish Commission of the State of Oregon to the Governor and the Forty-eighth Legislative Assembly. 28 p.

Paulik, G.J. 1973. Studies of the possible form of the stock-recruitment curve. In B.B. Parrish, ed., Fish Stocks and Recruitment, Proceedings of a Symposium held in Aarhus July 7-10, 1970, Denmark, 302-315.

Peterman, R.M. 1977. A simple mechanism that causes collapsing stability regions in exploited salmonid populations. J. Fish. Res. Board of Canada, 34: 1134-1142.

RASP. 1991. Regional assessment of supplementation project. Status Report September 30, 199 1. In press. Bonneville Power Administration.

Reisenbichler, R.R. and J.D. McIntyre. 1977. Genetic differences in growth and survival of juvenile hatchery and wild steelhead trout, Salmon gairdneri. J. Fish. Res. Board. Can. 34: 123-128.

Reisenbichler, 1984. Outplanting: Potential for harmful Genetic change in naturally spawning populations. In J.M. Walton and D.B. Houston ed. Proceedings of the Olympic wild fish conference. Peninsula College, Port Angeles, WA.

Ricker, W.E. 1973. Critical Statistics from two reproduction curves. In B.B. Parrish, ed., Fish Stocks and Recruitment, Proceedings of a Symposium held in Aarhus July 7-10, 1970, Denmark, 331-338.

Ricker, W.E. 1954. Stock and recruitment. J. Fish. Res. Board of Canada, 11:5 559-623.

Riggs, L. 1990. Principles for genetic conservation and production quality. Northwest Power Planning Council Contract C 90-005. Portland, OR.

Scientific Review Group. 1991. Review of fisheries supplementation in the context of activities related to the Columbia River Basin Fish and Wildlife plan. Memorandum to Wally Steucke, IPP Coordinator, Portland, OR. 7 p.

Skud, E. B. 1982. Dominance in fishes: the relation between environment and abundance.

Science 216: 144-149. 
Slobodkin, L.B. 1973. Summary and discussion of the symposium. In B.B. Parrish ed., Fish Stocks and Recruitment, Proceedings of a Symposium held in Aarhus July 7-10, 1970, Denmark, 7-14.

Smith, E. M., B. A. Miller, J. D. Rodgers and M. A. Buckman. 1985. Outplanting anadromous salmonids - a literature survey. U. S. Department of Energy, Bonneville Power Administration Project No. 85-68. Portland, OR.

Steward, C. R. and T. C. Bjomn 1990. Supplementation of salmon and steelhead stocks with hatchery fish: A synthesis of published literature. U.S. Department of Energy, Bonneville Power Administration Project 88 -100. Portland, OR. 
APPENDIX A

SUMMARY OF SELECTED

SUPPLEMENTATION LITERATURE 
Table A.l. Information contained in recent documents relevant to supplementation: Definition, Classification, and Planning

\begin{tabular}{|c|c|c|c|}
\hline $\begin{array}{c}\text { CITATION } \\
\text { (See Literature Cited) }\end{array}$ & $\begin{array}{c}\text { DEFINITION } \\
\text { OF SUPPLEMENTATION }\end{array}$ & $\begin{array}{l}\text { CLASSIFICATION OF PROJECT } \\
\text { DIVERSITY }\end{array}$ & PLANNING RECOMMENDATIONS \\
\hline $\begin{array}{l}\text { Miller et al. (1990) } \\
\text { Analysis of Salmon and Steelhead } \\
\text { Supplementation: Emphasis on Unpublished } \\
\text { Reports and Present Programs }\end{array}$ & $\begin{array}{l}\text { Planting all life stages of hatchery fish to enhance } \\
\text { wild/natural stocks of anadromous salmonids }\end{array}$ & $\begin{array}{l}\text { No stratification or classification of } \\
\text { projects other than the separation between } \\
\text { supplementation and non-supplementation } \\
\text { projects. Provides a summary of } 316 \\
\text { projects }\end{array}$ & $\begin{array}{l}\text { Planning recommendations can be extracted from the } \\
\text { report's conclusions. Recommends looking for factors } \\
\text { that caused decline before supplementation }\end{array}$ \\
\hline $\begin{array}{l}\text { Kapuscinsli al. (1991) } \\
\text { Genetic Conservation Guidelines for Salmon } \\
\text { and Steelhead Supplementation }\end{array}$ & $\begin{array}{l}\text { The use of artificial propagation while conserving } \\
\text { genetic resources, for the goal of restoring or } \\
\text { augmenting self-sustaining populations. Broken into } \\
\text { broad categories of restoration and augmentation }\end{array}$ & $\begin{array}{l}\text { No classification other than the distinction } \\
\text { found in definition between restoration and } \\
\text { augmentation }\end{array}$ & $\begin{array}{l}\text { Lists five steps in planning a supplementation project: } \\
\text { set goals, present status, feasibility, propagation options, } \\
\text { evaluate genetic risks. Listr five general steps in } \\
\text { planning a management program: goals, objectives, } \\
\text { identify problem, implement, and evaluate actions }\end{array}$ \\
\hline $\begin{array}{l}\text { Currens et al. (1991) } \\
\text { A Hierarchical Approach to Conservation } \\
\text { Genetics and Production of Anadmmous } \\
\text { Salmonida in the Columbia River Basin }\end{array}$ & None & None & $\begin{array}{l}\text { Recommends seven principals for designing genetic } \\
\text { resources reserves: 1) must address regional, local } \\
\text { human concerns; 2) hiemrchy of reserves must parallel } \\
\text { the hierarchy of genetic organizations; 3) maintain } \\
\text { demographic stability; 4) identify and protect habitats } \\
\text { corresponding to life history; 5) protect and restore } \\
\text { historical complexity of migratory patterns; } 6 \text { ) harvest } \\
\text { management must protect genetic reserves; } 7 \text { ) } \\
\text { management goals and objectives must clearly define } \\
\text { risks. Presents a schematic of the implementation steps }\end{array}$ \\
\hline
\end{tabular}


Table A.1 (cont'd).

\begin{tabular}{|c|c|c|c|}
\hline $\begin{array}{c}\text { CITATION } \\
\text { (See Literature Cited) }\end{array}$ & $\begin{array}{c}\text { DEFINITION } \\
\text { OF SUPPLEMENTATION }\end{array}$ & $\begin{array}{l}\text { CLASSIFICATION OF PROJECT } \\
\text { DIVERSITY }\end{array}$ & PLANNING RECOMMENDATIONS \\
\hline $\begin{array}{l}\text { Columbia B asin Fish and } \\
\text { W ildlife Authority (1991) } \\
\text { Integrated System Plan. } \\
\text { Chapter C Supplementation }\end{array}$ & $\begin{array}{l}\text { The stocking of fish into the natural habitat to increase the abun- } \\
\text { dance of naturally producing fish populations. Adjunct5 to this } \\
\text { definition included in the report are: [supplementation] is orie- } \\
\text { nted toward maintaining natural biological characteristics of the } \\
\text { population and reliance on mating capabilities of the natural } \\
\text { habitat. The report gives three uses of supplementation: seed } \\
\text { barren habitat, provide survival advantage to depressed stocks, } \\
\text { and speed rebuilding to carrying capacity }\end{array}$ & $\begin{array}{l}\text { No formal classification but life cycle analysis of } \\
\text { a supplemented population, supplementation } \\
\text { technology and guidelines (Table 57) could be } \\
\text { used as a basis for classification }\end{array}$ & $\begin{array}{l}\text { Gives planning guidelines or recommendations for } \\
\text { several aspects of supplementation: Life cycle nalyvis } \\
\text { of limiting factors, prerequisites for supplementation } \\
\text { (sufficient habitat, suitable stock and appropriate } \\
\text { technology), level of technology, hatchery practices, } \\
\text { genetic risks and stock status }\end{array}$ \\
\hline $\begin{array}{l}\text { Smith et al. (1985) } \\
\text { Gutplanting Anadmmous } \\
\text { Salmonids: A Literature Survey }\end{array}$ & $\begin{array}{l}\text { The release of fish from hatcheries al locations away from the } \\
\text { hatchery to increase natural production in streams determined to } \\
\text { be seeded or used at less than optimal levels. The author } 5 \\
\text { referred to this activity as out-planting, however, it appear } 5 \text { to be } \\
\text { close to the concept of supplementation }\end{array}$ & $\begin{array}{l}\text { The literature review did not classify individual } \\
\text { projects but summarized the information from } \\
\text { different projects under the categories: density, } \\
\text { survival, genetics, competition and carrying } \\
\text { capacity models }\end{array}$ & $\begin{array}{l}\text { The report goes through several planning seps in the } \\
\text { design of a supplementation project for the Willamette } \\
\text { River. The planning steps used by the author5 were: 1) } \\
\text { estimate adult returns and reproductive success, 2) } \\
\text { identify underseeded stream5 and reservoirs 3) ret } \\
\text { criteria for aelecting hatchery stocks, 4) evahtata the } \\
\text { use of an artificial spawning channel, 5) evaluate } \\
\text { harvest benefits, 6) describe design of evaluation, } 7 \\
\text { sensitivity analysis, 8) describe sampling methods and } \\
\text { budget }\end{array}$ \\
\hline $\begin{array}{l}\text { Scientific R eview G roup (1990) } \\
\text { R eview of Fisheries } \\
\text { Supplementation in the Context of } \\
\text { Activities Related to the Columbia } \\
\text { River Basin Fish and Wildlife } \\
\text { Plan }\end{array}$ & $\begin{array}{l}\text { The report does not offer a formal definition but recognizes the } \\
\text { need for a clear definition using specific terminology. } \\
\text { Development of useful objective } 5 \text { and evaluation priorities are } \\
\text { hampered by lack of clear definition of supplementation }\end{array}$ & $\begin{array}{l}\text { Does not review specific projects but suggests } \\
\text { that supplementation objectives could include: } \\
\text { restoration, intmduction, rearing augmentation, } \\
\text { and habitat augmentation }\end{array}$ & $\begin{array}{l}\text { The report recommended the following steps when } \\
\text { developing a supplementation project: 1) clearly state } \\
\text { hypotheses and objectives, 2) specify performance } \\
\text { measures, 3) establish baseline knowledge of target } \\
\text { stock, 4) use treatment and control atream to } \\
\text { determine changes. 5) analyze ceasonal habitat condi- } \\
\text { tions, utilition, and carrying capacity }\end{array}$ \\
\hline $\begin{array}{l}\text { Riggs (1990) } \\
\text { Principals for Genetic } \\
\text { Conservation and production } \\
\text { Q uality }\end{array}$ & $\begin{array}{l}\text { None. The report focuses on genetic conservation with reference } \\
\text { to all management activities (harvest, passage, habitat and } \\
\text { production) although hatcheries are given emphasis }\end{array}$ & $\begin{array}{l}\text { Non. The report does list management } \\
\text { opportunities which is a general form of } \\
\text { classification of the stream/stock subject to } \\
\text { management action. The opportunities are stated } \\
\text { here as objectives: 1) conserve native } \\
\text { populations, 2) facilitate natural population } \\
\text { productivity, 3) maintain natural stock identity } \\
\text { and productivity, 4) improve hatchery stock } \\
\text { naturalization, 5) increase hatchery stock } \\
\text { productivity, and 6) introduce and teat a new } \\
\text { stock }\end{array}$ & $\begin{array}{l}\text { The report describes seven step5 in implementation to } \\
\text { ensure production quality: 1) assess existing stock or } \\
\text { population status, 2) identify production alternatives, 3) } \\
\text { assess genetic impacts, 4) develop operational plans, 5) } \\
\text { conduct monitoring and evaluation, 6) identify } \\
\text { important research needs, and } 7 \text { ) facilitate information } \\
\text { transfer }\end{array}$ \\
\hline
\end{tabular}


Table A.1 (cont'd).

\begin{tabular}{|c|c|c|c|}
\hline $\begin{array}{c}\text { CITATION } \\
\text { (See Literature Cited) }\end{array}$ & $\begin{array}{c}\text { DEFINITION } \\
\text { OF SUPPLEMENTATION }\end{array}$ & $\begin{array}{l}\text { CLASSIFICATION OF PROJECT } \\
\text { DIVERSITY }\end{array}$ & PLANNING RECOMMENDATIONS \\
\hline $\begin{array}{l}\text { Isaksson (1988) } \\
\text { Salmon Ranching: a World } \\
\text { Review }\end{array}$ & $\begin{array}{l}\text { None, but defines salmon ranching and enhancement as } \\
\text { aquaculture practice } 5 \text { that aim to fully utilize the carrying } \\
\text { capacity of the natural environment into which juveniles are } \\
\text { stocked. Unlike enhancement, ranching permit5 selective } \\
\text { breeding and other forms of genetic manipulation to increase } \\
\text { production }\end{array}$ & $\begin{array}{l}\text { Distinguishes between salmon ranching and } \\
\text { enhancement operations. Describe5 historical and } \\
\text { contemporary ranching programs utiliing Pacific } \\
\text { and Atlantic salmon in countries worldwide }\end{array}$ & $\begin{array}{l}\text { Following an overview of the problem general } \\
\text { guidelines are given for coordination and management } \\
\text { to minimize the potential negative effect } 5 \text { of ranching } \\
\text { on wild stocks. Also discussed are economic concerns } \\
\text { and questions of national and international law that } \\
\text { affect both supplementation and salmon nttchittg }\end{array}$ \\
\hline $\begin{array}{l}\text { Taylor (1991) } \\
\text { A review of local adaptation in } \\
\text { Salmonidac, with particular } \\
\text { reference to Pacific and Atlantic } \\
\text { salmon }\end{array}$ & $\begin{array}{l}\text { None per SC, but discusses artificial propagation used in the } \\
\text { rehabilitation or enhancement of wild populations, as distinct } \\
\text { from salmon farming/ranching operations }\end{array}$ & $\begin{array}{l}\text { Focus is on biological diversity rather than project } \\
\text { divenity }\end{array}$ & Nothing relating to supplementation programs \\
\hline $\begin{array}{l}\text { Hindar et al. (1992) } \\
\text { Genetic effect5 of cultured fish on } \\
\text { natural fiah population5 }\end{array}$ & Nom & $\begin{array}{l}\text { Differentiates intentional fmm accidental releases of } \\
\text { cultured fish into natural environments, but doer } \\
\text { not distinguish between strategies in terms of } \\
\text { genetic or ecological consequences. Suggests that } \\
\text { most salmon are propagated and released to support } \\
\text { sport and commercial fisheries }\end{array}$ & $\begin{array}{l}\text { Identities the following needs: baseline data collection, } \\
\text { monitoring of gene flow fmm cultured to wild } \\
\text { populations, genetic risk assessment, and conservation } \\
\text { of natural population } 5\end{array}$ \\
\hline $\begin{array}{l}\text { Hard et al. (1992) } \\
\text { Pacific salmon and artificial } \\
\text { propagation under the endangered } \\
\text { species act }\end{array}$ & $\begin{array}{l}\text { Principally concerned with the role of artificial propagation in } \\
\text { assisting the conservation of salmon; consider5 both the status } \\
\text { and potential use of artificially propagated fish in Endangered } \\
\text { Species Act listing determination } 5 \text { and recovery plans. } \\
\text { Contains an excellent glossary of supplementation terms. } \\
\text { Does not show familiarity with supplementation concept } 5 \text { that } \\
\text { have recently evolved in the Columbia River Basin }\end{array}$ & $\begin{array}{l}\text { Distinguishes between production and conservation } \\
\text { hatcheries, criteria for meeting 'evolutionary } \\
\text { significant unit' (ESU) standards, and propagation } \\
\text { of listed and unlisted species. Hatchery program } \\
\text { differ in the degree of intervention, control, and } \\
\text { monitoring required to avert further decline and } \\
\text { facilitate recovery of the natural population; cf. } \\
\text { discussion of captive broodstock programs }\end{array}$ & $\begin{array}{l}\text { Artificial propagation should be implemented only after } \\
\text { other causes of decline ate addressed, and then only as } \\
\text { a temporary measure to facilitate recovery. Other } \\
\text { option } 5 \text { entailing less risk should be considered. If } \\
\text { supplementation is used, several technical issues need } \\
\text { to be addressed up front, including choice of donor } \\
\text { stock and procedures relating to bmodstockcollection } \\
\text { and mating, mating, and release }\end{array}$ \\
\hline $\begin{array}{l}\text { Waples (1991) } \\
\text { Genetic interactions between } \\
\text { hatchery and wild salmonids: } \\
\text { lesson5 from the Pacific } \\
\text { Northwest }\end{array}$ & $\begin{array}{l}\text { Not defined but familiarity with supplementation concepts and } \\
\text { regional programs is indicated. Recommend5 "monitoring } \\
\text { large-scale supplementation efforts' }\end{array}$ & $\begin{array}{l}\text { Contrasts management practices that have different } \\
\text { genetic consequences; i.e., production and } \\
\text { supplementation }\end{array}$ & $\begin{array}{l}\text { Apply baseline genetic data, together with information } \\
\text { on life history traits, to the selection and maintenance } \\
\text { of appropriate donor stock, expand genetic stock } \\
\text { identification efforts to include non-target population5 } \\
\text { and mixed populations; derign and implement hatchery } \\
\text { practices designed to minimize unwanted genetic } \\
\text { impacts; and devise a comprehensive genetic } \\
\text { monitoring program }\end{array}$ \\
\hline
\end{tabular}


Table A.2. Information contained in recent documents relevant to supplementation: Performance Standards, Identification of Genetic Risks, and Behavioral Riik

\begin{tabular}{|c|c|c|c|}
\hline $\begin{array}{c}\text { CITATION } \\
\text { (See Literature Cited) }\end{array}$ & PERFORMANCE STANDARDS & $\begin{array}{c}\text { IDENTIFICATION OF GENETIC } \\
\text { RISKS }\end{array}$ & $\begin{array}{c}\text { IDENTIFICATION OF } \\
\text { PHYSIOLOGICAL/BEHAVIORAL } \\
\text { RISKS }\end{array}$ \\
\hline Miller et al. (1990) & $\begin{array}{l}\text { Performance standards against which } \\
\text { projects were evaluated were not clearly } \\
\text { stated. For example, no genetic or natural } \\
\text { production standards, although they did } \\
\text { recognize genetic risks }\end{array}$ & $\begin{array}{l}\text { Recognized general concept. Listed three ways to reduce } \\
\text { genetic risks: 1) use some wild fish in brood stock, 2) } \\
\text { stock in a way that mimics natural, and 3) limit density }\end{array}$ & $\begin{array}{l}\text { Acknowledged presence and recommend } \\
\text { research in this area }\end{array}$ \\
\hline Kapuscinski et al. (1991) & $\begin{array}{l}\text { Does not explicitly state performance } \\
\text { standards, but are inferred in the text } \\
\text { especially conclusion section. For example, } \\
\text { error on the side of caution, maintain life } \\
\text { history patterns, maximize effective } \\
\text { population size }\end{array}$ & $\begin{array}{l}\text { Identified four genetic risks: 1) extinction, 2) loss of within- } \\
\text { population diversity, 3) loss of between-population diversity } \\
\text { (identity), 4) domestication divided into brood selection and } \\
\text { differences in hatchery and natural environment that result } \\
\text { in selection. Environmental components of traits negatively } \\
\text { altered by the hatchery could increase genetic risks. Lists } \\
\text { hatchery activity and genetic process involved in the four } \\
\text { genetic risks }\end{array}$ & $\begin{array}{l}\text { Recognized the impact of environmentally } \\
\text { modified traits that could hamper survival, } \\
\text { and inflict genetic risks. Hatchery fish should } \\
\text { be qualitatively similar to wild }\end{array}$ \\
\hline Currens et al. (1991) & $\begin{array}{l}\text { Monitoring and evaluation and, by } \\
\text { implication, performance standards should } \\
\text { be based on a program's specific objectives. } \\
\text { Performance standards are implied in the } \\
\text { text }\end{array}$ & $\begin{array}{l}\text { Lists genetic risks associated with artificial production as: } \\
\text { 1) loss of genetic diversity due to founder effects, genetic } \\
\text { drift and hybridization, 2) selection of traits } \\
\text { disadvantageous in nature, 3) removal of stimulus for } \\
\text { habitat protection, 4) implementing programs with no } \\
\text { definable end point, 5) financial uncertainty, 6) changing } \\
\text { social values }\end{array}$ & None \\
\hline $\begin{array}{l}\text { Columbia Basin Fish and } \\
\text { Wildlife Authority (1991) }\end{array}$ & $\begin{array}{l}\text { Performance standards should be identified } \\
\text { for each objeetive. Some possible perfor- } \\
\text { mance standards are indicated indirectly } \\
\text { throughout the report (see spawning } \\
\text { protocols for example). No specific list of } \\
\text { performance standards }\end{array}$ & & $\begin{array}{l}\text { Indirectly through general rearing and } \\
\text { release guidelines }\end{array}$ \\
\hline
\end{tabular}


Table A.2 (cont'd).

\begin{tabular}{|c|c|c|c|}
\hline $\begin{array}{l}\text { CITATION } \\
\text { (See Literature Cited) }\end{array}$ & PERFORMANCE STANDARDS & $\begin{array}{l}\text { IDENTIFICATION OF GENETIC } \\
\text { RISKS }\end{array}$ & $\begin{array}{c}\text { IDENTIFICATION OF } \\
\text { PHYSIOLOGICAL \& BEHAVIORAL RISKS }\end{array}$ \\
\hline Smith et al. (1985) & $\begin{array}{l}\text { Adult returns in treatment streams compared } \\
\text { to control streams appeared to be the } \\
\text { measure of success of outplanting }\end{array}$ & $\begin{array}{l}\text { The report reviewed selected literature on } \\
\text { genetic interactions between wild and } \\
\text { hatchery fish }\end{array}$ & None \\
\hline $\begin{array}{l}\text { Scientific Review Group } \\
\text { (1990) }\end{array}$ & $\begin{array}{l}\text { Recognized the need to develop perfor- } \\
\text { mance measures consistent with objectives }\end{array}$ & $\begin{array}{l}\text { Recognizes the need to detect and measure } \\
\text { genetic change and recommends focusing } \\
\text { attention on life history characteristics }\end{array}$ & None \\
\hline Riggs (1990) & No specific performance measures & $\begin{array}{l}\text { The entire report addresses genetic risks. } \\
\text { However, it identities three specific risks: } \\
\text { 1) extinction, 2) loss of within-population } \\
\text { genetic diversity, and 3) loss of between- } \\
\text { population diversity }\end{array}$ & None \\
\hline Isaksson (1988) & $\begin{array}{l}\text { Performance standards are not explicitly } \\
\text { stated, but repeated reference is made to } \\
\text { smolt-to-adult return rates and survival as } \\
\text { standards for comparison and program } \\
\text { evaluation }\end{array}$ & $\begin{array}{l}\text { Highlights the risk of "genetic } \\
\text { contamination" resulting from straying of } \\
\text { ranch-reared fish into neighboring } \\
\text { streams, but noted that straying may } \\
\text { benefit wild populations by introducing } \\
\text { new genetic material and reducing the } \\
\text { potential for inbreeding. Also emphasized } \\
\text { the Potential for selective breeding to } \\
\text { improve performance in ranching, but not } \\
\text { enhancement, programs }\end{array}$ & None \\
\hline
\end{tabular}


Table A.2 (cont'd).

\begin{tabular}{|c|c|c|c|}
\hline $\begin{array}{c}\text { ClTATION } \\
\text { (See Literature Cited) }\end{array}$ & PERFORMANCE STANDARDS & $\begin{array}{l}\text { IDENTIFICATION OF GENETIC } \\
\text { RISKS }\end{array}$ & $\begin{array}{l}\text { IDENTIFICATION OF } \\
\text { PHYSIOLOGICAL \& BEHAVIORAL } \\
\text { RISKS }\end{array}$ \\
\hline Taylor (1991) & $\begin{array}{l}\text { Performance standards are addressed obliquely } \\
\text { through a review of fitness-related traits (i.e., those } \\
\text { affecting survival and reproduction), evidence for } \\
\text { their variation among individuals and populations, } \\
\text { and evidence for environmental correlates }\end{array}$ & $\begin{array}{l}\text { Identifies risk of losing locally adapted traits in wild } \\
\text { populations through interbreeding with hatchery fish }\end{array}$ & $\begin{array}{l}\text { Reviews intraspecific variability in } \\
\text { physiological and behavioral traits thought to } \\
\text { have adaptive value }\end{array}$ \\
\hline Hindar et al. (1992) & $\begin{array}{l}\text { Does not consider programmatic standards but } \\
\text { reviews the potential impact of supplementation on } \\
\text { the performance of hatchery and wild fish } \\
\text { populations. Three general categories of impact } \\
\text { are noted: interbreeding, competition, and } \\
\text { introduction of pathogens }\end{array}$ & $\begin{array}{l}\text { Highlights genetic risks relating to hybridization, } \\
\text { outbreeding depression, reduced fitness, homogenization }\end{array}$ & $\begin{array}{l}\text { Reviewed literature for examples of changes } \\
\text { in performance traits (among hatchery fish } \\
\text { primarily) such as migration and concealment } \\
\text { that were presumably maladaptive }\end{array}$ \\
\hline Hard et al. (1992) & $\begin{array}{l}\text { Supplementation as a recovery measure should seek } \\
\text { to minimize genetic risk and maximize benefits to } \\
\text { the natural population. Success is inversely related } \\
\text { to the loss of genetic variability hatchery fish and } \\
\text { the extent to which hatchery and natural fish } \\
\text { diverge genetically. Post-release survival, fitness, } \\
\text { and adaptive potential are cited as performance } \\
\text { measures }\end{array}$ & $\begin{array}{l}\text { Genetic risks are discussed with reference to stock status, } \\
\text { broodstock management, hatchery environment and } \\
\text { protocols, the potential for genetic contamination, and } \\
\text { undesirable ecological interactions. Genetic risks should } \\
\text { be established before a supplementation program is } \\
\text { initiated }\end{array}$ & $\begin{array}{l}\text { Generally recognized but not discussed in } \\
\text { detail. The need to consider salmon } \\
\text { physiology and behavior in devising } \\
\text { successful release strategies was indicated }\end{array}$ \\
\hline Waples (1991) & $\begin{array}{l}\text { Changes within populations and interactions } \\
\text { between populations should be measured by } \\
\text { monitoring genetic and meristic characters, and } \\
\text { these data should be correlated with traditional } \\
\text { biological indices (survival rates, redd counts, } \\
\text { spawner-recruit ratios, etc.) }\end{array}$ & $\begin{array}{l}\text { Discusses genetic risks associated with hatchery practices } \\
\text { (e.g., inbreeding, artificial selection, and outbreeding } \\
\text { depression) and factors (e.g., broodstock management) } \\
\text { influencing their probability of occurrence and level of } \\
\text { impact. Emphasis is on hatchery populations rather than } \\
\text { natural populations }\end{array}$ & None \\
\hline
\end{tabular}




\section{Table A.3. Information contained in recent documents relevant to supplementation: Research and Recommendations}

\begin{tabular}{|c|c|c|}
\hline $\begin{array}{c}\text { CITATION } \\
\text { (See Literature Cited) }\end{array}$ & RECOMMENDED RESEARCH/MONITORING & RECOMMENDATIONS \\
\hline \multirow{2}{*}{ Miller et al. (1990) } & \multirow{2}{*}{ Recommend R\&D and monitoring listed specific research areas } & GENERAL \\
\hline & & $\begin{array}{l}\text { - Annual review of supplementation projects } \\
\text { - Identify (mark) hatchery salmon } \\
\text { - Factors related to survival need study } \\
\text { R \& D } \\
\text { - Identify limiting factors for wild production } \\
\text { - Impact of hatchery smolts on wild production \& migration } \\
\text { - Develop broodstock compatible with wild fish } \\
\text { - Identify natural production parameters for supplementation } \\
\text { - Explore use of streamside egg boxes }\end{array}$ \\
\hline \multirow[t]{4}{*}{ Kapuscinski et al. (1991) } & \multirow{4}{*}{$\begin{array}{l}\text { Favored the use of adaptive management. Other R\&D identified: } \\
\text { 1) causes of population decline, 2) population status, } 3 \text { ) proper } \\
\text { mixes of hatchery and wild in the hatchery broodstock and natural } \\
\text { spawning, 4) role of genetics and environment in life history, 5) } \\
\text { several hatchery studies. Risks due to selection and environmentally } \\
\text { altered fish. Rearing release and marking strategies, genetic risk of } \\
\text { increased variance in family size. No overall global design }\end{array}$} & $\begin{array}{l}\text { Supplementation should only be used with the goal of maintaining } \\
\text { genetic resources as first priority. Gives detailed rccommendationn } \\
\text { on choice of donor population (need to maintain similar genetic }\end{array}$ \\
\hline & & $\begin{array}{l}\text { resources, life history patterns and nature of originating } \\
\text { environments). Gives priorities for selecting target populations. } \\
\text { Mating methods - life history, effective populations. Hatchery rearing }\end{array}$ \\
\hline & & $\begin{array}{l}\text { - simulate natural incubation, simulate natural rearing, acclimate } \\
\text { hatchery fish, monitor for fitness, resolve uncertainty. Release } \\
\text { strategies - reduce stress, match natural age/dynamics, match }\end{array}$ \\
\hline & & size/time with natural, stocking densities. Handling returning adults \\
\hline Currens et al. (1991) & $\begin{array}{l}\text { Recommend research on: theory of genetic population structure of } \\
\text { the Columbia River salmon; develop tools for Population Viability } \\
\text { Analysis, describing genetic diversity and addressing polygenetic } \\
\text { variation. Also, need tools for describing historic genetic variation, } \\
\text { studies of local and regional cultures to design education programs }\end{array}$ & Identify conservation units and set up genetic reserves \\
\hline
\end{tabular}


Table A.3 (cont'd).

\begin{tabular}{|c|c|c|}
\hline $\begin{array}{c}\text { CITATION } \\
\text { (See Literature Cited) }\end{array}$ & RECOMMENDED RESEARCH \& MONITORING & RECOMMENDATIONS \\
\hline $\begin{array}{l}\text { Columbia Basin Fish and } \\
\text { Wildlife Authority (1991) }\end{array}$ & $\begin{array}{l}\text { Discusses the importance of research and monitoring and gives seven } \\
\text { steps: clearly define objective, identify, and develop experimental } \\
\text { design, collect data, interpret results, make adjustments in program. } \\
\text { The report also lists } 11 \text { genetic research areas }\end{array}$ & The entire report gives recommendations on several aspects of supplementation \\
\hline Smith et al. (1985) & $\begin{array}{l}\text { Recommended research on outplanting but did not identify general } \\
\text { topics }\end{array}$ & $\begin{array}{l}\text { Listed recommendations obtained from the literature. The authors' own } \\
\text { recommendations are: } 1 \text {. In streams managed for wild fish, adding hatchery fish } \\
\text { to streams to supplement natural production without affecting wild stocks may not } \\
\text { be possible. However, these guidelines will improve the chance of success: a) use } \\
\text { native or closely related stock, b) keep planting density within stream carrying } \\
\text { capacity, c) introduce fish using methods that minimii hatchery-wild interactions, } \\
\text { d) coordinate introductions of various life stages with existing wild populations, e) } \\
\text { operate the hatchery to ensure genetic quality of the fish. } 2 \text {. In streams managed } \\
\text { for hatchery fish smolt releases can quickly increase adult abundance }\end{array}$ \\
\hline $\begin{array}{l}\text { Scientific Review Group } \\
\text { (1990) }\end{array}$ & $\begin{array}{l}\text { Does not list specific research priorities but strongly recommends } \\
\text { timely organization of coordinated research on existing projects. } \\
\text { Stream classification and modelling are recommended as aids to } \\
\text { supplementation planning and evaluation }\end{array}$ & $\begin{array}{l}\text { The report posses the central question regarding supplementation: "Under what } \\
\text { set of conditions will supplementation of natural and wild production with hatchery } \\
\text { production add to total production of salmon, steelhead or other target fishes over } \\
\text { the long term?" Recommends research to answer the question }\end{array}$ \\
\hline Riggs (1990) & $\begin{array}{l}\text { Identifies the need for research but does not list specific research } \\
\text { needs }\end{array}$ & $\begin{array}{l}\text { The central recommendation of the report is to modify the Council's production } \\
\text { (doubling) goal to include: maintaining the genetic resources of salmon and } \\
\text { steelhead in native, naturalized and artificially propagated populations, with no } \\
\text { avoidable and irreversible loss of genetic diversity resulting from management } \\
\text { interventions or interactions }\end{array}$ \\
\hline
\end{tabular}


Table A.3 (cont'd).

\begin{tabular}{|c|c|c|}
\hline $\begin{array}{c}\text { CITATION } \\
\text { (See Literature Cited) }\end{array}$ & RECOMMENDED RESEARCH \& MONITORING & RECOMMENDATIONS \\
\hline Isaksson (1988) & $\begin{array}{l}\text { Formally acknowledges the historical importance of technical } \\
\text { innovation and experimentation in salmon ranching but does not } \\
\text { explicitly identify current research and monitoring needs }\end{array}$ & $\begin{array}{l}\text { Provides evidence to support argument that terminal fisheries should be imposed } \\
\text { and harvest restricted to the capacity of the least productive stock to protect wild } \\
\text { populations }\end{array}$ \\
\hline Taylor (1991) & $\begin{array}{l}\text { Suggests that emerging technologies such as DNA fingerprinting } \\
\text { combined with ecological studies can be used to estimate differential } \\
\text { fitness among phenotypes to improve the study of local adaptation. } \\
\text { Also recommends manipulative field experiments to evaluate the } \\
\text { effects of adaptive traits that have been altered through } \\
\text { interbreeding. By studying local adaptation we can better understand } \\
\text { the causes and magnitude of genetic and ecological diversity within } \\
\text { salmonid species, and use this as a basis for monitoring potential } \\
\text { genetic change following supplementation }\end{array}$ & None that pertain directly to supplementation \\
\hline Hindar et al. (1992) & $\begin{array}{l}\text { Recommends experimental releases of genetically marked hatchery } \\
\text { fish pool to full scale releases; also, monitoring of genetic } \\
\text { interactions between hatchery and wild populations }\end{array}$ & $\begin{array}{l}\text { Recapitulates management priorities and guidelines presented at the Fish Gene } \\
\text { Pools Symposium (Ryman, 1980). Novel recommendations include cataloging the } \\
\text { genetic characteristics of local wild populations prior to commencing operation, } \\
\text { and designating protected streams/stocks as genetic refuges. Describes ways to } \\
\text { minimize genetic risks (not all apply to supplementation): closed culture, } \\
\text { sterilization, careful design and siting of facilities, and local broodstock selection } \\
\text { and maintenance }\end{array}$ \\
\hline Hard et al. (1992) & $\begin{array}{l}\text { Many of the prescribed approaches are untested hypotheses rather } \\
\text { than proven concepts; while not explicitly stated appropriate } \\
\text { hypotheses can be extracted. Research needed to assess risk should } \\
\text { be conducted prior to program implementation; predicted and } \\
\text { measured gains in survivability and population status should be } \\
\text { weighed against genetic impacts. Methods suitable for monitoring } \\
\text { and evaluation are discussed }\end{array}$ & $\begin{array}{l}\text { Artificial propagation should neither impede the recovery of listed species nor } \\
\text { contribute to the decline of unlisted species. Provides information that can be } \\
\text { used to guide supplementation efforts in recovery situations. Recommends a } \\
\text { cautious approach of using hatcheries as a last resort, minimizing exposure (both } \\
\text { short- and long-term) to hatcheries facilities, and miniiiziig selective forces in } \\
\text { the hatchery }\end{array}$ \\
\hline Waples (1991) & $\begin{array}{l}\text { Further development and application of Genetic Stock Identification } \\
\text { (GSI) techniques is advocated. Genetic changes in hatchery } \\
\text { populations should be carefully monitored, and causes identified and } \\
\text { corrected. Computer simulations can be used to predict and evaluate } \\
\text { genetic changes. Pm-supplementation baseline data are desirable. } \\
\text { Gametic disequilibrium analysis can be used to detect introgression } \\
\text { of hatchery and natural fish. Various alternative genetic monitoring } \\
\text { approaches are discussed }\end{array}$ & $\begin{array}{l}\text { Genetic considerations must be an integral part of any comprehensive management } \\
\text { plan. Ensure that existing levels of genetic variability are not compromised by } \\
\text { management practices. Establish comprehensive monitoring programs }\end{array}$ \\
\hline
\end{tabular}




\section{RASP SUMMARY REPORT SERIES PART II}

SUPPLEMENTATION THEORY

December, 1992 


\section{RASP CONTRIBUTORS}

Scientists with expertise and interest in supplementation have contributed to this report, among them are: Tom Backman, Ed Bowles, Craig Busack, Rich Carmichael, Duane Fickeisen, Larry Lestelle, Jim Lichatowich, Rich Lincoln, Lars Mobrand, Willa Nehlsen, Rich Turner, Tom Vogel, and Bruce Watson. Numerous constructive and insightful comments to previous drafts were also received from the Scientific Review Group. 


\section{TABLE OF CONTENTS}

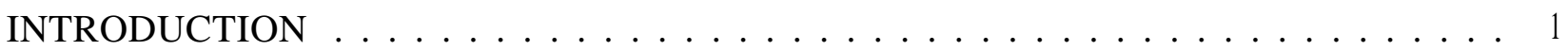

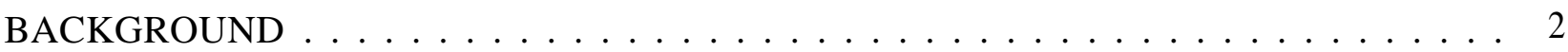

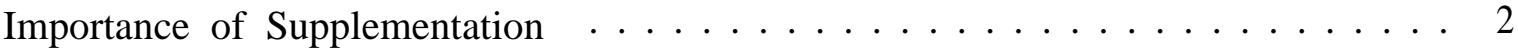

Origin and Goals of RASP . . . . . . . . . . . . . . . . . 3

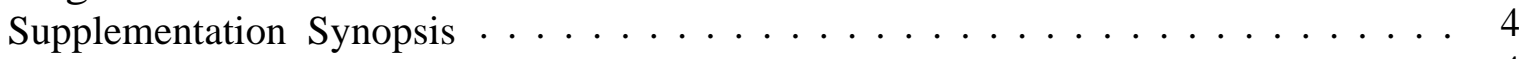

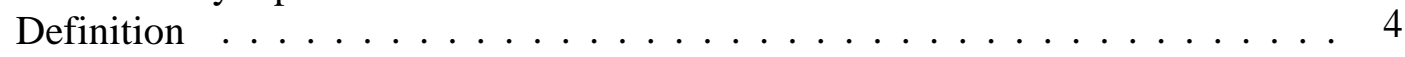

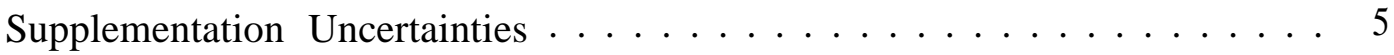

Planning Guidelines ......................... 5

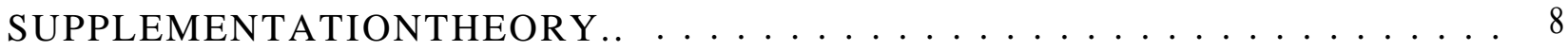

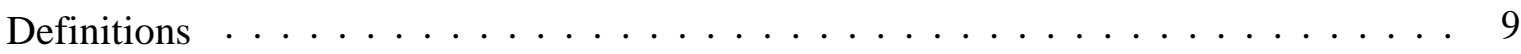

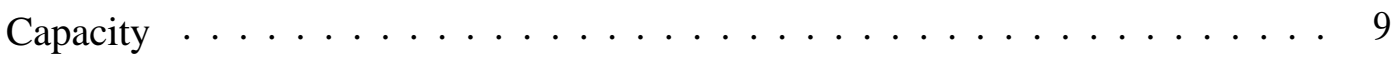

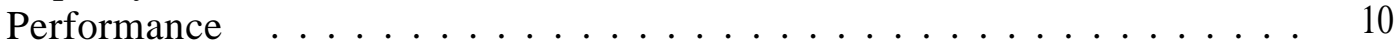

Stock-recruit relationship . . . . . . . . . . . . . . 10

The Role of Capacity in Supplementation Programs . . . . . . . . . . . . 13

Boundaries and Expectations of Supplementation . . . . . . . . . . 17

APPLICATION OF SUPPLEMENTATION THEORY TO PLANNING . . . . . , . . . . 22

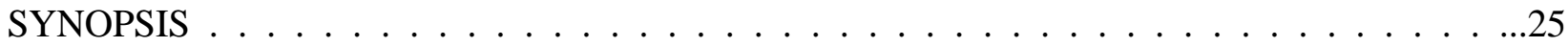

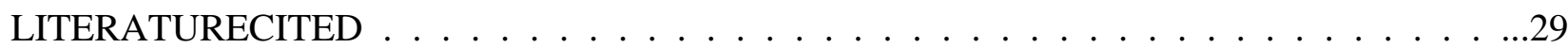




\title{
RASP SUMMARY REPORT SERIES: PART II.
}

\author{
SUPPLEMENTATION THEORY
}

\section{INTRODUCTION}

This report describes a theoretical basis for planning and implementation of supplementation programs in the Columbia Basin. Our purpose is to synthesize and characterize our current understanding of the theoretical aspects of supplementation. This information provides a bridge between the description of supplementation in Part I and the implementation guidelines contained in Parts III and IV of this report series. The application of these concepts is developed further in Parts III and IV.

The use of supplementation to achieve the goal of increasing natural production has recently received increased emphasis despite questions regarding the risks and benefits of supplementation (Waples 1991, Miller et al. 1990, Nickelson et al.1986, and McGie 1980). Although the increased emphasis is new, managers have high expectations for its success in the Columbia Basin (Table 1).

Managers implementing a relatively new program on a large scale, particularly where expectations are high, should examine the program's basic assumptions as part of the analysis of risks and benefits and to determine if the expectations of the program are reasonable. The description of a supplementation theory is an important step in the placement of boundaries on expected risks and benefits, the development of analytical models of supplementation, the identification of standards for performance evaluation, and as an aid to the development of planning guidelines.

This report is not intended to give specific answers to questions about the risks and benefits of supplementation or to give direction to the manager trying to plan a supplementation project, however, it does develop the foundation for Parts III and IV which do contain practical advice for managers designing supplementation programs. 
Table 1. Percent of total production increases attributable to supplementation in the Integrated System Plan. Computed from System Planning Model output'. (Duane Anderson, NPPC, personal communication)

\begin{tabular}{|c|c|c|c|c|c|}
\hline \multirow[b]{2}{*}{ SPECIES/STOCK } & \multicolumn{5}{|c|}{ COLUMBIA RIVER REGION } \\
\hline & LOWER & Mm & SNAKE & UPPER & ALL \\
\hline LATE COHO & $97.7 \%$ & & & & $97.7 \%$ \\
\hline EARLY COHO & $100.0 \%$ & $100.0 \%$ & & & $100.0 \%$ \\
\hline FALL CHINOOK & $0.0 \%$ & $37.4 \%$ & $51.2 \%$ & $0.0 \%$ & $8.6 \%$ \\
\hline SPRING CHINOOK & $88.4 \%$ & $64.0 \%$ & $74.3 \%$ & $34.75 \%$ & $65.4 \%$ \\
\hline SUMMER CHINOOK & & $6.3 \%$ & $66.9 \%$ & $38.4 \%$ & $43.5 \%$ \\
\hline SUMMER STEELHEAD A & $100.0 \%$ & $25.6 \%$ & $95.5 \%$ & $73.9 \%$ & $71.8 \%$ \\
\hline SUMMER STEELHEAD B & & & $72.0 \%$ & & $72.0 \%$ \\
\hline WINTER STEELHEAD & $48.0 \%$ & $100.0 \%$ & & & $60.2 \%$ \\
\hline ALL & $45.4 \%$ & $47.5 \%$ & $78.2 \%$ & $34.5 \%$ & $52.4 \%$ \\
\hline
\end{tabular}

'The Integrated System Plan addressed other stocks that were not modelled and are not included in Table 1.

\section{BACKGROUND}

\section{Importance of Supplementation}

This is the second in a series of four summary reports. Our goal is to make findings from the Regional Assessment of Supplementation Project (RASP) more accessible by grouping related topics into smaller but complete narratives on important aspects of supplementation. RASP has published the following reports under the general title RASP Summary Report Series: Pan I, Background, Description, Performance Measures, Uncertainty and Theory; Part II, Theoretical Framework and Models; Part III, Planning Guidelines; and Part IV, Regional Coordination of Research and Monitoring.

Supplementation is a major element of the program to increase salmon production in the Columbia Basin. The Fish and Wildlife Program of the Northwest Power Planning Council (NPPC) uses three approaches to protect and enhance salmon and steelhead in the Columbia River: 1) improve fish production; 2) improve passage in the mainstem; and 3) improve 
harvest management to support the rebuilding of fish runs (NPPC 1987). The fish production segment calls for a three-part approach: natural production, hatchery production, and supplementation. The ISP (CBFWA 1991) indicates that the fish management agencies and tribes expect supplementation to provide over half of the total production increases (Table 1).

\section{Origin and Goals of RASP}

RASP originated from a recognition by basin fisheries managers of a need to review supplementation and from a call for a review by the Columbia Basin Fish and Wildlife Authority. In August 1990, the NPPC gave conditional approval to proceed with the final design phase of the Yakima and Klickitat Production Project. The Council called on the Bonneville Power Administration (BPA) to "fund immediately a supplementation assessment to reevaluate, prioritize, and coordinate all existing and planned supplementation monitoring and evaluation activities in the basin.. . Provid[ing] for the participation of the fishery agencies and tribes and others having expertise in this area." RASP was initiated as a result of that request by the NPPC. Coordination of supplementation research was also recommended by the Supplementation Technical Work Group.

RASP addresses four principal objectives:

- $\quad$ provide an overview of ongoing and planned supplementation activities and identify critical uncertainties associated with supplementation

- construct a conceptual framework and spreadsheet model which estimates the potential benefits and risks of supplementation and prioritizes uncertainties based on their projected effects on the risks and benefits of a project

- $\quad$ provide guidelines for the development of supplementation projects

- develop a plan for regional coordination of research and monitoring.

RASP has further divided the four broad objectives into 12 technical topics:

- definition of supplementation

- description of the diversity of supplementation projects

- $\quad$ objectives and performance standards

- $\quad$ identification of uncertainties 
- $\quad$ supplementation theory

- development of a conceptual model of supplemented populations

- development of a spreadsheet model of risks and benefits of supplementation

- $\quad$ classification of stocks, streams, and supplementation strategies

- $\quad$ regional design of supplementation evaluation and monitoring

- $\quad$ guidelines for planning supplementation projects

- $\quad$ application of the spreadsheet model to supplementation planning

- $\quad$ experimental design and decision making with uncertainty.

Progress in each topic area has been presented in regular progress reports which are available from the Bonneville Power Administration.

\section{Supplementation Synopsis}

Definition RASP defined supplementation as: Supplementation is the use of artificial propagation in an attempt to maintain or increase natural production while maintaining the long-term fitness of the target population, and keeping the ecological and genetic impacts on nontarget populations within specified biological limits.

The purpose of supplementation is to increase or maintain natural production ${ }^{2}$ and that objective must be achieved without a loss of long-term fitness in the target population. Each supplementation project must hold the genetic and ecological impacts on nontarget populations to specified limits. Supplementation is clearly a departure from conventional hatchery programs and it reflects a changing management paradigm (for a historical perspective on the change see Part I of this series).

Supplementation presents the managers with a new challenge: to integrate natural and artificial production systems in the Columbia Basin in a way that yields sustainable increases in total and natural production. This will call for new ideas in the physical design and operation of hatcheries as well as a better technical understanding of genetics, behavior, competition and predation - fields that were not strongly emphasized in the domain of artificial propagation until recently.

\footnotetext{
${ }^{2}$ Natural production - production resulting from naturally produced progeny that have spent their entire lives in their natural habitat.
}

RASP Summary Report Series, Part II: Supplementation Theory

December, 1992 /Page 4 
Supplementation Uncertainties Supplementation as defined above is a nascent management strategy (CBFWA 1991). Since we have limited management experience and a limited research data base, supplementation must be implemented with substantial uncertainty. An important purpose of planning is to identify and manage the critical uncertainties - those uncertainties with the potential to determine success or failure of the project.

Supplementation uncertainties are a product of three factors: 1) the ecological factors that determine productivity in the stream ecosystem, or our perception of them, 2) the objectives of the project, and 3) the supplementation strategies. The presence of uncertainty automatically presents the manager with risk - risk of failure, risk of unintended impacts (genetic or ecological) and risk of future surprise outcomes. Uncertainty and risk are inseparable elements in fisheries programs. Where you find one you will always find the other (Figure 1).

Risk can be characterized and assessed through models that substitute assumptions for the critical uncertainties or by the simple listing of uncertainties and review of the literature. The critical uncertainties must be "managed" to reduce or contain the risks of project failure. One step to reduce risk to acceptable levels is to monitor the appropriate parameters in a way that gives early warning of a problem. RASP calls this "risk containment monitoring." Research carried out within an adaptive management framework is an additional way to manage uncertainties and reduce risk. (For a detailed discussion of uncertainties see Part I of this report series.) The need to identify and manage the production, genetic and ecological uncertainties associated with supplementation implies careful planning and evaluation of supplementation projects.

Planning Guidelines Planning guidelines developed by RASP are comprised of 8 steps (Figure 2). The first step establishes the project's goals; steps 2 to 4 are fact-finding and descriptive; steps 6 and 7 are analysis; step 8 is evaluation. For a detailed presentation of the planning guidelines, see Part III of this report series.

- Step 1 -- the objectives describe the desired future condition of the stream/stock system (expected benefits);

- Step 2 -- the template describes the healthy stream/stock system; Step 3 -- the patient describes the current condition of the stream/stock system;

- Step 4 -- the diagnosis identifies limiting factors that prevent the patient from reaching the objective;

- Step 5 -- at this point the original objective should be reviewed and revised if appropriate; 


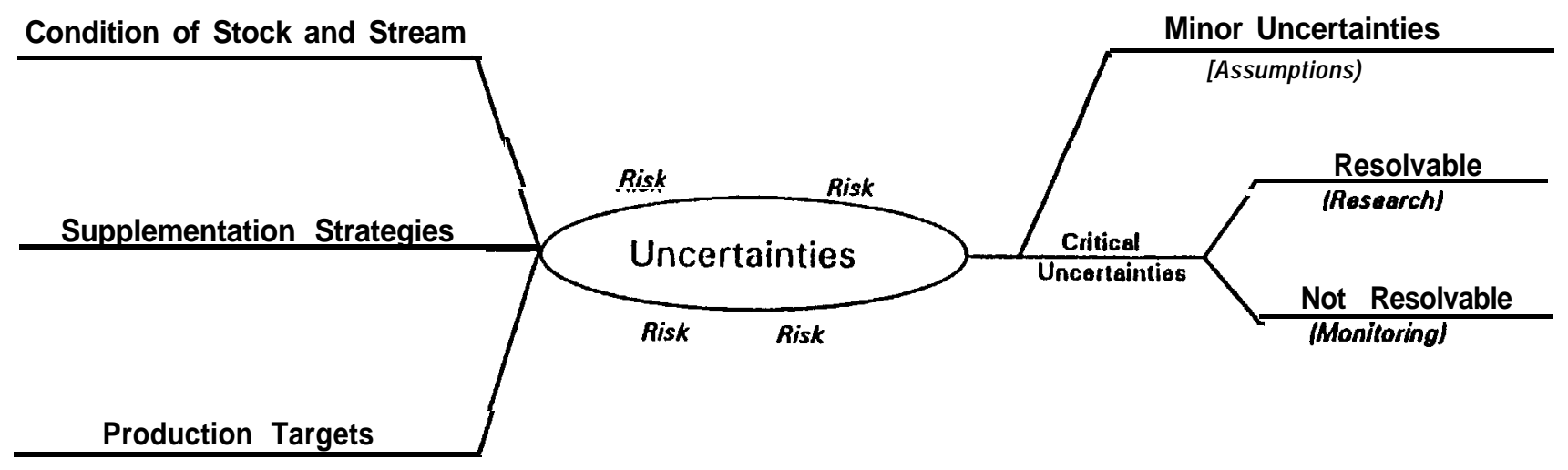

Figure 1. Schematic representation of the origin and treatment of supplementation uncertainties. 


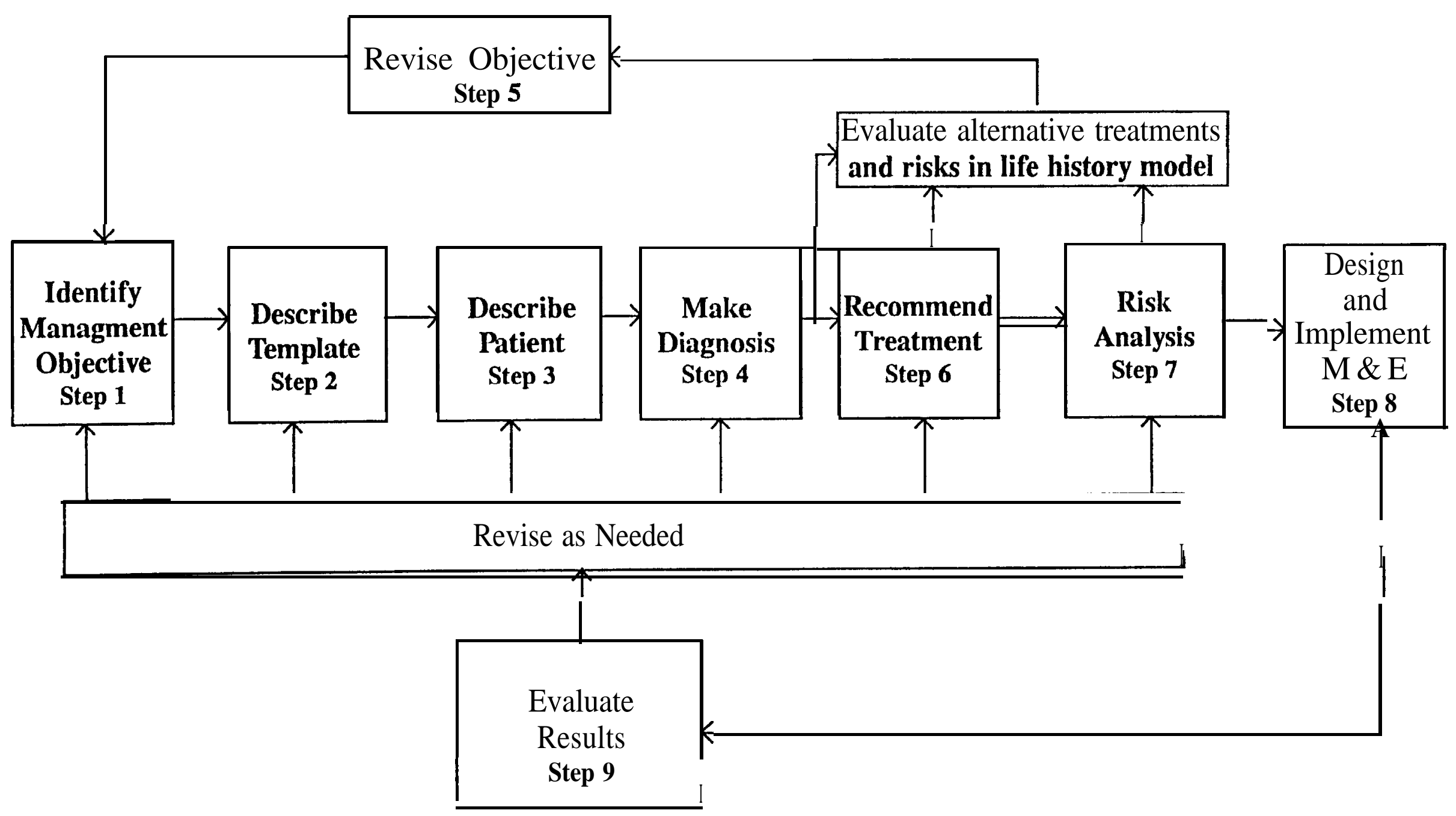

Figure 2. A Sequence of Planning Steps for Supplementation Projects. 
- Step 6 -- the treatment describes the supplementation strategies expected to realize the benefits set forth in the objective;

- Step 7 -- risk analysis describes the uncertainties associated with the recommended treatments; and

- Step 8 -- monitoring and evaluation (M\&E) presents general guidelines for the design of M\&E.

The planning analysis prescribed by RASP includes three elements important to the life history-habitat relationship of the target stock: geography, time, and biology. The salmon's life history is comprised of important biological functions such as spawning, migration, feeding, and escaping predators and the series of geographically and seasonally connected places where those functions are carried out (Thompson 1959). The increase in natural production achieved through the use of supplementation is a test of our understanding of the relationships among the life histories of the target stock, the natural habitat and artificial spawning, rearing and release practices.

\section{SUPPLEMENTATION THEORY}

The expectation that we can increase natural production by adding artificially propagated fish to natural habitats is based on our understanding of the artificial and natural production systems. Realizing the expected increases in production depends on how well the two systems are integrated The theory presented here is an attempt to describe important features of natural and artificial production systems as a basis for the development of supplementation planning and monitoring and evaluation $(\mathrm{M} \& \mathrm{E})$ guidelines. In biology, fundamental principles are generally not stated as laws but as frameworks of concepts (Mayr 1982). The theory described in this report is comprised of framework of concepts relevant to the development of a supplementation program.

Biologists often view the biological systems that support and produce important fish species such as Pacific salmon as having different levels of organization, i.e., physiological system, individual organism, population and community (Warren 1971). Although the levels of biological organization are interlinked, managers often concentrate their efforts and define their programs within the limits of particular levels (Warren 1971). Our development of a supplementation theory emphasizes the population or stock level of organization. Although managers often regulate harvest on stock aggregates, contemporary restoration employing artificial propagation is usually targeted on a specific stream/stock system. The definition of supplementation (see page 4) also focuses attention on the population - the need to avoid

RASP summary Report Series, Part II: Supplementation Theory

December, 1992 / Page 8 
genetic and ecological impacts on target and non-target populations. Stocks, as defined by Ricker (1972), are the basic management units upon which the conservation of the species depends (Rich 1938). It is the diversity contained within and between stocks that must be conserved if management of the fisheries is to be sustainable in the face of natural and manmade changes in the environment.

The focus on the population level of organization does not mean that the physiological condition of supplemented fish or the behavioral differences between individual wild and hatchery fish and other questions outside the population level are not important. It does imply that the principal uncertainties related to supplementation will ultimately be evaluated at the population level. We want to answer the question: Did natural production of the supplemented population increase without imposing unacceptable impacts on long-term fitness and productivity to target and nontarget populations in the subbasin? That is basically a population level question.

\section{Definitions}

Supplementation theory ${ }^{3}$ presented here is a framework comprised of three concepts:

Capacity - Each stream/stock system to be supplemented has a potential capacity for natural production which is determined by the interaction of the biotic and abiotic components of the system including all the habitats inhabited by the stock throughout its life cycle. Potential capacity is the theoretical upper limit or boundary of production for a given stream/stock system. It always constrains production to a lower level. Since potential capacity depends on the optimum interaction of many biotic and abiotic elements, it is rarely achieved, and its value is in recognizing conceptual boundaries on production in a qualitative way. Although capacity cannot be empirically measured, a qualitative assessment of the salient features of historic and current capacities for natural production should be a prerequisite to any supplementation program. Managers need to address the question: Given changes in the factors that determine the capacity of a system to be supplemented, are the expectations for an increase in natural production reasonable? Potential capacity and the prevailing environmental system determine the realized capacities (that portion of the potential capacities that can be actually achieved in a given stream stock/system under different environmental conditions)(Warren et al. 1979).

\footnotetext{
${ }^{3}$ In the development of this theory we have made use of the ideas and terminology found in various publications authored by Professor Charles Warren. We have cited specific publications in the text. Dr. Warren described a general theoretical basis for biological systems. Our approach is much narrower in scope focusing on supplemented populations of anadromous salmonids and therefore our use of terms might differ from that of Dr. Warren.
} 
Hatchery facilities, the genetic structure of the hatchery brood stock, and rearing and release procedures influence realized capacities for natural production in supplemented systems.

Performance - Performance of a stream/stock system is that part of the realized capacity that is measured in terms of interest to the fisheries manager - production and productivity of a target population, for example. Performance is an outcome of the operation of the system at all levels of biological organization even though it may be measured at a specific level. Although performance can be measured as production and productivity, it cannot be interpreted or evaluated without information on the specific environment ${ }^{4}$, i.e., we cannot explain or evaluate performance (production) of a population without a knowledge of its environment (flows, condition of the spawning gravel, temperature, etc.). For a supplemented system, where an evaluation of the outcome of the program is important, the population and its environment must be monitored.

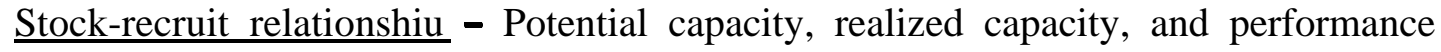
provide a conceptual basis for describing a supplemented salmonid system. To gain further insight, we have found it helpful to examine those concepts through the lens of a stock-recruitment relationship. Stock-recruitment relationships are a way of expressing the performance of a stream/stock system. They are based on a fundamental assumption in fisheries management of a relationship between the quality and quantity of a spawning population and recruitment of the adult progeny. It is because of the latter that we have included stock-recruitment in our conceptual framework.

Spawner-recruit data fitted to a Beverton-Holt model often show considerable variation around the calculated relationship (Figure 3 ). This variation is referred to as noise or background variability. However, in our conceptual framework, the noise around a single curve is interpreted as a family of relationships (Figure 4). Each curve describes the realized capacity of a stock for a given environmental condition over a range of spawning densities. The family of curves describes the realized capacity of the system and each observation or point is a measured performance. Potential capacity is the ultimate production possible for an ideal combination of biotic and abiotic elements of the system.

${ }^{4}$ In this text the terms environment and habitat have the following definitions:

Habitat - the actual physical setting the salmon lives in or migrates through. Habitat is the riffle or pool, the overhanging vegetation, substrate and water. Environment - the habitat including the surrounding landscape, climate, etc. that indirectly influence habitat.

RASP Summary Report Series, Part II: Supplementation Theory 


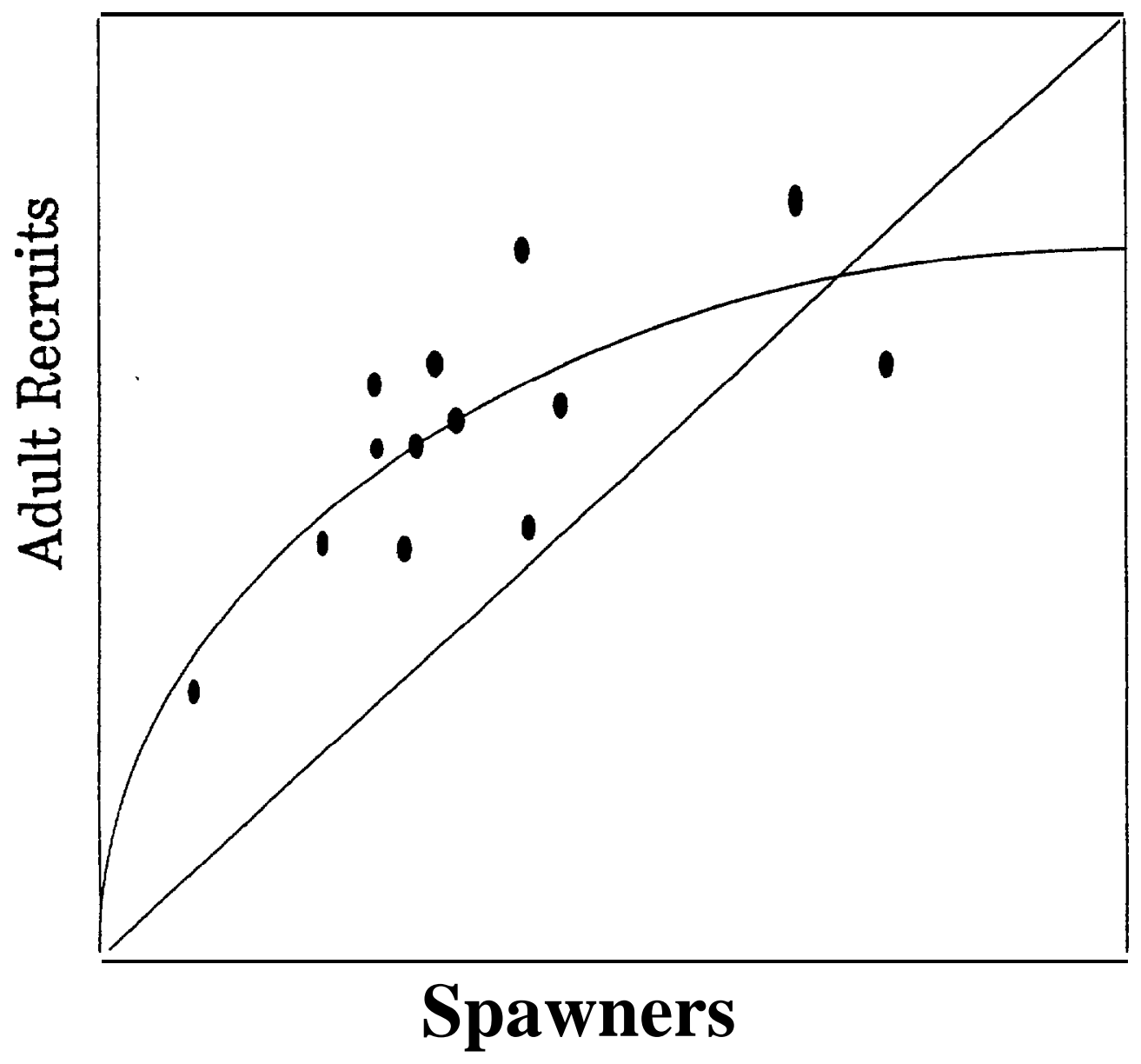

Figure 3. Hypothetical stock-recruit relationship for a salmon population. 


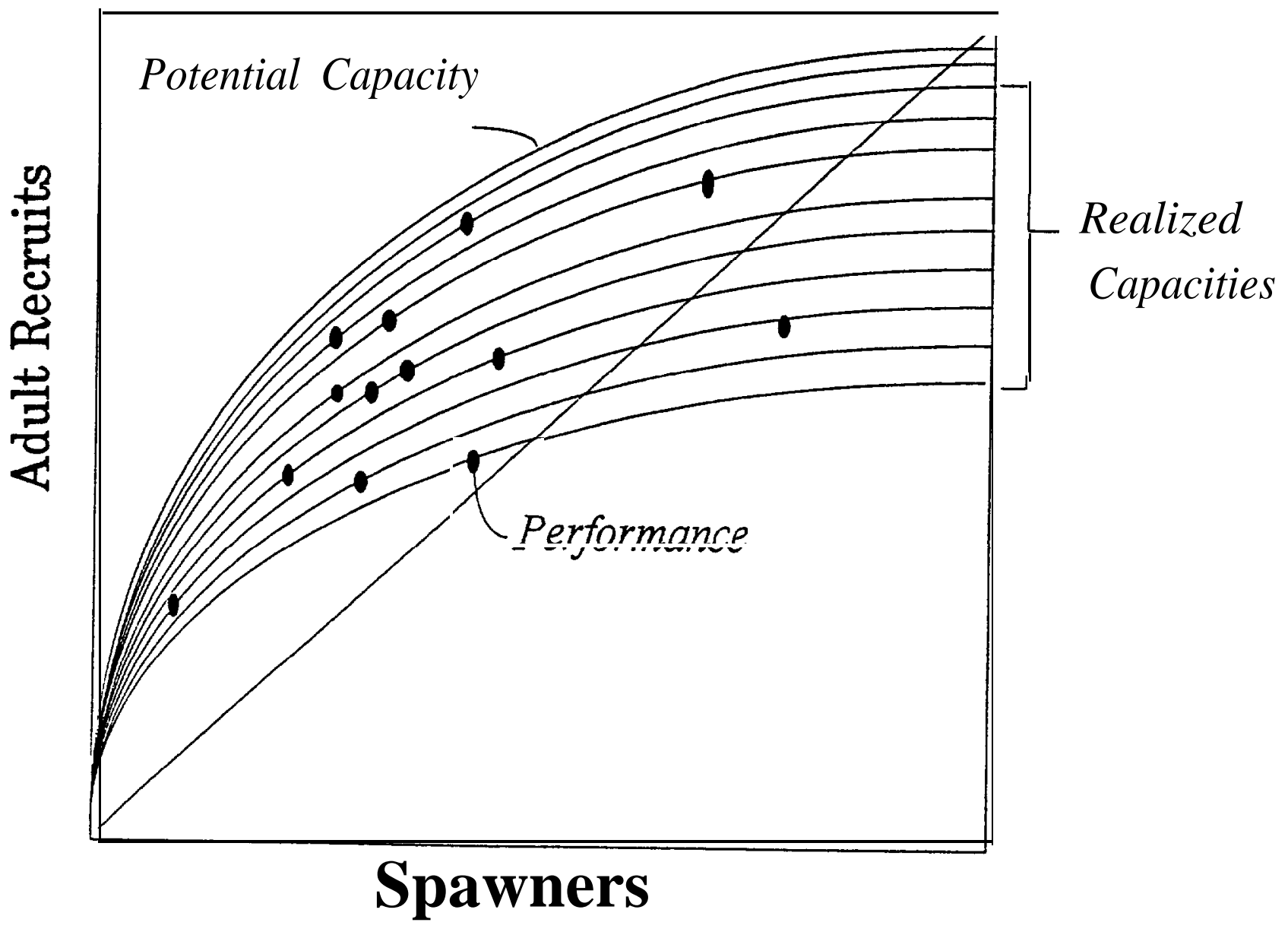

Figure 4. Capacity, realized capacity and performance illustrated through stockrecruitment relationship. (See text for explanation of terms.) 


\section{The Role of Capacity in Supplementation Programs}

Interaction among elements of the environment (e.g., geomorphic setting, vegetation, climate) and the biological system (e.g., stock life histories, genetic structure and diversity of the stock and competitors and predators) determine the potential capacity of the system to produce salmonids. A system defined in terms of anadromous salmonids includes the chain of habitats (subbasin, mainstem, estuary and ocean) the populations pass through or reside in throughout their life history as well as the competitors and predators in each of those habitats. The relationship between the sequence of habitats and the salmon population is dynamic, i.e., the timing of the use of the habitats by multiple life histories of a stock is an important component of capacity.

Our use of the term capacity is consistent with Warren et al. (1979) in that we use it as a theoretical concept. Although it can be discussed and qualitatively described, it can never be empirically measured. Realized capacity is indexed in a set of performances assessed under different environmental conditions. Potential capacity can be thought of as the ultimate production reality, the ultimate boundaries or constraints on the scope of production.

Potential and realized capacity are comprised of and encompass all the possible responses of a population of interest to variations in the environmental and biological systems.

Potential capacity can change with the long-term evolution of the physical attributes of the system. An exception is the rapid change brought on by human manipulation such as dam building or natural phenomena such as massive land slides. A dam or landslide may rapidly change a system but the effect will remain for a long time. In the mainstem Columbia, dams are long-term modifications of the habitat that alter capacity of the system through the inundation of riverine habitat. In addition, mortality caused by the dams and reservoirs is also an important determinant of the capacity of subsystems whose juveniles and adults must pass those dams. Variable flows and changes in dam operation cause year-to-year fluctuations in mortality at the dams and influence realized capacities indexed through performance measures such as survival. The same rationale would indicate that long-term cycles in ocean productivity (Ware and Thompson 1991) describe an oscillation in capacity; although, annual variation in ocean upwelling within those oscillations will influence the annual measures of performance (Nickelson et. al. 1986).

In addition to the environmental components illustrated in the examples above, capacity is determined by biological features of the stream/stock system. A major difference between the physical environment and the biological system is the ability of the components of the biological system to retain their histories through inheritance (Mayr 1988). The retention of historical experience in the genotype permits the population to adapt to its environment and to retain the probability of adapting to changes in its environment. It is critical to use knowledge of adaptation in the design of supplementation projects to ensure successful 
integration of natural and artificial production. Warren and Liss (1980) have argued that knowledge of adaptation should be the basis of sound fisheries management and science.

An important determinant of capacity is the degree to which a population has adapted to the range of environmental conditions it normally encounters in the system (subbasin, mainstem estuary and ocean). Human activities that shift environmental conditions so much that there is little overlap with the range of conditions to which the population is adapted can threaten the population's existence or productivity and ultimately can alter the system's capacity. Conversely, a stock's genetic structure can be altered by selective fisheries or hatchery practices, thus reducing the degree of adaptation to the environment. It is important to remember that the physical environment and the adaptation of the population to that environment are inseparable components of capacity. This means, for example, that a definition of capacity that merely relates habitat area to smolt output is not consistent with our use of the term capacity because it does not attempt to account for the influence of adaptation. The adaptation or lack of adaptation of the native stock to current habitat conditions is an important consideration in planning of supplementation projects. In addition hatchery practices must be designed to prevent loss of adaptation or genetic drift.

Life history is one way to evaluate the adaptation of a population to its environment. The relationship between life history and environment is adaptive (Schaffer and Elson 1975), and therefore, an important determinant of capacity. For example, migration timing of fall chinook salmon in the Lewis River, Washington, was suggested as an important determinant of natural production (McIsaac 1990). In Eucher Creek, Oregon, Nawa et al. (1988) determined that the time of spawning and the age structure of adult fall chinook were important determinants of incubation survival in unstable streambeds. A mismatch between the life history of hatchery stock and flow patterns reduced the success of coho supplementation in Oregon's coastal streams (Nickelson et al. 1986). Reimers (1973) and Schluchter and Lichatowich (1977) found multiple juvenile life histories in stocks of chinook salmon from the Sixes and Rogue rivers in Oregon. The different life histories exhibited different patterns of habitat utilization and made different contributions to the adult production. A diversity of life histories permits greater capacity by making optimal use of habitat and increases resiliency, which is important to sustaining production. These few examples illustrate the importance of the relationship between life history and the environment.

Life history patterns can be classified in many ways depending on the objective and point of view (Warren and Liss 1980). For our purpose, the important life history traits are those that are indicators of adaptation to a stream's habitat and are also associated with the measures of performance i.e., post-release survival, reproductive success, long-term fitness and ecological interactions (see Part I of this report series).

RASP Summary Report Series, Part II: Supplementation Theory

December, 1992 /Page I4 
Supplementation adds another component to the realized capacities of salmon production systems - the physical size and operational practices of the hatchery. Hatcheries can be considered a subunit of the salmon production system. In the hatchery, the manager exercises control over the environment for the purpose of increasing survival during the term of captivity of the salmon. Because hatcheries do circumvent much of the freshwater incubation and rearing mortality, they may be considered analogous to a "super tributary" from the standpoint of smolt production. The release of hatchery-reared fish may contribute to natural production in underseeded subbasins. The release of smolts may also add an incremental production to that obtained from smolts naturally produced in the subbasin. Although hatcheries can control habitat variability and improve survival during captivity, hatchery practices can also alter long-term fitness or life histories which reduces the capacity. In addition, hatchery-induced behavior and ecological effects can influence post-release survival (performance) of the hatchery fish relative to naturally produced salmon. So hatcheries can both improve (super tributary) and decrease capacity of a stream/stock system.

In the past, performance of the hatchery was often limited to measures of production, i.e., number of eggs taken or pounds of smolts released. However, in supplemented systems, the measure of hatchery performance needs to be broadened to be consistent with the objective of increasing natural production and with the role of the hatchery in determining system capacity. From that standpoint, hatchery performance must include measures that reflect the idea that capacity is a function of the population's adaptation to the system's environment, i.e., genetics of the population and/or its life history patterns should be monitored. The source and method of obtaining brood stock, brood stock management, breeding strategies, and rearing and release strategies are important considerations in the design of hatcheries which are intended to supply fish for supplementation.

The existence of a relationship between the quality and quantity of naturally spawning parents and the recruitment of their offspring is a fundamental assumption underlying many fisheries management programs. Quality of the parents refers to the genetic structure of the stock and its adaptation to the prevailing environment which was discussed earlier. The relationship between the quantity of spawning parents and recruitment of their progeny is often explained through stock-recruit models which express performance as a function of density-dependent regulation.

Throughout its life history a population of salmon is subjected to density-dependent and density-independent mortality (Figure 5). Survival from fry to parr and parr to smolts are shown in Figure 5 to be a function of the density of the population. This has important implications to supplementation programs which attempt to increase the density of fry, par-r, or smolts - the life stages that are subjected to density-dependent regulation. Even where it is determined that freshwater habitat is underseeded, the life stage, timing, location, and stock released into the stream can, if not carefully considered, reduce the benefits of supplementation through density-dependent processes or as Royal (1972) has suggested, the 

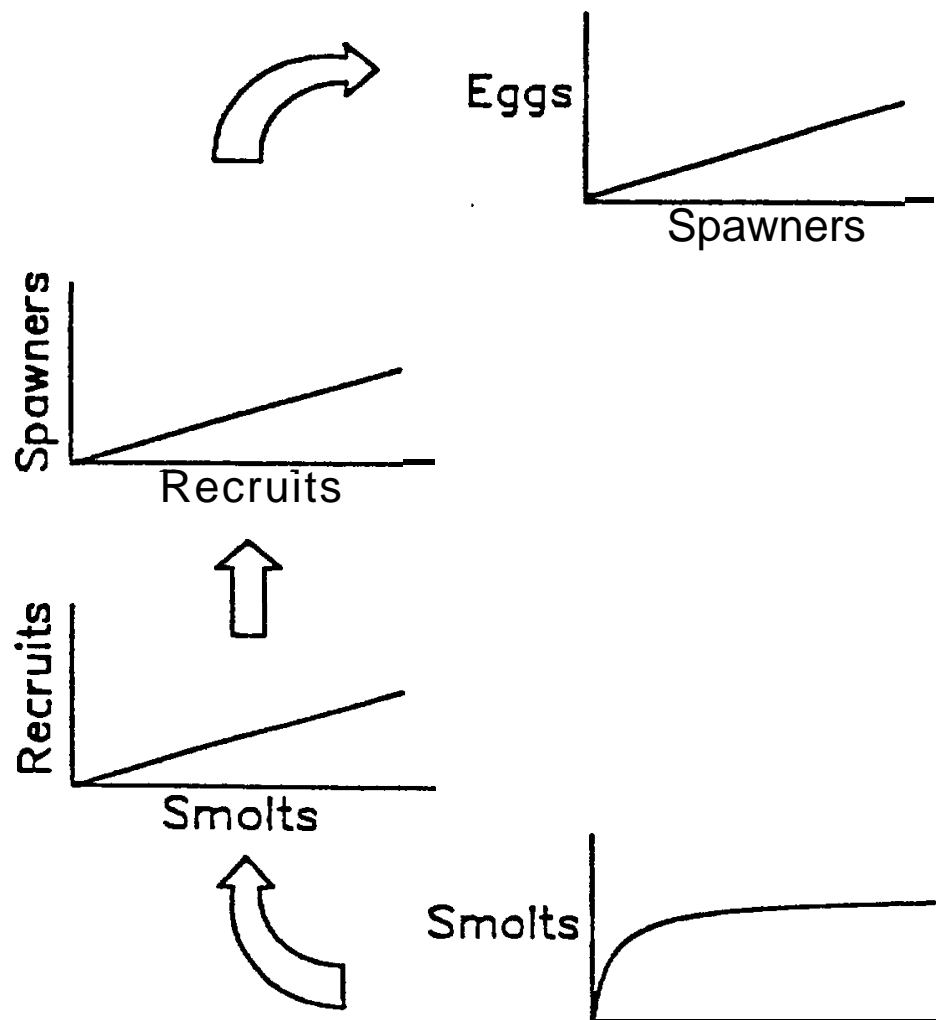

Spawners
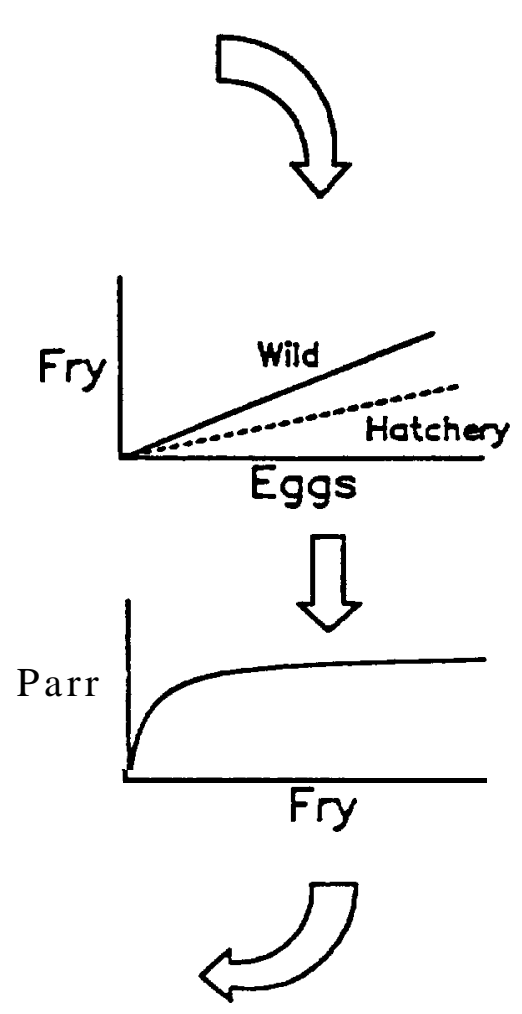

Figure 5. The life-history relations that would be the primary components of a model to evaluate strategies to supplement wild stocks of salmon and steelhead with hatchery fish. The dashed line in the egg-to-fry relation illustrates how the production of fry from hatchery spawners would be less than that from wild spawners if the hatchery fish were less fit (from Bjornn and Steward). 
imposition of density barriers. Since supplementation adds individuals to the habitat and seeks to increase density, its role in regulating recruitment through density-dependent process must be considered in the design and scale of projects.

\section{Boundaries and Expectations of Supplementation}

Habitat degradation as well as density-independent mortality can reduce realized capacity of a stream/stock system to a fraction of its historical level (Figure 6). This may occur at any stage in the life cycle.

In the case of density-dependent mortality, the realized capacities of the stream/stock system, although less than historic, may represent full seeding of the degraded habitat. In this case, since the habitat is fully seeded, natural production cannot be increased through

supplementation without restoration of at least part of the historical capacity. In this situation, supplementation is used to speed the rebuilding of the natural run after the habitat has been improved. Figure 7 shows the capacity for natural production has been restored through habitat restoration, the restoration of natural capacity was accelerated through supplementation, and in addition, realized capacity has been artificially incremented through hatchery production.

Two outcomes of the sequence of events shown in Figures 6 and 7 are presented in Figure 8 . In both outcomes, capacity is reduced by habitat degradation, then it is increased by a combination of habitat restoration and supplementation. While supplementation is in progress there is an additional component of production attributed to artificial propagation - the super tributary. When supplementation is terminated, natural production in scenario A continues at the new level of the restored habitat whereas in scenario B, natural production drops below the presupplementation level. Scenario B could result from inappropriate hatchery practices causing reduced fitness of the stock, indicating a failure of the supplementation program.

Large increases in density-independent mortality such as adult or juvenile mortality at dams and adult harvest can artificially limit smolt production in individual subbasins i.e., not enough spawners return to the subbasin to fully seed the habitat. One way to visualize this situation is through a shift in the replacement line in the relationship between spawners and the number of smolts leaving the subbasin (Figure 9). Managers attempting to increase natural production in stream/stock systems in this condition are faced with a particularly difficult problem. For example, assume smolt production in the stream/stock system shown in Figure 9 were increased by enough hatchery-reared fish to ensure that the returning adults fully seeded the habitat. The natural density-dependent limitation would not permit sufficient natural smolt production in the subbasin to overcome the density-independent (smolt-to-adult) mortality and fully seed the habitat in the succeeding generation. Supplementation alone could never restore the complete natural production cycle to historical levels. 


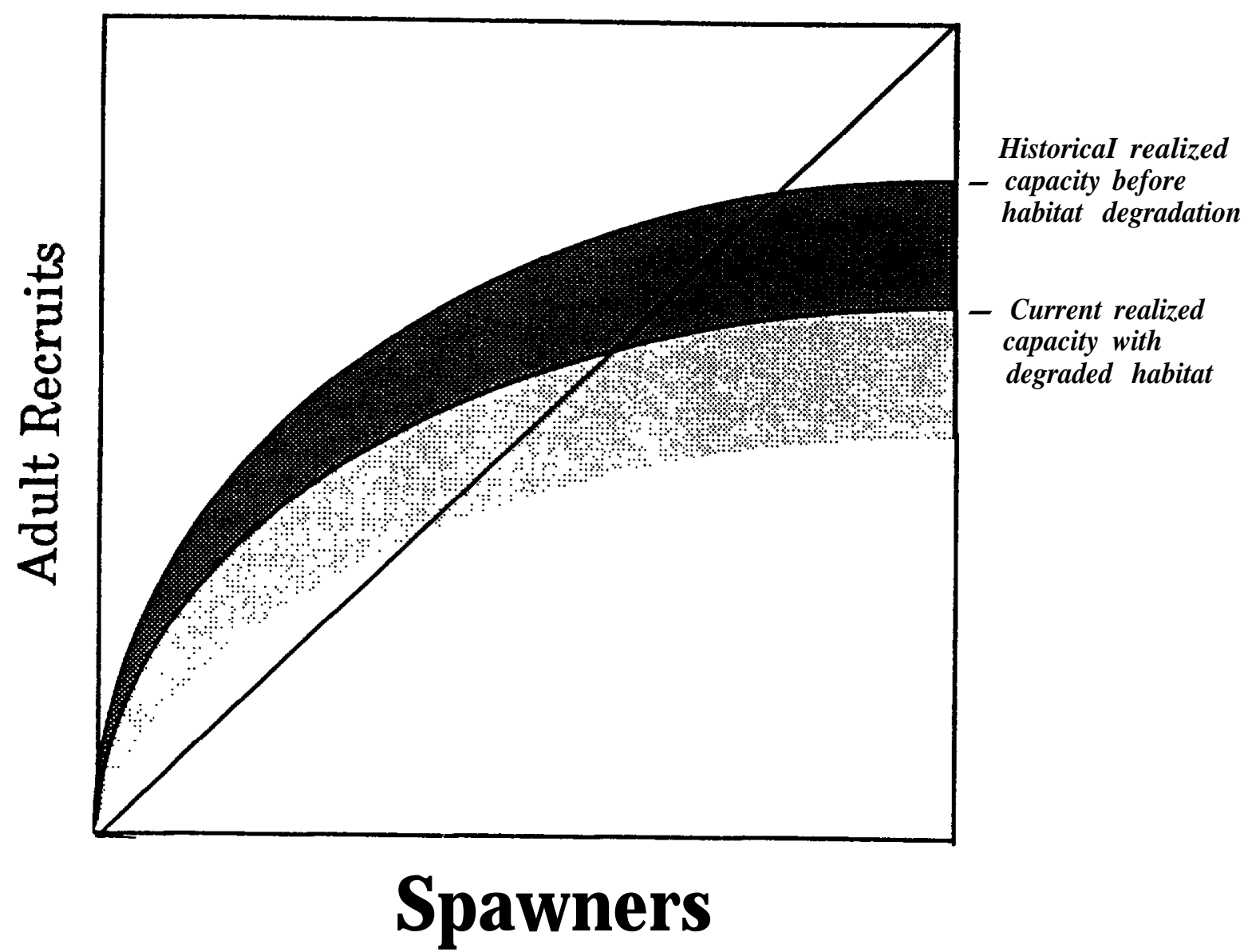

Figure 6. Hypothetical stock-recruitment relationship showing historic capacity and the current capacity which has been reduced by habitat degradation. The families of curves shown in Figure 4 are contained in the shaded areas. 


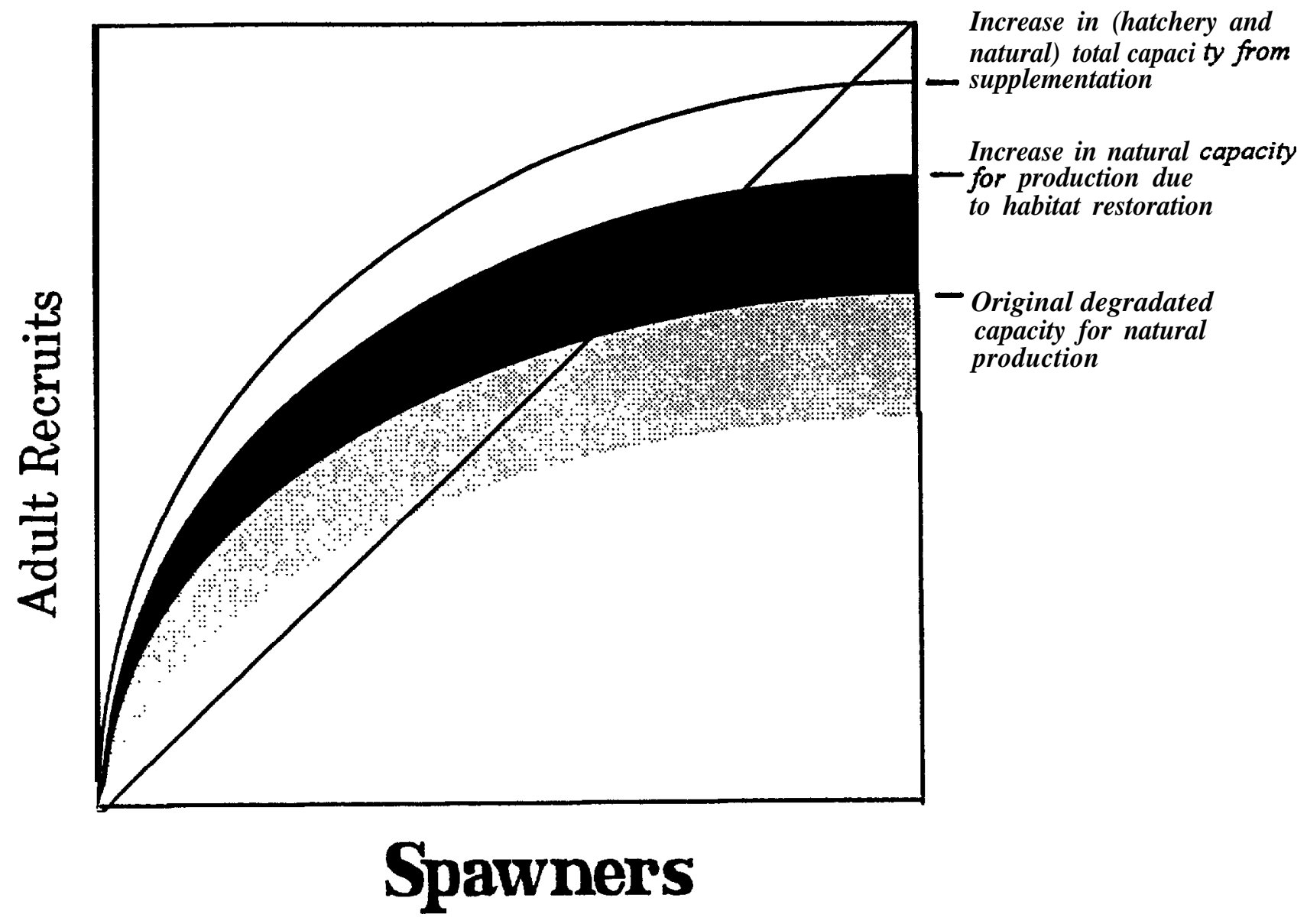

Figure 7. Hypothetical stock-recruitment curve from Figure 6 showing an increase in natural production due to habitat restoration and supplementation. An additional increment of total production comes from a combination of artificial production and natural production. 

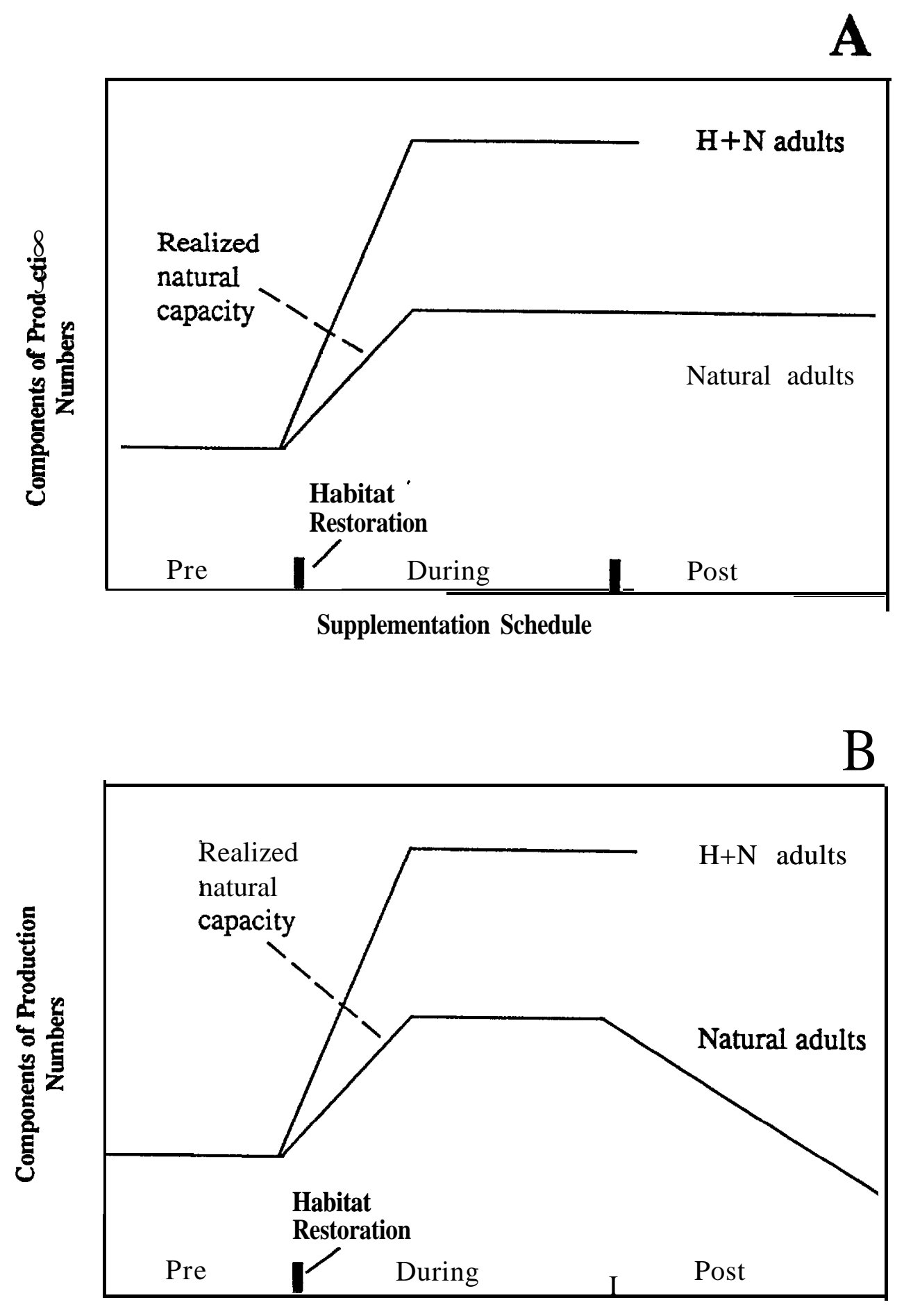

SupplementationSchedule

Figure 8. Schematic diagrams of the outcomes of supplementation shown in Figures 6 and 7. In A, realized natural capacity is increased following habitat restoration and supplementation. After supplementation is terminated, natural production remains at the new level. In $B$, natural production declines following the termination of supplementation. (See text for explanation.) (Adapated from Bowles and Leitzinger, 1991) 


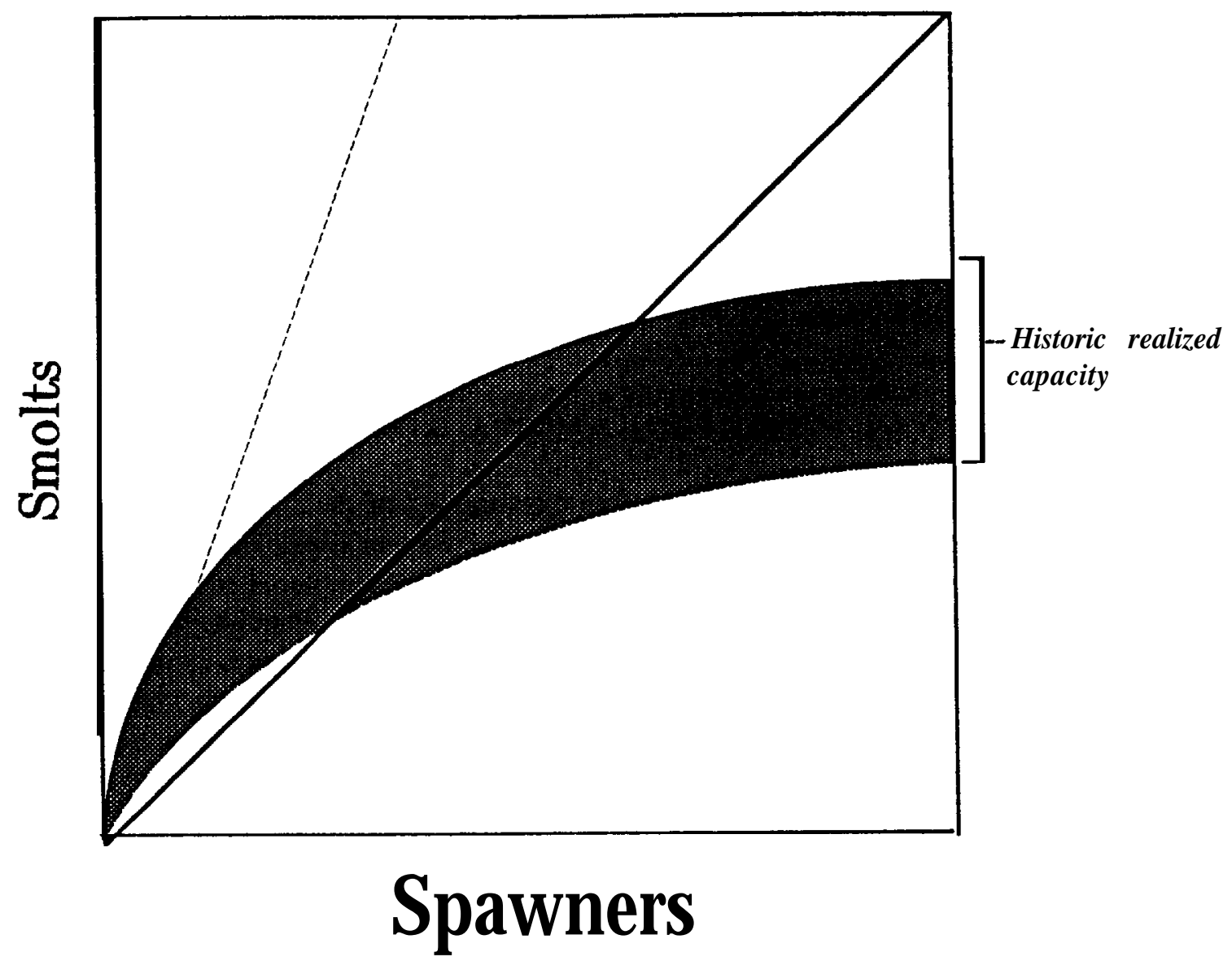

Figure 9. A hypothetical stock-recruitment curve (spawners-smolts leaving the subbasin). The dashed line represents a shift in replacement due to an increase in density-independent mortality after the fish leave the subbasin. 
The situation shown in Figure 9 would leave the freshwater rearing habitat underseeded unless the source of mortality were corrected or the habitat were seeded with hatchery-reared fry, pat-r or smolts on a continuous basis. In this example, supplementation can increase the number of smolts naturally produced in a subbasin and enhance adult escapement, however when supplementation is terminated, natural production will return to the presupplementation levels (Figure 10A) i.e., supplementation has not reduced the fitness of the stock. Figure 10B presents a scenario that appears to show success during supplementation, but natural production is declining indicating that the release of hatchery-reared fish has reduced the population's fitness. The latter is therefore inconsistent with the definition of supplementation. These scenarios do not exhaust the range of possible applications of supplementation nor the outcomes. They do illustrate important constraints and boundaries of supplementation and consequences of the misapplication of the technology. Development of an initial, conceptual plan using the terms of reference illustrated above will be useful to managers beginning to develop supplementation projects.

\section{APPLICATION OF SUPPLEMENTATION THEORY TO PLANNING}

In the previous sections, we described a framework comprised of the three concepts: capacity, performance, and stock-recruitment and we discussed the constraints those concepts place on supplementation. The framework described stream/stock systems in terms of their capacity. It explained how the capacity of natural systems is indexed through measures of performance and which parts of natural systems must be considered if management is to achieve its objectives through supplementation. The latter includes habitat-life history relationships and density-dependent and density-independent regulation of production and productivity. To be useful, the theory should guide the development of an approach to supplementation that maintains consistency among the elements of the program including the conceptual framework, definition of supplementation, planning guidelines, and monitoring and evaluation.

Capacity introduces important concepts to the planning of supplementation projects. It is evident from the previous discussion, that supplementation planning must be based on an analysis of the biotic and abiotic components of the stream/stock system as opposed to focusing all planning on the design of hatchery facilities. Hatchery design affects system capacity and must be considered in that context, i.e., in relation to habitat and life history. A first step in supplementation planning is a qualitative assessment of historical and current capacity. Supplementation planning should identify potential changes in capacity and the likelihood that those changes can be reversed by management action including supplementation. Through planning, the concept of capacity, thus far described in abstract terms and through illustration, is expressed in concrete details relevant to the particular stream/stock system and the management objectives.

RASP Summary Report Series, Part II: Supplementation Theory

December, 1992 / Page 22 


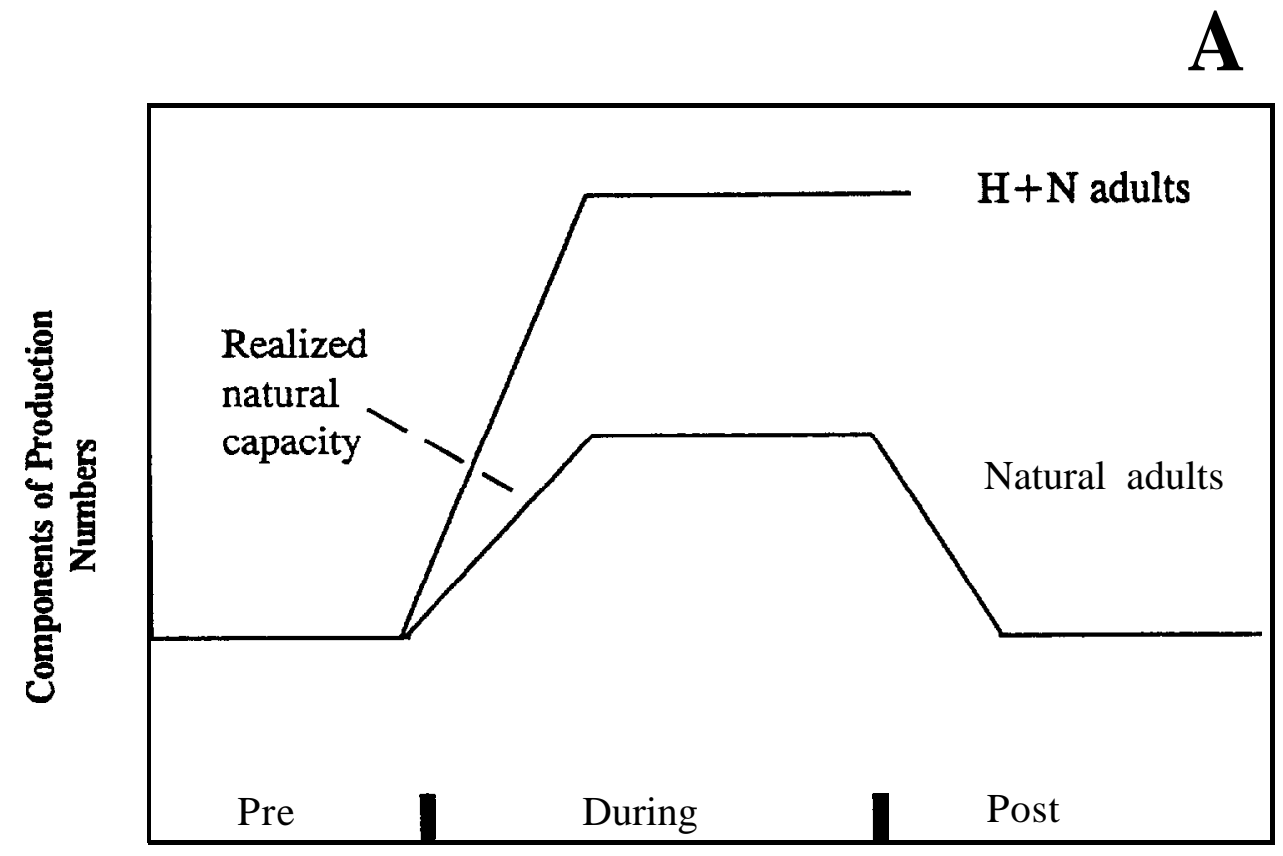

Supplementation Schedule

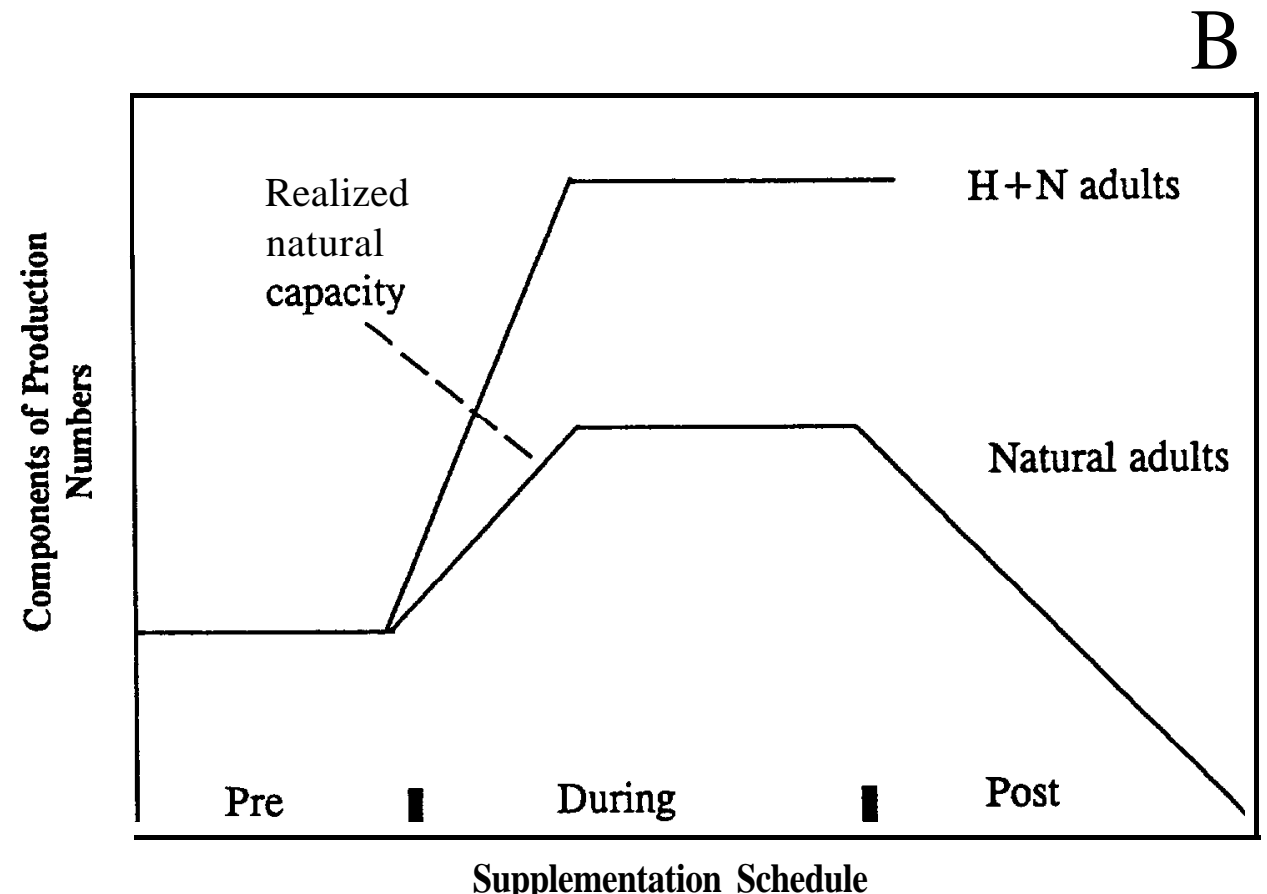

Figure 10. Schematic diagram of the outcomes of supplementation. In $A$, the realized natural capacity of the system is increased during supplementation then returns to the presupplementation level when supplementation is terminated. In $B$, supplementation has increased realized natural capacity during supplementation but has altered ability of the stock to survive in natural system so that realized natural capacity declines after supplemenation is terminated. (Adapted from Bowles and Leitzinger, 1991). 
In Part III of this report series, RASP has proposed a procedure for developing those concrete details under the title of Patient/Template Analysis. Elements of the analysis include population demographics; life-history patterns; the timing and location of important lifehistory events (spawning, rearing and migration); physical habitat features for each life stage such as the hydrograph, habitat quality and quantity, and blockages; biotic factors such as competitors and predators; and survival by life-history stage.

Once the comparative analysis of the biotic and abiotic components of the current and historical stream/stock system has been completed, that information is diagnosed to determine if supplementation is the appropriate management activity. The diagnosis evaluates the system in terms of capacity to answer the questions: Has capacity changed? If capacity has changed, are the changes permanent, irreversible alterations? and Can the changes be circumvented by the addition of artificial capacity alone or in combination with restoration?

The selection of hatchery treatments is another way that capacity is considered in the supplementation planning process. The hatchery as super tributary is the traditional role of artificial propagation. However, under supplementation, the design of hatchery facilities and their operation must be consistent with the abiotic and biotic factors that comprise capacity as previously described. Hatchery practices are selected to minimize the chance that they will reduce the capacity of the natural production system by identifying and circumventing the random sources of mortality in the environment and by minimizing selective sources of mortality. This is a departure from the traditional approach which viewed the hatchery and its operation as an independent or neutral element in the ecosystem.

Supplementation is a part of the Council's program to double the salmon and steelhead runs in the Columbia River. The Council's genetic policies imply that the increase in production should be sustainable. In fact, Riggs (1990) has stipulated that sustainable increases in production cannot be achieved without conservation of genetic resources. Sustainable redevelopment requires that objectives be specified in terms of resource quantity and quality (Regier and Baskerville 1986). In the absence of specified targets for resource quality, redevelopment programs wander into trouble, focusing on short term horizons while relegating sustainability to unenforced platitudes (Regier and Baskerville 1986). With respect to supplementation, RASP has proposed to measure production quality as post-release survival, reproductive success, long-term fitness, and ecological interactions.

Specification of resource quality changes the way risks are assessed. The analysis of risks and benefits of supplementation projects must take into account post-release survival of hatchery-reared fish relative to their wild counterparts, the reproductive success of the supplemented population, the potential loss of long-term fitness in the target and nontarget populations resulting from supplementation, and the ecological impact on target and nontarget populations from competition and/or predation attributable to supplementation, These aspects of risk have generally not been part of hatchery planning.

RASP Summary Report Series, Part II: Supplementation Theory

December, 1992 /Page 24 
The measures of production quantity and quality discussed above give the manager a picture of the performance of the supplemented stream/stock system, but that picture is still not as complete as it needs to be. Having some understanding of the relationship between spawners and their recruited progeny is an important additional dimension of performance which aids in the effective management of supplemented salmon and steelhead populations. A stockrecruitment relationship is an expression of performance at different levels of stock size and is a way of increasing understanding and improving the assessment of performance.

Different forms of the S-R relationship have been suggested for salmon and steelhead populations (Figure 11). The curves in Figure 11 show compensatory mortality disappears in the limit as the density of spawners approaches zero (Ricker 1973). Thus mortality rate at the origin represents mortality of progeny from density-independent causes alone. This value is used in the System Planning Model to indicate productivity of individual subbasins in the Columbia. In addition the density-independent mortality rate (or survival rate) at low stock sizes indicates the target survival or increases in capacity that hatcheries need to achieve to justify the removal of eggs from depleted wild populations.

As population size increases, a larger fraction of the progeny die as a result of being eaten by predators or through competition for limited resources. This is known as compensatory mortality (Neave 1953). However, density-dependent process can work in reverse, whereby mortality decreases as spawning-stock size increases, referred to as depensatory mortality (Neave 1953). The potential for substantial depensatory effects in the Columbia Basin is high given the increase in the smolt-to-adult mortality as a result of fishery and passage problems, combined with the likelihood for increased impacts by predators. One possible result of depensatory mortality would be extirpation of the population (Figure 12a), if the rate of loss to predation is highest at low smolt abundances. Another possibility could be to trap a population in a lower stability domain (Figure 12b), as described by Peterman (1977). Peter-man (1987) asserts that the only way a population can overcome such depensatory effects is through artificial enhancement or through a beneficial stochastic event. The use of $\mathrm{S}-\mathrm{R}$ models and their implication to the design and evaluation of supplementation projects is discussed in greater detail in Part IV of this report series.

\section{SYNOPSIS}

RASP has proposed a conceptual framework to guide the planning, implementation and evaluation of supplementation projects. The framework is comprised of three primary elements: Capacity, performance, and stock recruitment. Potential capacity defines the ultimate limits of a system, the product of the optimum interaction among the elements of the biotic and abiotic components of the system and its prevailing environment. Realized capacity represents the specific developmental trajectory of the system given natural fluctuations in the environment, the natural evolution of the physical habitat, human alterations in the habitat, 

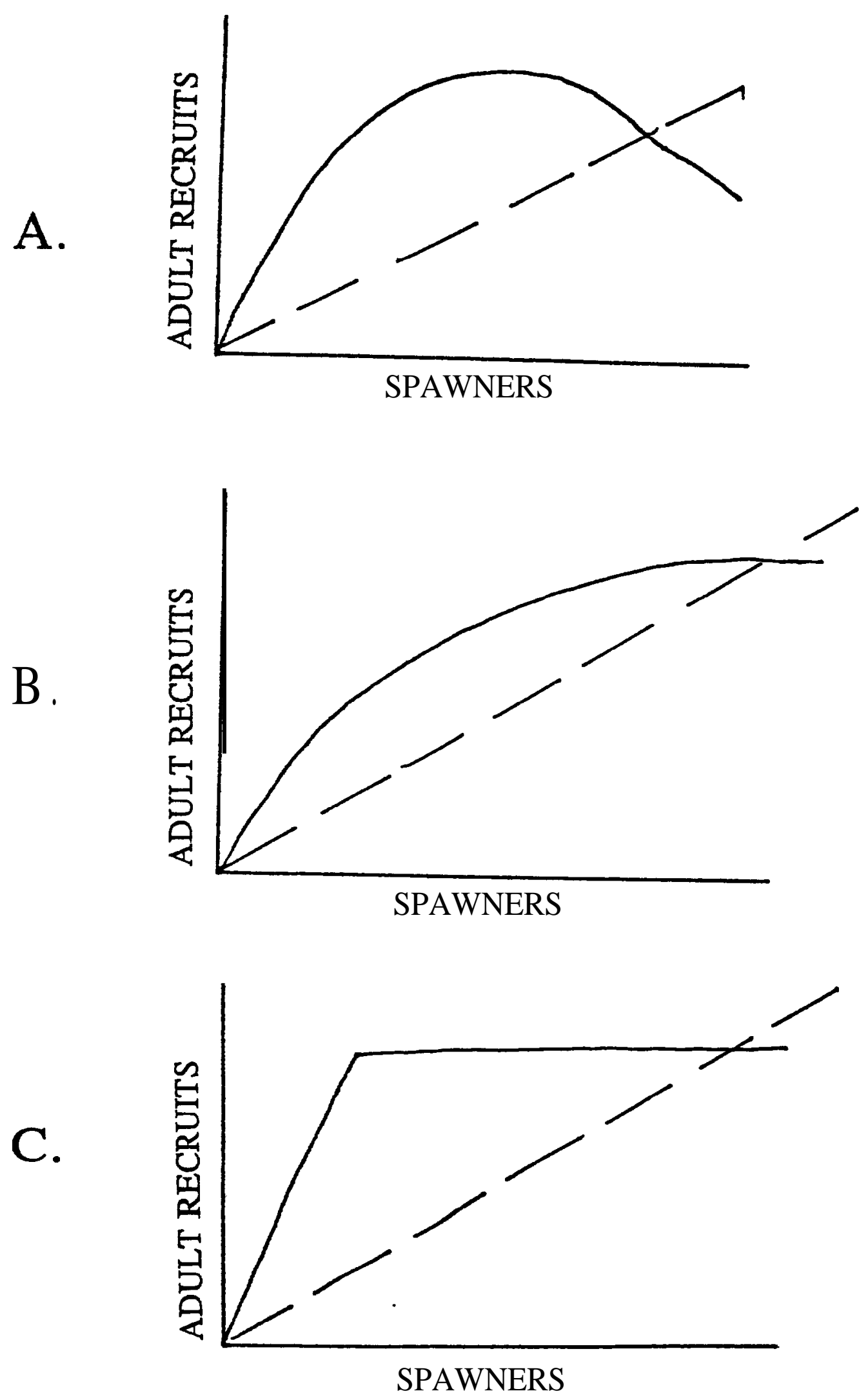

Figure 11. Stock-recruitment curves with alternative models of compensatory mortality: (A) the dome-shaped Ricker form; (B) the asymptotic Beverton-Holt form; (C) the rectilinear form. Dashed line represents the number of adult recruits needed to replace spawning stock size. 

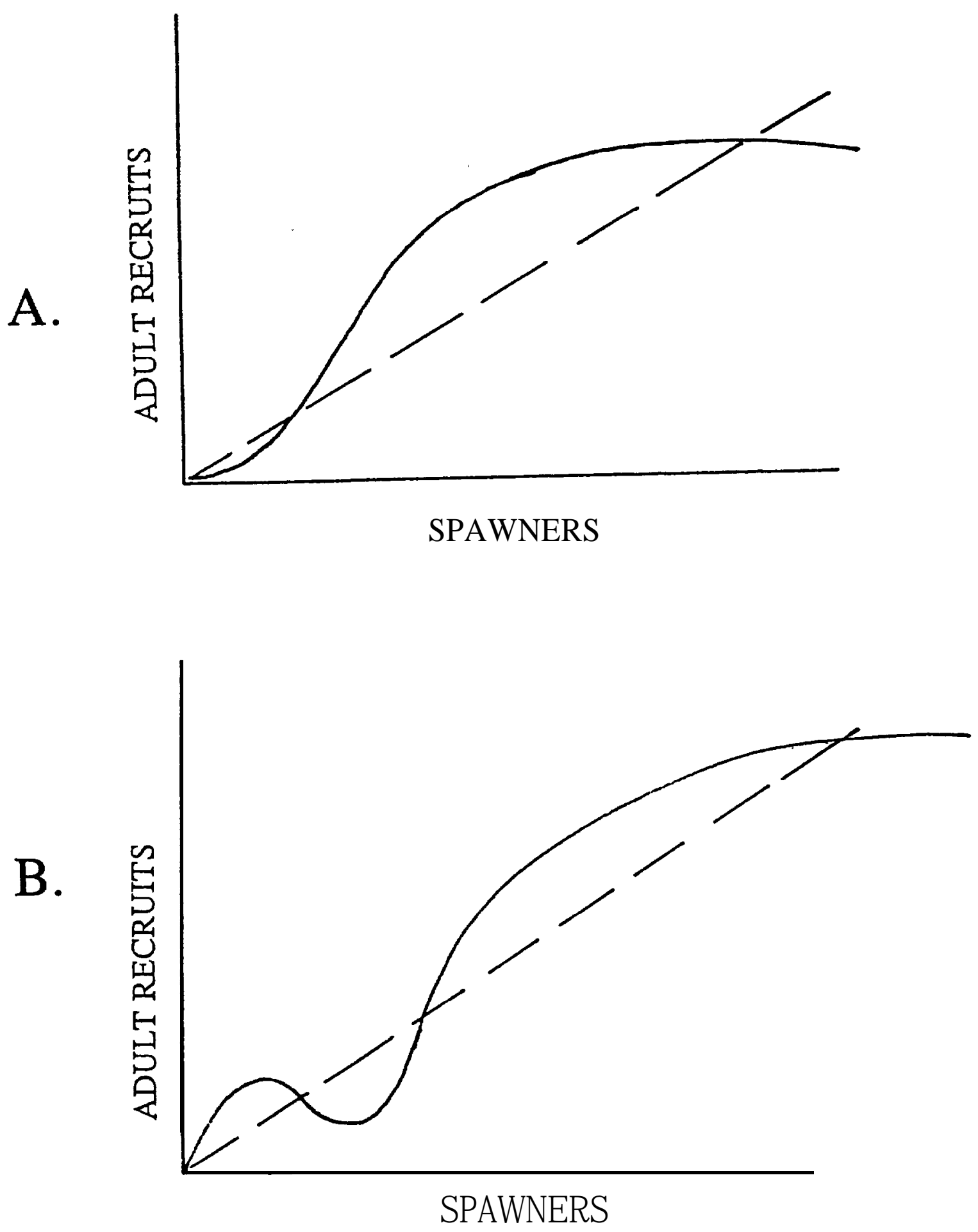

Figure 12. Stock-recruitment curves with depensatory mortality operating: (A) population goes to extinction at low spawning stock size; (B) multiple stability domains exist across a wide range of spawning stock sizes. Dashed line represents the number of adult recruits needed to replace spawning stock size. 
and adaptation of the stock. Because they are comprised of numerous interactions, capacities cannot be measured directly except as the performance of attributes important to the manager such as production and productivity.

The conceptual framework places boundaries on the risks and benefits of supplementation. The changes in capacity that generate the need for supplementation need to be carefully examined to determine if supplementation is the appropriate restoration strategy and what expectations are reasonable. Throughout the planning of a supplementation project the way that the physical habitat and the life histories of the stock interact needs to be considered. 


\section{LITER ATUR E \\ C I T E D}

Bowles, E., and E. Leitzinger. 1991. Salmon Supplementation in Idaho rivers: Experimental design. Idaho Dept. of Fish and Game, Boise, Idaho, Project 89-098. 166 p.

Columbia Basin Fish and Wildlife Authority. 199 1. Integrated system plan. Portland, OR. 527 p.

Mayr, E. 1982. Tow ard a New Philosophy of Biology. Harvard University Press. Cambridge, MA, 564 p.

Mayr, E. 1988. The Growth of Biological Thought: Diversity, Evolution, and Inheritance. Harvard University Press. Cambridge, MA, 974 p.

McGie, A.M. 1980. An analysis of relationships between hatchery coho salmon transplants and adult escapements in Oregon coastal watersheds. Oregon Dept. of Fish and Wildlife, Corvallis, OR. Information Rept. Series, Fisheries 80-6, 19 p.

McIsaac, D.O. 1990. Factors affecting the abundance of 1977-79 brood wild fall chinook salmon (Oncoryhnchus tshaw ytscha) in the Lewis River, Washington. Ph.D. dissertation University of Washington, Seattle, WA. 174 p.

Miller, W.H., T.C. Coley, H.L. Burge, and T. T. Kisanuki. 1990. Analysis of salmon and steelhead supplementation: Emphasis on unpublished reports and present programs. U. S. Department of Energy Bonneville Power Administration, Portland, OR. Project No. 88-100.

Nawa, R.K., C.A. Frissell, and W.J. Liss. 1988. Life history persistence of anadromous fish stocks in relation to stream habitats and watershed classification. Oak Creek Laboratory of Biology, Oregon State University, Corvallis,OR. 37 p.

Neave, F. 1953. Principles affecting the size of pink and chum salmon populations in British Columbia. J. Fish. Res. Board of Canada, 9(9)

Nickelson, T.E., M.F. Solazzi, and S.L. Johnson. 1986. Use of hatchery coho salmon (O ncorhynchus kisutch) presmolts to rebuild wild populations in Oregon coastal streams. Can. J. Fish. Aquat. Sci., 43(12) 2443-2449. 
Northwest Power Planning Council. 1987. Columbia River Basin Fish and Wildlife Program (Amended). Portland, OR.

Peterman, R.M. 1977. A simple mechanism that causes collapsing stability regions in exploited salmonid populations. J. Fish. Res. Board of Canada, 34: 1134-1142.

Peterman, R.M. 1987. Review of the components of recruitment of Pacific salmon. Pages 417-429 in M.J. Dadswell, R. J. Klauda, C.M. Moffitt, R.L. Saunders, R.A. Rulifson, and J.E. Cooper, editors. Common strategies of anadromous and catadromous fishes. American Fisheries Society Symposium 1. American Fisheries Society, Bethesda, Maryland.

Regier, H.A., and G.L. Baskerville. 1986. Sustainable redevelopment of regional ecosystems degraded by exploitive development. In W.C. Clark and R.E. Munn, (Eds.), Sustainable Development of theBiosphere. Cambridge University Press, Cambridge, MA, 75-103.

Reimers, P.E. 1973. The length of residence of juvenile fall chinook salmon in Sixes River, Oregon. Research Reports of the Fish Commission of Oregon. 4:2, 43 p.

Rich, W.H. 1939. Local populations and migration in relation to the conservation of Pacific salmon in the western states and Alaska. Fish Commission of Oregon, Salem, OR. Contribution 1, reprinted from Publication No. 8, American Assoc. for the Advancement of Science. pp. 45-50.

Ricker, W.E. 1972. Hereditary and environmental factors affecting certain salmonid populations. In The Stock Concept in Pacific Salmon. H.R. MacMillan Lectures in Fisheries, The University of British Columbia. 19-160.

Ricker, W.E. 1973. Critical Statistics from two reproduction curves. In B.B. Parrish (ed.), Fish Stocks and Recruitment, Proceedings of a Symposium held in Aarhus July 7-10, 1970, Denmark, 331-338.

Riggs, L. 1990. Principles for genetic conservation and production quality. Northwest Power Planning Council Contract C 90-005. Portland, OR.

Royal, L.A. 1972. An examination of the anadromous trout program of the Washington State Game Department. Washington Dept. of Game, Olympia WA, 176 p.

Schaffer, W.M., and P.F. Elson. 1975. The adaptive significance of variations in life history among local populations of Atlantic salmon in North America. Ecology 56: 577-590. 
Schluchter, M., and J.A. Lichatowich. 1977. Juvenile life histories of Rogue River spring chinook salmon O ncorhynchus tshuw ytscha (Walbaum), as determined from scale analysis. Oregon Department of Fish and Wildlife, Corvallis, OR: Information Report Series, Fisheries No. 77-5. 24 p.

Thompson, William F. 1959. An approach to population dynamics of Pacific red salmon. Trans. of the Am. Fish. Soc. 88: 206-209.

Waples, R.S. 1991. Genetic interactions between hatchery and wild salmonids: Lessons from the Pacific Northwest. Can. J. Fish. Aquat. Sci. 48(Suppl. 1): 124-133.

Ware, D.M., and R.E. Thompson. 1991. Link between long-term variability in upwelling and fish production in the northeast Pacific 0 cean. Can. J. Fish. Aquat. Sci. 48: 2296-2306.

Warren, C. E. 1971. Biology and Water Pollution Control. W. B. Saunders Co. Philadelpha. 434 p.

Warren, C.E., M. Allen, and J.W. Haefner. 1979. Conceptual frameworks and the philosophical foundations of general living systems theory. Behavioral Sci. 24: 296310.

Warren, C.E., and W.J. Liss. 1980. Adaptation to aquatic environments. In R.T. Lackey and L.A. Nielsen (Eds.), Fisheries Management. John Wiley \& Sons, New York, 1540. 


\title{
RASP SUMMARY REPORT SERIES PART III
}

\author{
PLANNING GUIDELINES
}

December, 1992 


\section{RASP CONTRIBUTORS}

Scientists with expertise and interest in supplementation have contributed to this report, among them are: Tom Backman, Ed Bowles, Craig Busack, Rich Carmichael, Duane Fickeisen, Larry Lestelle, Jim Lichatowich, Rich Lincoln, Lars Mobrand, Willa Nehlsen, Rich Turner, Tom Vogel, and Bruce Watson. Numerous constructive and insightful comments to previous drafts were also received from the Scientific Review Group. 


\section{TABLE OF CONTENTS}

INTRODUCTION

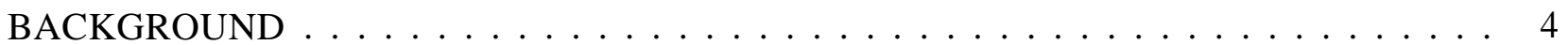

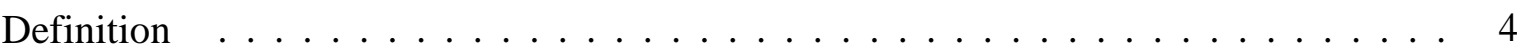

Supplementation Uncertainties $\ldots \ldots \ldots \ldots \ldots \ldots \ldots \ldots \ldots \ldots$

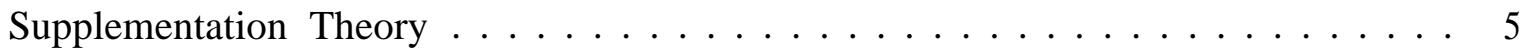

Policies and Statutes . .................... 7

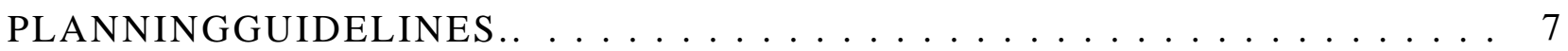

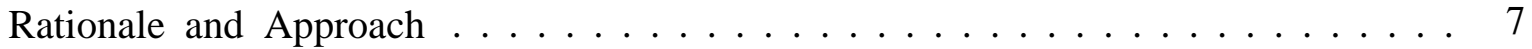

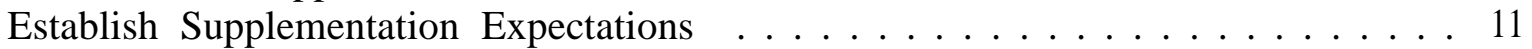

Identifv Existing Management Obiectives (Step 1) . . . . . . . . 12

Describe the Template $($ Step 2) . . . . . . . . . . . . . . 12

Describe the Patient (Step 3) . . . . . . . . . . . . 13

Diagnosis (Step 4) . . . . . . . . . . . . . . . . . 13

Revise the Objective (Step 5) . . . . . . . . . . . . . . . . 19

Recommend Treatment $($ Step 6$) \ldots \ldots \ldots \ldots 22$

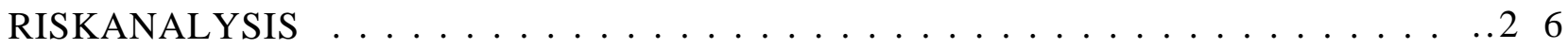

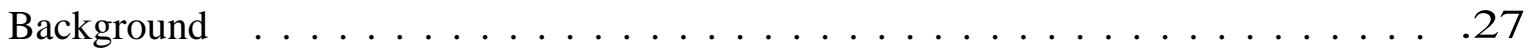

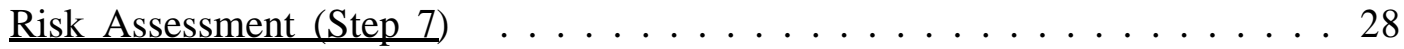

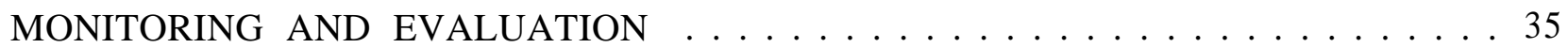

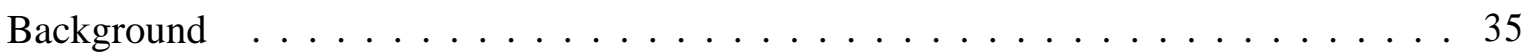

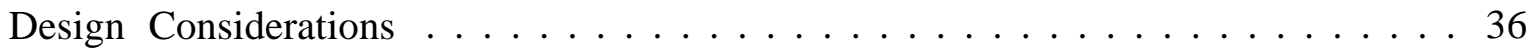

Statistical Power ....................... 37

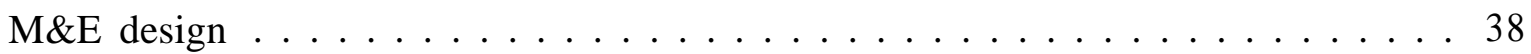

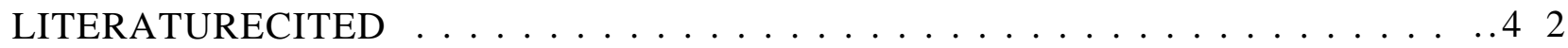

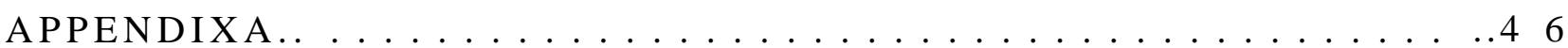

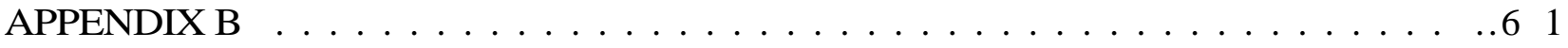

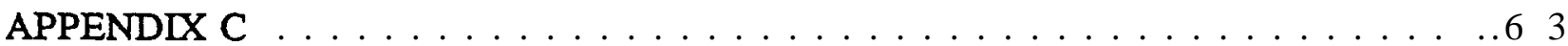

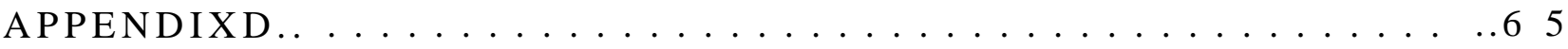




\title{
RASP S-Y REPORT SERIES: PART III.
}

\author{
PLANNING GUIDELINES
}

\section{INTRODUCTION}

The purpose of this progress report is to describe a set of guidelines to be used by managers to design supplementation projects, and by reviewers to evaluate supplementation proposals. Topics included in this document are: a brief review of supplementation in the Columbia Basin, planning guidelines comprised of eight specific steps, a discussion of risk analysis, and guidelines for the design of monitoring and evaluation. Since this is a progress report, the ideas herein will be subject to revision, particularly when supplementation research and experience produces new information.

This is the third in a series of four summary reports. Our goal is to make findings from the Regional Assessment of Supplementation Project (RASP) more accessible by grouping related topics into brief reports on important aspects of supplementation. RASP is planning or has already published the following reports under the general title Sunolementation in the Columbia River Basin: Part I, Background, Description, Performance Measures, Uncertainty and Theory (completed); Part II, Theoretical Framework and Models (in preparation); Part III, Planning Guidelines; and Part IV, Regional Coordination of Research and Monitoring.

Supplementation is a major element of the program to increase salmon and steelhead production in the Columbia Basin. The Fish and Wildlife Program of the Northwest Power Planning Council (NPPC) uses three approaches to protect and enhance salmon and steelhead in the Columbia Basin: 1) improve fish production; 3) improve passage in the mainstem; and 3) improve harvest management to support the rebuilding of fish runs (NPPC 1987). The fish production segment calls for a three-part approach: natural production, hatchery production and supplementation. The ISP (CBFWA 1991) indicates that the fish management agencies and tribes expect supplementation to provide over half of the total production increases (Table 1). 
Table 1. Percent of total production increases attributable to supplementation in the ISP. Computed from System Planning Model output? (Duane Anderson, NPPC, personal communication).

\begin{tabular}{|c|c|c|c|c|c|}
\hline \multirow[b]{2}{*}{ S P E C I E S / S T } & \multicolumn{5}{|c|}{ COLUMBIA RIVER REGION } \\
\hline & $\mathrm{CK} \mathbf{L} \mathbf{O}$ & - $\mathrm{MaD}$ & SNAKE & UP P E R & $\mathbf{A} \mathbf{L} \mathbf{L}$ \\
\hline LATE COHO & $97.7 \%$ & - & - & & $97.7 \%$ \\
\hline EARLY COHO & $100.0 \%$ & $100.0 \%$ & & - & $100.0 \%$ \\
\hline FALL CHINOOK & $0.0 \%$ & $37.4 \%$ & $51.2 \%$ & $0.0 \%$ & $8.6 \%$ \\
\hline SPRING CHINOOK & $88.4 \%$ & $64.0 \%$ & $74.3 \%$ & $34.7 \%$ & $65.4 \%$ \\
\hline SUMMER CHINOOK & & $6.3 \%$ & $66.9 \%$ & $38.4 \%$ & $43.5 \%$ \\
\hline SUMMER STEELHEAD A & $100.0 \%$ & $25.6 \%$ & $95.5 \%$ & $73.9 \%$ & $71.8 \%$ \\
\hline SUMMER STEELHEAD B & - & & $72.0 \%$ & - & $72.0 \%$ \\
\hline WINTER STEELHEAD & $48.0 \%$ & $100.0 \%$ & - & - & $60.2 \%$ \\
\hline ALL & $45.4 \%$ & $47.5 \%$ & $78.2 \%$ & $34.5 \%$ & $52.4 \%$ \\
\hline
\end{tabular}

The Integrated System Plan addressed other stocks that were not modelled and are not included in Table 1.

In August 1990, the NPPC gave conditional approval to proceed with the final design phase of the Yakima and Klickitat Production Project. The Council called on the Bonneville Power Administration (BPA) to "fund immediately a supplementation assessment to reevaluate, prioritize and coordinate all existing and planned supplementation monitoring and evaluation activities in the basin.. . Provid[ing] for the participation of the fishery agencies and tribes and others having expertise in this area." RASP was initiated as a result of that request by the NPPC. Coordination of supplementation research was also recommended by the Supplementation Technical Work Group. 
RASP addresses four principal objectives:

- $\quad$ provide an overview of ongoing and planned supplementation activities and identify critical uncertainties associated with supplementation

- construct a conceptual framework and spreadsheet model which estimates the potential benefits and risks of supplementation and ranks the importance of uncertainties based on their projected effects on the risks and benefits of a project

- $\quad$ provide guidelines for the development of supplementation projects

- develop a plan for regional coordination of research and monitoring.

RASP has further divided the four broad objectives into technical topics:

- definition of supplementation

- description of the diversity of supplementation projects

- objectives and performance standards

- $\quad$ identification of uncertainties

- $\quad$ supplementation theory

- development of a conceptual model of supplemented populations

- development of a spreadsheet model of risks and benefits of supplementation

- $\quad$ classification of stocks, streams, and supplementation strategies

- $\quad$ regional design of supplementation evaluation and monitoring

- $\quad$ guidelines for planning supplementation projects

- $\quad$ application of the spreadsheet model to supplementation planning

- $\quad$ experimental design and decision making with uncertainty. 
Progress in each topic area has been presented in regular progress reports which are available from the Bonneville Power Administration.

\section{BACKGROUND}

This section defines definessupplementation and gives an overview of uncertainties related to supplementation, theoretical considerations, and relevant policies and statutes.

\section{Definition}

RASP's working definition of supplementation is: Supplementation is the use of artificial propagation in an attempt to maintain or increase natural production while maintaining the long term fitness of the target population, and keeping the ecological and genetic impacts on nontarget populations within specified biological limits.

The purpose of supplementation is to increase or maintain natural production' and that objective must be achieved without a loss of long term fitness in the target population. Each supplementation project must hold the genetic and ecological impacts on nontarget populations to specified limits. Supplementation is clearly a departure from conventional hatchery programs and it reflects a changing management paradigm (for a historical perspective on the change see Part I of this series).

Supplementation presents managers with a new challenge: to integrate natural and artificial production systems in the Columbia Basin in a way that yields sustainable increases in total and natural production. This will call for new ideas in the physical design and operation of hatcheries as well as a better technical understanding of genetics, behavior, competition and predation - fields that were not strongly emphasized in the domain of artificial propagation until recently.

\section{Supplementation Uncertainties}

Supplementation as defined above is a nascent management strategy (CBPWA 1991). Since we have only limited management experience and research results, supplementation must be implemented with substantial uncertainty. An important purpose of planning is to identify and manage the critical uncertainties - those

1 Natural production - production resulting from naturally produced progeny that have spent their entire life in their natural habitat. 
uncertainties for which the choice of assumption in the supplementation plan can determine success or failure of the project.

Supplementation uncertainties are a product of three factors: 1) ecological factors that determine productivity in the stream ecosystem, or our perception of them, 2) supplementation strategies, and 3) objectives of the project. The presence of uncertainty automatically presents the manager with risk - risk of failure, risk of unintended impacts (genetic or ecological), and risk of future surprise outcomes. Uncertainty and risk are inseparable elements in fisheries programs. Where you find one you will always find the other (Figure 1).

Risk can be estimated and assessed through models that substitute assumptions for the critical uncertainties or by listing the uncertainties and reviewing the relevant literature. The critical uncertainties must be "managed" to reduce or contain the risks of project failure. One step to reduce risk to acceptable levels is to monitor the appropriate parameters in a way that gives early warning of a problem. RASP calls this "risk containment monitoring." Research carried out within an adaptive management framework is an additional way to manage uncertainties and reduce risk. (For a detailed discussion of uncertainties see Part I of this series of reports.)

\section{Supplementation Theory}

The expectation that we can increase natural production by adding artificially propagated fish to natural habitats is based on our understanding of the artificial and natural production systems. Realizing the expected increases in production depends on how well the artificial and natural systems are integrated. Supplementation theory is an attempt to generalize our understanding of natural and artificial production and to establish guidelines for integrating the two.

Supplementation theory rests on three concepts: 1) capacity - each stream/stock system has a capacity to produce salmon and steelhead determined by the interaction of abiotic and biotic factors operating through the stock's life history, 2) performance - performance of a stream/stock is that part of the capacity realized in any given time interval, and 3) gtock-recruit relationship - there is a relationship between the quality and quantity of a spawning population and recruitment of the adult progeny. The elements of a supplementation theory are discussed in more detail in Parts I and II of this series. 
Condition of Stock and Stream
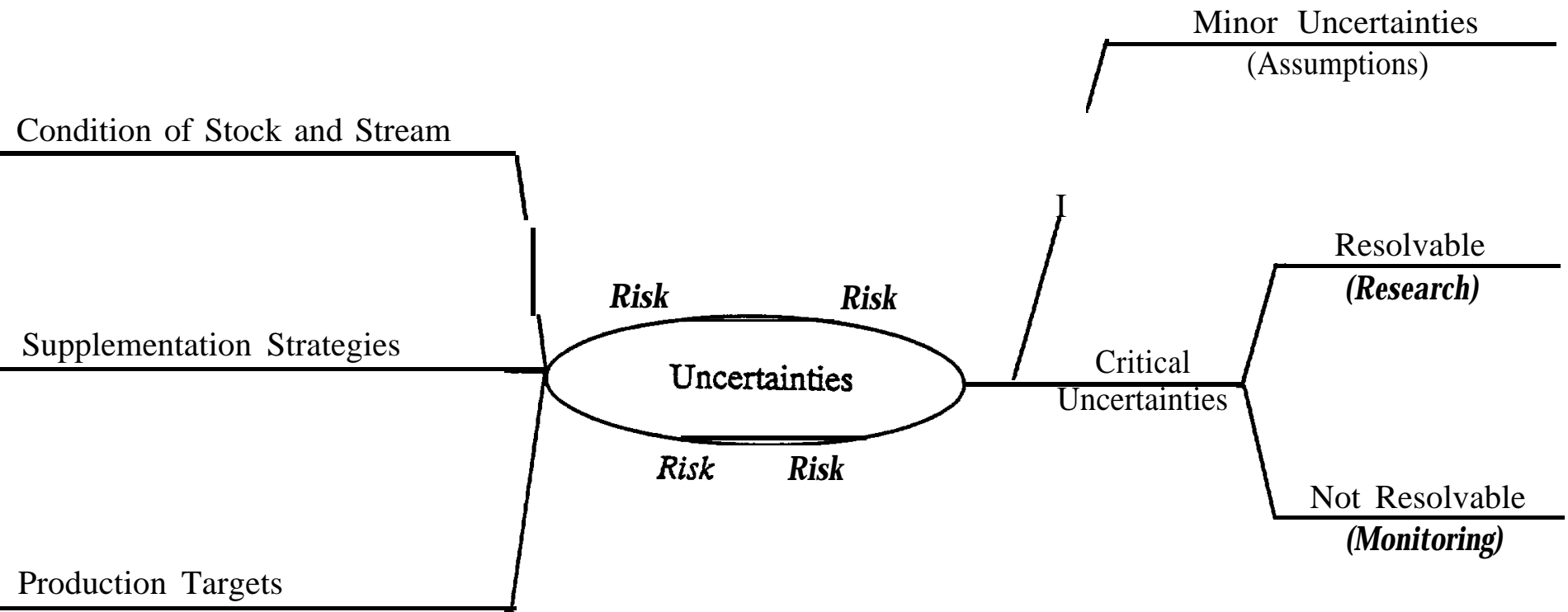

Figure 1. Schematic representation of the origin and treatment of supplementation uncertainties. 
For planning purposes, the concepts of capacity and performance and stockrecruitment models are embedded in a broader "clinical" model of the target stream and stock. The basic elements of the "clinical" model are: template - the healthy stream/stock system, patient - the current condition of the stream/stock system in need of restoration, diagnosis - the comparison of template and patient that leads to identification of limiting factors, and treatment - the specific strategies to remove or circumvent the limiting factors.

\section{Policies and Statutes}

In addition to the guidelines given in this report, the manager planning a supplementation project must take into account appropriate state, federal and tribal policies and statutes and the policy guidelines in the Council's Fish and Wildlife Plan (NPPC 1987). For example, see Oregon's Natural Production and Wild Fish Management Rules (Oregon Administrative Rules 635-07-501 through 529 and 63507-800 through 815) and Idaho's Anadromous Fishery Management Plan (Idaho Department of Fish and Game 1991). An Environmental Impact Statement under the National Environmental Policy Act of 1971 might be required for supplementation projects.

A manager planning a supplementation project should coordinate his/her proposed activities with other management activities in the subbasin and in proximate subbasins.

\section{PLANNING GUIDELINES}

Detailed planning guidelines recommended by RASP are presented in this section.

Rationale and Approach

The planning guidelines are comprised of 9 steps (Figure 2) which are described within the context of a clinical model. In the first step goals are established, steps 2 to 4 are fact-finding and descriptive; steps 6 and 7 involve analysis of risks and benefits, and in steps 8 and 9 an evaluation is conducted. The steps are:

1. Identify Management Objectives. The objectives describe the desired future condition of the stream/stock system (expected benefits).

2. Describe Template. The template describes the healthy stream/stock system. 


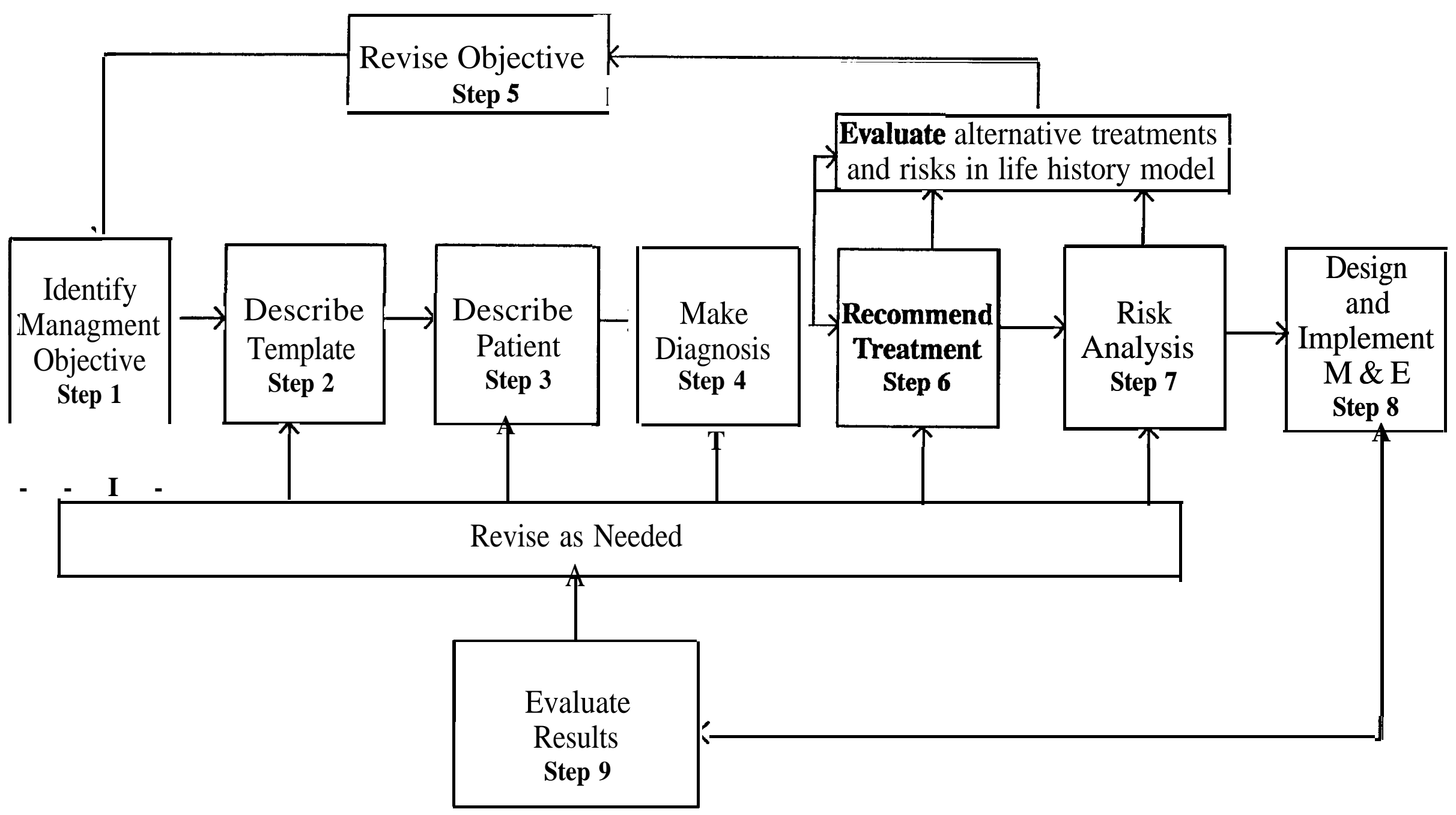

Figure 2. A Sequence of Planning Steps for Supplementation Projects. 
3. Describe Patient. The patient describes the current condition of the stream/stock system.

4. Make Diagnosis. The diagnosis identifies limiting factors that prevent the patient from reaching the objective.

5. Revise Objective. At this point the original objective should be reviewed and revised if appropriate.

6. Recommend Treatment. The treatment describes the supplementation strategies' expected to realize the benefits set forth in the objective.

7. Risk Analysis. Risk analysis describes the uncertainties associated with the recommended treatments.

8. Design and Implement Monitoring and Evaluation. Monitoring and evaluation $(\mathrm{M} \& \mathrm{E})$ presents general guidelines for the design of $\mathrm{M} \& \mathrm{E}$.

9. Evaluate Results. The results are evaluated as the project plan is implemented and the plan is revised as needed.

Chapter C of the ISP (CBFWA 1991) discusses several topics relevant to supplementation planning. Those topics are in general agreement with the RASP guidelines. However, the ISP gives greater emphasis to implementation (description of supplementation technology and treatment guidelines). In another report that emphasized genetic conservation, Kapuscinski et al. (1991) listed five steps in the development of a supplementation plan:

1. State the goal of the proposed supplementation.

2. Define the current status of the populations targeted for supplementation and those that are inadvertently affected.

3. Determine the feasibility of improving the status of the targeted population, while not negatively impacting adjacent populations, and considering problems imposed by passage around dams, habitat loss, and fishery harvest (Riggs 1990, appendix VII). 
4. Identify options available for each step in propagation.

5. Evaluate genetic risks associated with each option for a given step in propagation, based on an understanding of genetic processes involved.

These steps are also in general agreement with the eight steps in the RASP planning guidelines.

Supplementation is the attempt to increase natural production in a stream/stock system whose performance is consistently below capacity and where the ecological processes that determine the yield of salmon are still largely functioning or are repairable. Supplementation might be used to increase natural production in a system where a production bottleneck created by a natural or a man-made disturbance has been removed. In that case, the natural rate of recovery is accelerated through the use of appropriate supplementation strategies. Depressed natural production might be increased through supplementation if a major cause of the decline is an artificial source of density-independent or depensatory mortality (mainstem passage, for example). In addition, a population depleted by over-harvest might be unable to recover naturally even if harvest is reduced if the population has been forced into a stable equilibrium at a lower density. This condition might result from competition or predation following a shift in species dominance brought on by the original depletion. Peterman (1977) described the theoretical basis for multiple stability regions in salmon production functions. Supplementation might be needed to build up numbers of the target population so it can "break out" of the lower stability region and reestablish a higher stable equilibrium. The restoration of extirpated stocks is another purpose of supplementation.

Successful ecological restoration is the acid test of our understanding of how the elements of an ecosystem function (Bradshaw 1990). Restoration, measured as an increase in natural production and accomplished through the use of supplementation, is a test of our understanding of the relationships among the life history of the target stock, its habitat, and artificial propagation. This understanding is developed and demonstrated through the completion of steps $2-6$ in the planning process (template, patient, diagnosis, revise objectives, and treatment). The guidelines proposed by RASP ask the manager planning a supplementation project to fist look back in time at the stream/stock system before degradation occurred and then to describe how the original system functioned. This is an essential step because it focuses attention on ecological relationships early in the planning process.

RASP Summary Report Series, Part III: Ptanning Guidelines

December, 1992 /page IO 
When using supplementation as a management tool, the manager should avoid the traditional approach of focusing exclusively on production numbers - hatchery sizing, feed programming, release targets, and contribution goals. A focus on rebuilding numbers while ignoring the restoration of habitat and life history diversity and important ecological relationships will not yield sustainable results. Restoration must attempt to set things straight rather than preserve what we have disturbed (Vrijenhoek 1989). Accordingly, RASP has emphasized the relationship between habitat and life histories and the comparative analysis of the historic and current status of those relationships.

Stocks, as defined by Ricker (1972), are the basic management units upon which the conservation of the species depends (Rich 1938). It is the diversity contained within and between stocks that must be conserved if the fisheries are to be managed sustainably in the face of natural and man-made changes in the environment. When defining the boundaries around stocks the manager must take into account the tradeoff between the risk of a loss of diversity within and between stocks - the types 2 and 3 . genetic risks of Busack (1990). Drawing a wide geographic circle around a stock could precipitate management activities that reduces between-stock diversity if the circle inadvertently included more that one distinct stock. Conversely, a small circle might exclude a legitimate part of a stock and contribute to loss of within-stock diversity.

The planning guidelines presuppose that the physical boundary of the target population has been defined and its genetic characterization completed. The process of setting stock boundaries is currently the subject of a debate, however, it is a debate that cannot be resolved with our present level of knowledge. The type of stock designation (broad or narrow) effects treatment options, risk assessment and risk management in a supplementation project. For example, a narrow stock designation manages risk by restricting treatment strategies. A broader stock designation allows greater management flexibility, but it requires extensive monitoring and evaluation to manage risk.

\section{Establish Supplementation Expectations}

This section describes steps 1 - 6 of the recommended planning process in detail. These steps help establish expectations for supplementation and lead to development of a proposed approach for the supplementation project. 


\section{Ldentifv Existing Management Objectives (Step 1 )}

Every major subbasin in the Columbia River has at least generalized objectives contained in statewide management plans (for example, see Oregon's Species Management Plans and Idaho's Anadromous Fishery Management Plan). In addition, management objectives for specific subbasins are found in subbasin planning documents, hatchery master plans, and in individual regional, district or tribal planning documents. Management objectives might be inferred from harvest regulations, stocking programs, and agency comments on forest practice applications, environmental impact statements, and proposed water quality and land use regulations. Since all of these sources shape management objectives, they should be reviewed and incorporated into the initial description of objectives.

\section{Describe the Template (Step 2)}

The template analysis attempts to describe the system's historical performance through an evaluation of life history and habitat. The template is a pattern against which the present condition (patient) and proposed future condition (objective) are compared to identify limiting factors and reasonable expectations for increased natural production. The template analysis makes use of historical and contemporary information from within the stream/stock to be supplemented, and, when necessary, it uses inferences drawn from the literature on stocks outside the target subbasin. These guidelines, and the template analysis in particular, are based on the premise that the harmonious interaction between life history and habitat is an important determinant of natural production.

The template should not be confused with the objective. The template describes the historical performance of the stream/stock system and the objective describes that part of the template that management activities will attempt to restore. In few cases the template and objective will be the same, in very few cases the objective might exceed the template, although in most cases the objective will represent a part of the original performance.

The template analysis attempts to describe three elements important to the life historyhabitat relationship of the target stock: geography, time, and biology. The salmon's life history involves important biological functions such as spawning, migration, feeding, and escaping predators which are carried out in a series of geographically and seasonally connected places (Thompson 1959). There are several possible approaches to the template analysis. 
Figures 3, 4 and 5 show a schematic representation of the life history-habitat relationship in a stream/stock system proposed for supplementation. The figures are intended to illustrate the template/patient analysis for a typical spring chinook population from a mid-Columbia subbasin. Correspondence between habitat and life history is represented by tongues and grooves; and, in the template population, all of the habitats and life histories are present (Figure 3). The patient illustration shows that two life history patterns and their associated habitats are missing. The remaining life history/habitats show diminished performance (Figure 4). In this hypothetical example, the objectives of the supplementation project are to restore two life history patterns and their associated habitats (Figure 5).

Figures 3 - 5 were intentionally simplified to illustrate the concepts underlying the template/patient analysis. The actual analysis is more complicated and is based on the compilation of a substantial data base. RASP encourages the manager to adapt his/her approach to the characteristics of the specific stock/stream system to be supplemented. To assist the manager, RASP has prepared a set of tables which identify the life history and habitat information needed to complete a patient/template analysis (see Appendix A).

\section{Describe the Patient (Step 3)}

In this step, the existing status of the stock and habitat to be supplemented is described (Figure 4). The manager should refer to Appendix A for a description of the information needed to complete the patient description.

\section{Diagnosis (Step 4)}

The diagnosis is a comparison of the template and patient for the purpose of identifying the factors limiting natural production, selecting the appropriate management activity to correct or circumvent the limitation, and describing the life history-habitat relationships that management should attempt to rebuild or repair.

The completed diagnosis should result in a clear problem statement - identification of that which prevents attainment of an objective, If Tables A.1 - A.3 in Appendix A were used to describe the template and patient, the questions in Table 2 will be useful in completing the diagnosis.

The questions in Table 2 are divided into three categories: those questions that describe the stream ecosystem and its capacity, questions that describe the performance (production) of the target population, and questions that describe the 


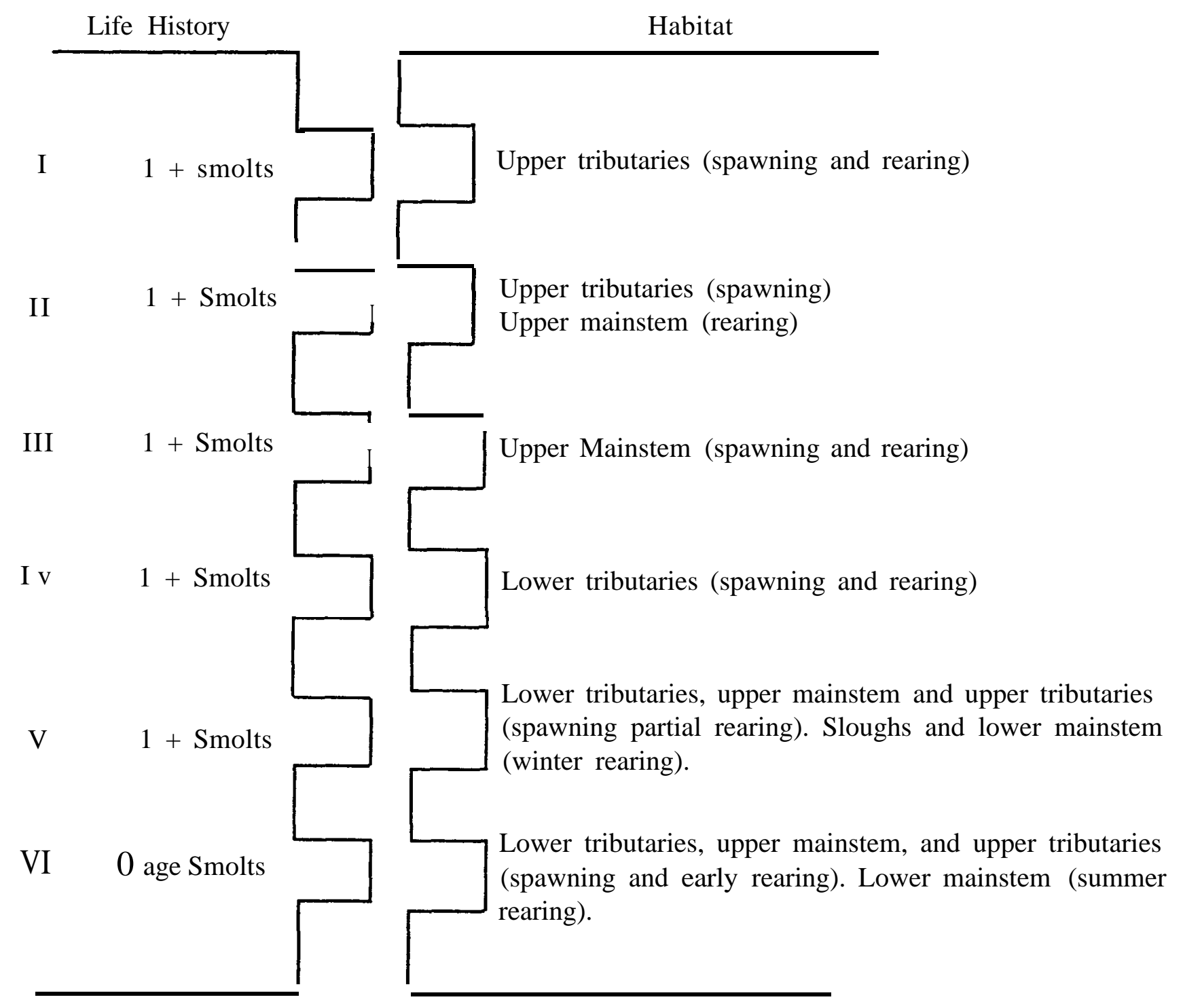

Figure 3. Hypothetical life histories and their associated habitats for a spring chinook population in a mid-Columbia subbasin. The combined life histories and habitat constitute the template. 


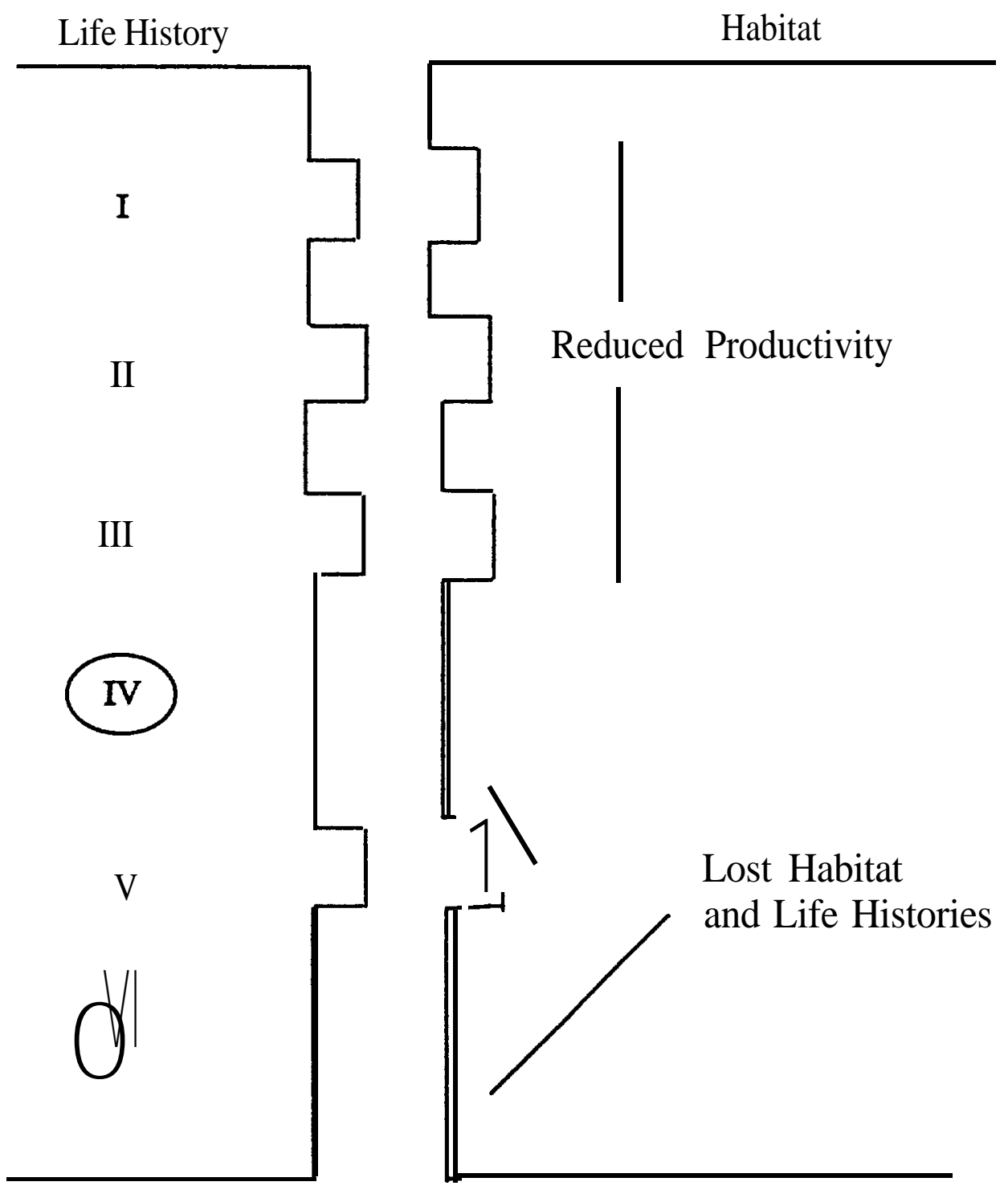

Figure 4. The patient from Figure 3 showing the current condition of the life histories and habitat of a hypothetical spring chinook population. Two life histories and their associated habitats have been lost. The remaining habitats and life histories have diminished productivity. 


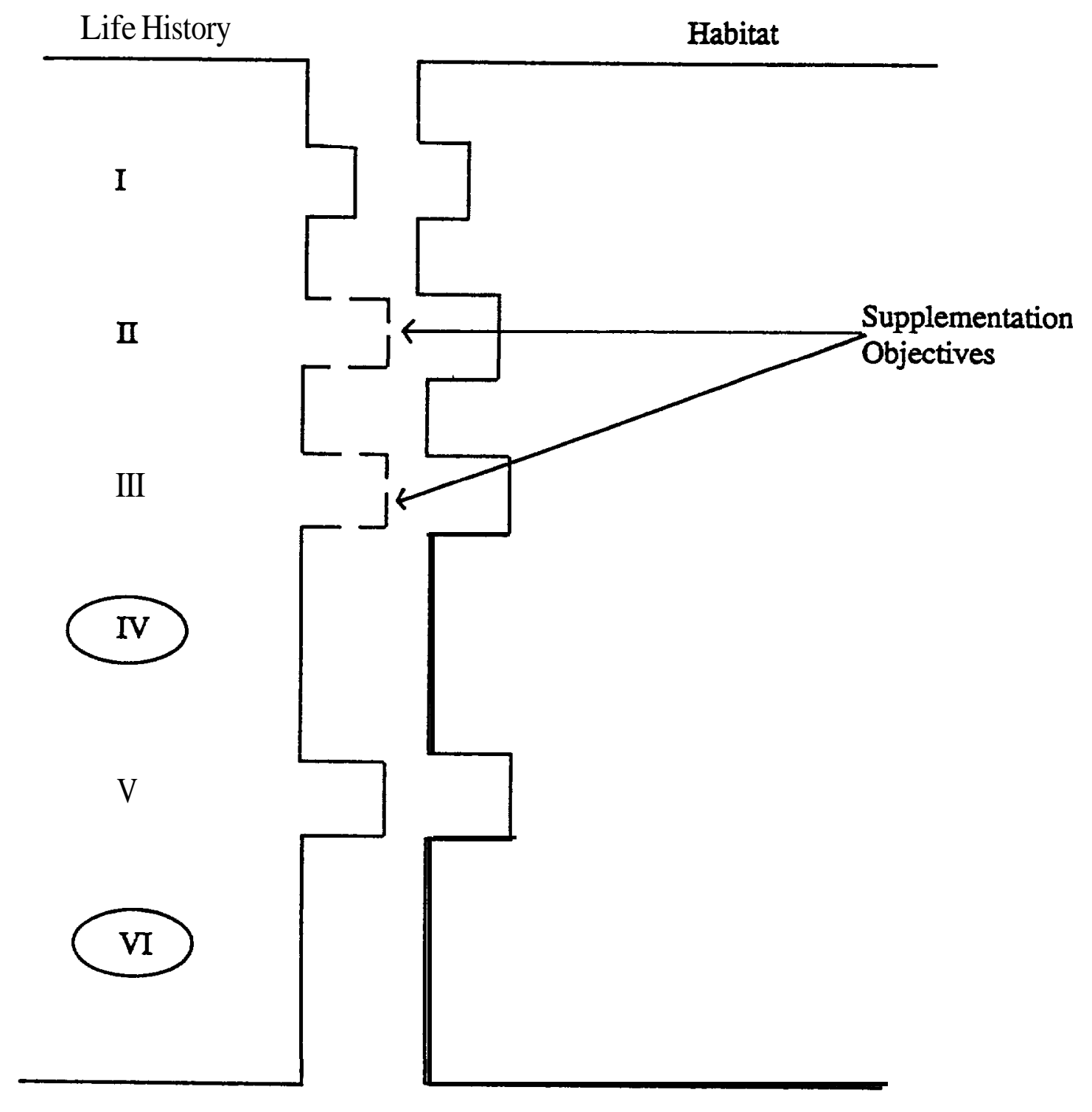

Figure 5. The patient population from Figure 4 showing the objectives of a restoration program which will employ supplementation. 
Table 2. Diagnosis Procedure. This series of questions is intended to help diagnose the target stream/stock.

\section{CAPACITY/ECOSYSTEM DESCRIPTION}

1) Can the template/patient be described with sufficient detail to identify the factor(s) preventing the patient from achieving the objective? If yes, continue. If no see Conclusion A.

2) Does the template/patient comparison suggest that current natural production is less than historic? If no, see Conclusion B. If yes, continue.

3) a. Are the historic life history patterns present in the patient population?

b. Has the quality and quantity of abiotic and biotic habitat been altered?

c. Is the difference between template and patient due to fishery management activities?

d. Is the difference between template and patient due to factors outside the basin such as passage?

4) Describe the factors above (3a-3d) that contribute to the difference between template and patient. Proceed to the next set of questions.
5) a) Is the habitat fully seeded at each life history stage?

b) Are density, growth, survival, by life stage in the patient comparable to other populations reported in the literature?

c) Has the distribution of the target population within the subbasin been reduced?

d) Can the adult stock production function be described?

e) Is the population controlled by density independent or density dependent factors at each life stage?

6) Do the answers to $5 a-5 e$ suggest the potential to increase natural production? If no, see conclusion B. If yes, continue.

7) Do the answers to $5 a-5 e$ generally support the target population size contained in the objective? If no, see Conclusion C. If yes, continue.
POPULATION LIMITING FACTORS

8) a. Has the timing of life history events changed putting them out of synch with flow and temperature patterns?

b. Have flow and temperature changed in a way that is detrimental to the completion of template life history patterns?

c. Are there biotic interactions limiting production of the target population?

d. Are there full or partial migration blocks (juvenile and adult) that were not present in the template?

e. Can specific mortality factors be identified such as fine sediment in spawning gravels or improperly screened diversions?

f. Would the planting of hatchery fish create a bottleneck at a later life history stage/habitat?

g. Have fecundity, sex ratio, or reproductive success changed?

h. Are there genetic changes that might account for the differences in template and patient.

9) Are the limiting factors correctable? If yes, see Conclusion D. If no, see Conclusion C.

\section{CONCLUSIONS}

A) Implement field surveys and/or literature review to obtain the information.

6) There appears to be no problem for which attempts to increase natural production are a logical solution.

C) Revise objective and continue diagnosis.

D) Implement appropriate management activities to achieve objective. 
limiting factors. Answers to the questions in Table 2 lead to one of the four conclusions listed at the bottom of the table. The four conclusions are described below:

A recognition that there is not enough information to describe the patient sufficiently to determine appropriate enhancement measures and or management actions. (A) Identification of the appropriate management action to increase natural production requires a minimal understanding of the life history - habitat relationship in the stream/stock system. This is especially true where the integration of natural and hatchery production (supplementation) is being proposed. If basic information on life history, distribution and habitat quality is not available to complete the patient description, the chances of selecting strategies that will yield long-term success are reduced. Under those circumstances, it may be prudent to delay supplementation until the data can be obtained.

A recognition that there is no problem, i.e. the performance of the system is at its natural production capacity.(B) The template and patient comparison might reveal that the performance of the stream/stock is comparable to historic production and it is not reasonable to assume additional capacity for natural production. In that case, any increase in total production would have to come from a well-planned conventional hatchery - a conventional hatchery that added to and did not replace natural production. Such a program must be designed to minimize risk to the natural production system.

A recognition that the existing management objective needs revision. $(C)$ The template/patient analysis might show that the management expectations for the target stream/stock are not consistent with its potential i.e., the target stock size in the objective is too high or too low. Assuming the manager has confidence in the analysis, the objective should be changed and the diagnosis repeated.

\section{$A$ recommendation to implement specific management activities to circumvent or} correct the limitation in natural production. @) The diagnosis might lead to the conclusion that natural production can be increased through management action. The management activities might include supplementation, habitat improvement, water management, removal of barriers, harvest regulation, or some combination of the above. The manager must explain how the factors limiting production will be corrected by the chosen management activity. Supplementation is an appropriate strategy if the objective includes increases in natural production and the constraints on production can be circumvented through the use of artificial propagation.

RASP Summary Report Series, Part III: Planning Guidelines

December, 1992 /page 18 
The diagnosis should result in a clear problem statement and a recommendation for a management action to overcome the problem and achieve the goal. If supplementation is the management activity chosen, the objective will probably have to be revised.

\section{$\underline{\text { Revise the Obiective (Step 5) }}$}

At this point in the development of the supplementation plan, the manager should revisit the objective to determine if it is consistent with the template/patient analysis. The objective should describe what part of the template production can be reasonably obtained through supplementation. In general, management objectives are limited to numerical targets stated as the number of juveniles released from the hatchery and/or the expected number of adults in the catch and escapement. Numerical targets are important measures of performance, however, RASP has identified additional performance standards that should be incorporated into supplementation objectives: post-release survival, reproductive success long-term fitness and ecological interactions. Once supplementation has been identified as an 'appropriate management activity, the objective should be reviewed and these new performance standards included.

The RASP definition of supplementation implies that the manager has some discretion when setting the criteria for post-release survival, ecological interactions, and reproductive success. The definition also implies no discretion with regard to the goal of maintaining long-term fitness of the target stock.

The following hypothetical scenario is discussed to illustrate setting quantitative objectives based on the four performance measures. The example uses codes to indicate fishes with different parental life histories:

$\mathrm{T}$, is the progeny of wild parents,

$T_{1}$ is the progeny of one wild and one hatchery parent that spawned naturally,

$\mathbf{T}_{\mathbf{2}}$ is the progeny of hatchery parents, that spawned naturally,

$\mathbf{T}_{\mathbf{3}}$ is a hatchery produced fish.

While recognizing that it may currently be impossible to monitor all the types described above, the concept of fish types has considerable value in planning, 
especially when using the RASP spreadsheet model as a planning tool. (See Part II in this report series.)

Consider an upper basin, summer steelhead population which is essentially wild (has never been supplemented) and is currently depressed. Some of the conditions that caused the initial depression have been eliminated (e.g., a tributary dam has been removed), and improvements in others (passage at mainstem dams) can be anticipated. Spawning and rearing habitat in the subbasin is excellent in quality and currently is utilized primarily by a large population of rainbow trout which supports a fishery of some intensity.

In good years, abundance is maintained, but managers fear that three or four bad years in succession could result in critical depression or extinction. The managers' fundamental objective is to use supplementation to increase the abundance of the population rapidly and substantially, and to preserve as much as possible of the native gene pool. The managers decide, based on the template/patient analysis that it is realistic to double spawning escapement by the third generation of supplementation:

$$
\left(\sum N_{\mathrm{i}}\right)_{\text {affer } 2 \text { generations }}=2 N_{0_{\text {now }}}
$$

They also have set the constraint that this escapement will be maintained with a terminal fishery that harvests an average of $20 \%$ of the returns. Therefore, they have set the objective that escapement to the subbasin should be 2.5 times the current average. Secondarily, the managers would like to re-establish a terminal steelhead fishery, which has been closed for a number of years. The managers determine to accomplish these general objectives by sustained smolt supplementation utilizing local broodstock. In this example, the project objectives would include:

Post-release survival. Through modeling, it has been estimated that, given the number of smolts that can be produced, the objective can only be accomplished if the postrelease survival (smolt -to-adult) of supplemented fish is at least $50 \%$ of the wild rate. The survival target of $50 \%$ of the wild rate becomes a part of the project's objective.

Reproductive success. Model runs also indicate that targeted production increases cannot be maintained unless egg-to-smolt survival of $\mathbf{T}_{\mathbf{2}}$ and $\mathbf{T}_{1}$ fish is, respectively, 80 and 90 percent of the wild rate:

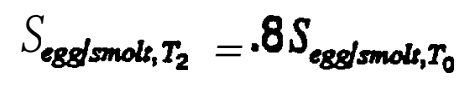

RASP Summary Report Series, Part III: Planning Guidelines

December, 1992 /page 20 


\section{$S_{\text {egg/smolu, } T_{1}}=.9 S_{\text {egglsmok, } T_{0}}$}

Equally necessary, on the basis of model runs, is the preservation of the presuppIemented age distribution and mean fecundity in $\mathbf{T}_{\mathbf{3}}$ fish:

$$
F e c_{T_{3}}=F e c_{T_{0}}
$$

An additional management objective is that the "homing fidelity" of $\mathbf{T}_{\mathbf{3}}$ fish be at least $90 \%$ of the wild rate, and that $\boldsymbol{T}_{2} \mathrm{~s}$ and $\mathbf{T}_{1} \mathrm{~s}$ home at rates equivalent to wild fish.

Those three criteria also become part of the project's objective.

Ecological interactions. The managers decide to accept a 50\% reduction in abundance of rainbow trout by the third generation, if necessary. They plan to implement acclimation and release strategies that might reduce this impact. The tradeoff between resident trout and steelhead should be specified in the objective.

Long-term fitness. Direct measures of long-term fitness are difficult if not impossible to obtain from a naturally reproducing population of salmon. Obviously, long-term fitness cannot be measured in the short term. However, measures of short-term fitness can be used to estimate long-term fitness. A reduction in long-term fitness might be measured indirectly as an unintended change in life history or demographic parameter such as migration or spawning timing, age structure, spawning distribution, or juvenile rearing patterns. Minimum viable population analysis and monitoring of the effective population size are other tools that can provide insight to long-term fitness. Additional evidence of a probable change in long-term fitness may be obtained from an analysis of biochemical genetic descriptors of the supplemented population measured over time. The specific parameters to be monitored for change must be specified in the objective before supplementation begins with sufficient lead time to obtain reliable baseline estimates.

\section{$\underline{\text { Recommend Treatment (Step 6) }}$}

To reach this step, the diagnosis should have indicated that supplementation alone or in combination with another management action such as habitat restoration is a candidate strategy to restore or increase natural production in a stream/stock system. 
In this step of the planning process, the manager develops and evaluates alternative supplementation strategies. The operative word is alternative. The RASP model, which was developed as a tool for managers planning supplementation, (Figure 2) achieves its full value if it is used to compare the risks and benefits of reasonable alternative treatment strategies.

General guidelines for treatments selection. Kapuscinski et al. (1991) and Chapter c of the ISP (CBFWA 1991) discuss the selection of supplementation strategies and Reisenbichler and McIntyre (1986) give guidelines for integrating natural and artificial production of salmonids. Those reports offer important guidance for development of alternative supplementation strategies. The following discussion will draw heavily on the advice they contain.

The development of alternative treatments must consider genetic risks, habitat bottlenecks, natural life history patterns, and the physical constraints of the hatchery facilities. Supplementation strategies are comprised of six basic elements: brood stock selection, mating protocols, escapement management, incubation and rearing practices, release variables, and project scale. In the discussion that follows, we present alternative approaches to each of these basic elements and, in some cases, recommend priorities for the alternative treatments. In specific situations the recommended priorities might be altered because of unique qualities or conditions in a stream/stock system. In those cases, the manager should justify the deviation from the priorities given here.

Broodstock Selection When supplementation will increase natural production in an existing population, the best way to insure long-term fitness in the target stock is to select brood fish that are similar in genetic resources, life history, and originating environments (ecological similarity). Each of the three similarity factors is discussed below :

Genetic Similarity. Analysis of the genetic structure of the donor and target population should be completed to determine if the stocks are phylogenetically similar. The manager should consult with a geneticist to obtain help in determining genetic similarity. Distance from the target stream may be used as a surrogate for genetic similarity if the habitats in the donor and target stream are similar. However, even streams that are close may support genetically different stocks. For example, Wade (1986) reported reduced resistance to the parasite Ceratomyxa shasta in the native stock the Nehalem River, Oregon. He attributed the change in resistance to the planting of nonresistant fish from the 
nearby Trask stock. It's important to avoid mixing ancestrally divergent populations even if they are in close proximity.

Life History Similarity. Comparable life history patterns between the donor and patient stock might reflect genetic similarity and also afford the best opportunity for the donor stock to adapt to the habitat and environmental conditions in the target stream.

Ecological Similarity. If a non-native stock is selected as the donor, ecological similarity can be evaluated through a template/patient analysis (Appendix A). In this case, the patient is the donor stock described in the context of its native stream and habitat which should then be compared to the target stream/stock. Human alteration of the donor and target habitats must be taken into account.

When selecting a brood source the target population should be the first priority, however, the number of brood fish removed should not create genetic risks for the donor stock (Busack 1990 and Ryman and Laikre 1991). The second priority is a neighboring population that has the greatest degree of similarity using the three criteria discussed above. The last priority is a hatchery stock that meets the similarity criteria. If the target stock is facing extinction, a different set of criteria should be used (for a discussion of those see Kapuscinski et al. (1991)).

If the priorities listed above have to be changed, the following overall constraints should guide the selection of a donor stock: maintain the genetic resources, life history patterns, and self-sustainability of the donor population; the candidate stocks should be evaluated against the three similarity factors; and the effective population size of the hatchery population should be maximized.

Mating Protocols After the choice of broodstock, mating is the next most important activity that influences the hatchery gene pool. When selecting mating strategies the manager needs to consider life history and effective population size.

Life History. All of the donor stock's life histories should be represented in the fish bred in the hatchery. To achieve this goal the broodstock should reflect the following characteristics in the natural population: age structure, time of spawning, spawning location, migration timing and, where possible, juvenile smolt migration. 
Effective Population Size. The effective population size of the fish bred in the hatchery should be maximized (See Kapuscinski et al. (1991) for a discussion of ways to maximize effective population size).

In addition, managers should review the seven spawning guidelines presented in the ISP (CBFWA 1991).

Escapement Management Once supplementation is underway, the manager must decide how the broodstock will be selected from the mix of wild and hatchery fish returning to the target stream. The proportion of hatchery and wild fish in the hatchery broodstock and in natural spawning areas might be regulated by agency policies (the Oregon Wild Fish Policy, for example). In the absence of policy guidelines, the hatchery broodstock should be selected from returning adults according to the following in priority order:

- breed only naturally-produced adults in the hatchery

- $\quad$ breed a mixture of hatchery and wild adults

- $\quad$ as a last priority, breed only hatchery fish.

Selecting the appropriate strategy will depend on a balance of genetic risks (Busack 1990) associated with the removal of naturally produced fish from a small population and the genetic effect from repeated use of hatchery fish in the broodstock. A genetic risk assessment should address uncertainty associated with each of the possible strategies for using returning adults.

Incubation and Rearing Practices Post-release survival may be heavily influenced by the rearing methodologies and physical habitat of the hatchery. Survival is dependent on fish health, and in general, the manager has to be concerned about two kinds of fish health:

- $\quad$ clinical health in the hatchery which is threatened by disease, poor nutrition that leads to physiological anomalies, and stress from crowding or chemical quality of the water 
- $\quad$ ecological health which is threatened by lack of predator avoidance, inability to compete for food and space, and release to the stream at sixes, times and places that differ from the normal life history patterns of the stock.

The first concern has received a lot of attention and there are generally accepted procedures to ensure clinical health of a hatchery population. To maintain ecological health, the manager should attempt, to the extent possible, to incubate and rear the juveniles in ways that reflect natural conditions. Ultimately natural conditions for rearing should reduce random mortality while duplicating the natural selective mortality (Bowles and Leitzinger 1991). Recent research in this area should lead to the development of natural rearing practices. For the present, the manager should consult Kapuscinski et al. (1991) for specific suggestions.

Release Variables The time, size, and place of release of hatchery-reared fish can have important effects on life history, post-release survival and the genetic structure of the stock. The first priority should be to mimic natural life history. Hatchery practices that mimic natural life history have a better chance of achieving project objectives (Reimers 1979), particularly in areas with existing natural production. Sixes, times and places of release consistent with natural life history can be derived from the template/patient analysis (Appendix A).

Project Scale The number of fish released into a stream may be governed by policies that limit the proportion of hatchery and natural fish on the spawning grounds (see Oregon's Wild Fish Policy and Bowles and Leitzinger 1991). In the absence of specific policies, the number of fish released into the target stream should not exceed the natural stream's capacity. The manager can derive some guidance on stocking level, frequency and duration from a comparison of patient rearing densities with published densities (see Appendices A and C). In the absence of data on stocking densities, start at a conservative scale and gradually work up to the final release numbers based on monitoring information. The exception to this guideline is the target stream/stock locked into a stable equilibrium at a density lower than historic because of predation or competition (See Part I of this series).

Use of captive broodstock for restoration of depleted stocks Restoration of depleted stocks of salmon and steelhead has become a regularly occurring challenge for fishery managers and it is likely that the number of salmon and steelhead stocks in need of restoration will increase. Planning and implementation of restoration programs are complicated, requiring knowledge and skills in many areas and a wide array of tools 
and strategies. Captive brood is an unconventional approach to broodstock management that has been used in commercial aquaculture and has had Limited use in salmonid restoration projects.

Captive brood as used here refers to anadromous salmonids held in captivity through all or most of their life cycle in order to build a mature broodstock for artificial propagation. Captive broods may be reared entirely in fresh water or in a combination of fresh and salt water in a sequence that mimics the natural residence in those environments. The fish may be held in captivity from the egg through mature adult or wild juveniles may be captured and held to maturity. Captive brood has recently been applied to the recovery of the Red Fish Lake sockeye.

Captive brood technology has potential benefits and risks. Because the benefits and risks have not been evaluated through appropriate monitoring and evaluation, captive brood should be considered an experimental approach and used with caution and only in circumstances where there are no acceptable alternatives.

Model evaluation Once the alternative supplementation strategies have been devised, the manager should evaluate the risks and benefits of each treatment. There are several approaches to this analysis. RASP recommends that at least part of the evaluation of risks and benefits be completed though the use of a life-history model which was designed specifically to assist in evaluating alternative supplementation strategies. Part II of this series should be consulted for a detailed description of the model and its use.

\section{RISK ANALYSIS}

This section describes the critical role of risk analysis in planning a supplementation project (in the Background section) and the recommended process for accomplishing a risk analysis and assessment.

\section{Background}

Supplementation involves use of technology to increase natural production while limiting negative impacts on important natural attributes of the target and non-target stocks. Identifying and making provision to manage the risks of those impacts are important tasks in the planning of supplementation projects. Risk analysis is a form of technology assessment. According to Brooks (1973), technology assessment should 
attempt to reduce the gap in opposing values that often generates conflict regarding the use of technology, determine the appropriate scale for the application of a technology, and promote innovation and adaptation in a technology. A fourth purpose is to prevent surprise - failures or deviations from the expected results following the application of a technology (Timmerman 1986).

The use of supplementation technology to restore or enhance natural production in the Columbia Basin is controversial. The controversy is fueled by divergent values held by agencies and organizations that possess political influence in the basin. Those values conflict in part because of the uncertainty surrounding the potential success or the potential negative side effects of supplementation, and because supplementation is associated in positive and negative ways with the past performance of conventional hatcheries. The gap in values that fuels the controversy can be reduced through knowledge. Some of the uncertainties can be reduced through the application of existing knowledge while some will require new research. As new information and understanding reduce the uncertainties surrounding supplementation, the issues and debate will become more focused on specific questions and a smaller number of less divergent values should emerge (Brooks 1973). A risk analysis that results in a timely and efficient reduction of uncertainties and/or a plan for managing risks will help reduce the conflict that currently surrounds the use of supplementation in the Columbia Basin.

When setting the scale of a supplementation project, the manager must take into account life histories and habitat quality, potential straying and introgression with nontarget populations, the genetically effective population size (Ryman and Laikre 1991), and economic efficiency (CBFWA 1991). The presence of multiple stability regions within a stock's production functions would also influence project scale. The scale of a supplementation project is an important determinant of the nature and number of critical uncertainties and therefore is an important consideration in risk analysis.

Technologies with successful histories often slip into monocultures. Failure to recognize changing environments or public attitudes may lead to homogenous technologies, which are less innovative and adaptive (Brooks 1973). Because supplementation attempts to integrate two production systems (natural and artificial) to achieve a higher level of natural production, and because there are a number of uncertainties associated with supplementation, innovation and adaptation are essential elements in the overall program. In addition, the Council's policy of adaptive management requires flexibility in the design and implementation of management programs in the basin. However, large investments in fixed physical facilities may be 
an impediment to innovation and adaptation in supplementation. Risk analysis must consider the design of fixed facilities and the flexibility of those facilities to "adapt" to new information.

Surprise is defined as a major program failure or deviation from the expected and is often the product of too much reliance on unexamined assumptions regarding the use of a technology. Although we should try to conduct management programs and supporting research and monitoring in ways that minimize surprise, it is also important that we learn enough to act appropriately when surprise occurs.

All of the purposes of technology assessment listed above are relevant to risk analysis and management for supplementation. Throughout this stage of the planning process, the manager should keep in mind the overall purposes of risk analysis - to reduce conflict, set the project scale, promote adaptation, and prevent or respond effectively to surprise.

\section{Risk Assessment (Step 7)}

Risk assessment is comprised of two tasks:

- $\quad$ Estimating risk. Risk may be estimated by a qualitative assessment of uncertainties or through a quantitative procedure that produces an estimate of the probability of success of the project.

- $\quad$ Managing risk. If the manager decides to complete the project plan, after reviewing the probability of success or its reciprocal, the risk of failure, he or she must develop a strategy to manage the risk associated with a project's critical uncertainties.

Estimating Risk Risks associated with a proposed supplementation project may be described qualitatively by listing the critical uncertainties and weighing their effect based on experience and a review of the literature. Another approach is to incorporate a subset of uncertainties into a model which generates a numerical estimate of risk. We have labelled these two ways of estimating risk Type 1 and Type 2. They are not independent estimates. Type 1 risk assessment, which is based on a listing of critical uncertainties, must be completed for each project. Since a Type 2 risk assessment requires the prior identification of critical uncertainties, it cannot be attempted until after the Type 1 assessment has been completed. 
During project planning, all uncertainties are initially managed by making appropriate assumptions. An uncertainty is critical if the choice of assumption will determine success or failure of the project. The choice of assumptions for minor uncertainties will have small effects on the project outcome. For example, a project attempting to restore an extirpated stock might list among its critical uncertainties the quantity, quality and distribution of spawning and rearing habitat, especially if it is known that habitats have been degraded since extirpation of the native stock. Another critical uncertainty might be the choice of donor stock, especially if the habitat and life histories of the only available donor stock are not similar to those of the native stock. Minor uncertainties might include appropriate temperature regimes for incubation and rearing, feed programming, broodstock capture and holding methods, preventative hygiene, pond density, and grading practices. Not all supplementation projects will necessarily have critical uncertainties associated with them. It is conceivable that some small scale projects may not identify critical uncertainties. Other projects may identify several critical uncertainties.

The universe of uncertainties for a given project is the product of three factors: the condition of the stock and stream, or our perception of them; supplementation strategies applied to the system; and management expectations or objectives expressed as production targets (Figure 1). The combination of those factors will produce a unique set of uncertainties for a given project although there will be some overlap among projects. RASP (in preparation) gives a hierarchial description of potential supplementation uncertainties and outlines approaches to their identification. The manager attempting to list uncertainties for a specific project should consult RASP (in preparation).

Type 1 risk is broadly defined as the sum of the critical uncertainties associated with a project. The assessment of those risks is the qualitative weighing and comparison of the critical uncertainties for alternative treatments including the no action alternative. Critical uncertainties should be identified for all dimensions of the management objective including long-term fitness, reproductive success, ecological interactions, post-release survival, and the numerical production targets. Tables $3 \mathrm{a}-\mathrm{e}$ are provided as work sheets to aid in estimating Type 1 risk and in completion of the risk analysis for each dimension of the objective. The worksheets call for a list of critical uncertainties (if there are any); their potential impact on the specific dimension of the objective, i.e. numerical production targets, post-release survival, reproductive success, ecological interactions and long-term fitness; the overall impact of the 
Table 3a. Risk Analysis Numerical Targets Work Sheet

\section{MANAGEMENT OBJECTIVE}

\section{Numerical Targets:}

Treatment Alternative:

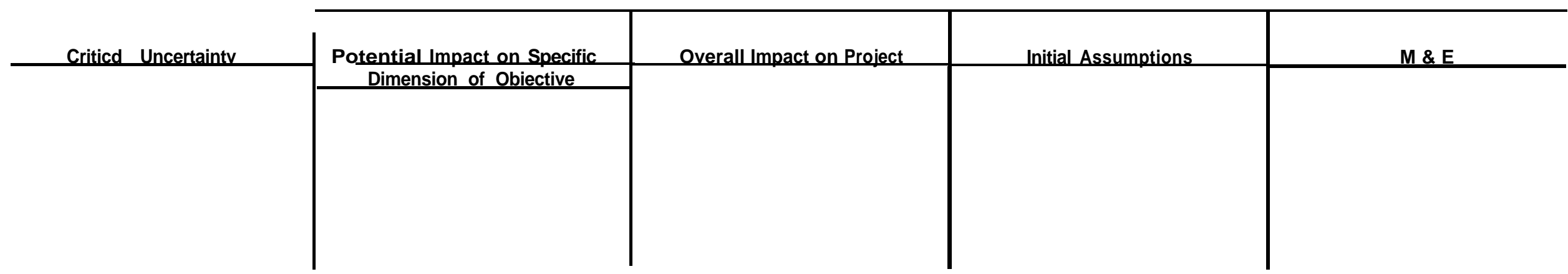

Table 3b. Risk Analysis Post Release Survival Work Sheet

\section{MANAGEMENT OBJECTIVE}

Post Release Survival:

Treatment Alternative:

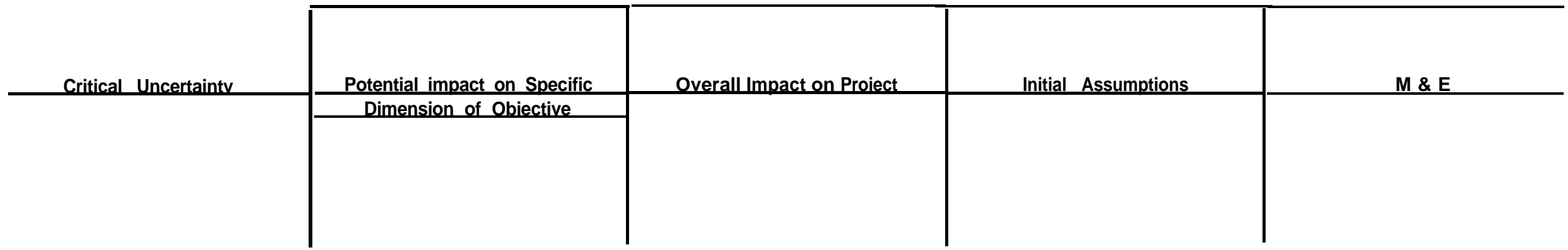


Table 3c. Risk Analysis Reproductive Success Work Sheet

\section{MANAGEMENT OBJECTIVE}

Reproductive Success:

Treatment Alternative:

Critical Uncertalntv

\begin{tabular}{|c|c|} 
Potential Impact on Specific & Overall Impact on Project \\
\hline Dimension of Objective &
\end{tabular}

Initial Assumptions

M\&E

Table 3d. Risk Analysis Ecological Interactions Work Sheet

\section{MANAGEMENT OBJECTIVE}

Ecological Interactive:

Treatment Alternative:

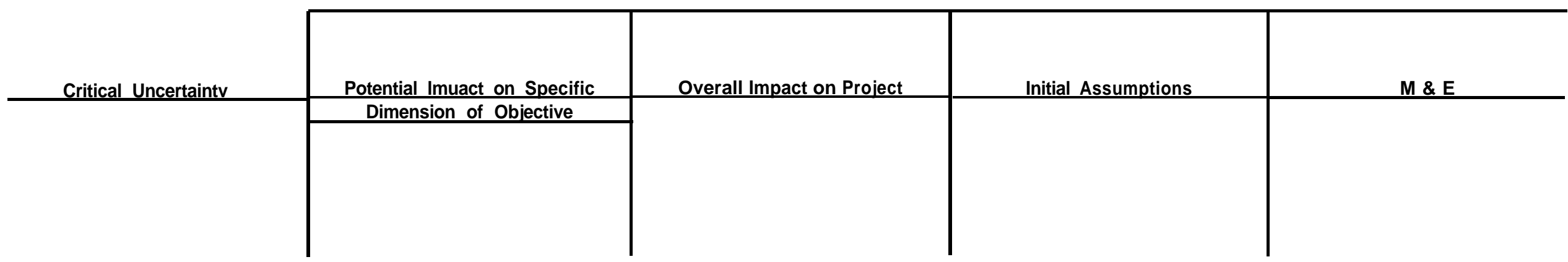


Table 3e. Risk Analysis Long Term Fitness Work Sheet

MANAGEMENT OBJECTIVE

Long Term Fitness:

Treatment Alternative:

\begin{tabular}{l|l|l|l|}
\cline { 2 - 4 } Critical Uncertainty & Potential impact on Specific & Overall Impact on Project & Initial Assumotions \\
\cline { 2 - 5 } & Dimension of Objective & & \\
& & &
\end{tabular}


project; the initial (planning) assumptions; and a description of how the uncertainty (risk) will be managed through monitoring and evaluation. Tables $3 \mathrm{a}-\mathrm{e}$ are a critical part of the planning process. In effect, they summarize the outcome of all the previous steps.

The following suggestions should help the manager attempting to complete Tables $3 \mathrm{a}$ e: The treatment alternative should be described in terms of the six basic elements of the treatment listed on pages 22 - 25. Each critical uncertainty listed in the table should include its minimum acceptable value. For example, a target value for postrelease survival will have been stated in the first section of Table $3 b$, and the ability to achieve that target might be a critical uncertainty. Assume, for example, that the target for post-release survival is $50 \%$ of the survival rate of the wild fish. In the example, at a post-release survival of less than $50 \%$ but greater than $10 \%$ the project will be continued with a diminished benefit/cost ratio, however, at a post-release survival of less than $10 \%$ of the wild fish, the project will be terminated. The $10 \%$ survival level is the minimum acceptable value for this example. Under the column labelled "Potential Impact on Specific Dimension of the Objective," the range of observed values should be reported along with an estimate of the most probable impact. In the previous example, the range in post-release survivals from the literature should be reported. In the example given above, the overall impact on the project is termination if post-release survivals are below 10\%. Where appropriate, the initial assumption for each of the six basic elements of the treatment should be described for each critical uncertainty.

In a Type 2 risk assessment the manager analyzes critical uncertainties through a model and derives a numerical estimate of the probability of success or failure of a supplementation project. This type of risk assessment will generally focus on a subset of the critical uncertainties which are associated with a particular aspect of supplementation. For example, in the Treatment section above, we recommended that the RASP life history model be used to identify and evaluate risks associated with specific supplementation strategies. The life history model allows the manager to assess the benefits and risks of various treatment alternatives. However the model cannot evaluate risk associated with all critical uncertainties and all dimensions of the objective. The RASP model can also be used to rank (prioritize) uncertainties according to their projected impact on production (see Part Il in this report 
series).Type 2 risk assessment may also employ less complex models. For example, at each life stage, we might assign numerical probabilities of success conditioned by the specific supplementation treatment. The simple sum or product of the life stage probabilities gives a single numerical estimate of the chance of success and the reciprocal is an index of risk.

Type 2 assessments reduce risk to a numerical estimate which is more convenient for decision makers than the Type 1, qualitative list of critical uncertainties. However, the numerical estimates may give a false sense of concreteness and mask the dynamics of the components of risk. The numerical estimates of Type 2 risk have variances which are a measure of the risk associated with their use. In some cases, high variances might render the numerical estimate of risk no more useful than the qualitative weighing of critical uncertainties (Type 1).

The purpose of risk assessment is to give the decision maker technical advice regarding the probability of achieving the management objectives by using supplementation. The assessment must include all dimensions of the management objective i.e., long-term fitness of the native stock, reproductive success, ecological interactions and post-release survival as well as the numerical targets for adult returns (Tables $3 \mathrm{a}-\mathrm{e}$ ).

Risk assessment is tied to decision making, however, there is a clear distinction between the two. Risks associated with the use of technology such as supplementation can be determined through an objective, scientific process. The consequences of alternative choices can described through analysis, but there is no scientific basis for making the final decision i.e., deciding how much risk to accept (Brooks 1973). While the final decision has to include consideration of the scientific analysis, it must also incorporate economic considerations, community values and political processes as well.

Managing Risk. By definition, critical uncertainties can bring about the failure of a supplementation project. Since they determine the success or failure of a project, the risk associated with the critical uncertainties must be "managed" to reduce their potential negative effect and improve the probability that the supplementation project will achieve its objective. Risk management is accomplished in three ways:

- Initially, the critical uncertainties listed in Tables $3 \mathrm{a}$ - e are managed through reasonable assumptions. The assumptions should 
be based on a review of the literature and they should be subjected to a review by qualified experts.

- The risks associated with some uncertainties can be removed or reduced by research. A brief outline of the research design is called for in Tables $3 \mathrm{a}-\mathrm{e}$. The next section (Monitoring and Evaluation) gives more information on the design of research on the critical uncertainties.

- $\quad$ Some uncertainties may not be amendable to research. The risks associated with those uncertainties are managed through monitoring designed to contain risk by giving early warning of an error in a assumption from Tables $3 \mathrm{a}-\mathrm{e}$.

The manager must show how each critical uncertainty will be addressed either through research or monitoring. In many cases, research and monitoring costs can be minimized through cooperative efforts among supplementation projects through global design (see Part IV of this series).

\section{MONITORING AND EVALUATION}

This section describes the purpose of monitoring and evaluation and suggests elements to consider in designing and implementing a monitoring and evaluation program.

\section{Background}

The objectives of project-level monitoring and evaluation (M\&E) are to reduce or remove the critical uncertainties identified in Tables $3 \mathrm{a}-\mathrm{e}$ and thereby improve the probability of a project's success (risk management), to monitor population variables that give warning of an error in planning assumptions (risk containment monitoring), and to document the return on project investment (accountability). M\&E is a pivotal step in the planning process and it is linked to all of the previously described steps (Figure 2) through the Council's policy of adaptive management (NPPC 1987).

Few stream/stock systems being proposed for supplementation will have sufficient information to complete all the steps described in the previous sections of this report, particularly Tables A.1 - A.3 in Appendix A. However, under adaptive management, all the steps need not be completed before implementation. We encourage managers to 
address all the steps with existing information, whether that information is qualitative or quantitative. Adaptive management permits projects to proceed to the implementation stage with a degree of caution commensurate with the number of critical uncertainties (Tables $3 \mathrm{a}-\mathrm{e}$ ) and the degree of risk. For example, projects with a large number of critical uncertainties and high risk may initially be implemented with temporary facilities and at a scale no larger than that dictated by the needs of the M\&E program.

$\mathrm{M} \& \mathrm{E}$ in an adaptive management context permits the manager to Yearn by doing." Under adaptive management, planning for projects that contain critical uncertainties assumes a different role. The planning steps described in this report become an iterative process driven by information obtained through $M \& E$. Key elements in the process i.e., template/patient analysis, diagnosis, and risk analysis are repeated at regular intervals to incorporate the new information. The objective of an iterative planning process is to eventually reduce or eliminate the critical uncertainties. In this context, planning is not a one-time activity but it becomes an important part of the $\mathrm{M} \& \mathrm{E}$, at least until the uncertainties are resolved. The iterative planning process then is the basis for a regular project review.

Design Considerations

The generally accepted approach to scientific investigations includes the sequence:

- Devise alternative hypotheses

- Devise the experiments to exclude one or more hypotheses

- $\quad$ Carry out the experiment, evaluate the results, and then recycle the procedure (Platt 1964).

The M\&E plan for a supplementation project begins with the template/patient analysis which leads to the list of critical uncertainties (Tables $3 \mathrm{a}-\mathrm{e}$ ). Where there is sufficient information on the stream/stock system, the design of the M\&E can begin by the derivation of hypotheses from critical uncertainties. For stream/stock systems with insufficient baseline information, preliminary surveys will have to be completed. Ward (1978) recommends field surveys to estimate the structure and function of the system prior to the formulation of hypotheses and the design of environmental impact 
studies. A failure to carry out the survey or a survey that merely catalogues rather than determines functional relationships often restricts the success of the M\&E (Ward 1978).

Ecological questions, particularly those dealing with salmon production and productivity, are not easy to partition into mutually exclusive, alternative hypotheses. Factors that determine production often have a large degree of interaction. When independence is incorrectly assumed, hypothesis testing can lead to misleading conclusions (Quinn and Dunham 1983).

Conventional wisdom seems to suggest that experimental design is the formulation a series of null and alternative hypotheses along with appropriate statistical tests. While the development of hypotheses is critical to the overall scientific approach, the purpose of experimental design within that approach, which is often overlooked, is to identify and remove irrelevant sources of variability thereby increasing the power of the test of the null hypothesis (Cohen 1988). For a discussion of experimental design in fisheries management including alternative design approaches, see McAllister and Peterman (1992).

\section{Statistical Power}

Conventional analysis of $\mathrm{M} \& \mathrm{E}$ information in fisheries attempts to reject a null hypotheses which is usually stated as no effect. For example, a null hypothesis for supplementation might be: There is no difference in smolt-to-smolt survival between naturally produced and supplemented salmon. When a null hypothesis is rejected the significance level $(\propto)$ of the test is also reported. When the data fail to reject the null hypothesis, managers often fail to report power of the test (Peterman 1990) or the probability that the test will lead to a rejection of the null hypothesis (Cohen 1988). This failure can lead to erroneous conclusions if the power of the test is low and the manager decides to accept the null hypothesis (Peterman 1990).

To illustrate the point above, consider this example: A manager is experimenting with release timing and size to increase smolt-to-smolt survival of supplemented fish. The objective is to increase the survival of supplemented fish to equal the survival of naturally produced fish. The data fails to reject the null hypothesis and the manger assumes the experiment was a success and survival of supplemented and natural fish is equivalent. However, because of a small sample size and high sampling variability, 
the power of the test is low. In this case the manager erroneously terminates the experiment when in fact the survival of supplemented fish has not changed and remains below that of natural fish.

The importance of statistical power lies in its capacity to minimize the potentially harmful results of decisions based on erroneous conclusions. Incorporating statistical power into the experimental designs improves the quality of experiments and demonstrates to decision makers the risks associated with decisions based on experimental results. Some variables such as survival and adult abundance are difficult to measure with high levels of statistical power. DeLibero (1986) concluded that the best one could expect from survival studies of hatchery fish is a coefficient of variation of $25 \%$. In most cases, over reasonable experimental periods, that level of variation would lead to low statistical power. Lichatowich and Cramer (1979) found that studies of survival and abundance may require 20 to 30 years to produce an $80 \%$ chance of detecting a $50 \%$ change.

Power of an experiment can be improved by the choice of variables to be measured. Although survival and abundance of adult salmon and steelhead are important variables that measure the performance of supplementation, our inability to measure them with reasonable statistical power suggests the need to search for alternatives (Lichatowich and Cramer 1979). Appropriate performance measures such as size and timing of juvenile migration (Lichatowich and Cramer 1979) could serve as surrogates for survival and abundance in some experimental designs. Appropriate performance measures could give an early indication of the success of a supplementation strategy or indicate corrective action long before the outcome in terms of returning adults can be determined.

\section{M\&E design}

To improve the probability of success of supplementation projects, the risk associated with critical uncertainties needs to be managed by reasonable assumptions followed by research and/or monitoring. Prior to designing the research or monitoring projects, the critical uncertainties should be subjected to a qualitative scoping process (Table 4) to establish priorities and set guidelines for the experimental design. 
Table 4. Scoping process for critical supplementation uncertainties.

\begin{tabular}{||l|l||}
\hline \multicolumn{1}{|c|}{ FACTORS } & \multicolumn{1}{c||}{ COMMENTS } \\
\hline \hline $\begin{array}{l}\text { critical } \\
\text { Uncertainties }\end{array}$ & $\begin{array}{l}\text { List initial assumptions (see Tables 3a - 3e) used in } \\
\text { developing the supplementation plan and projections. }\end{array}$ \\
\hline Applicability & $\begin{array}{l}\text { Describe the relationship between the uncertainty and } \\
\text { supplementation objectives (see Tables 3a -3e). }\end{array}$ \\
\hline $\begin{array}{l}\text { Prioritize critical } \\
\text { uncertainties }\end{array}$ & $\begin{array}{l}\text { Determine the relative importance of the critical } \\
\text { uncertainties. Some uncertainties can be evaluated } \\
\text { through the RASP model; others will have to be ranked } \\
\text { by qualitative weighing of the potential impact on } \\
\text { objectives. }\end{array}$ \\
\hline Hypotheses & $\begin{array}{l}\text { Where possible convert the assumptions associated with } \\
\text { each uncertainty to testable hypotheses or monitoring } \\
\text { elements. }\end{array}$ \\
\hline Feasibility & $\begin{array}{l}\text { State the feasibility of testing the hypotheses: identify } \\
\text { sources of variability, baseline data needs, controls, } \\
\text { blocks, } \\
\text { etc. }\end{array}$ \\
\hline Statistical Considerations & $\begin{array}{l}\text { State the desired level of statistical power. How reliable } \\
\text { do the research results have to be? Can the desired } \\
\text { level of statistical power be achieved? }\end{array}$ \\
\hline Remaining needs & $\begin{array}{l}\text { List species, stocks, strategies and areas within the } \\
\text { subbasin for which the uncertainty is critical. }\end{array}$ \\
\hline Scope & $\begin{array}{l}\text { Will the experiments pose a biological risk? } \\
\text { Qunlikely to be met under current plans. }\end{array}$ \\
\hline Opportunities & $\begin{array}{l}\text { Are there other supplementation projects better suited } \\
\text { extrapolated to other projects? }\end{array}$ \\
\hline \hline
\end{tabular}


Once the project has undergone preliminary scoping, those projects that are identified as high priority and feasible will require statistical design. Green (1979) gives ten basic statistical rules for the design of environmental studies:

1. Be able to state concisely to someone else what question you are asking. Your results will be only as coherent and as comprehensible as your initial conception of the problem.

2. Take replicate samples within each combination of time, location, and any other controlled variable. Differences among can only be demonstrated by comparison to differences within.

3. Take an equal number of randomly allocated replicate samples for each combination of controlled variables. Putting samples in representative or typical places is not random sampling.

4. To test whether a condition has an effect, collect samples both where the condition is present and where the condition is absent but all else the same. An effect can only be demonstrated by comparison with a control.

5. Carry out some preliminary sampling to provide a basis for evaluation of sampling design and statistical analysis options. Those who skip this step because they do not have enough time usually end up losing time.

6. Verify that your sampling device is sampling the population you think you are sampling, with equal and adequate efficiency over the entire range of sampling conditions to be encountered. Variation in efficiency of sampling from area to area biases among-area comparisons.

7. If the area to be sampled has a large-scale environmental pattern, break the area up into relatively homogenous subareas and allocate samples to each in proportion to the size of the subarea. If it is an estimate of total abundance over the area that is desired, make the allocation proportional to the number of organisms in the subarea.

8. Verify that your sample unit size is appropriate to the size, densities, and spatial distribution of the organisms you are sampling. Then estimate the number of replicate samples required to obtain the precision you want. 
9. Test your data to determine whether the error variation is homogenous, normally distributed, and independent of the mean. If it is not, as will be the case for most field data, then: (a) appropriately transform the data, (b) use a distribution-free (nonparametric) procedure, (c) use an appropriate sequential sampling design, or (d) test against simulated $\mathrm{H}_{\mathrm{o}}$ data.

10. Having chosen the best statistical method to test your hypothesis, stick with the result. An unexpected or undesired result is not a valid reason for rejecting the method and hunting for a better one.

These basic rules should be consulted in the design of supplementation projects as well as their supporting research projects. While the ten rules give a set of guidelines that are generally applicable to environmental studies, the individual project leader will have to determine if, and how, they apply in each specific case. A conscientious review and application of the appropriate rules will improve the quality of supplementation investigations. 


\section{LITERATURE}

CITED

Bowles, E. and E. Leitzinger. 1991. Salmon supplementation studies in Idaho rivers: Experimental design. Idaho Dept. of Fish and Game, Boise, ID, Project 89098. $166 \mathrm{p}$.

Bradshaw, A.D. 1990. Restoration: An acid test for ecology. Restoration Ecology. Eds. W.R. Jordan III, M.E. Gilpin, and J.D. Aber. Cambridge University Press, Cambridge. 23-29.

Brooks, H. 1973. Technology assessment as a process. Int. Soc. Sci. J., 25:3 253262.

Busack, C. 1990. Yakima/Klickitat production project genetic risk assessment. Manuscript. Genetics Unit, Washington Department of Fisheries, Olympia, WA. 21 p.

Carl, L.M. and M.C. Healey. 1984. Differences in enzyme frequency and body morphology among three juvenile life history types of chinook salmon (Oncorhynchus tshczwytschu) in the Nanaimo River, British Columbia. Can. J. Fish. Aquut. Sci. 41: 1070-1077.

Cederholm, C.J., L.R. Reid, and E.O. Sale. 1980. Cumulative effects of logging road sediment on salmonid populations in the Clearwater River, Jefferson County, Washington. Contribution No. 543, College of Fisheries, University of Washington, Seattle. 35 p.

Cohen, J. 1988. Statistical Power Analysis for the Behavioral Sciences. 2nd Edition. Lawrence Erlbaum Assoc., Publishers. Hillsdale, NJ. 567 p. 
Columbia Basin Fish and Wildlife Authority. 1991. Integrated system plan. Portland, OR. 527 p.

DeLibero, F.E. 1986. A statistical assessment of the use of the coded wire tag for chinook (Oncorhynchus tschawytscha) and coho (0. kisutch) studies. Ph.D. Dissertation, Univ. of Wash., Seattle, WA 227 p.

Everest, F.H. 1973. Ecology and Management of summer steelhead in the Rogue River; Oregon State Game Commission, Fishery Research Report No. 7, 48 p.

Green, R.H. 1979. Sampling Design and Statistical Methods for Environmental Biologists. Wiley and Sons, New York.

Hall, J.D. and R.L. Lantz. 1969. Effects of logging on the habitat of coho salmon and cutthroat trout in coastal streams. In Symposium on Salmon and Tiout in Streams. Ed. T.G. Northcote. 355-375.

Idaho Department of Fish and Game. 1991. Idaho's anadromous fishery management plan. Boise, ID.

Kapuscinski, A.R., C .R. Steward, M.L. Goodman, C.C. Krueger, J. H. Williamson, E. Bowles, and R. Carmichael. 1991. Genetic conservation guidelines for salmon and steelhead supplementation. Unpublished manuscript, $55 \mathrm{p}$.

Lichatowich, J. and S. Cramer. 1979. Parameter selection and sample sizes in studies of anadromous salmonids. Oregon Dept. of Fish and Wildlife Information Report Series, Fisheries Number 80-1, Portland, OR. 25 p.

McAllister, M.K. and R.M. Peterman. 1992. Experimental design in the management of fisheries: A review. North Am. J. of Fish. Man. 12:1 1-18.

Nicholas, J.W. and D.G. Hankin. 1988. Chinook salmon populations in Oregon coastal river basins: Description of life histories and assessment of recent trends in run strengths. Oregon Department of Fish and Wildlife, Information Reports (Fish) 88-1, second edition. (Printed by Oregon State University Extension Service, Catalog Number EM 8402, Corvallis).

Northwest Power Planning Council. 1987. Columbia River Basin Fish and Wildlife Program (Amended). Portland, OR. 
Peter-man, R.M. 1977. A simple mechanism that causes collapsing stability regions in exploited salmonid populations. J. Fish. Res. Board of Canada, 34: 1134-1 142.

Peterman, R.M. 1990. Statistical power analysis can improve fisheries research and management. Can. J. of Fish. and Aquatic Sci. 47:1 2-15.

Platt, J.R. 1964. Strong inference. Science, 146:3642 347-352

Quinn, J.F. and A.E. Dunham. 1983. On hypothesis testing in ecology and evolution. The American Naturalist, 122:5 602-617.

RASP. 1991. Regional assessment of supplementation project. Annual Progress Report, December 3 1, 1991. Bonneville Power Administration.

Reimers, P.E. 1973. The length of residence of juvenile fall chinook salmon in Sixes River, Oregon. Research Reports of the Fish Commission of Oregon. 4:2 43 p.

Reimers, P.E. 1979. Success in a hatchery program with fall chinook salmon by simulating the natural life history of the stock. Progressive Fish Culturist 41:4.

Reisenbichler, R.R. and J.D. McIntyre. 1986. Rish culture in fisheries management. In Proceedings of a Symposium on the Role of Fish Culture in Fisheries Management, at Lake Ozark, Missouri, March 31-Apri13, 1985. Ed. R.H. Stroud. 365-374.

Rich, W.H. 1938. Local Populations and Migration in Relation to the Conservation of Pacific Salmon in the Western States and Alaska. Contribution No. 1, Fish Commission of the State of Oregon. 6 p.

Ricker, W.E. 1972. Hereditary and environmental factors affecting certain salmonid populations. In The Stock Concept in Pacfic Salmon. Ed. R.C. Simon and P.A. Larkin, MacMillan Lectures in Fisheries, University of British Columbia. 19160.

Riggs, L. 1990. Principles for genetic conservation and production quality. Northwest Power Planning Council Contract C 90-005. Portland, OR.

Ryman, N. and L. Laikre. 1991. Effects of supportive breeding on the genetically effective population size. Conservution Biology 5:325-329. 
Schluchter, M. and J.A. Lichatowich. 1977. Juvenile life histories of Rogue River spring chinook salmon Oncorhynchus tshawytscha (Walbaum as determined from scale analysis. Oregon Department of Fish and Wildlife, Corvallis, OR: Information Report Series, Fisheries No. 77-5. 24 p.

Smith, E. M., B. A. Miller, J. D. Rodgers and M. A. Buckman. 1985. Outplanting anadromous salmonids - a literature survey. U. S. Department of Energy, Bonneville Power Administration Project No. 85-68. Portland, OR.

Thompson, W. F. 1959. An approach to population dynamics of the Pacific red salmon. Trans. Am. Fish. Soc. 88 :3 206-209.

Timmerman, P. 1986. Mythology and surprise in the sustainable development of the biosphere. In W.C. Clark and R.E. Mum, eds. Sustainable Development of the Biosphere, International Inst. for Applied Systems Analysis, Laxenburg, Austria, 435-452.

Vrijenhoek, R.C. 1989. Population genetics and conservation. In Conservation for the Twenty-first Century. Eds. D. Western and M. C. Pearl. Oxford University Press, New York, 89-98.

Wade, Mark. 1986. The relative effects of ceratomyxa shasta on crosses of resistant and susceptible stocks of summer steelhead. Master of Science, Oregon State University, 1986.

Ward, D.V. 1978. Biological Environmental Impact Studies: Theory and Methods. Academic Press, 157 p. 


\section{APPENDIX A}

GUIDELINES FOR COMPLETING
A TEM PLATE/PATIENT ANALYSIS 


\section{APPENDIX A}

\section{GUIDELINES FOR COMPLETING A Te mplate/Patient ANALYSIS}

Tables A. 1 - A.3 of Appendix A describe the three important life history stages of spawning and incubation, rearing, and migration in terms of habitat, timing, survival and demographics. Completing Tables A.1 - A.3 requires a significant level of understanding of the relationships among the stock's life histories, its habitat, and production. Under the policy of adaptive management, it is not necessary complete the template/patient analysis to implement a project, but the manager must supply what is known in all the information categories. In many cases the only information available to the manager to complete the tables will be qualitative. Information gaps in Tables A. 1 - A.3 lead to uncertainties which are addressed in the risk analysis and project monitoring and evaluation. As new information is obtained, the gaps are reduced and uncertainties, risks and project methodology are modified as appropriate. For those projects that are implemented with a great deal of uncertainty, planning becomes an iterative process.

A brief description of the information called for under each life history is given below. Where appropriate, the manager should indicate whether limiting factors are density-independent or density-dependent.

Spawning and Incubation

Tables A. la - A. $1 \mathrm{~b}$ require the information described in this section.

Life History Type is a designation given to a group of fish whose spawning time or location, rearing habitat preference and/or migration timing are similar within the group. There may be multiple life histories within each stock. The tables should be expanded so that there is a line for each life history.

Smolt Age describes age at smoltification: 0,1,2,or mixed.

Habitat describes the area in the subbasin or tributary where fish of a specific life history type spawn.

Habitat Ouantity is either a physical measure of the habitat area or an estimate of the percent of the total area available or suitable for spawning. 
Table A.1a. Template/patient analysis - spawning and incubation.

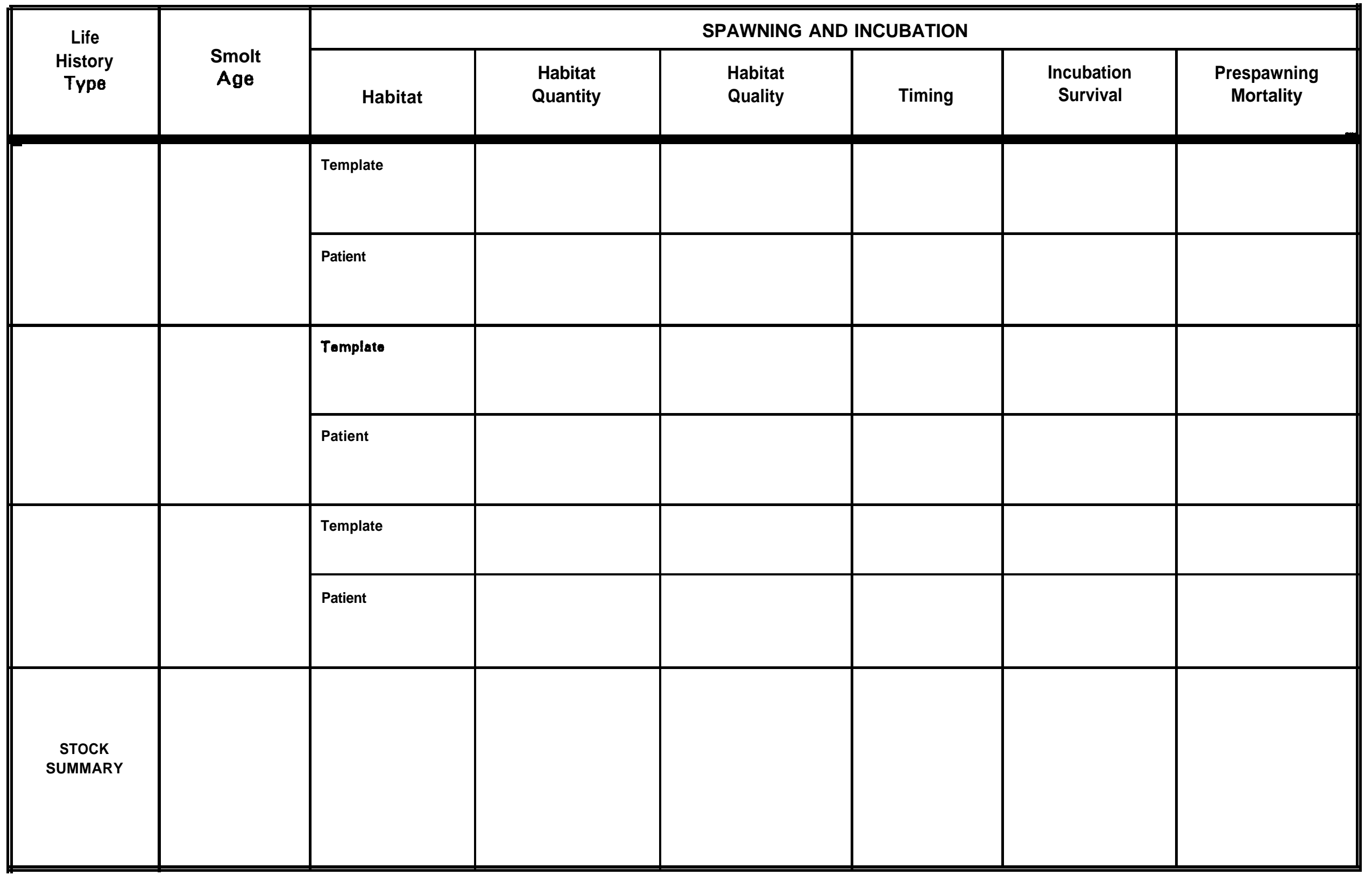


Table A.1 b. Template/patient analysis - spawning and incubation.

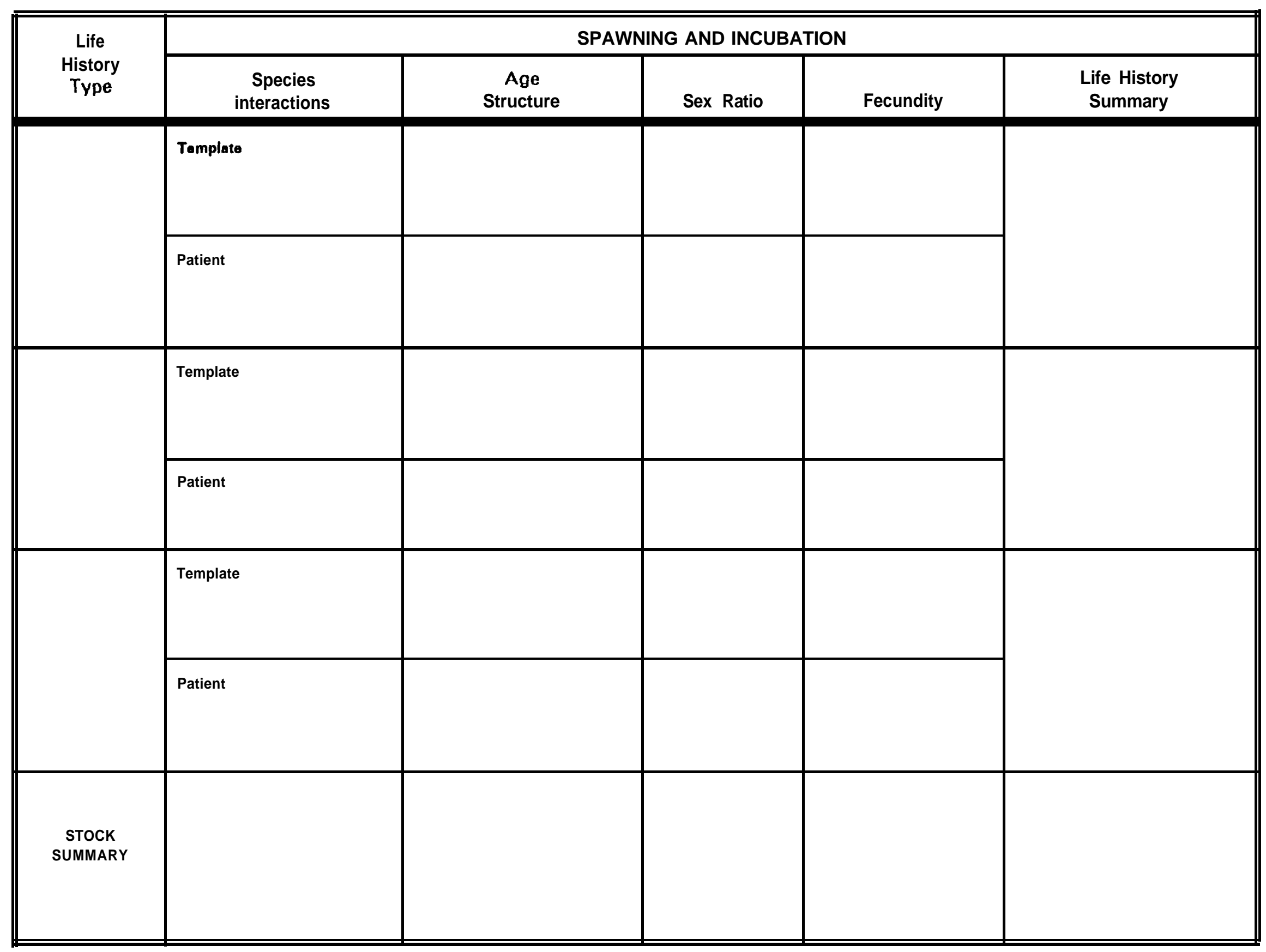


Table A.2a. Template/patient analysis - spring/summer rearing.

\begin{tabular}{|c|c|c|c|c|c|c|c|c|c|}
\hline \multirow{2}{*}{$\begin{array}{c}\text { Life } \\
\text { History } \\
\text { Type }\end{array}$} & \multicolumn{9}{|c|}{ SPRING/SUMMER REARING } \\
\hline & Habitat & $\begin{array}{l}\text { Habitat } \\
\text { Quantity }\end{array}$ & $\begin{array}{l}\text { Habitat } \\
\text { Quality }\end{array}$ & Timing & Density & Growth & Survival & $\begin{array}{c}\text { Species } \\
\text { Interactions }\end{array}$ & $\begin{array}{l}\text { Life History } \\
\text { Summary }\end{array}$ \\
\hline & Template & & & & & & & & \\
\hline & Patient & & & & & & & & \\
\hline & Template & & & & & & & & \\
\hline & Patient & & & & & & & & \\
\hline & Template & & & & & & & & \\
\hline & Patient & & & & & & & & \\
\hline & Template & & & & & & & & \\
\hline & Patient & & & & & & & & \\
\hline
\end{tabular}


Table A.2a. cont'd.

\begin{tabular}{|c|c|c|c|c|c|c|c|c|c|}
\hline \multirow{2}{*}{$\begin{array}{l}\text { Life } \\
\text { History } \\
\text { Type }\end{array}$} & \multicolumn{9}{|c|}{ SPRING/SUMMER REARING } \\
\hline & Habitat & $\begin{array}{l}\text { Habitat } \\
\text { Quantity }\end{array}$ & $\begin{array}{l}\text { Habitat } \\
\text { Quality }\end{array}$ & Timing & Density & Growth & Survival & $\begin{array}{c}\text { Species } \\
\text { Interactions }\end{array}$ & $\begin{array}{l}\text { Life History } \\
\text { Summary }\end{array}$ \\
\hline & Tomplate & & & & & & & & \\
\hline & Patient & & & & & & & & \\
\hline & Template & & & & & & & & \\
\hline & Patient & & & & & & & & \\
\hline $\begin{array}{c}\text { STOCK } \\
\text { SUMMARY }\end{array}$ & & & & & & & & & \\
\hline
\end{tabular}


Table A.2b. Template/patient analysis - fall/winter rearing.

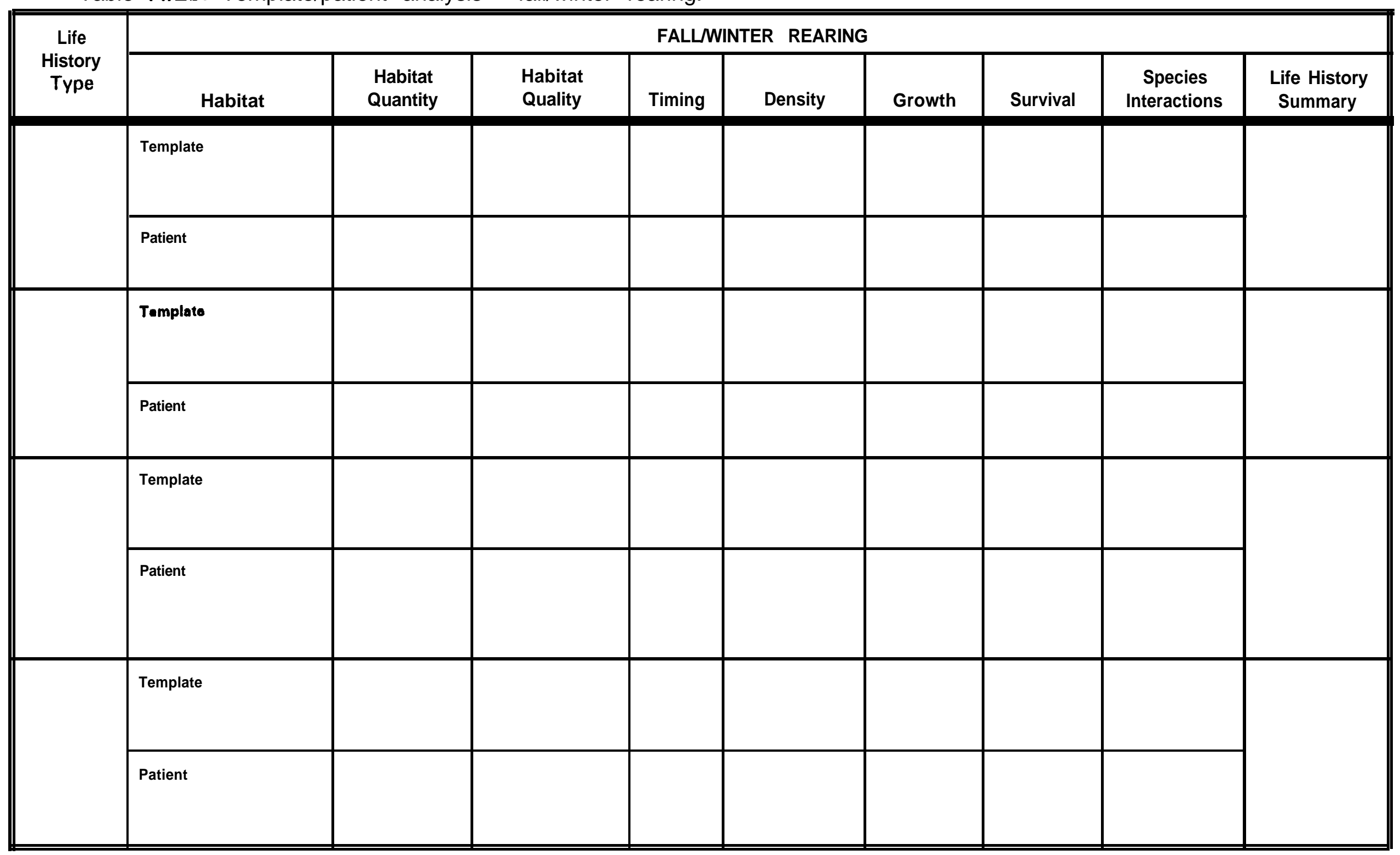


Table A.2b. cont'd.

\begin{tabular}{|c|c|c|c|c|c|c|c|c|c|}
\hline \multirow{2}{*}{$\begin{array}{l}\text { Life } \\
\text { History } \\
\text { Type }\end{array}$} & \multicolumn{9}{|c|}{ FALL/WINTER REARING } \\
\hline & Habitat & $\begin{array}{l}\text { Habitat } \\
\text { Quantity }\end{array}$ & $\begin{array}{l}\text { Habitat } \\
\text { Quality }\end{array}$ & Timing & Density & Growth & Survival & $\begin{array}{c}\text { Species } \\
\text { Interactions }\end{array}$ & $\begin{array}{l}\text { Life History } \\
\text { Summary }\end{array}$ \\
\hline & Template & & & & & & & & \\
\hline & Patient & & & & & & & & \\
\hline & Template & & & & & & & & \\
\hline & Patient & & & & & & & & \\
\hline $\begin{array}{c}\text { STOCK } \\
\text { SUMMARY }\end{array}$ & & & & & & & & & \\
\hline
\end{tabular}


Table A.3a. Template/patient analvsis - presmolt migration

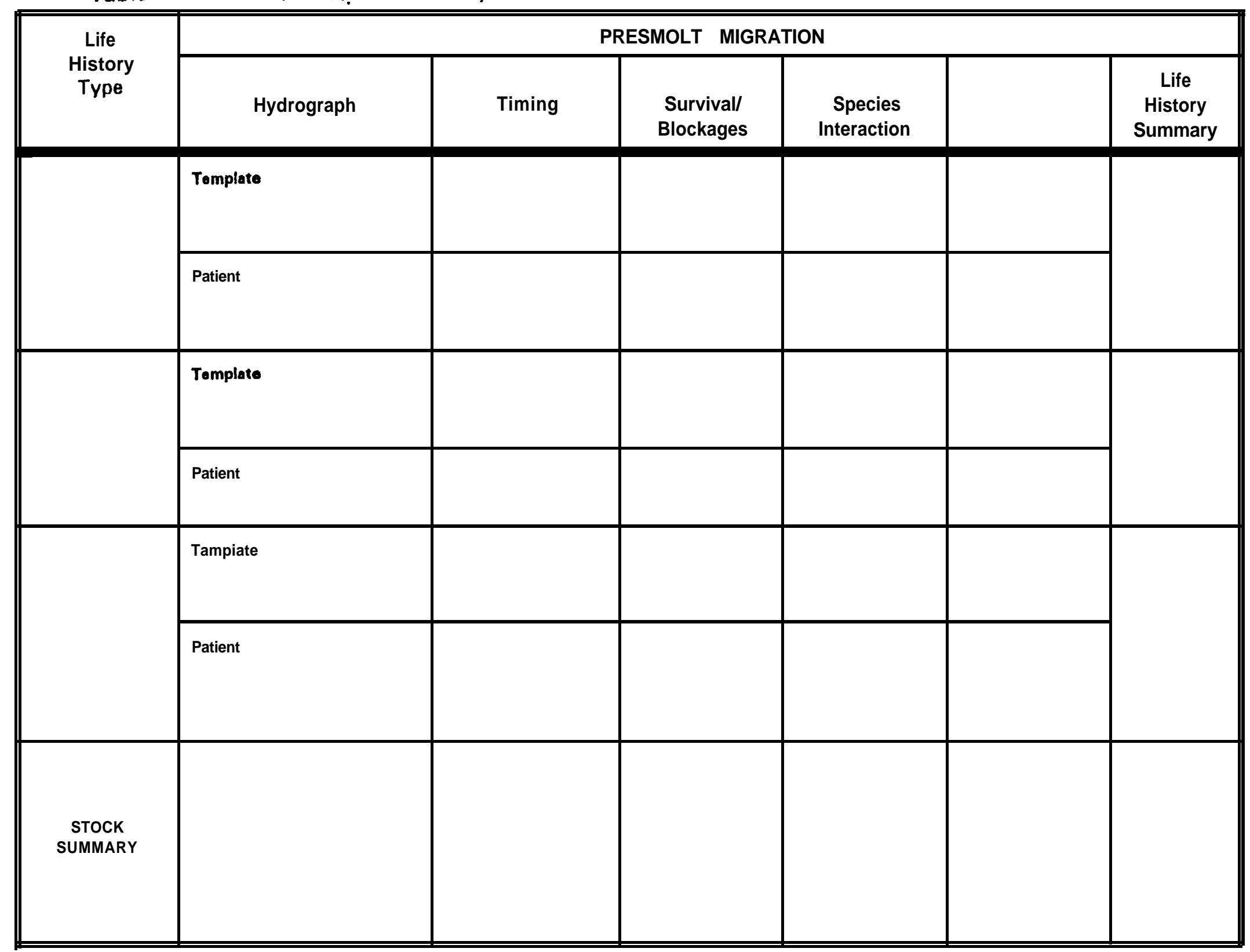


Table A.3b. Template/patient analysis - smolt migration

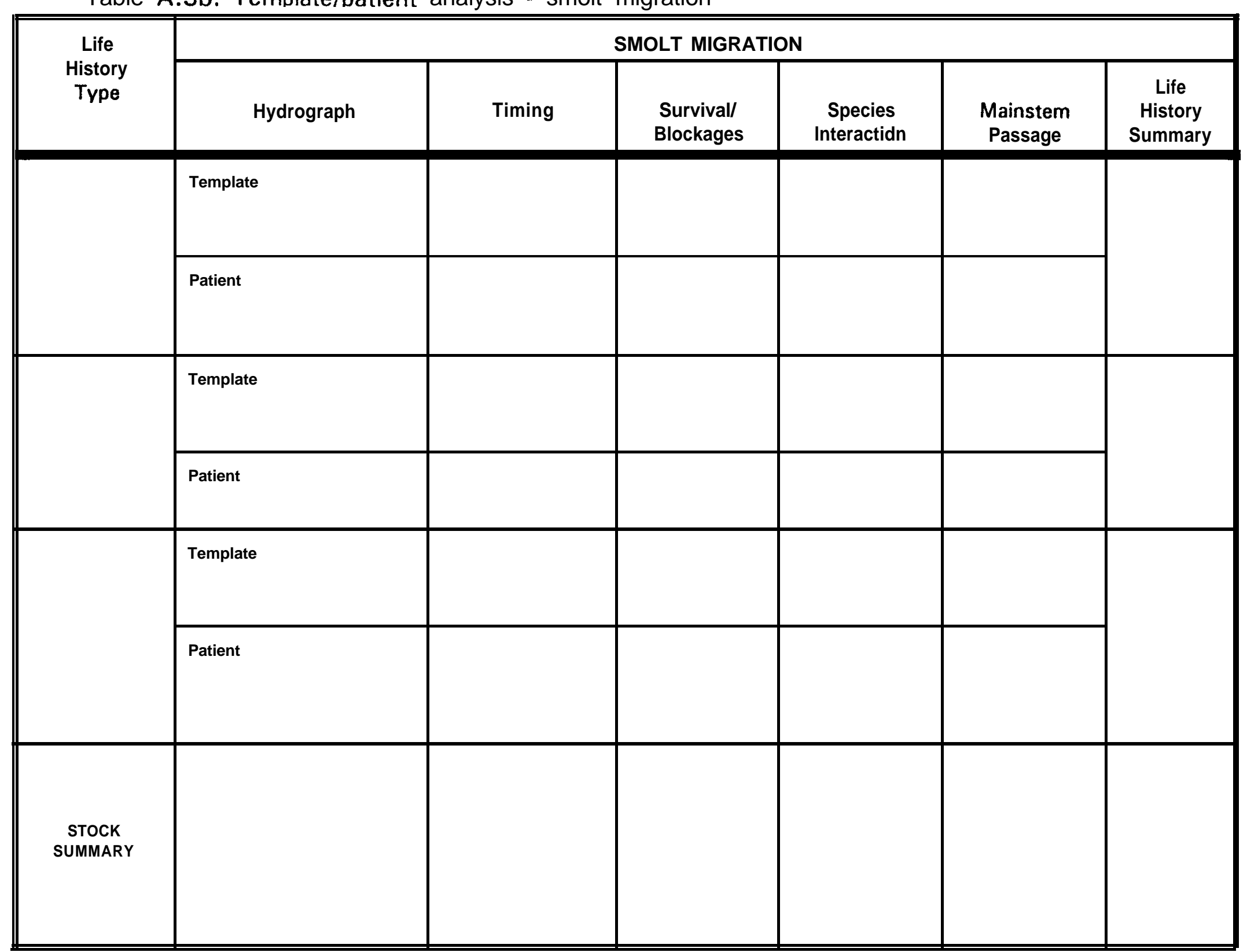


Table A.3c. Template/patient analysis - adult migration

\begin{tabular}{|c|c|c|c|c|c|c|c|}
\hline \multirow{2}{*}{$\begin{array}{l}\text { Life } \\
\text { History } \\
\text { Type }\end{array}$} & \multicolumn{7}{|c|}{ ADULT MIGRATION } \\
\hline & Hydrograph & Timing & $\begin{array}{l}\text { Survival/ } \\
\text { Blockages }\end{array}$ & $\begin{array}{c}\text { Species } \\
\text { Interaction }\end{array}$ & $\begin{array}{c}\text { Ocean } \\
\text { Distribution }\end{array}$ & $\begin{array}{c}\text { Fisheries } \\
\text { Interception } \\
\text { Ocean/Estuaries/ } \\
\text { Rivers }\end{array}$ & $\begin{array}{c}\text { Life } \\
\text { History } \\
\text { Summary }\end{array}$ \\
\hline & Tempiote & & & & & & \\
\hline & Patient & & & & & & \\
\hline & Template & & & & & & \\
\hline & Patient & & & & & & \\
\hline & Template & & & & & & \\
\hline & Patient & & & & & & \\
\hline $\begin{array}{c}\text { STOCK } \\
\text { SUMMARY }\end{array}$ & & & & & & & \\
\hline
\end{tabular}


Habitat Ouality is an estimate of the biophysical condition of the habitat relative to survival or productivity. For spawning habitat, quality might be described in terms of gravel composition (\% fines) or the stability of the streambed (frequency and depth of scour).

Timing gives the interval (dates) when spawning occurs and the peak (Julian Week) of spawning activity.

Incubation Survival gives the survival from egg to fiy. This might be extrapolated from the relationship between survival and percent fines in the gravel (Cederholm et al. 1980 and Hall and Lantz 1969).

Prespawning Mortality can be estimated directly from surveys or indirectly from counts at dams or diversions and redd counts adjusted for redd:fish ratio. Indicate if disease is a mortality factor.

Species Interaction is an estimate of the effects of competitors or predators on successful spawning and incubation.

Age Structure is simply the age distribution of the spawning population.

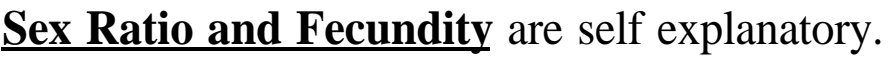

Life Historv Summary records summary comments and observations regarding a single life history type across all factors influencing spawning success. Conclusions such as the apparent limiting factor can be entered here.

Stock Summary records summary comments and observations across all life history types for a given factor influencing spawning success.

\section{Rearing}

Tables A.2a - A.2b require the information described below:

Life Historv Type. See description under spawning and incubation.

Habitat. See explanation under spawning and incubation above.

Habitat Ouantitv. See explanation under spawning and incubation above. 
Habitat Ouality is an estimate of the physical quality of the rearing habitat relative to survival and production. For rearing, measures of habitat quality might include: the pool to riffle ratio, temperature, flows (absolute and seasonal patterns), stream structure, condition of the riparian zone, winter refugia, etc.

Timing gives the interval (dates) when rearing occurs in the specific section/area of the subbasin or tributary identified under Habitat.

Density gives the rearing density of juveniles. Appendix B gives rearing densities of juvenile chinook and steelhead reported in the literature for comparative evaluation.

Growth gives the size at the end of the interval (spring/summer or fall/ winter).

Survival gives the survival to the end of the interval. Appendix B gives survivals of juvenile chinook and steelhead reported in the literature for comparative evaluation.

Species Interaction is an estimate of the effects of predators or competitors on rearing.

Life Historv Summarv records summary comments and observations across all factors influencing rearing success. This might include a comparative evaluation of rearing density and survival between the target stream and values reported in the literature (Appendix B).

Stock Summarv records summary comments and observations across all life history types for a given component of rearing success.

Migration

Tables A.3a - A.3c present information related to migration at different stages. The information is described below:

Life Historv Tvne. See description under spawning and incubation.

Hydrograph describes the relationship between flow patterns and migration.

Timing describes the normal timing of migration. 
Survival/Blockages describes impediments to migration (except mainstem passage problems) and problems causing mortality during migration. For example, an impassible dam or mortality at irrigation diversions would be listed here.

Species Interaction is an estimate of the effect of competitors or predators on migration. For example, predation by squaw fish would be described.

Mainstem Passage gives the effect of mainstem passage problems on survival of smolt migrants.

Ocean Distribution gives the ocean distribution of the stock.

Fisheries Interception gives the points of fishing interception of the stock in the ocean, estuary and river.

Life History Summary records summary comments and observations across all factors influencing migration success.

Stock Summary records summary comments and observations across all life history types for a given component of migration success.

As stated above, in very few if any cases, will the manager be able to complete the template/patient analysis shown in Tables A.1 - A.3. At first, the task might appear impossible and the manager may be tempted to skip it altogether. However, this is an important step in the planning process and even a partial analysis will be worth the effort. RASP recognizes that any attempt at historical reconstruction will include some thoughtful speculation and will be subject to debate and criticism. In the absence of hard information, a review of the literature, thoughtful speculation, and debate are important ingredients of successful planning and the identification of the best supplementation strategies. Information that can be used to describe the template may be obtained from the following:

- $\quad$ Historical reports from the target stream/stock. In the ideal situation, the manager has sufficient empirical observations from historical reports to complete the template analysis.

- $\quad$ Historical reports from similar streams/stocks. Appropriate information from nontarget streams/stocks can be used in the template analysis. 
- $\quad$ Back calculate from Dublished literature. The template can be back calculated from published reports which describe the life histories of the target or a similar nontarget stream/stock at a point between the healthy condition and the current state of degradation.

- $\quad$ Back calculate from the natient. In some cases, the description of the patient will provide insight help in completing part of the template analysis.

To help the manager complete the template analysis, Appendix B summarizes selected literature on salmon life history/habitat relationships. Appendices $\mathrm{C}$ and $\mathrm{D}$ give the reported ranges in rearing density and survival of chinook salmon and steelhead. 


\section{APPENDIX B}

SELECTED REFERENCES ON

LIFE HISTORY 
Appendix B. Selected References on Life History.*

\begin{tabular}{|c|c|c|c|c|}
\hline Paper & Species/Stock & Life History Diversity & Relationship to Habitat & Importance to Production \\
\hline Reimers, P.E. (1973) & $\begin{array}{l}\text { Fall chinook, } \\
\text { Sixes River, Oregon }\end{array}$ & $\begin{array}{l}\text { Identified five life histories based on } \\
\text { duration of fresh water/estuarine } \\
\text { residence and timing of ocean } \\
\text { entrance. }\end{array}$ & $\begin{array}{l}\text { Related life history types to fresh } \\
\text { water and estuarine hebitat. Also } \\
\text { discussed the influence of } \\
\text { temperature. }\end{array}$ & $\begin{array}{l}\text { Discussed the relationship between life } \\
\text { histories and potential enhancement, } \\
\text { including hatchery enhancement. } \\
\text { Identified most successful life history } \\
\text { pattern and its principal habitats. }\end{array}$ \\
\hline $\begin{array}{l}\text { Schluchter and Lichatowioh } \\
\text { (19771 }\end{array}$ & $\begin{array}{l}\text { Spring chinook, } \\
\text { Rogue River, Oregon }\end{array}$ & Identified seven juvenile life histories. & $\begin{array}{l}\text { Related life history types to fresh } \\
\text { water estuarine habitat. Discussed } \\
\text { influence of growth on life history. }\end{array}$ & $\begin{array}{l}\text { Discussed relative importance of juvenile } \\
\text { life history types in the adult population. }\end{array}$ \\
\hline Carl and Healey (1984) & $\begin{array}{l}\text { Chinook salmon, } \\
\text { Nanaimo River, } \\
\text { British Columbia }\end{array}$ & $\begin{array}{l}\text { Identified three juvenile life histories. } \\
\text { Variation in allelic frequencies in the } \\
\text { three life histories indicated genetic } \\
\text { differences. Also observed } \\
\text { morphological differences. }\end{array}$ & $\begin{array}{l}\text { Suggested genetic edaption to early } \\
\text { salt water rearing in one life history. }\end{array}$ & $\begin{array}{l}\text { Discussed the implication of this work to } \\
\text { hatchery enhancement. }\end{array}$ \\
\hline Everest (1973) & $\begin{array}{l}\text { Summer steelhead. } \\
\text { Rogue River, Oregon }\end{array}$ & $\begin{array}{l}\text { Seven life history patterns based on } \\
\text { duration of residency in fresh and salt } \\
\text { water. Steelheed entered the river in } \\
\text { three distinct groups by time, but } \\
\text { these were not treated as separate } \\
\text { racial components. }\end{array}$ & $\begin{array}{l}\text { Rogue summer steelhead moved into } \\
\text { small tributaries to spawn. These } \\
\text { tributaries were intermittent or dry in } \\
\text { summer. }\end{array}$ & $\begin{array}{l}\text { Habitat use, i.e. spawning in intermittent } \\
\text { streams made spawning, timing, and } \\
\text { flow patterns critical to production. }\end{array}$ \\
\hline Nicholas and Hankin (1988) & $\begin{array}{l}\text { Chinook salmon, } \\
\text { Oregon coastal } \\
\text { streams }\end{array}$ & $\begin{array}{l}\text { Comprehensive review of life } \\
\text { histories of chinook salmon in } 27 \\
\text { coastal basins. }\end{array}$ & $\begin{array}{l}\text { Discussed life history end habitat } \\
\text { relationships. }\end{array}$ & $\begin{array}{l}\text { Discussed implications of life history to } \\
\text { natural and artificial production. }\end{array}$ \\
\hline
\end{tabular}

2 This is not intended to be a complete survey of the life history literature. These papers will give managers helpful insights into life history and assist them in preparing the template/patient analysis. 
APPENDIX C

SURVIVAL OF JUVENILE

CHINOOK AND STEELHEAD 
Appendix C. Survival of juvenile chinook and steelhead.

(From Smith et al. 1985)

\section{SURVIVAL \%}

\begin{tabular}{|c|c|c|c|c|c|}
\hline Species & $\begin{array}{l}\text { State/ } \\
\text { River }\end{array}$ & $\begin{array}{l}\text { Egg } \\
\text { to } \\
\text { Fry }\end{array}$ & $\begin{array}{c}\text { Egg } \\
\text { to } \\
\text { Smolt }\end{array}$ & $\begin{array}{c}\text { Fry } \\
\text { to } \\
\text { Smolt }\end{array}$ & $\begin{array}{c}\text { Smolt } \\
\text { to } \\
\text { Adult }\end{array}$ \\
\hline \multirow{3}{*}{$\begin{array}{l}\text { SPRING } \\
\text { CHINOOK }\end{array}$} & $\frac{\text { Idaho }}{\text { Lemhi R. }}$ & 20.6 & 9.8 & $21.2^{\circ}$ & \\
\hline & $\frac{\text { Washington }}{\text { Yakima R. }}$ & & 10.9 & & \\
\hline & $\begin{array}{l}\frac{\text { Oregon }}{\text { Warm Springs R. }} \\
\text { John Day R. } \\
\text { Lookingglass Cr. } \\
\text { Fall Creek }\end{array}$ & & $\begin{array}{l}3.5 \\
5.2 \\
9.5\end{array}$ & $12.4^{b}$ & \\
\hline \multirow{2}{*}{$\begin{array}{l}\text { FALL } \\
\text { CHINOOK }\end{array}$} & $\frac{\text { California }}{\text { Klamath R. }}$ & 14.5 & & & \\
\hline & $\frac{\text { B.C. }}{\text { Big Qualicum }}$ & 19.8 & & & \\
\hline \multirow[t]{4}{*}{ STEELHEAD } & $\frac{\text { Idaho }}{\text { Lemhi R. }}$ & & & 2.0 & \\
\hline & $\begin{array}{c}\text { Washinaton } \\
\text { Snow Cr. } \\
\text { Gobar Cr. } \\
\text { Kalama R. }\end{array}$ & & $\begin{array}{l}.09 \\
.86 \\
\end{array}$ & 4.6 & \\
\hline & $\begin{array}{l}\text { Oregon } \\
\text { N.F. Umpqua R. }\end{array}$ & & .01 & & \\
\hline & $\frac{\text { B.C. }}{\text { Keogh R. }}$ & & .51 & & \\
\hline
\end{tabular}

a Presmolts released at 500/b in 1973 and $398 / \mathrm{b}$ in 1974.

b Presmolts released at an average length of $75 \mathrm{~mm}$ in 1970 and $56 \mathrm{~mm}$ in 1971 . 


\section{APPENDIX D}

REARING DENSITIES IN NATURAL HABITAT FOR JUVENILE CHINOOK AND STEELHEAD 
Appendix D. Rearing densities in natural habitat for juvenile chinook and steelhead. (From Smith, et al 1985)

Juvenile Chinook Rearina Densitv

\begin{tabular}{|c|c|c|c|c|c|c|c|}
\hline $\begin{array}{c}\text { Statel } \\
\text { River }\end{array}$ & $\begin{array}{l}\text { Agel } \\
\text { Size }\end{array}$ & Season & Fish $/ \mathrm{m}^{2}$ & $\begin{array}{l}\text { State/ } \\
\text { River }\end{array}$ & $\begin{array}{l}\text { Agel } \\
\text { Size }\end{array}$ & Season & Fish $/ \mathrm{m}^{2}$ \\
\hline $\begin{array}{l}\frac{\text { Idaho }}{\text { Big Springs Cr. }} \\
\text { Big Springs Cr. } \\
\text { Lehmi R. } \\
\text { Lehmi R. } \\
\text { Salmon R. } \\
\text { Clearwater R. } \\
\text { S.F. Salmon R. } \\
\text { Lochsa R. }\end{array}$ & $\begin{array}{l}\text { Age } 0 \\
\text { Age } 0 \\
\text { August }\end{array}$ & $\begin{array}{l}\text { end of summer } \\
\text { winter } \\
\text { end of summer } \\
\text { winter }\end{array}$ & $\begin{array}{l}2.08 \\
1.40 \\
1.29 \\
0.61 \\
0.26 \\
0.25 \\
0.06 \\
0.032\end{array}$ & $\begin{array}{l}\frac{\text { Idaho }}{\text { Big Spring Cr. }} \\
\text { Big Spring Cr. } \\
\text { Lshmi R. } \\
\text { Lehmi R. } \\
\text { Salmon R. } \\
\text { Clearwater R. } \\
\text { S.F. Clearwater R. } \\
\text { S.F. Clearwater R. } \\
\text { Lochsa R. }\end{array}$ & $\begin{array}{l}\text { Age } 0 \\
\text { Age } 0 \\
\text { Age } 0 \\
\text { Age } 1+ \\
\text { Age } 0\end{array}$ & $\begin{array}{l}\text { end of summer } \\
\text { winter } \\
\text { end of summer } \\
\text { winter } \\
\text { August }\end{array}$ & $\begin{array}{l}0.93 \\
0.54 \\
0.70 \\
0.13 \\
0.11 \\
0.08 \\
0.34 \\
0.44 \\
0.34\end{array}$ \\
\hline $\begin{array}{l}\text { Washinaton } \\
\text { Wind R. } \\
\text { Wenatchee R. } \\
\text { Entiat R. } \\
\text { Kalama R. }\end{array}$ & $\begin{array}{l}\text { Age } 0 \\
\text { Age } 0 \\
\text { Age } 0 \\
\text { Smolt }\end{array}$ & & $\begin{array}{l}0.09 \\
0.08 \\
0.06 \\
0.073\end{array}$ & $\begin{array}{l}\text { Washinaton } \\
\text { Wind R. } \\
\text { Wenatchee R. } \\
\text { Entiat R. } \\
\text { Snow Cr. } \\
\text { Salmon Cr. } \\
\text { Snow Cr. } \\
\text { Snow Cr. } \\
\text { Gobar Cr. }\end{array}$ & $\begin{array}{l}\text { Age } 0 \\
\text { Age } 0 \\
\text { Age } 0 \\
\text { Smolt } \\
\text { Smolt } \\
\text { Fry } \\
\text { Smolt } \\
\text { Smolt }\end{array}$ & & $\begin{array}{l}0.12 \\
0.04 \\
0.08 \\
0.022 \\
0,017 \\
0.70 \\
0.03 \\
0.037\end{array}$ \\
\hline \multirow[t]{2}{*}{$\begin{array}{l}\text { Oregon } \\
\text { White R. } \\
\text { Warm Springs R. } \\
\text { John Day R. } \\
\text { Fish Cr. } \\
\text { Warm Springs } \\
\text { (Shitike Cr.) } \\
\text { Middle Fork } \\
\text { John Day } \\
\text { Siletz \& } \\
\text { Nestucca R. }\end{array}$} & $\begin{array}{l}\text { Age } 1+ \\
\text { Age } 0 \\
\text { Age } 0 \\
\text { Early Sept. } \\
\text { Fry }\end{array}$ & & $\begin{array}{l}0.08 \\
0.05 \\
0.19 \\
0.01 \\
0.05 \\
0.05 \\
\\
0.72\end{array}$ & $\begin{array}{l}\text { Oregon } \\
\text { White R. } \\
\text { Warm Springs R. } \\
\text { John Day R. } \\
\text { Trout Cr. } \\
\text { Bakeoven Cr. } \\
\text { Buck Hollow Cr. } \\
\text { S.F. John Day R. } \\
\text { M.F. John Day R. } \\
\text { Chesnimus Cr. } \\
\text { Umatilla R. } \\
\text { Meacham Cr. } \\
\text { Camp Cr. }\end{array}$ & $\begin{array}{l}\text { Age } 1+ \\
\text { Age } 0 \\
\text { Age } 0\end{array}$ & $\begin{array}{l}\text { Mid August } \\
\text { Late July } \\
\text { Late July } \\
\text { Early Sept. } \\
\text { Early Sept. } \\
\text { Late July } \\
\text { Early Aug. } \\
\text { Mid-Aug. } \\
\text { Mid-Aug. }\end{array}$ & $\begin{array}{l}0.10 \\
0.05 \\
0.80 \\
0.69 \\
2.65 \\
7.32 \\
0.03 \\
0.08 \\
0.61 \\
0.77 \\
0.36 \\
0.87\end{array}$ \\
\hline & & & & $\begin{array}{l}\text { California } \\
\text { Manzanita Cr. } \\
\text { Trinity R. } \\
\text { Godwood Cr. } \\
\text { N. Caspsr Cr. }\end{array}$ & $\begin{array}{l}\text { Age } 0 \\
\text { Age } 1+ \\
\text { All ages } \\
\text { All ages }\end{array}$ & & $\begin{array}{l}0.69 \\
0.23 \\
0.14 \\
0.64\end{array}$ \\
\hline $\begin{array}{l}\text { B.C. } \\
\text { Cowichan R. } \\
\text { Big Qualicum R. } \\
\text { Keogh R. }\end{array}$ & $\begin{array}{l}\text { Age } 3 \text { mos. } \\
\text { Age } 3 \text { mos. } \\
\text { Smolt }\end{array}$ & & $\begin{array}{l}0.18 \\
0.30 \\
0.027\end{array}$ & $\begin{array}{l}\frac{B . C .}{B i g} \text { Qualicum R. } \\
\text { Carnation Cr. } \\
\text { Keogh R. } \\
\text { Quinsam R. }\end{array}$ & $\begin{array}{l}\text { Age } 3 \text { mos. } \\
\text { Smolt } \\
\text { Smolt } \\
\text { Smolt }\end{array}$ & & $\begin{array}{l}0.021 \\
0.006 \\
0.016 \\
0.02\end{array}$ \\
\hline
\end{tabular}

Juvenile Steelhead Rearina Densitv 


\title{
RASP SUMMARY REPORT SERIES PART I-V
}

\author{
DESCRIPTION OF A SUPPLEMENTATION MODEL AND \\ REGIONAL COORDINATION OF RESEARCH \\ AND MONITORING
}

December, 1992 


\section{TABLE OF CONTENTS}

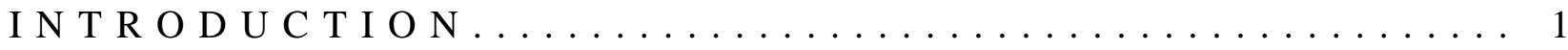

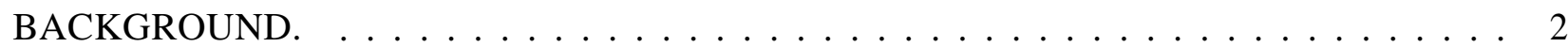

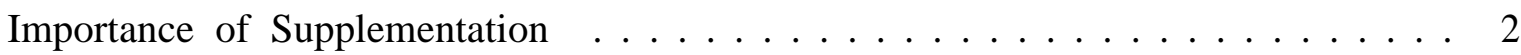

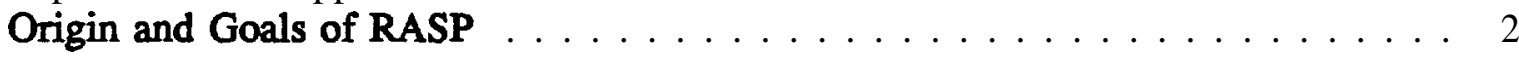

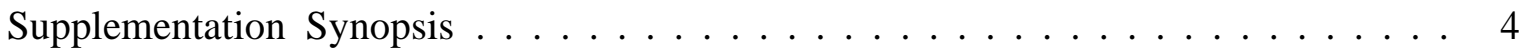

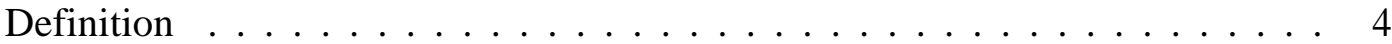

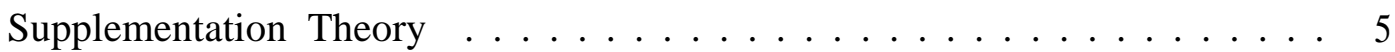

Planning Guidelines .................. 5

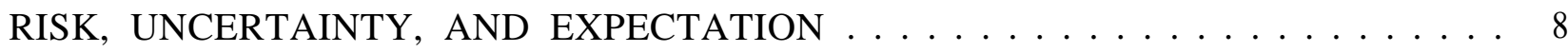

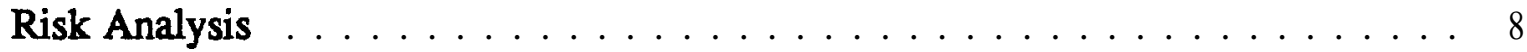

Other Classifications of Uncertainties ................. 10

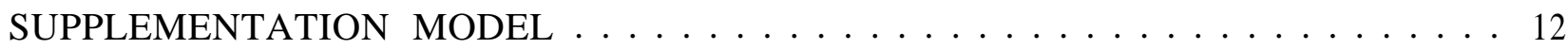

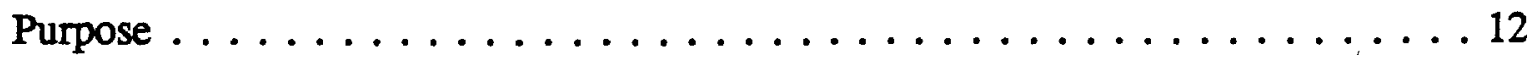

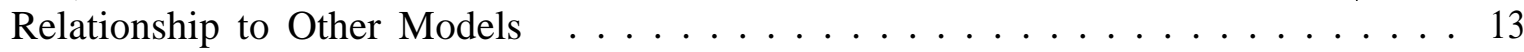

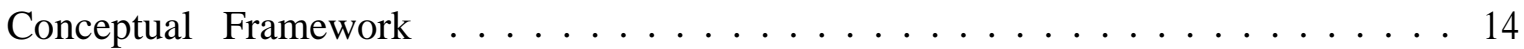

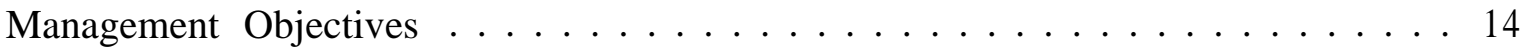

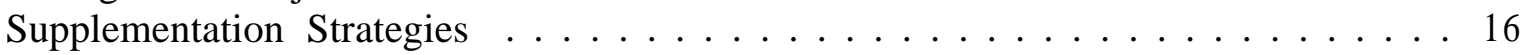

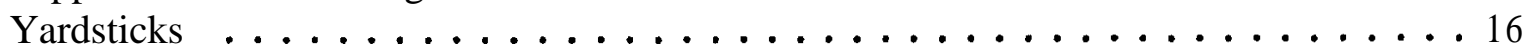

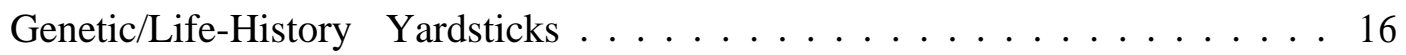

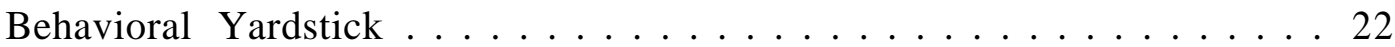

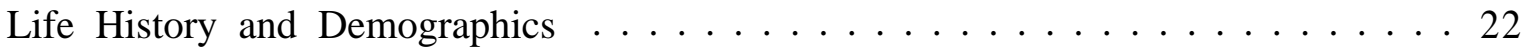

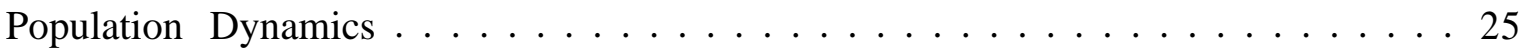

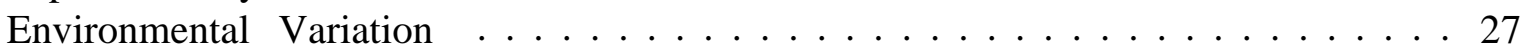

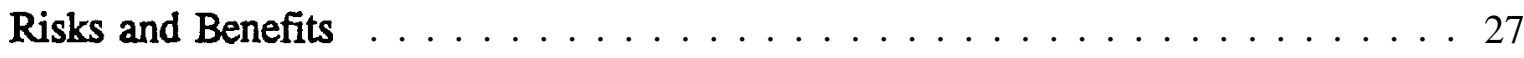

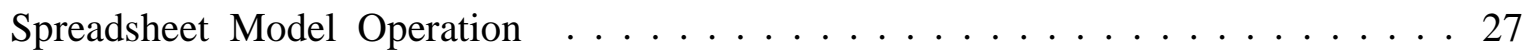

Examples of Model Output . . . . . . . . . . . . . . . . . 29

REGIONAL COORDINATION OF RESEARCH AND MONITORING ........ 39

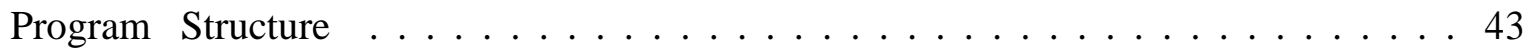

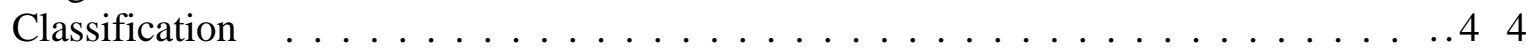

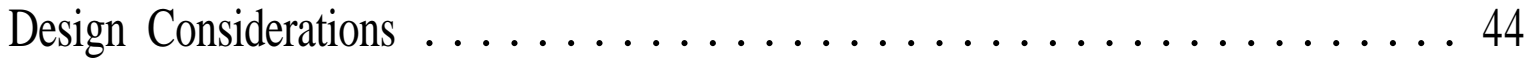

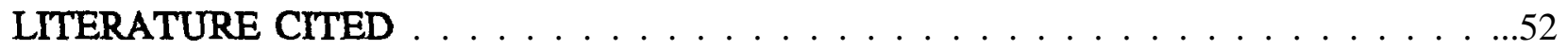




\title{
RASP SUMMARY REPORT SERIES: PART IV.
}

\author{
DESCRIPTION OF A SUPPLEMENTATION MODEL \\ AND \\ REGIONAL COORDINATION OF RESEARCH AND MONITORING
}

\section{INTRODUCTION}

This report describes a framework for a basin-wide monitoring and evaluation (M\&E) program for supplementation programs and a spreadsheet model which was developed as a planning tool for fishery managers.

Managers who are planning a supplementation project must simultaneously consider and weigh information on potential hatchery treatments, stream habitats, stock characteristics, and potential outcomes of the manipulation of rearing and release strategies. To accommodate this analysis, we developed a life-history model that incorporates a range of supplementation alternatives. The model is not a quantitative, predictive tool, but is meant to help the manager assess the relative effects of different hatchery treatments. The model should be viewed as a scratch pad the manager can use to weigh and compare alternative treatments and strategies. This report describes the spreadsheet model and demonstrates how it might be used in supplementation planning through example outputs.

When fully implemented, the proposed supplementation programs in the Columbia River will constitute significant human intervention in the natural production systems of the basin. However, the use of supplementation on the scale proposed for the Columbia Basin is relatively new. It will be implemented with uncertainties regarding its effectiveness and safety (RASP 1992b and CBFWA 1991). During the planning of supplementation projects, uncertainties are evaluated through risk analysis. Project implementation can proceed even with risks when sufficient $\mathrm{M} \& \mathrm{E}$ is in place to either eliminate the critical uncertainties or reduce the risk associated with them through risk containment monitoring. Project level M\&E is described in Part III, but there is also a need to organize data collection among projects through a regionally coordinated program to ensure efficient use of M\&E funds. In addition, some questions cannot be resolved by information obtained from a single project. Integration of sampling designs, data collection, and analysis among projects is needed to resolve those questions. This report describes an approach to the regional coordination of supplementation $\mathrm{M} \& \mathrm{E}$. 
This is the fourth in a series of four summary reports. Our goal is to make findings from the Regional Assessment of Supplementation Project (RASP) more accessible by grouping related topics into smaller but complete narratives on important aspects of supplementation. RASP is planning or has already published the following reports under the general title

Supplementation in the Columbia River Basin: Part I, Background, Description, Performance Measures, Uncertainty and Theory; Part II, Supplementation Theory; and Part III, Planning Guidelines. This report, Part IV, Description of a Supplementation Model and Regional Coordination of Research and Monitoring, completes the series.

\section{BACKGROUND}

This section provides an overview of supplementation and of the RASP project. It includes an introduction to supplementation theory and to recommended planning guidelines.

\section{Importance of Supplementation}

Supplementation is a major element of the program to increase salmon production in the Columbia Basin. The Fish and Wildlife Program of the Northwest Power Planning Council (NPPC) uses three approaches to protect and enhance salmon and steelhead in the Columbia River: 1) improve fish production; 3) improve passage in the mainstem; and 3) improve harvest management to support the rebuilding of fish runs (NPPC 1987). The fishproduction segment calls for a three-part approach that includes natural production, hatchery production, and supplementation. The Integrated System Plan (ISP) (CBFWA 1991) indicates that the fish management agencies and tribes expect supplementation to provide over half of the total production increases (Table 1).

\section{Origin and Goals of RASP}

RASP originated from basin fisheries managers who recognized a need to review supplementation and from a call for such a review by the Columbia Basin Fish and Wildlife Authority. In August 1990, when the Council gave conditional approval to proceed with the final design phase of the Yakima and Klickitat Production Project, it called on the Bonneville Power Administration (BPA) to "fund immediately a supplementation assessment. The purpose of that assessment was to reevaluate, prioritize, and coordinate all existing and planned supplementation monitoring and evaluation activities in the basin... Provid[ing] for the participation of the fishery agencies and tribes and others having expertise in this area." Coordination of supplementation research was also recommended by the Supplementation Technical Work Group. RASP was initiated as a result of the general recognition for coordination and the request by the NPPC. RASP addresses four principal objectives:

- $\quad$ provide an overview of ongoing and planned supplementation activities and

RASP Summary Report Series, Part IV: Supplementation Model and Regional Coordination December, 1992 /Page 2 
Table 1. Percent of total production increases attributable to supplementation in the ISP. Computed from System Planning Model output? (Duane Anderson, NPPC, personal communication)

\begin{tabular}{|l|cccc|c|}
\hline \multicolumn{5}{|c|}{ COLUMBIA RIVER REGION } \\
SPECIES/STOCK & L O W E R & MID & SNAKE & UPPER & ALL \\
\hline \hline LATE COHO & $\mathbf{9 7 . 1 \%}$ & - & & - & $97.7 \%$ \\
EARLY COHO & $100.0 \%$ & $100.0 \%$ & & & $100.0 \%$ \\
FALL CHINOOK & $0.0 \%$ & $37.4 \%$ & $51.2 \%$ & $0.0 \%$ & $8.6 \%$ \\
SPRING CHINOOK & $88.4 \%$ & $64.0 \%$ & $74.3 \%$ & $34.7 \%$ & $65.4 \%$ \\
SUMMER CHINOOK & & $6.3 \%$ & $66.9 \%$ & $38.4 \%$ & $43.5 \%$ \\
SUMMER STEELHEAD A & $100.0 \%$ & $25.6 \%$ & $95.5 \%$ & $73.9 \%$ & $71.8 \%$ \\
SUMMER STEELHEAD B & & & $72.0 \%$ & & $72.0 \%$ \\
WINTER STEELHEAD & $48.0 \%$ & $100.0 \%$ & & & $60.2 \%$ \\
\hline ALL & $45.4 \%$ & $47.5 \%$ & $\mathbf{7 8 . 2 \%}$ & $\mathbf{3 4 . 5 \%}$ & $\mathbf{5 2 . 4 \%}$ \\
\hline
\end{tabular}

- identify critical uncertainties associated with supplementation

- construct a conceptual framework and spreadsheet model which estimates the potential benefits and risks of supplementation and prioritizes uncertainties based on their projected effects on the risks and benefits of a project

- $\quad$ provide guidelines for the development of supplementation projects

- $\quad$ develop a plan for regional coordination of research and monitoring

RASP has further divided the four broad objectives into 12 technical topics:

- definition of supplementation

- description of the diversity of supplementation projects

- $\quad$ objectives and performance standards

'The ISP addressed other stocks that were not modelled and are not included in Table 1. 
- $\quad$ identification of uncertainties

- $\quad$ supplementation theory

- development of a conceptual model of supplemented populations

- development of a spreadsheet model of risks and benefits of supplementation

- $\quad$ classification of stocks, streams, and supplementation strategies

- $\quad$ regional design of supplementation evaluation and monitoring

- $\quad$ guidelines for planning supplementation projects

- $\quad$ application of the spreadsheet model to supplementation planning

- $\quad$ experimental design and decision making with uncertainty

Progress in each topic area has been presented in regular progress reports which are available from the Bonneville Power Administration.

\section{Supplementation Synopsis}

This section provides a synopsis of the RASP project's definition of supplementation, an emerging theoretical basis for supplementation, and planning guidelines.

Definition RASP defined supplementation as: Supplementation is the use of artificial propagation in an attempt to maintain or increase natural production while maintaining the long-term fitness of the target population, and keeping the ecological and genetic impacts on nontarget populations within specified biological limits.

The purpose of supplementation is to increase or maintain natural production $\mathbf{2}^{\mathbf{2}}$ and that objective must be achieved without a loss of long-term fitness in the target population. Each supplementation project must hold the genetic and ecological impacts on nontarget populations within specified limits. Supplementation is clearly a departure from conventional hatchery programs and it reflects a changing management paradigm (for a historical perspective on the change see Part I of this series),

\footnotetext{
2 Natural production - production resulting from naturally produced progeny that have spent their entire life in their natural habitat.
}

RASP Summary Report Series, Part IV: Supplementation Model and Regional Coordination

December, 1992 / Page 4 
Supplementation presents the managers with a new challenge: to integrate natural and artificial production systems in the Columbia Basin in a way that yields sustainable increases in total and natural production. Meeting that challenge will call for new ideas in the physical design and operation of hatcheries as well as a better technical understanding of genetics, behavior, competition and predation - fields that were not strongly emphasized in the domain of artificial propagation until recently.

Supplementation Theorv The expectation that we can increase natural production by adding artificially propagated fish to natural habitats, is based on our understanding of the artificial and natural production systems. Realizing the expected increases in production depends on how well the two systems are integrated. Supplementation theory is an attempt to describe important features of the natural and artificial production systems as a basis for developing supplementation planning and M\&E guidelines.

Supplementation theory as developed by RASP is a framework comprised of three concepts:

Capacity - Each stream/stock system has a potential capacity for natural production which is determined by the interaction of abiotic and biotic components of the system including all the habitats utilized by the stock throughout its life history.

Performance - Performance of a stream/stock is that part of the realized capacity that is measured in terms of interest to the fishery manager. For example, production and productivity of specific salmon populations might be a measure of performance.

Stock-recruit relationshin - A basic assumption in salmon management is the existence of a relationship between the quality and quantity of a spawning population and recruitment of adult progeny. Supplementation attempts to increase the quantity of natural production while not reducing population quality such as fitness, reproductive success, post-release survival, etc. We have found it useful to examine the potential outcomes of supplementation through the lens of stock-recruitment relationships.

A detailed description of the elements of a supplementation theory is given in Part II of this report series.

Planning Guidelines Planning guidelines developed by RASP are comprised of 9 steps (Figure 1). The first step establishes the project's goals; steps 2 to 4 are fact-finding and descriptive; steps 6 and 7 are analysis; and steps 8 and 9 are evaluation.

- $\quad$ Step 1 - the objective describes the desired future condition of the stream/stock system (expected benefits) 
- $\quad$ Step 2 - the template describes the healthy stream/stock system

- Step 3 - the patient describes the current condition of the stream/stock system

- Step 4 - the diagnosis identifies limiting factors that prevent the patient from reaching the objective

- $\quad$ Step $\mathbf{5}$ - at this point the original objective should be reviewed and revised if appropriate

- $\quad$ Step 6 - the treatment describes supplementation strategies expected to achieve the benefits set forth in the objective

- $\quad$ Step 7 - risk analysis describes the uncertainties associated with the recommended treatments

- $\quad$ Step $8-M \& E$ presents general guidelines to control risk through properly designed research or monitoring

- $\quad$ Step 9 - results are evaluated and the program revised where necessary

Planning of management activities such as supplementation requires an understanding of how the ecological system functions and how it responds to human intervention at the life historyhabitat level. The salmon's life history is comprised of important biological functions such as spawning, migration, feeding, and escaping predators and a series of geographically and seasonally connected places where those functions are carried out (Thompson 1959). The increase in natural production achieved through the use of supplementation is a test of our understanding of the relationships among the life histories of the target stock; the natural habitat; and artificial spawning, rearing, and release practices. The planning guidelines described in Part III describe a process for systematically evaluating those relationships. 


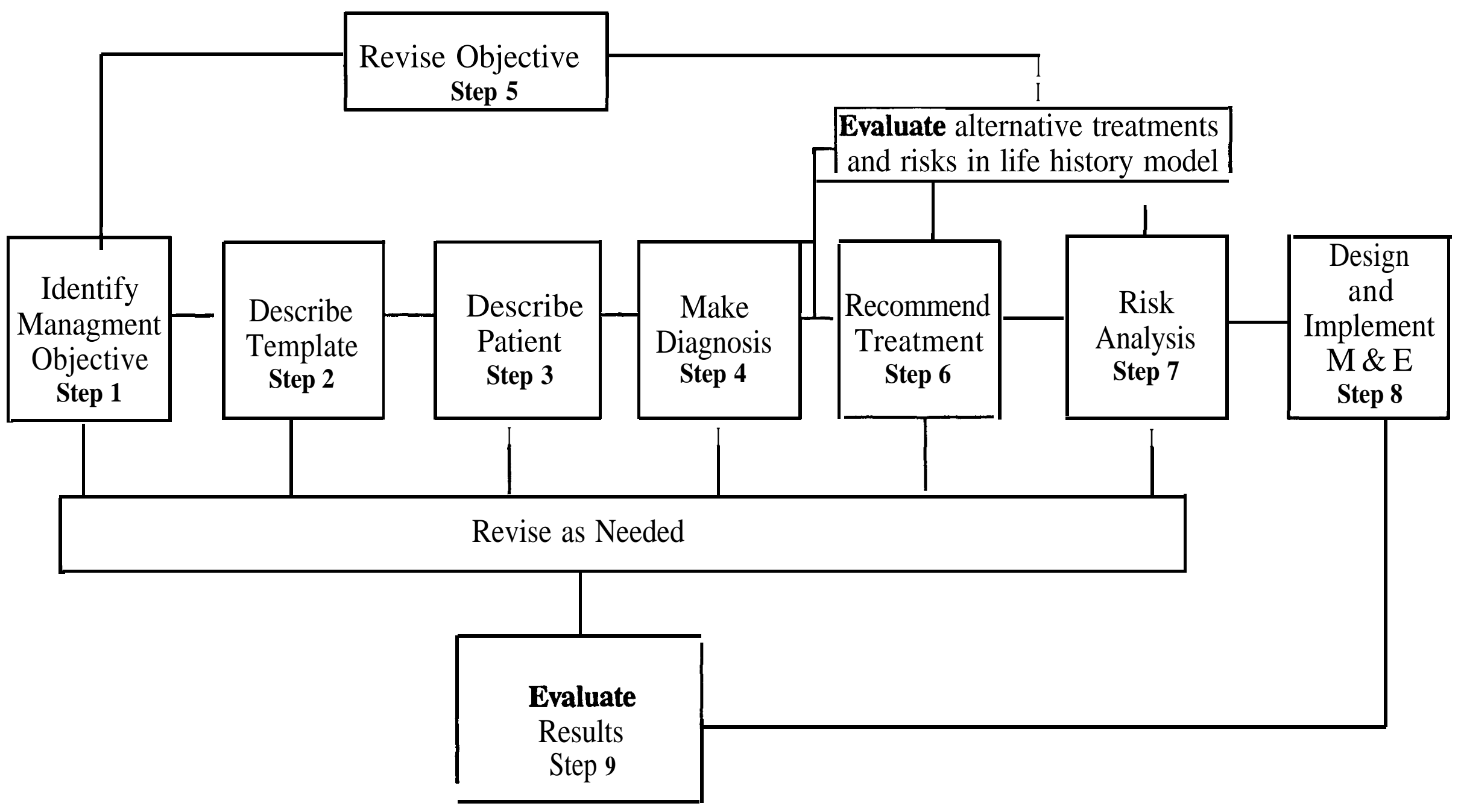

Figure 1. A sequence of planning steps for supplementation projects. 


\section{RISK, UNCERTAINTY, AND EXPECTATION}

This section describes analysis of risks, uncertainties, and expectations associated with planning a supplementation project.

\section{Risk Analysis}

In supplementation planning, as in other activities where a biological resource is to be manipulated, what we don't know is at least as important in shaping the program as what we do know and can control. This is because our ignorance often outweighs our knowledge of the functional relationships in stream ecosystems and the consequences of our manipulation of those relationships. Consequently, management decisions, whether to initiate programs or to take no action, are often made with uncertainty, which automatically presents the manager with risk - risk of failure, risk of unintended side effects (genetic or ecological), and risk of future surprise outcomes. Uncertainty and risk are inseparable elements in fisheries programs: where you find one you will always find the other.

The uncertainties associated with a supplementation project result from a combination of three factors: the productive processes in the stream ecosystem, or our perception of them; the supplementation strategies; and the objectives (performance targets) of the project (Figure 2). Those factors interact to produce a unique set of uncertainties for a given project although there will be some overlap among projects. This means that uncertainties must be evaluated on a case-by-case basis. The planning guidelines described in Part III help the manager identify uncertainties as a part of an analysis of important biotic and abiotic features of the ecosystem, alternative supplementation treatments, and the manager's expectations or objectives. In addition, RASP (1992a) has developed a framework for linking hatchery practices to changes in attributes of salmonids which affect survival. The framework gives managers a rapid checklist which can be used to identify potential uncertainties associated with hatchery practices.

Careful planning of each supplementation project will identify several uncertainties. During project planning, all uncertainties are initially managed by making appropriate assumptions. The critical uncertainties are managed through appropriate M\&E (see Figure 2). An uncertainty is critical if the choice of assumption determines success or failure of the project, whereas an uncertainty is minor if the choice of assumption has only minor effects on the project's outcome. For example, a project attempting to restore an extirpated stock might list among its critical uncertainties the quantity, quality, and distribution of spawning and rearing habitat, especially if it is known that habitats have been degraded since extirpation. Another critical uncertainty might be the choice of donor stock, especially if the habitat and life histories of the only available donor stock are not similar to those of the native stock. 


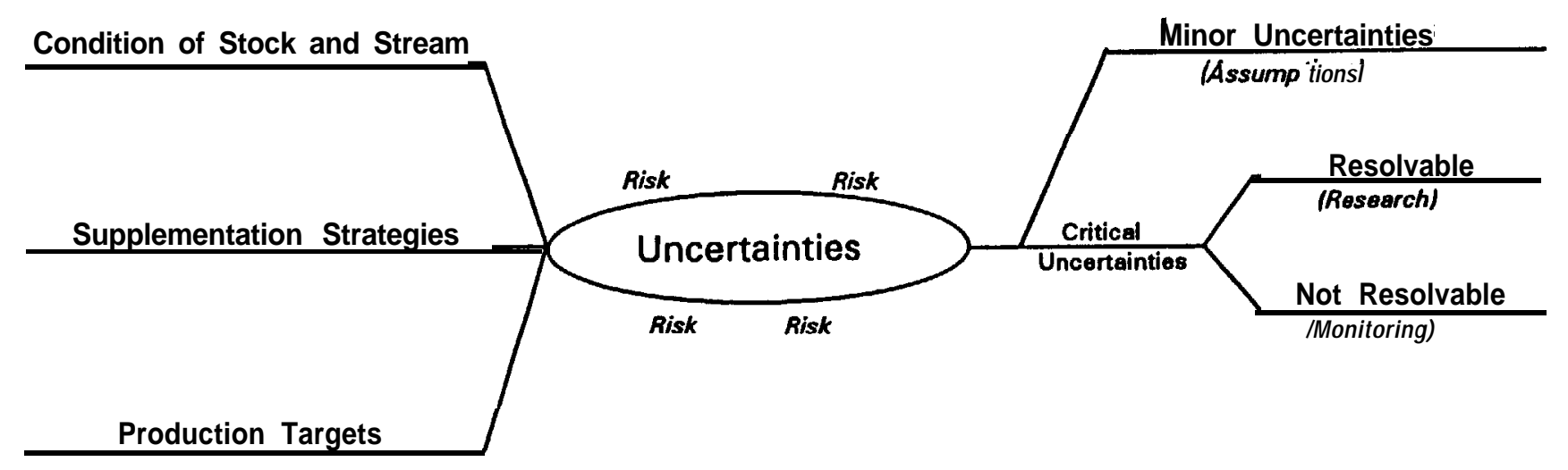

Figure 2. Schematic representation of the origin and treatment of supplementation' uncertainties. 
Minor uncertainties might include appropriate temperature regimes for egg incubation and juvenile rearing, feed programming, broodstock capture and holding methods, preventative hygiene, pond density, and grading practices.

RASP developed a procedure (see Tables 3a-e in Part III) which assesses risk by weighing and comparing critical uncertainties associated with alternative treatments including the treatment of no action. The risk analysis developed by RASP lists the project's critical uncertainties (if there are any), describes their potential impact on the ecological dimensions of the project objective (e.g. numerical production targets, post-release survival, reproductive success, ecological interactions, long-term fitness), estimates their potential impact on the project's objectives, lists the assumptions associated with each critical uncertainty, and describes how the uncertainties and their associated risks will be managed through monitoring or evaluation.

The separation of uncertainties into critical and minor (see Figure 2) is an important step in the process of analyzing risks. However, those categories do not constitute the only classification of uncertainties which a manager might find useful when planning a supplementation project.

\section{Other Classifications of Uncertainties}

Hilbom (1992 and 1987) classified uncertainties by the frequency of change they produce, and the nature of the underlying causes of those changes (Table 2). Frequent changes (noise) result from annual variability in climate, river runoff, etc. Less frequent change (uncertain states of nature) often involves a shift in the functional relationships that determine the potential capacity of a system. States of nature might change as a result of long-term cycles in ocean productivity, changes in the genetic structure of a stock, or through habitat degradation. The least frequent change is called surprise or an unexpected outcome of a management action. Hilbom's (1987) classification of uncertainty gives the managers a useful framework for organizing a large number of uncertainties prior to dealing with them through $\mathrm{M} \& \mathrm{E}$.

The three types of uncertainty listed in Hilbom (1987) influence the design of supplementation M\&E (see Table 2). Noise occurs fresuently enough to be characterized statistically and must be taken into account in the design of experiments. The analysis of the power of a statistical test is an important way that year-to-year variability is accounted for in the design of M\&E (see Part III). The state of nature exerts an important influence on the expectations of supplementation. For example, density-independent mortality at mainstem dams represents a change in the state of nature that can limit the outcome of supplementation in the upper basin. To manage uncertainty about the state of nature, the manager develops hypotheses which are tested through M\&E. The design of experiments to test hypotheses regarding the state of nature must account for the effects of noise. Surprise, which by

RASP Summary Report Series, Part IV: Supplementation Model and Regional Coordination December, 1992 / Page IO 
Table 2. A scheme for classifying* uncertainties based on the frequency of change in the stream/stock system. The influence of each type of uncertainty on M\&E is described.

\section{CLASSIFICATION OF UNCERTAINTY}

\begin{tabular}{|c|l|l|l|}
\hline & NOISE & \multicolumn{1}{|c|}{$\begin{array}{c}\text { UNCERTAIN } \\
\text { STATUS OF NATURE }\end{array}$} & SURPRISE \\
\hline \hline $\begin{array}{c}\text { Frequency } \\
\text { of } \\
\text { Change }\end{array}$ & $\begin{array}{l}\text { Year to year changes, } \\
\text { climatic variability, etc. } \\
\text { Less frequent change. Changes } \\
\text { in major functional } \\
\text { relationships that determine } \\
\text { potential capacity, i.e. long- } \\
\text { term ocean productivity cycles, } \\
\text { loss of genetic diversity and } \\
\text { major habitat degradation. }\end{array}$ & $\begin{array}{l}\text { Unanticipated outcomes } \\
\text { of management actions. }\end{array}$ \\
\hline $\begin{array}{c}\text { Influence } \\
\text { on } \\
\text { M\&E }\end{array}$ & $\begin{array}{l}\text { Statistical characterization of } \\
\text { frequency distribution. } \\
\text { Probabilities estimated. } \\
\text { Influences sample sizes and } \\
\text { ability to detect changes. }\end{array}$ & $\begin{array}{l}\text { Needs longer time periods to } \\
\text { develop statistical } \\
\text { characterizations. Leads to } \\
\text { tests of hypothesis about } \\
\text { functional relationships. }\end{array}$ & $\begin{array}{l}\text { Risk containment } \\
\text { monitoring to give } \\
\text { warning of surprise. }\end{array}$ \\
\hline
\end{tabular}

*The classification categories, noise, uncertain state of nature, and surprise are from Hilborn (1987 and 1992). 
definition cannot be identified beforehand, must be detected early through risk-containment monitoring. The design of M\&E for specific projects must consider all three types of uncertainty.

Another way to classify uncertainties is to divide them into those that are specific to an individual project and those that are global and shared by several projects. The effect of a specific irrigation diversion on juvenile or adult migration is an example of a project-specific uncertainty. Genetic uncertainties such as the consequences of outbreeding depression are broadly applicable to all supplementation projects. Global uncertainties may be divided into two types:

- Uncertainties that can be resolved through studies at one or a few locations and the results applied to other projects

- Uncertainties that can only be resolved through coordinated research at several projects or locations. In this case, the individual projects become experimental units (treatments or controls) in a larger M\&E design

The identification of uncertainties and the evaluation of risks associated with them are important tasks in supplementation planning. However, the evaluation of risks must be balanced with an analysis of the expected benefits. when planning a supplementation project, the fishery manager attempts to account for stock or life-history diversity, habitat degradation, and genetic and behavioral effects of hatchery practices among other factors in the analysis of risks and benefits. One way to evaluate the effect of several treatment alternatives and ecological factors on risks and benefits is through spreadsheet models. The next section describes such a model.

\section{SUPPLEMENTATION MODEL}

The spreadsheet model which was developed by RASP is described in this section. Information on the intended use of the model, its conceptual framework and underlying assumptions, and application is provided. Examples of model output are also provided and described.

\section{Purpose}

The supplementation model simulates the life history stages of naturally produced and supplemented anadromous salmonids. It was designed to provide a tool to examine the effects 
of alternative hatchery treatments and assumptions about production and fitness $\mathbf{s}^{\mathbf{3}}$ on potential outcomes of supplementation. The model's intended use is to assist managers planning individual supplementation projects. Heuristic models of this kind are meant to give qualitative results to be used in formulating hypotheses rather than as quantitative predictive tools for management (Larkin 1973; Hutchings 1991).

\section{Relationship to Other Models}

The RASP spreadsheet model is one approach to modeling supplementation in the basin. Use of more than one approach can be helpful in fully evaluating potential risks and benefits of supplementation. Other approaches include those of Bjomn and Steward (1990), Lee and Hyman (199 1), and Byrne et al. (1992). Hutchings (1991) modelled possible outcomes of inadvertent supplementation (through straying of cultured fish) of Atlantic salmon.

The supplementation model developed by RASP draws from data and concepts found in recent models of production, life history, and supplementation in the Columbia Basin. Specifically, we used the data base contained in the System Planning Model (SPM) (NPPC 1989) and the life history and fitness concepts developed by Bjomn and Steward (1990). The supplementation model uses transfer coefficients, maturity schedules, fecundity, carrying capacities, and survival at zero density from the SPM unless updated information is available for a specific basin or stock.

The model developed by Bjomn and Steward (1990) tracks six genetic groups through successive life history stages and generations. Bjomn and Steward (1990) assigned a lower fitness to hatchery-reared fish in the natural environment relative to their native counterparts. Fitness of the hatchery fish improved with each successive generation of natural spawning. The RASP model builds on those concepts in two important ways. First, RASP has developed a separate estimate of fitness for fish subjected to six categories of hatchery practices and supplementation strategies. In addition, the RASP model contains the option to use three different scenarios for the rate of change in fitness of the progeny of hatchery fish (see Genetic Yardsticks for more detailed explanation). Second, the RASP spreadsheet model tracks four genetic groups as opposed to six in Bjomn and Steward (1990). Given the current understanding of the effects of hatchery practices on fitness in the natural habitat, there is little to be gained by increasing the number of genetic groups beyond four. The matrix of four genetic groups and three fitness scenarios used in the RASP model can easily be expanded.

\footnotetext{
${ }^{3}$ RASP recognizes that the term "fitness" has a restricted definition when used in a genetic sense, for example, Falconer (1970) says: 'The proportionate contribution of offspring to the next generation is called fitness of the individual." However, the term fitness also has a wide variety of applied meanings. Our use of fitness refers to the long-term, phenotypic performance and not the more restrictive genetic definition.
}

RASP Summany Report Series, Part IV: Supplementation Model and Regional Coordination December, 1992 /Page 13 
The RASP model is similar to the model described in Byrne et al. (1992) in that both are life-cycle models that incorporate stock-production relationships at intermediate life stages. Both monitor the abundance of natural and hatchery production groups in a similar manner. The major distinction is that the RASP model enables a wider range of supplementation treatments to be easily modeled and compared. This permits the operator to explore uncertainty of the relative effects of different strategies.

Hatchery and wild fish survive at different rates because of genetic, behavioral, and physiological changes induced by the hatchery environment. In recognition of this, the SPM discounts the survival of hatchery fish relative to the survival of wild fish by $50 \%$ (NPPC 1989). The RASP spreadsheet model accounts for reduced survival and reproductive success in hatchery fish due to behavioral and physiological changes induced by the hatchery environment. However, our estimates of behavioral or physiological effects are preliminary and need further work.

The model developed by Lee and Hyman (1991) improved on the SPM by incorporating stochastic variation at each life-history stage; however, their model did not recognize differences in fitness in hatchery and wild populations. Environmental variation is incorporated in the RASP model as described on page 28. The RASP model builds on the features of these other models in another important way. Predation effects during downstream migration are modeled using one of the three functional responses of predators described by Holling (1959). The user can select which functional response to apply.

\section{Conceptual Framework}

The conceptual framework for the supplementation model is comprised of seven major elements: management objectives; supplementation strategies; genetic, behavioral, and physiological yardsticks; life history and demographics; environmental variation; Population dynamics; and the risks and benefits of supplementation (Figure 3).

\section{Management Objectives}

Supplementation is a tool used to achieve a specific management objective. The management objective and its components - reproductive success, post-release survival, fitness and ecological interactions - place important constraints on the choice of supplementation strategies and on the determination of risks and benefits. For example, an objective that includes the preservation of the characteristics of the native population will have a different range of supplementation options compared to an objective that attempts to reestablish an anadromous population in barren habitat. 


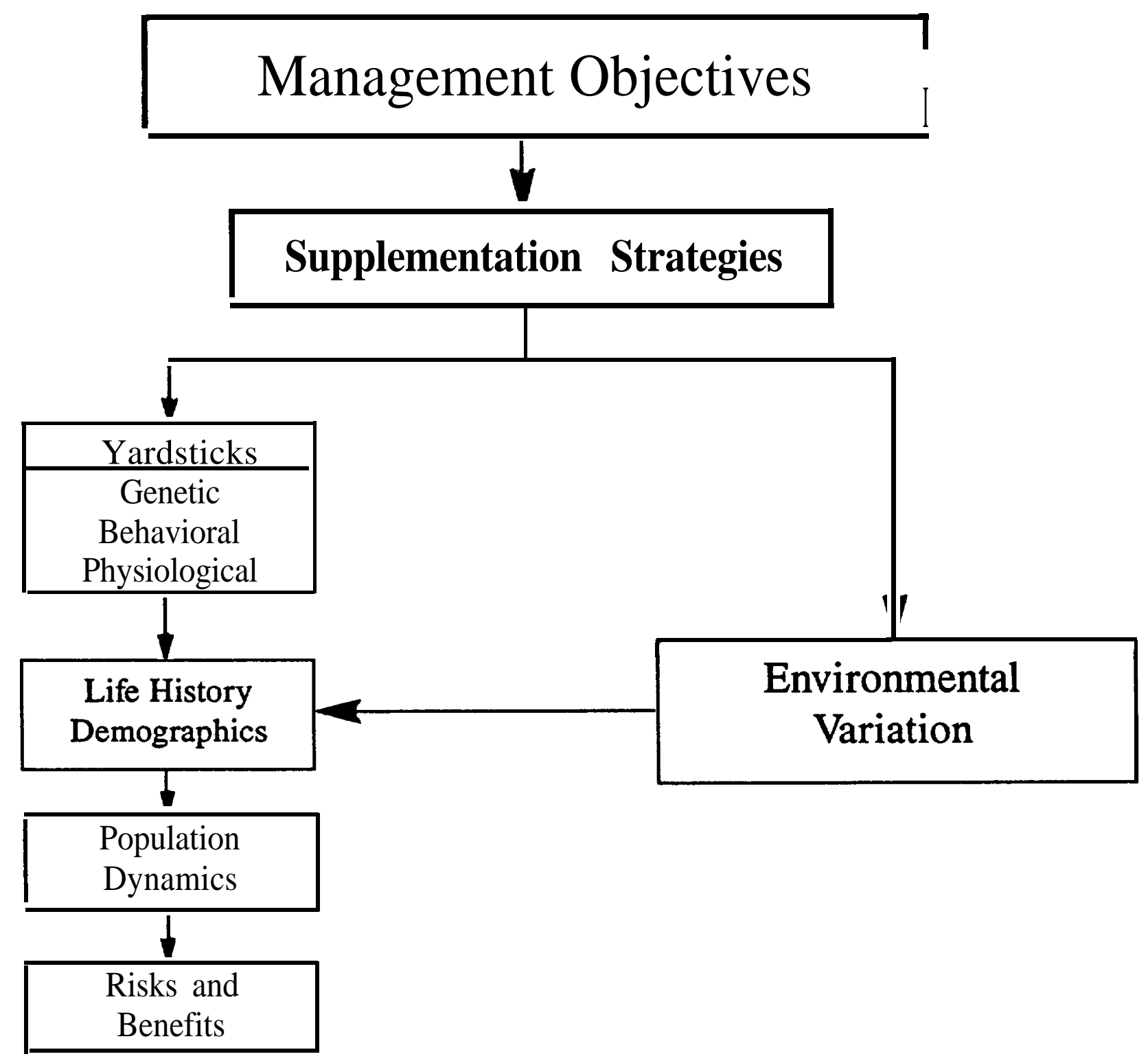

Figure 3. Schematic diagram of the components of the conceptual framework for a model of risks and benefits of supplementation. 


\section{Supplementation Strategies}

RASP developed and distributed a questionnaire designed to identify supplementation strategies and to characterize the recipient stocks and streams for planned and ongoing supplementation projects in the Columbia Basin. The questionnaire (SUPQUEST) covered eight general categories: project longevity, targeted life stage, broodstock strategies, mating, incubation strategies, rearing strategies, release strategies, and quality-control strategies. This information is used in the model in three ways: 1) to identify the appropriate genetic yardstick (Figure 4); 2) to determine the appropriate behavioral/physiological yardstick; and 3) to identify the life-history stage at which the spreadsheet model introduces hatchery-reared fish into the target stream. The timing of release has important consequences, particularly when the life stage released precedes or coincides with a life stage subjected to densitydependent regulation in the target stream.

\section{Yardsticks}

A yardstick describes an index of the relative effect on risks and benefits of supplementation due to the use of various broodstock, propagation, rearing, and release strategies. In the spreadsheet model, yardsticks modify the natural survival rate between life-history stages for the donor or target stock. RASP uses yardsticks to estimate effects when their existence is inferred from existing literature, but the exact nature and extent of the effect cannot be determined for all supplementation strategies. The term yardsticks implies a range of possible effects. In this report, yardsticks are estimates obtained either from consultation with experts or as a result of discussions among the members of RASP.

Genetic/Life-Historv Yardsticks Artificial propagation of salmonids can pose risks of genetic change to the propagated and supplemented stocks (Busack 1990). In addition, life-history traits such as time of spawning have been altered by artificial propagation (Waples 1991). These changes may translate to reduced productivity of the stock with obvious consequences to the risks and benefits of supplementation.

Two geneticists were asked to estimate fitness in the natural environment for salmon subjected to six categories of hatchery practices (see Figure 4). In the supplementation model, these estimates of fitness modify (increase or decrease) survival rates between life history stages (Figure 5). For example, if a hatchery practice reduces fitness by half, the cumulative, natural survival between life-history stages will be reduced by half. Wild fish are always assigned a fitness of 1 .

The supplementation model tracks four types of fish through several life history stages and generations (Table 3, and see Figures 4 and 5). A fish is assigned to a type based on its parental history (hatchery or wild) and the recovery scenario (Figure 6).

RASP Summary Report Series, Part IV: Supplementation Model and Regional Coordination December, 1992 /Page 16 


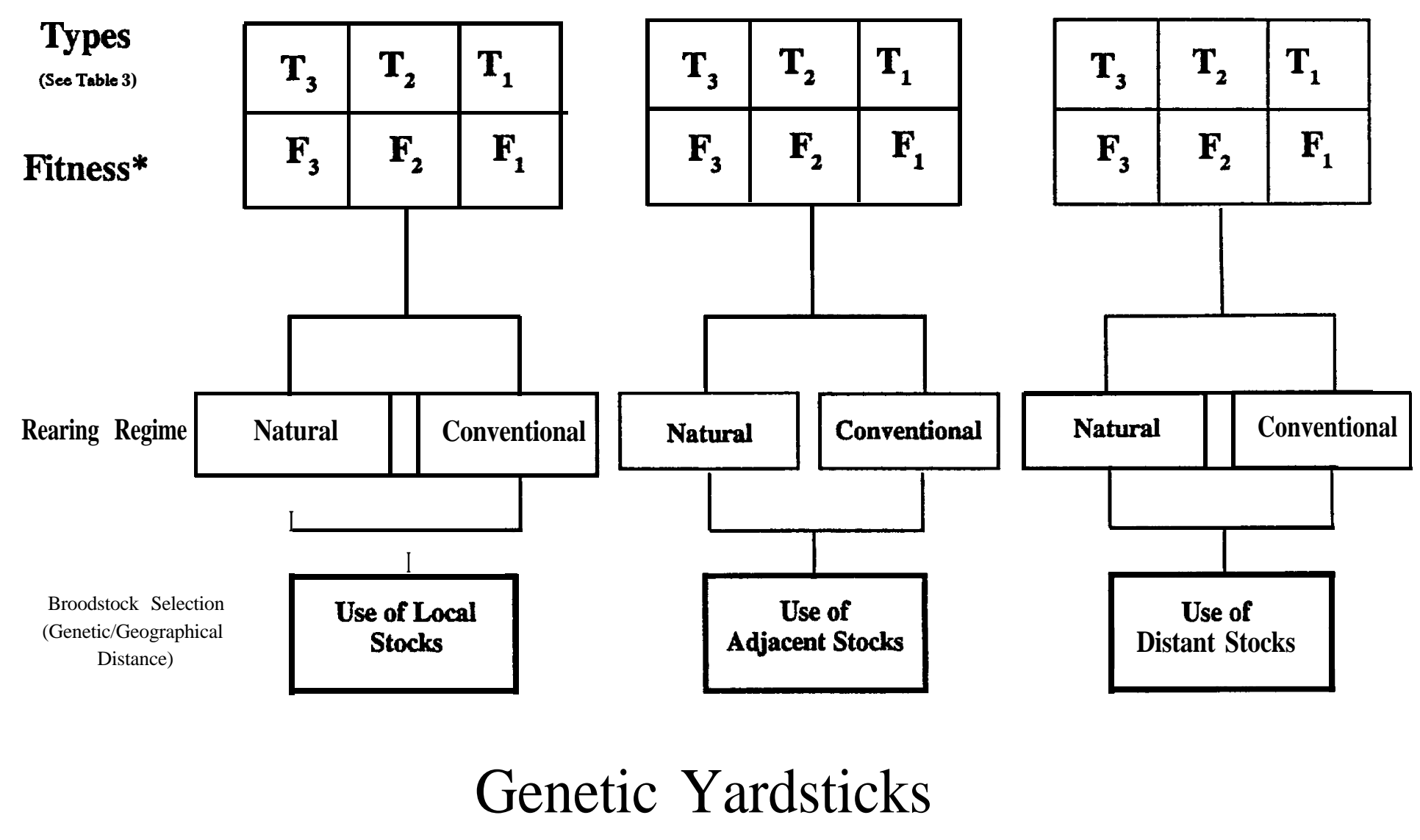

*Native fish $\left(\mathbf{T}_{\boldsymbol{}}\right.$ are always assigned a fitness coefficient of 1 .

Figure 4. Categories of broodstock and rearing regimes for which estimates of fitness were obtained from geneticists. Natural rearing refers to rearing conditions that mimic the natural environment. Conventional rearing refers to standard hatchery rearing ponds and practices. Natural and conventional also refer to the duration of rearing. Fry plants would be considered natural and full-term smolt releases conventional. 


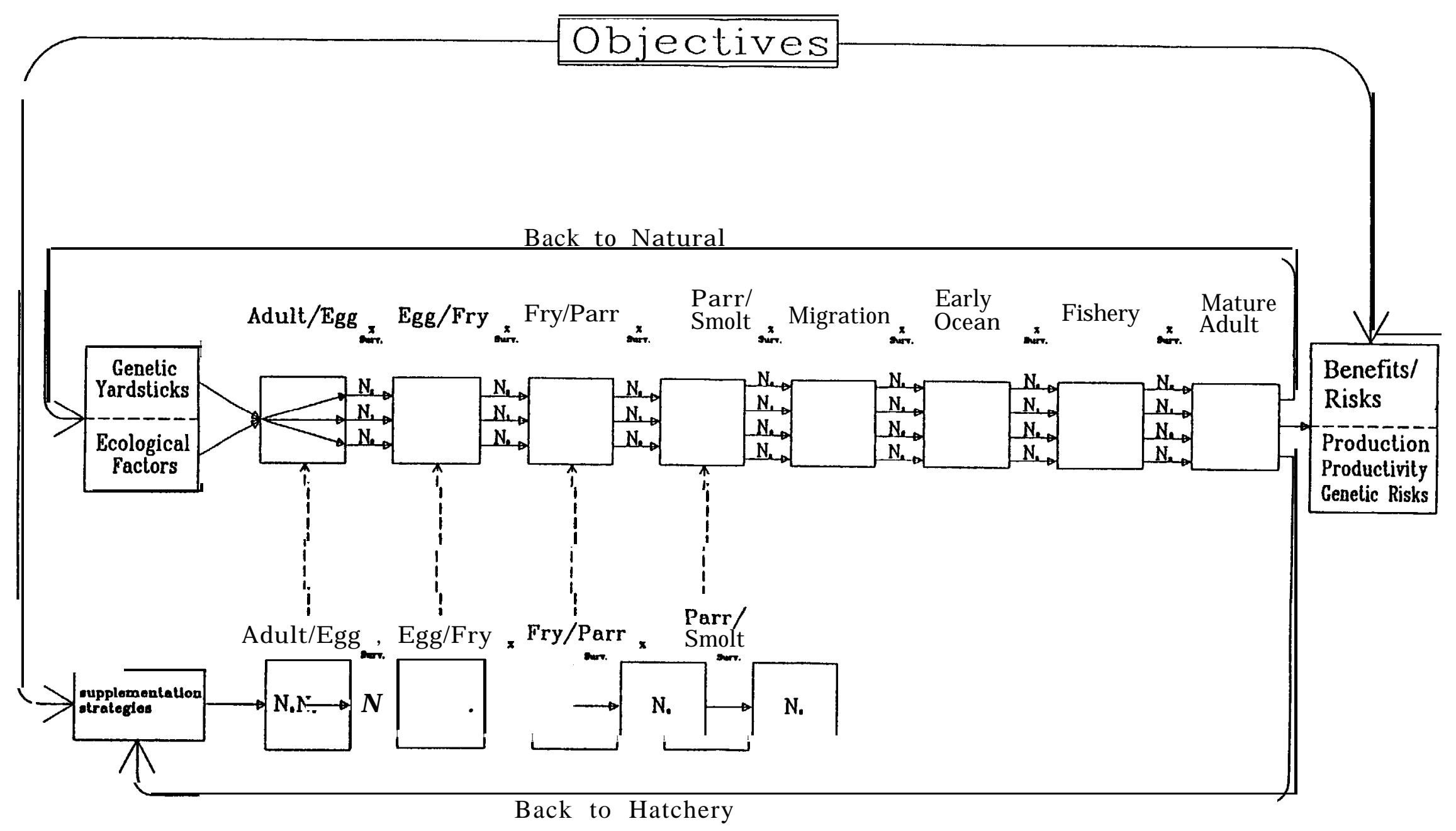

Figure 5. Diagram of the conceptual framework for a model to assess the benefits and risks of supplementation. Genetic yardsticks and ecological factors modify survival between life history stages. Behavioral yardsticks discussed in the text are not shown in the diagram. $\mathbf{N}_{\mathbf{0}}-\mathrm{N}_{\mathbf{3}}$ signify the actual number of fish surviving between life history stages, corresponding to the types $\left(\mathrm{T}_{0}-\mathrm{T}_{3}\right)$ discussed in the text and in Table 3. 


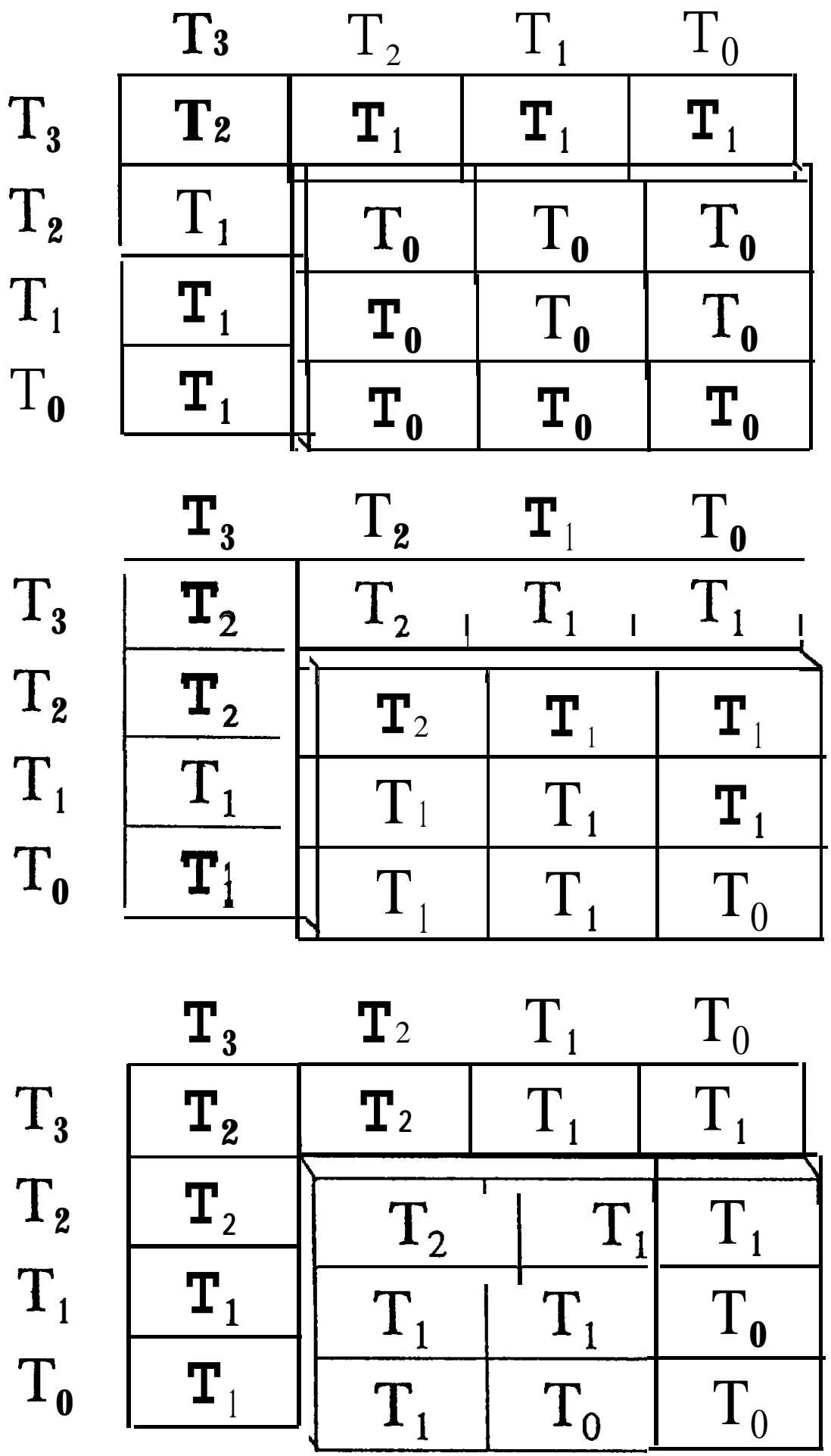

\section{SCENARIO I}

Progeny of fish one generation removed from the hatchery $\left(T_{2}\right)$ attain all the characteristics of th native stock.

\section{SCENARIO $\mathbf{I}$}

Hatchery fish never attain all thc characteristics of the native fish.

\section{SCENARIO $\mathbf{~ I I}$}

Intermediate between Scenario I and II. Native fish that mate wir the progeny of hatchery $x$ native crosses $\left(\mathbf{T}_{\mathbf{1}}\right)$ attain the characteristics of native fish $\left(\mathrm{T}_{0}\right)$

Figure 6. Possible breeding outcomes for the four fish types as modified by three recovery scenarios. 
Table 3. Description of fish types developed in the conceptual model and tracked in the spreadsheet model.

\begin{tabular}{|c|l|}
\hline Designation & \multicolumn{1}{c|}{ Description } \\
\hline $\mathbf{T}_{\mathbf{3}}$ & Hatchery produced fish that return to spawn naturally. \\
\hline $\mathbf{T}_{\mathbf{2}}$ & $\begin{array}{l}\text { Progeny whose parents were both hatchery produced fish }\left(\mathbf{T}_{\mathbf{3}}\right) \text { that } \\
\text { spawned naturally. }\end{array}$ \\
\hline $\mathbf{T}_{\mathbf{1}}$ & Progeny with one native and one hatchery parent. \\
\hline $\mathbf{T}_{\mathbf{0}}$ & Progeny whose parents were naturally produced.* \\
\hline
\end{tabular}

${ }^{*} T_{0}$ takes on a different definition in Scenario I, II, and III (see Figure 5).

Recovery scenarios were developed to address the question: How rapidly does the hatchery influence on fitness diminish with successive generations of natural spawning? Because of a lack of information on this subject, RASP developed three scenarios based on different assumptions regarding the rate of recovery of fitness in the progeny of hatchery fish (see Figure 6). The first scenario makes the assumption that progeny of fish one generation removed from the hatchery (Type $\mathbf{T}_{2}$ ) attain the fitness of wild fish (Type $\mathbf{T}_{0}$ ). The second scenario makes the assumption that hatchery fish and their progeny never attain the fitness of wild fish. The third scenario is intermediate and makes the assumption that the progeny of a hatchery $\mathrm{X}$ wild cross (Type $\mathbf{T}_{1}$ ) that subsequently mate with wild fish attain the fitness of wild fish (Type To).

While the model tracks individual fish types, RASP recognizes that identification and tracking of the same types in a real population would not be possible or desirable. The unit of interest in management is the population, and changes in the genetic characteristics of the population is the focus of study rather than individual fish. It might be more useful to assign types to populations and measure the change at the population level (personal communication Robin Waples, letter from Robin Waples to Rich Carmichael, September 27, 1991). Future modifications of the model should attempt to address this concern.

Dr. Craig Busack provided estimates of fitness for each fish type ${ }^{4}$ (Table 4) and combination of treatments (see Figure 4). Dr. Busack's estimates were reviewed by Dr. Graham Gall. The fitness estimates (see Table 4) obtained from Dr. Busack are multiplicative so, for example, a first-generation hatchery fish $\left(\mathrm{T}_{3}\right)$ reared under conventional hatchery conditions whose parents came from the local stock was assigned a fitness of 0.59 (Table 5). Table 5 is

\footnotetext{
4 Except $T_{0}$ (wild fish) which always has a fitness of 1.
} 
Table 4. Changes in fitness of hatchery fish exposed to different broodstock selection and rearing practices. Fitness is relative to a wild standard of 1.0 and fitness factors are multiplicative. The estimates were provided by Dr. Craig Busack and reviewed by Dr. Graham Gall.

\begin{tabular}{|l|l|c|}
\hline \multicolumn{1}{|c|}{ Category } & \multicolumn{1}{|c|}{$\begin{array}{c}\text { Treatment } \\
\text { or Pedigree }\end{array}$} & Fitness \\
\hline \hline \multirow{3}{*}{ Domestication Effects } & \multicolumn{1}{|c|}{$\mathrm{T}_{\mathbf{3}}$} & .85 \\
& $\mathrm{~T}_{\mathbf{2}}$ & .9 \\
& $\mathrm{~T}_{\mathbf{1}}$ & .95 \\
\hline \multirow{3}{*}{ Brood Stock Obtained from: } & Local Stock & $1.0^{*}$ \\
& Adjacent Stock & .7 \\
& Distant Stock & .1 \\
\hline \multirow{2}{*}{ Rearing Program (Inadvertent Selection) } & Natural & $1.0^{*}$ \\
\hline
\end{tabular}

*No loss of fitness.

Table 5. Fitness estimates used in the spreadsheet model for three fish types, three broodstock types, and two rearing regimes.

\begin{tabular}{|c|c|c|c|c|}
\hline \multirow[b]{2}{*}{$\underline{\text { Broodstock }}$} & \multirow[b]{2}{*}{ Rearing Regime } & \multicolumn{3}{|c|}{ TYPES } \\
\hline & & $\mathbf{T}_{3}$ & $\mathbf{T}_{2}$ & $\mathbf{T}_{1}$ \\
\hline \multirow[t]{2}{*}{ Local } & Conventional & .59 & .63 & .665 \\
\hline & Natural & .85 & .9 & .95 \\
\hline \multirow[t]{2}{*}{ Adjacent } & Conventional & .42 & .441 & .466 \\
\hline & Natural & .59 & .63 & .665 \\
\hline \multirow[t]{2}{*}{ Distant } & $\begin{array}{l}\text { Conventional } \\
\text { fatural }\end{array}$ & .06 & .063 & .066 \\
\hline & & .085 & .09 & .095 \\
\hline
\end{tabular}


the genetic yardstick incorporated into the supplementation model. Figure 7 shows the sequence of steps leading to the estimates of genetic/life-history yardstick.

RASP recognizes the limitations of this approach to the evaluation of changes in fitness. Through the use of yardsticks, the supplementation model incorporates ideas and assumptions about genetic change that cannot be measured or have not been measured in actual practice. We have documented the conceptual framework used to arrive at the yardsticks and have attempted to obtain reasonable estimates of fitness. We feel it is important to test these assumptions in the spreadsheet model, while recognizing the tentative nature of the actual numbers. The alternative - to wait until fitness is measured under actual conditions - would leave the managers with no help in making their decisions.

Behavioral Yardsticks In their first year after release, hatchery-reared fish generally exhibit a lower survival than their wild counterparts. Behavioral modification imparted by the hatchery experience may cause part of the differential in survival. For example, feeding efficiency might be impaired by learned behavior in the hatchery. Lack of exposure to predators may produce behavior that makes the hatchery fish vulnerable to predation when released into the natural environment.

The RASP model adjusts the post-release survival of hatchery fish downward compared to wild fish by factors that can be modified to evaluate the effect of a range of hatchery fish performances. Default values in the model set hatchery fish survival to be between about $15 \%$ to $100 \%$ of that of wild fish, depending on the life stage supplemented and the culture practices applied. The default values were formulated from a variety of sources, mainly through personal contacts and are included as suggested starting values. The important feature of these factors is that they can be simply altered to explore the effect of uncertainty in their values. The model provides two sets of survival adjustment factors, one set associated with conventional rearing practices and one for natural-type or innovative practices.

\section{Life History and Demographics}

The model divides the fish's life cycle into a number of discreet stages. It then simulates how a population responds quantitatively and qualitatively to supplementation by tracking the four fish types stepwise through each stage (see Figure 5) and moves a fraction of the fish from one life stage to the next. The behavioral and genetic yardsticks enter the model as modifiers of the natural survival between life-cycle stages. Beginning with an initial in-river adult population size, computations of survivors or their progeny arc made at each of the following stages in the order listed:

1 - Returns to Subbasin

- Adults returning to subbasin 
Conceptual Model

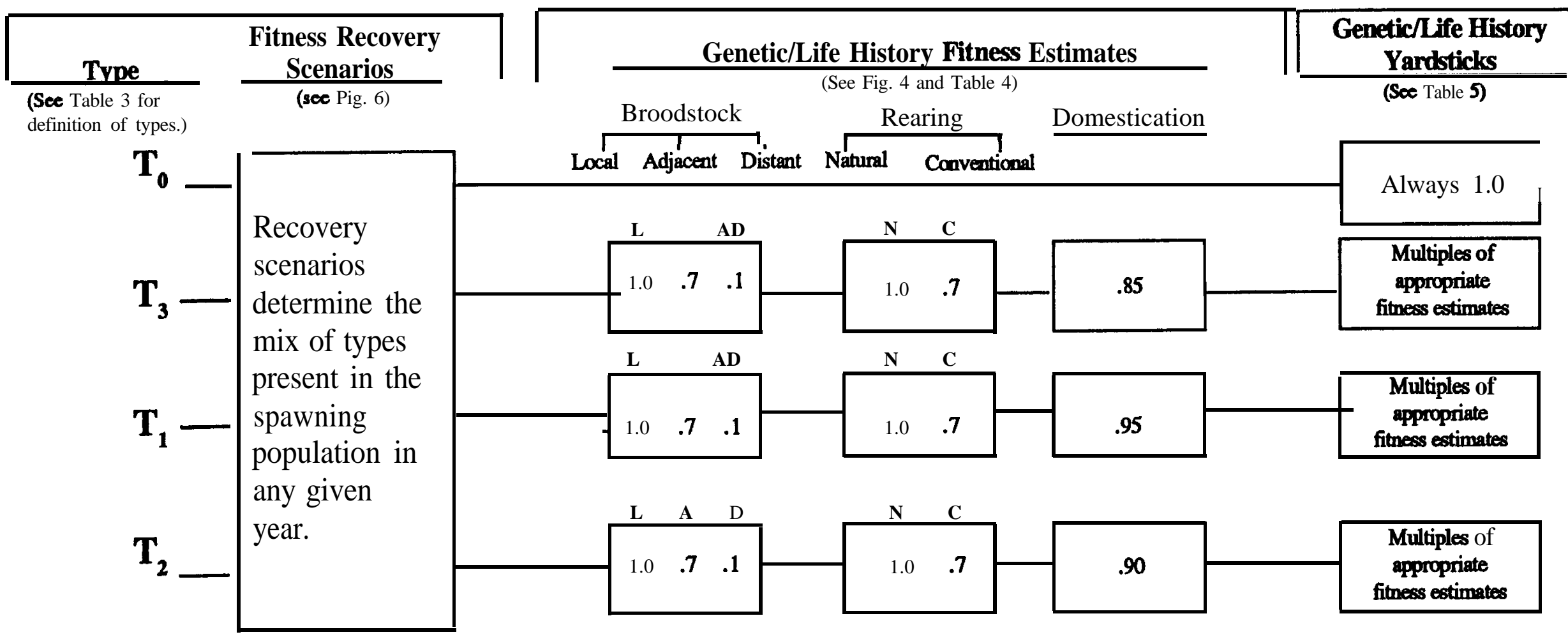

Figure 7. Development of Genetic/Life-History Yardsticks. The genetic/life-history yardsticks start with the concept that a supplemented population is comprised of at least four types $\left(\mathrm{T}_{0}-\mathrm{T}_{3}\right)$ of fish based on parental and rearing history. These types are called conceptual because their identification in the population may not be possible. In the conceptual model, the three hatchery-influenced types are assumed to have different fitness (survivals) in the natural habitat relative to the wild fish $\left(T_{0}\right)$ which always has a fitness of 1.0 . The recovery scenarios represent different assumptions regarding the change in fitness of hatchery-reared fish toward the fitness of the wild population. To convert the types of fish assumed to be present in the population under different recovery scenarios to a numerical modifier of survival in the spreadsheet model, fitness of the three hatchery-influenced types was estimated for three broodstock collection strategies, two rearing strategies, and domestication. The appropriate fitness estimates are multiplied to arrive at a yardstick value. 
- Brood stock capture prior to terminal harvest

- Terminal harvest

- Brood stock capture after terminal harvest

- Adults remaining after pre-spawning mortality

- Brood stock capture after pre-spawning mortality

- Spawners surviving in hatchery

- Spawners surviving in nature

- Potential gametes

2 - Subsequent Juvenile Population

- Fertihzed eggs in hatchery

- Fertilized eggs in nature by type

- Fry in hatchery

- Fry in nature

- Pre-smolts in hatchery

- Pre-smolts in nature

- Smolts prior to initiation of emigration

- Smolts departing subbasin

- Smolts after mainstem Columbia passage

- Smolts departing estuary

3 - Post-Juvenile Population (for each of post-juvenile age 1, 2, 3 and 4 fish)

- Pre-harvest (in ocean)

- Ocean harvest

- Post harvest (in ocean)

- Returns to Columbia basin

- Mainstem river harvest

- Strays outside subbasin of origin (within basin)

- Adults returning to subbasin

Basic demographic characteristics of the natural and hatchery-fish populations such as maturity schedules and fecundity are incorporated at the appropriate life-history stage. The maturity schedules are based on specific-subbasin information to the extent possible. These values remain fixed for a model run, though it is recognized that maturation has a genetic component which can be altered through fisheries (Ricker 1981) and hatchery practices (papers cited in Steward and Bjomn 1990).

The model assumes random mating of hatchery and wild spawners in nature. The number of zygotes of each fish type $\left(\mathrm{T}_{0}-\mathrm{T}_{3}\right)$ is determined simply by the proportion of the four types spawning in the subbasin. 


\section{Population Dynamics}

The model assumes an underlying relationship between spawner stock size and production based on simple stock-production (S-P) functions. Factors affecting production are more complex than can be reflected in simple S-P functions, but it is unlikely that a more rigorous approach to modelling population dynamics would improve confidence in results (Hilbom and Walters 1992). Moreover, S-P modelling concepts as employed in the supplementation model are familiar to most workers who will be using the model, which should facilitate use of the model.

The model assumes the basic underlying production function for salmon populations in the Columbia Basin follows the Beverton-Holt model which is consistent with Bjomn and Reiser (1991) and the SPM (NPPC 1989). Parameter estimates for smolt carrying capacity and survival at low density used in the SPM provide a convenient starting point for the RASP supplementation model.

The multi-stage modelling approach described by Moussalli and Hilbom (1986) and Hilbom and Walters (1992) was employed to estimate production for each of the freshwater life stages. The approach involves desegregating a population's stock-production function into separate functions for each major life stage. This provides a way of modelling stage-specific carrying capacity; hence variation in emergent fry, summer-fall, and winter capacities can be evaluated. Since supplementation can occur at different stages of a freshwater life cycle, this is needed to evaluate interactions between natural and introduced fish at appropriate times in the fresh-water life history.

The method used to estimate stage-specific capacity utilizes either available information about capacities at different life stages, or assumptions about those values. When capacities are based on assumptions, the model can be used to test the relative effect of uncertainty in those assumptions on the outcome of supplementation. This approach to estimating stage-specific production parameters also affords a convenient way to model the relative effect of habitat enhancement measures in combination with supplementation.

The supplementation model includes a provision for assumptions about the effect of predators on the supplemented population during smolt migration within the subbasin. The model uses three approaches to the interactions between the target population and predators. The first assumes that predators prey on migrant smolts at a constant rate with no provision for predator satiation, regardless of smolt density (Figure 8a). Holling (1959) described the predator response in this case as a Type I functional response. Much of the modelling in the Columbia River uses this approach, The second and third approaches assume that the rate of predation is dependent on the density of migrants (prey). They assume either a Type II or Type III functional response by predators (Figures $8 \mathrm{~b}$ and 8c), as described by Holling (1959). The Type II response leads to extinction of the prey population at low densities,

RASP Summary Report Series, Part V: Supplementation Model and Regional Coordination December, 1992 / Page 2.5 

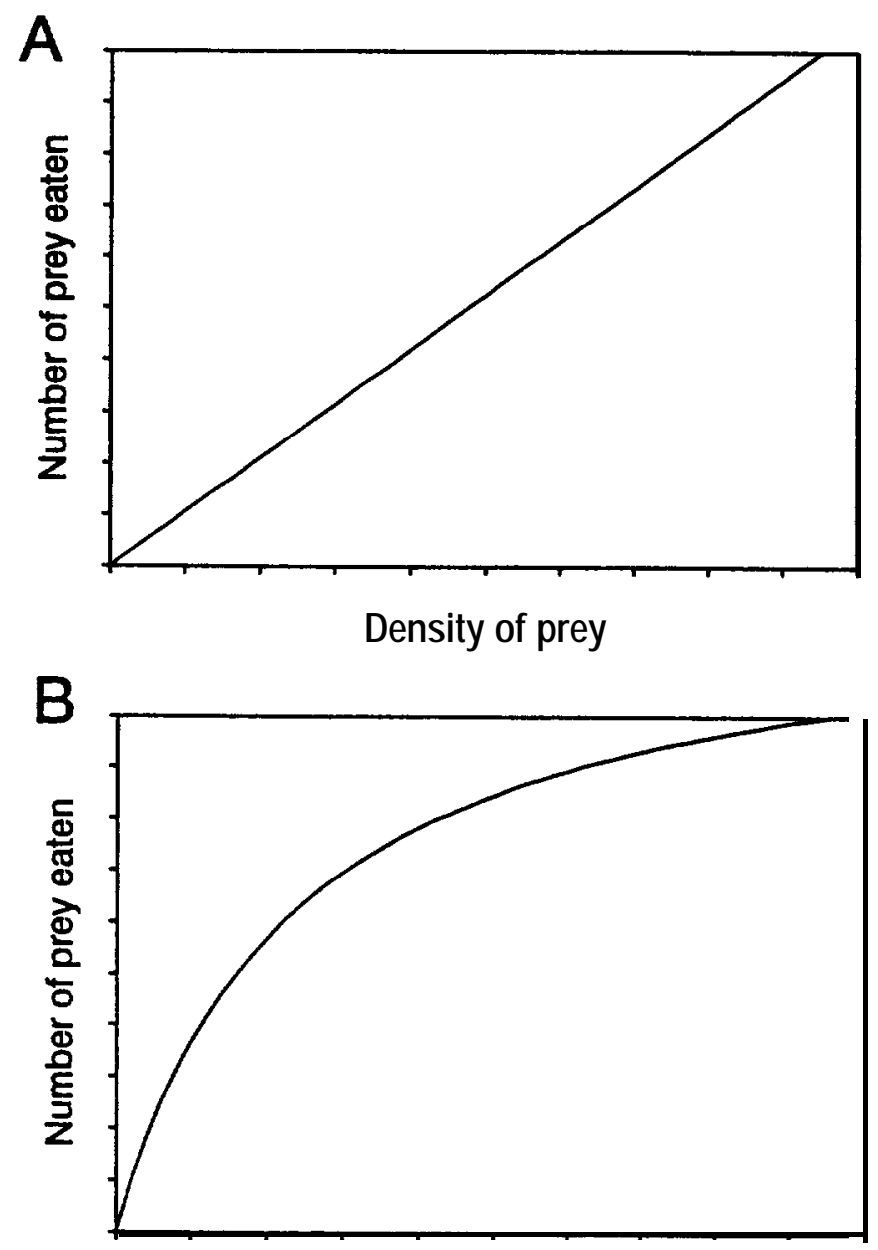

Density of prey

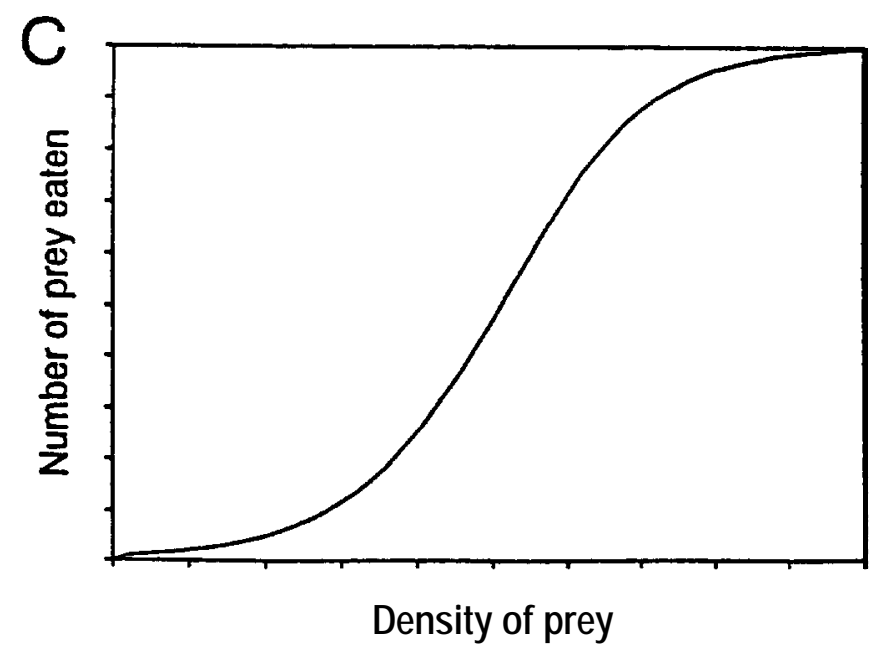

Figure 8. Functional responses of predators to increasing prey density: (A) Type I without predator satiation, demonstrating predator effects independent of prey density; (B) Type II, having highest rate of predation at low prey density; (C) Type III, showing low predator effects at low prey density due to switching to alternative prey species. 
while the Type III tends to produce multiple stability domains (Peterman 1977 and 1987). Peterman (1987) argues that multiple stability domains are more common than biologists recognize and recommends that more attention be given to assessing their importance. Mace (1983), Wood (1984), and Fresh and Schroder (1987) provide evidence for Type II and Type III functional responses by either birds or fish to juvenile salmon populations. The techniques used to model the two predator responses were described by Peterman (1977) for Type III and by Hilbom and Walters (1992) for Type II.

\section{Environmental Variation}

The model incorporates two sources of environmental variation in a manner similar to the SPM (NPPC 1989). First, survival during downstream passage through the Snake and Columbia mainstems can be varied in the supplementation model using the same survivalflow relationship employed in the SPM. A SO-year runoff record (1929-1978) was used to generate a set of passage survivals to below Bonneville Dam, assuming flows were regulated for the entire period under "current operations. n The model currently estimates passage survival past four or eight dams (or none, if this feature is turned off); additional data sets can be generated as needed. The 50-year survival record was converted to six different survival files; three that maintain the same sequence of years but vary the start year, and three that apply a random selection of survivals.

The second source of variation is meant to encompass all other influences of environmental variation on survival. Similar to the SPM, this variation in survival is based on a log-normal function and is applied during the estuarine life stage.

\section{Risks and Benefits}

The model estimates the benefits of supplementation as increased production and productivity of the combined natural and hatchery stock. Risk is measured as reduced production and productivity in the naturally spawned population and in the supplemented reach or in adjacent, nontarget reaches. Model outputs will permit the evaluation of the genetic-risks described by Busack (1990).

\section{Spreadsheet Model Operation}

The supplementation model was developed within the spreadsheet environment of Quattro Pro (version 3.0 by Borland). It was designed to be highly interactive with the operator. The model provides menu-driven operations for exploring a wide variety of supplementation strategies applied in various stream/stock conditions. The spreadsheet can be easily modified for customized operations. The model requires at least $2 \mathrm{MB}$ of PAM. Processing time is enhanced significantly with an 80386 or 80486 processor. 
To initiate a modelling exercise, the operator selects from a menu of pre-configured subbasin/stock files or, if none exists for the population of concern, proceeds through a setup routine to configure a new input file. Some of the base parameter values to be specified are smolt carrying capacity, winter vs. summer habitat capacities, fecundities maturation schedules, survivals between life stages, age at smolt migration, and homing fidelity. Some or most of these values can be obtained from data files used in the SPM. Parameter values can be modified prior to each model run.

The supplementation treatment is defined by the following: life stage to supplement, duration of supplementation in years, numeric release goals, broodstock source, broodstock policy, and rearing technique. The stock can be supplemented at the spawner, egg, emergent fry, fall pre-smolt, or smolt stages. The model can be run without supplementation or with supplementation at one or more life stages. The duration of supplementation must be specified. Treatments can be interrupted (stopped) or modified once within a single model run.

Options are available to define the broodstock source, collection schedule, and associated policy in the model. Broodstock can be collected from within or from outside the subbasin. If a local stock is used, the collection schedule must be defined, i.e., collection prior to or after terminal harvest. Policy constraints include: how long a particular type of collection practice is followed, whether the fish are selected randomly or not, the sex ratio, and limits as to how much of the natural and total run can be taken for broodstock. The ratio of first-generation hatchery fish to wild fish on the spawning grounds can be specified. Innovative or conventional culture practices within the hatchery can be specified.

The model adjusts the survival of supplemented fish by applying the multiplicative correction factors (yardsticks) to the population's natural survival rates prior to supplementation. The model applies two survival adjustments: 1) those due to hatchery treatments that affect survival of hatchery fish in nature (first-generation effects only) or of wild fish in the hatchery; 2) those due to hatchery treatments that cause genetic changes altering fitness of hatchery fish in the natural environment. These factors encompass the behavioral and genetic yardsticks previously described. The model will either apply a standard set of default values, or the values can be varied to evaluate the effect of uncertainty in the yardsticks. The default value for domestication effects for $\mathbf{T}_{\mathbf{3}}$ fish (see Table 4) was further partitioned to represent different durations of rearing in the hatchery as follows: fry release -0.95 ; presmolt release -0.90 ; smolt release -0.85 .

The relative importance of the genetic yardsticks is determined in part by the recovery scenario (see Figure 6). The operator must select one of the three recovery scenarios for each model run, or elect to have the model generate output for all three scenarios as part of the same run.

RASP Summary Report Series, Part IV: Supplementation Model and Regional Coordination December, 1992 / Page 28 
Subbasin smolt survival can be specified as constant, i.e., making it density-independent, or variable to reflect densitydependent predation losses. Density-dependent losses can reflect either a Type II or Type III functional response of predators as previously described.

Stochastic variation in downstream passage survival and estuarine survival can be switched on or off.

The operator then specifies the number of years to be modeled (maximum of 60) and initiates the run. After all computations are completed, the operator can review on screen a variety of model output, electing to print selected graphs or tabular results before proceeding to generate a new model run. Output, either graphic or tabular, are provided in the following categories:

- Natural spawners (all types) time series

- Composition of natural spawners time series

- Composition of hatchery spawners time series

- Smolts departing subbasin time series

- Adult recruits to Columbia plus harvest time series

- Stock-recruit plot for in-nature spawners

- Stock-recruit plot for total spawners

- Recruits per in-nature spawner time series

- Recruits per in-hatchery spawner time series

- Recruits per total spawners time series

- Eggs per female and natural egg deposition time series

Other types of summary output can be generated through simple modifications to the spreadsheet.

\section{Examples of Model Output}

Supplementation of a hypothetical spring chinook population was modeled to illustrate the kind of results and output the model generates. Example runs demonstrate how the model explores the effects of different assumptions on the outcome of supplementation. Modelling exercises can be used to evaluate how well hatchery fish must perform to achieve supplementation objectives.

Parameter values for the hypothetical stock are given in Table 6 . The initial population size was set at 2,000 each for male and female spawners. The river mouth was assumed to be upstream of four dams on the mainstem Columbia River. Smolt survival within the subbasin was set to be density-independent. The subbasin was supplemented with an annual release of 2,000,000 smolts. Six model runs are presented to illustrate the relative effects of different hatchery broodstock and culture practices on the outcome of supplementation (Table 7). The first run modelled the population without supplementation. Each of the other model runs set 
Table 6. Parameter values for modelling supplementation of a hypothetical spring chinook population in one subbasin of the Columbia River.

Smolt carrying capacity

Smolt age at outmigration

1

\begin{tabular}{|c|c|c|c|c|c|}
\hline \multirow{2}{*}{\multicolumn{2}{|c|}{ Stage transfer coefficient }} & \multicolumn{4}{|c|}{ Ocean age } \\
\hline & & \multirow{2}{*}{$\begin{array}{r}\text { All/Age } 1 \\
0.60 \\
0.90\end{array}$} & \multirow[t]{2}{*}{ Age 2} & \multirow[t]{2}{*}{ Age 3} & \multirow[t]{2}{*}{ Age 4} \\
\hline $\begin{array}{l}\text { Egg to fry survival } \\
\text { (low density in nature) }\end{array}$ & $\begin{array}{l}\text { in nature } \\
\text { in hatchery }\end{array}$ & & & & \\
\hline $\begin{array}{l}\text { Fry to fall presmolt surv. } \\
\text { (low density in nature) }\end{array}$ & $\begin{array}{l}\text { in nature } \\
\text { in hatchery }\end{array}$ & $\begin{array}{l}0.66 \\
0.85 \\
\end{array}$ & & & \\
\hline $\begin{array}{l}\text { Presmelt to smolt survival } \\
\text { (low density in nature) }\end{array}$ & $\begin{array}{l}\text { in nature } \\
\text { in hatchery }\end{array}$ & $\begin{array}{l}0.66 \\
0.85\end{array}$ & & & \\
\hline Smolt to smolt survival ${ }^{1 /}$ & & 0.55 & & & \\
\hline Juvenile passage survival ${ }^{2 \prime}$ & & 0.50 & & & \\
\hline Estuarine survival & & 0.13 & & & \\
\hline Ocean natural survival & & 0.50 & 0.60 & 0.70 & 0.80 \\
\hline Ocean harvest rate & & 0.02 & 0.01 & 0.04 & 0.04 \\
\hline Adult passage survival ${ }^{3 /}$ & & 0.60 & & & \\
\hline Columbia R. harvest rate & & 0.07 & & & \\
\hline Subbasin harvest rate & & 0.14 & & & \\
\hline Homing fidelity (to subbasi & & 0.97 & & & \\
\hline Pre-spawning survival & $\begin{array}{l}\text { in nature } \\
\text { in hatchery }\end{array}$ & $\begin{array}{l}0.80 \\
0.80\end{array}$ & & & \\
\hline Eggs/female & $\begin{array}{l}\text { natural } \\
\text { hatchery }\end{array}$ & $\begin{array}{l}2,100 \\
2,100\end{array}$ & $\begin{array}{l}3,800 \\
3,800\end{array}$ & $\begin{array}{l}6,100 \\
6,100 \\
\end{array}$ & \\
\hline Age/sex distribution" & $\begin{array}{l}\text { natural-m } \\
\text { natural-f } \\
\text { hatchery-m } \\
\text { hatchery - f }\end{array}$ & $\begin{array}{r}11 \% \\
1 \% \\
11 \% \\
1 \%\end{array}$ & $\begin{array}{l}82 \% \\
89 \% \\
82 \% \\
89 \%\end{array}$ & $\begin{array}{r}7 \% \\
10 \% \\
7 \% \\
10 \%\end{array}$ & $\begin{array}{l}0 \% \\
0 \% \\
0 \% \\
0 \%\end{array}$ \\
\hline
\end{tabular}

"Smolt survival within the subbasin.

${ }^{\boldsymbol{2}}$ Downstream passage survival between the subbasin and the Columbia R. mouth.

3/ Upstream passage survival between the Columbia R. mouth and the subbasin.

N Steady state input used to calculate maturation rates. 
Table 7. Description of six examples for comparing smolt supplementation strategies with a hypothetical spring chinook population. Stochastic variation using identical patterns of variation was applied in each run. Thirty brood years were modelled.

\begin{tabular}{|c|c|c|c|c|c|c||}
\hline Run no. & Smolt release goal & $\begin{array}{c}\text { Brood stock } \\
\text { source }\end{array}$ & $\begin{array}{c}\text { Type of } \\
\text { rearing }\end{array}$ & $\begin{array}{c}\text { Max \% hatch. fish } \\
\text { in natural escape. }\end{array}$ & $\begin{array}{c}\text { Functional response } \\
\text { of predators }\end{array}$ & $\begin{array}{c}\text { Genetic recovery } \\
\text { scenario }\end{array}$ \\
\hline \hline 1 & 0 & none & none & 0 & Type I & III \\
\hline 2 & $2,000,000$ & local & conventional & 50 & Type I & III \\
\hline 3 & $2,000,000$ & local & innovative & 50 & Type I & III \\
\hline 4 & $2,000,000$ & local & innovative & 10 & Type I & III \\
\hline 5 & $2,000,000$ & imported - distant & conventional & 50 & Type I & III \\
\hline 6 & $2,000,000$ & imported - distant & innovative & 50 & Type I & III \\
\hline
\end{tabular}

"' During smolt migration within the subbasin. 
the ratio of naturally spawning hatchery to wild fish at a maximum of 50\%, (except Run 4 , which set the ratio of $10 \%$ ). Runs that employed local broodstock took a maximum of $50 \%$ of the natural spawning population for broodstock (Runs 2, 3, and 4). Runs 5 and 6 imported brood fish from a distant stock. Each of the Runs 2-6 used recovery Scenario III. The model's default values for behavioral and genetic yardsticks were used in all cases.

All runs were made with stochastic variation generated from the same files. Differences in output between runs, therefore, is not due to changes in the way variation was generated. The file used to produce stochastic variation in downstream passage survival maintained the same sequence of annual runoff patterns. Each example was run for 30 years.

Six graphs are presented for each run: 1) natural spawner time series (Figure 9), 2) composition of natural spawner time series (Figure 10) 3) smolts leaving the subbasin time series (Figure 11)) 4) adult recruits to the Columbia River plus ocean harvest time series (Figure 12) , 5) stock-recruit plot for natural spawners (Figure 13), and 6) recruits per natural spawner time series (Figure 14). Each figure shows one graph for each of the six model runs.

For the hypothetical population shown, supplementation using local broodstock and conventional culture practices had an adverse effect on natural production (Run 2). Natural spawner abundance and natural smolt yield declined (see Figures 9 and 11 ) though the total numbers of smolts (including hatchery smolts) increased slightly.

The freshwater survival advantages accrued by taking natural stock eggs into the hatchery was negated by poor performance after release. This result was reflected in the number of adult recruits (see Figure 12) and the spawner-recruit plot (see Figure 13). In this case, the natural spawning population was essentially mined with no benefits obtained.

In contrast, supplementation using local broodstock and innovative cultural practices increased the natural spawning population and maintained or slightly increased natural smolt production (Run 3; see Figures 9 and 11). However, if the ratio of hatchery to wild fish in the natural spawning population was decreased from .5 to . 1, then production also dropped (Run 4). The composition of the natural spawning population changed accordingly (see Figure 10 ).

Runs 5 and 6 used imported broodstock. These model runs represent a worst-case scenario with regard to the genetic compatibility of the donor to the natural stock. Conventional culture practices (Run 5) resulted in a slight decrease in natural production compared to the no supplementation model run, but had better results compared to local stock and conventional culture practices (Run 2, see Figures 9 and 11). At first glance, these results appear contradictory. However, the use of local broodstock (Run 2) mined the natural spawning population while in Run 5 no natural spawners were removed for artificial

RASP Stunmary Report Series, Part IV: Supplementation Model and Regional Coordination

December, 1992 / Page 32 
A

NATURAL SPAWNERS - RUN 1 NOSUPPLEMENTATION

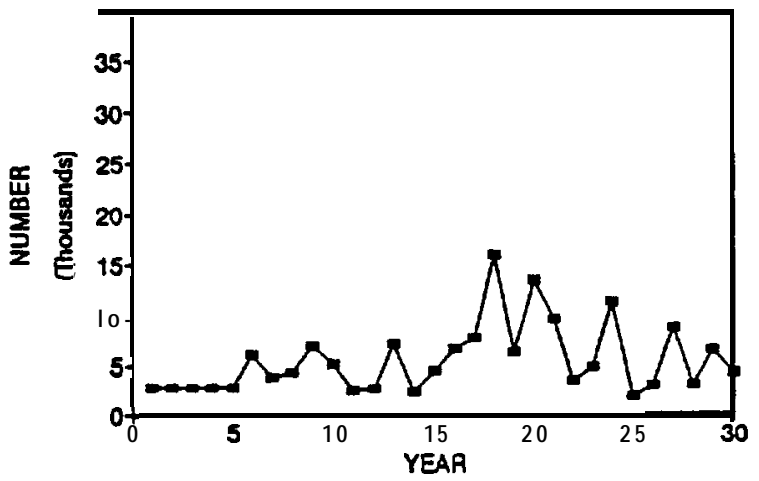

C LOCAL BRDSTK - INNOVAT. REAR - $<50 \% \mathrm{H}$

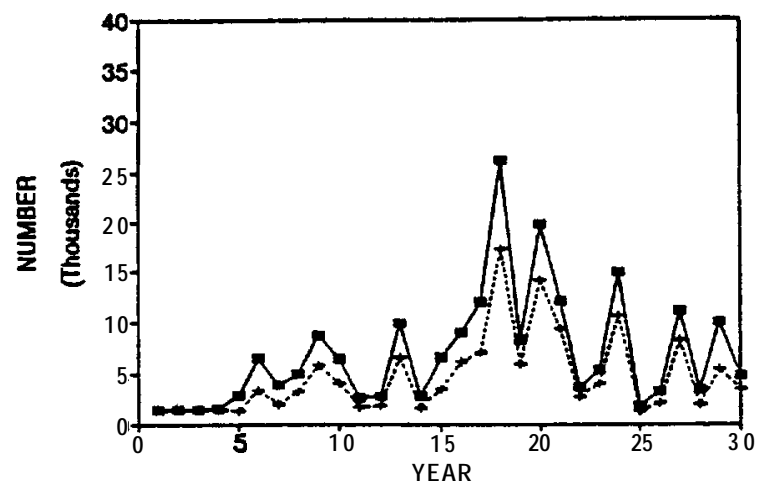

E DSNT. BRDSTK - CONVEN. REAR - $<50 \% \mathrm{H}$

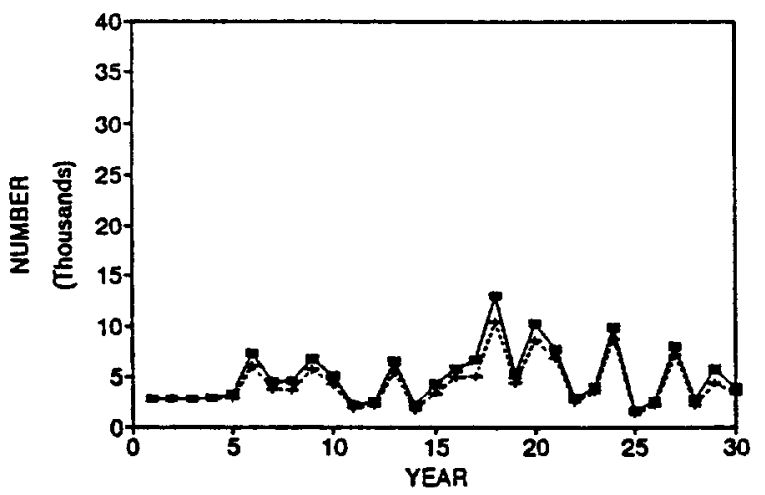

NATURAL SPAWNERS - RUN 2

LOCAL BRDSTK - CONVEN. REAR. - $<50 \% \mathrm{H}$

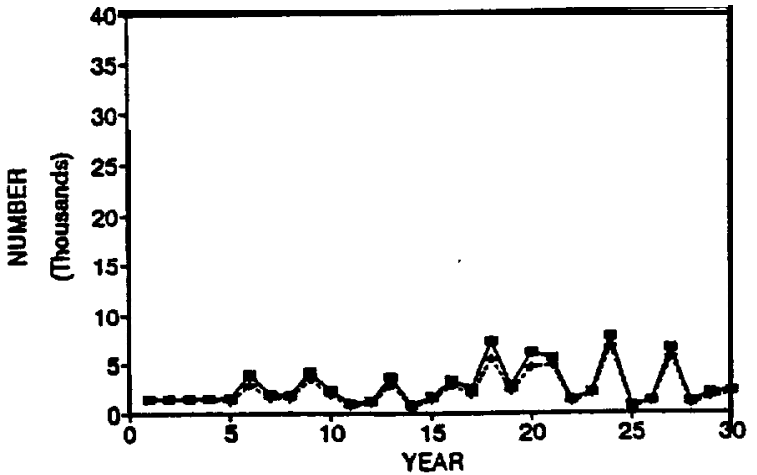

NATURALSPAWNERS-RUN4 LOCAL BRDSTK - INNOVAT. REAR - $<10 \% \mathrm{H}$

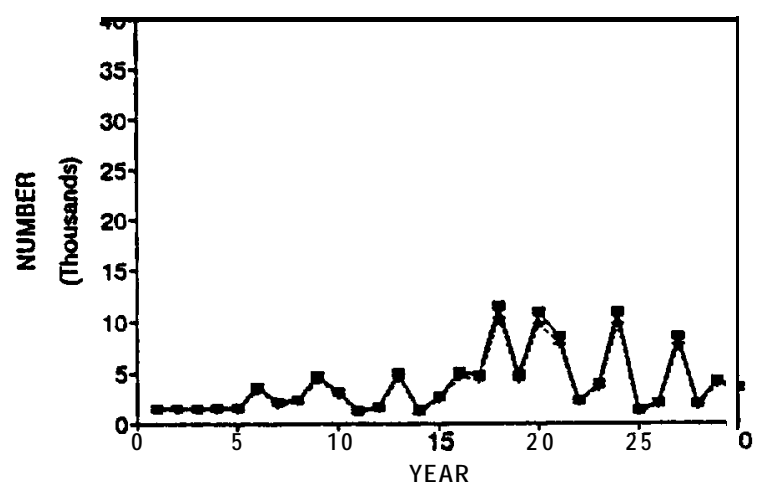

NATURAL SPAWNERS - RUN 6

DSNT. BRDSTK - INNOVAT. REAR. - $<50 \% \mathrm{H}$

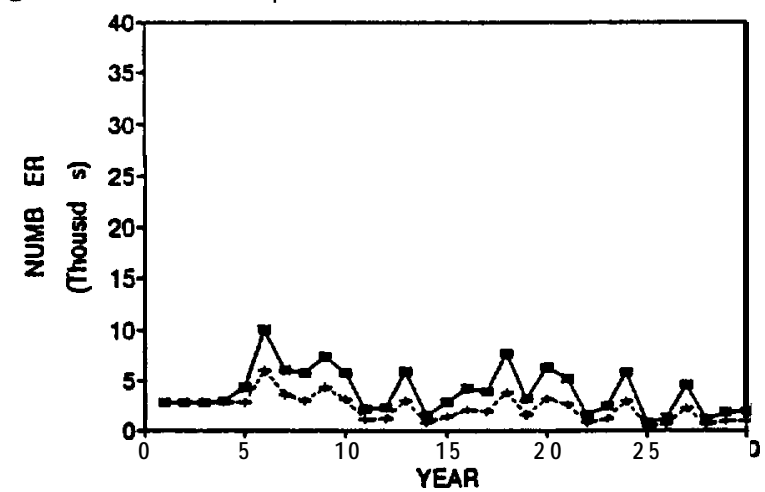

Figure 9. Numbers of natural spawners in a hypothetical Columbia R. subbasin without supplementation (A) and with smolt supplementation (B-F). Supplementation strategies shown use either local or distant brood stock, conventional or innovative rearing, and $10 \%$ or $50 \%$ maximum hatchery spawners allowed on spawning grounds. Totals include hatchery fish spawning in nature. Smolt release goal was two million fish. Genetic recovery scenario III was used. 
A

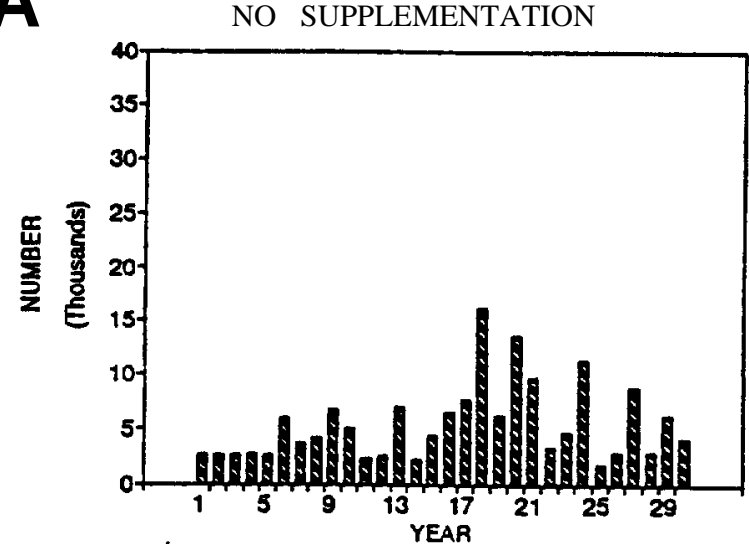

COMPOSITION OF NATURAL SPAWNERS -RUN 3 LOCAL BRDSTK - INNOVAT. REAR $-<50 \% \mathrm{H}$

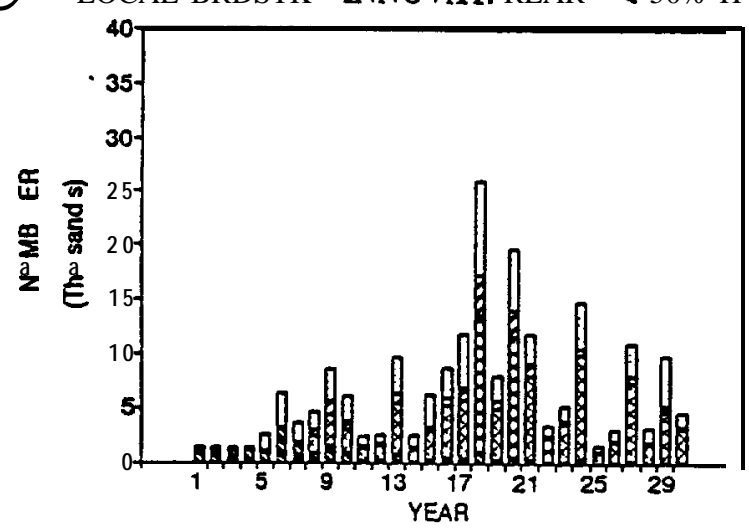

COMPOSITION OF NATURAL SPAWNERS - RUN 5
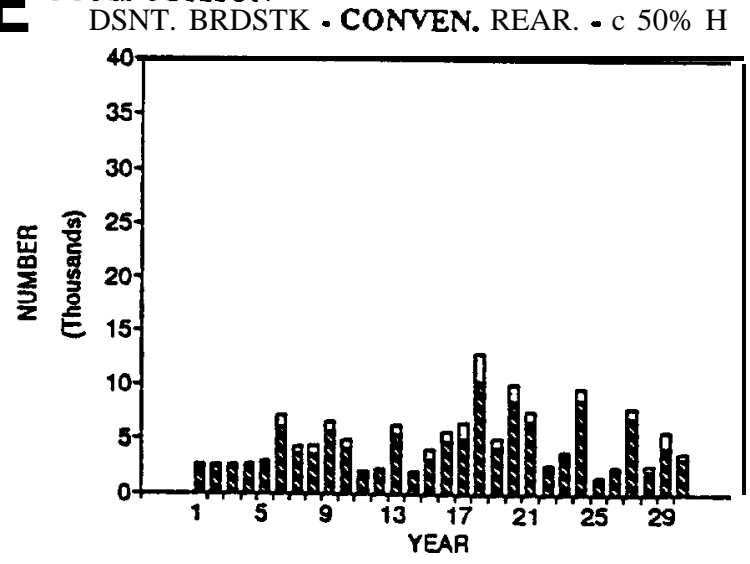

B COMPOSITION OF NATURAL SPAWNERS - RUN 2 LOCAL BRDSTK - CONVEN. REAR. - <50\% H

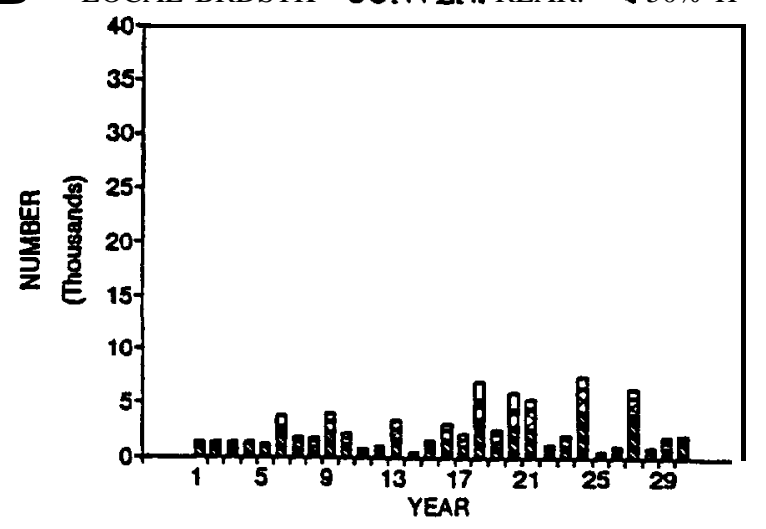

COMPOSITION OF NATURAL SPAWNERS -RUN 4 LOCAL BRDSTK - INNOVAT. REAR - $<\mathbf{1 0 \%} \mathrm{H}$

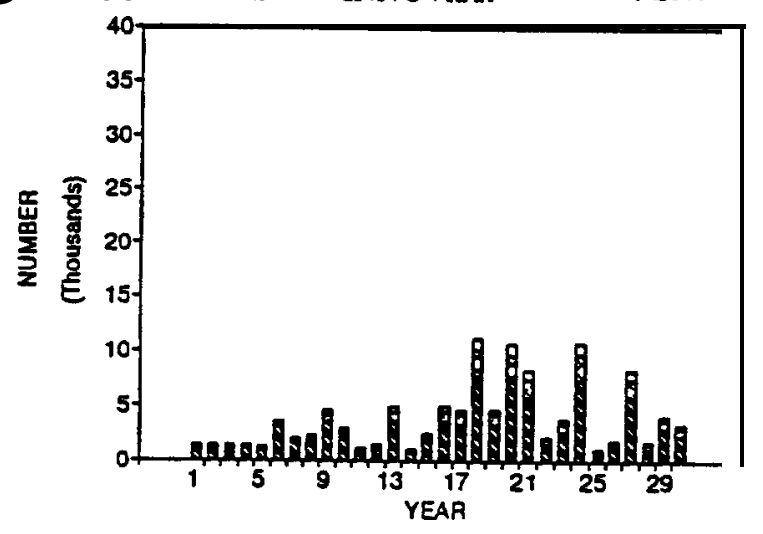

COMPOSITION OF NATURAL SPAWNERS -RUN 6 DSNT. BRDSTK - INNOVAT. REAR, $\bullet<50 \% \mathrm{H}$

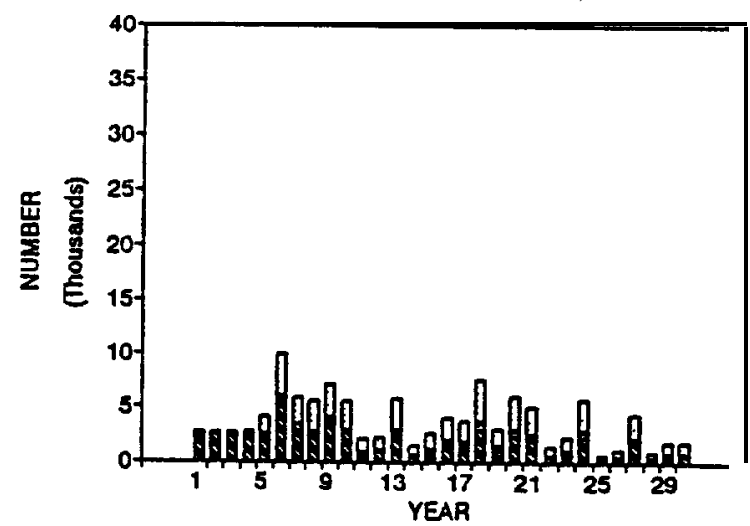

Figure 10. Composition of natural spawners by fish type without supplementation (A) and with smolt supplementation (B-F). Supplementation strategies shown use either local or distant brood stock, conventional or innovative rearing, and $10 \%$ or $50 \%$ maximum hatchery spawners allowed on spawning grounds. Smolt release goal was two million fish. Genetic recovery scenario III was used. 
A

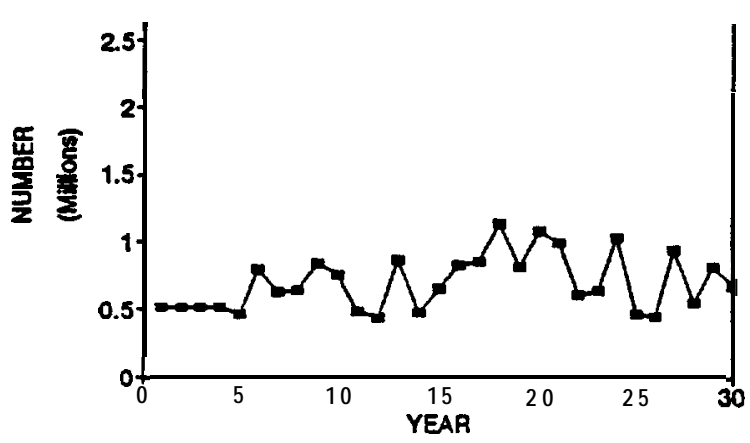

SMOLT YTELD - RUN 3

LOCAL BRDSTK - INNOVAT. REAR. - < $50 \% \mathrm{H}$

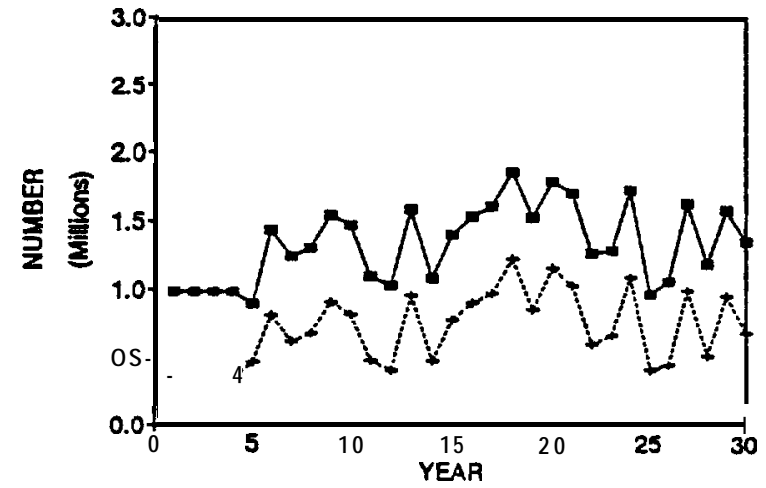

E DSNT. BRDSTK - CONVEN. REAR - $<\mathbf{5 0 \% ~ H}$

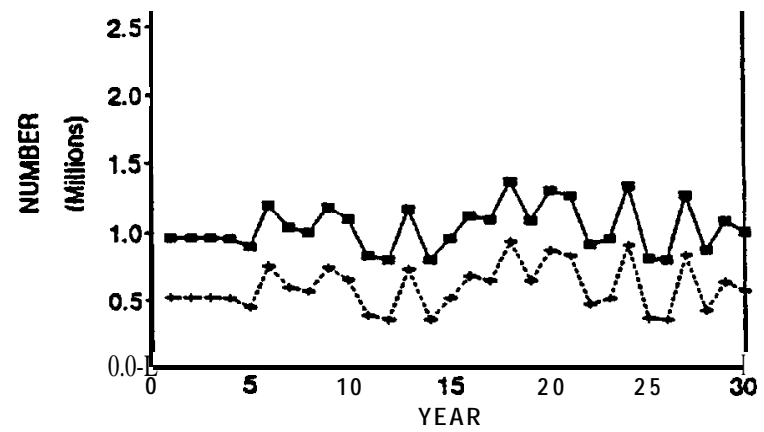

SMOLT YIELD - RUN 2 LOCAL BRDSTK - CONVEN. REAR - $<50 \% \mathrm{H}$

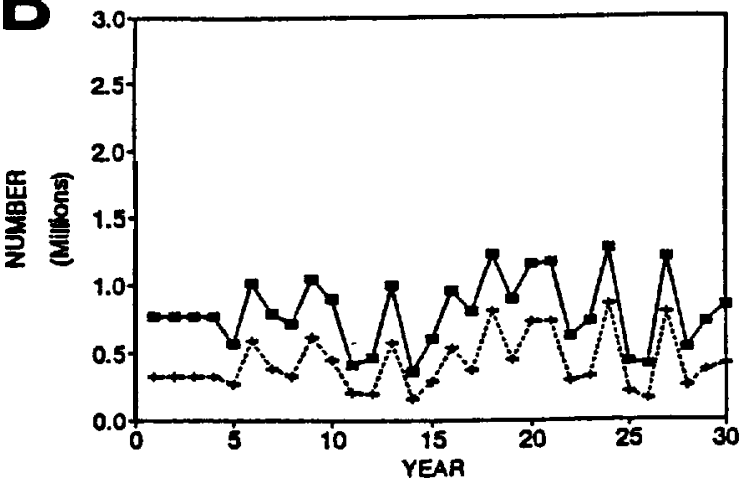

SMOLT YIELD - RUN 4

1 LOCAL BRDSTK - INNOVAT. REAR - < 10\% H

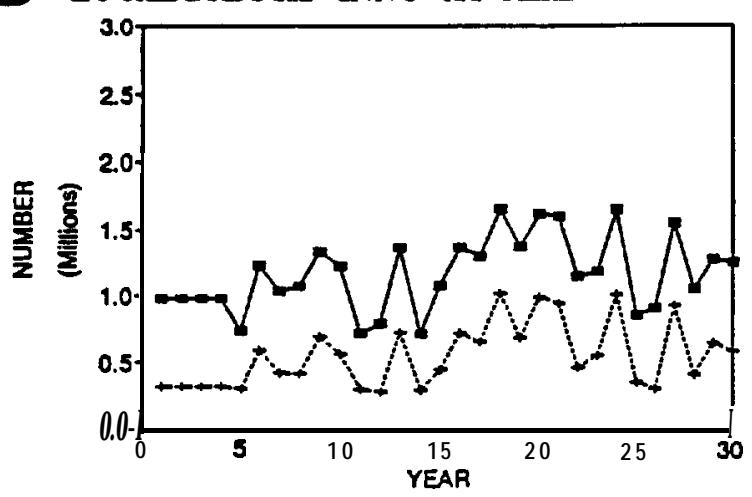

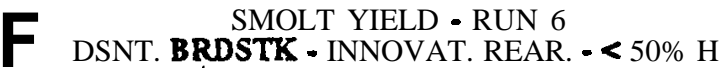

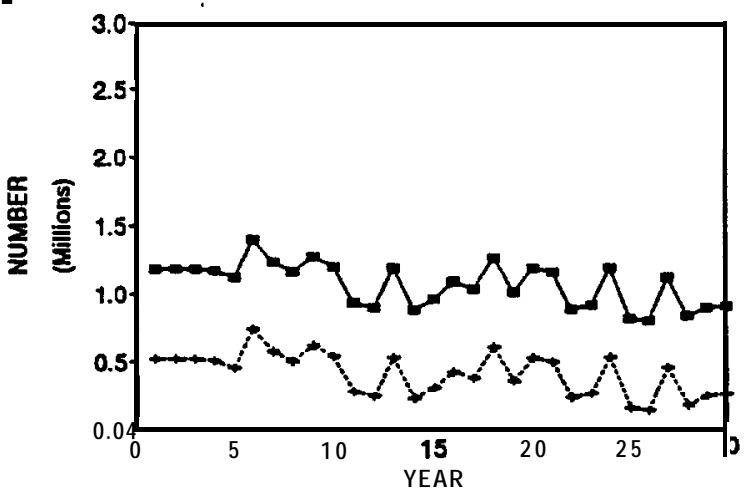

\section{$\rightarrow$ Total $\quad-$ TO+Tl + T2 fish $]$}

Figure 11. Numbers of smolt emigrating from a hypothetical Columbia R. subbasin (at the mouth) without supplementation (A) and with smolt supplementation (B-F). Supplementation strategies shown use either local or distant brood stock, conventional or innovative rearing, and $10 \%$ or $50 \%$ maximum hatchery spawners allowed on spawning grounds. Totals include hatchery produced smolt Smolt release goal was two million fish. Genetic recovery scenario III was used. 
A

RECTS. TO COLUMBIA PLUS HARVEST - RUN 1 NO SUPPLEMENTATION

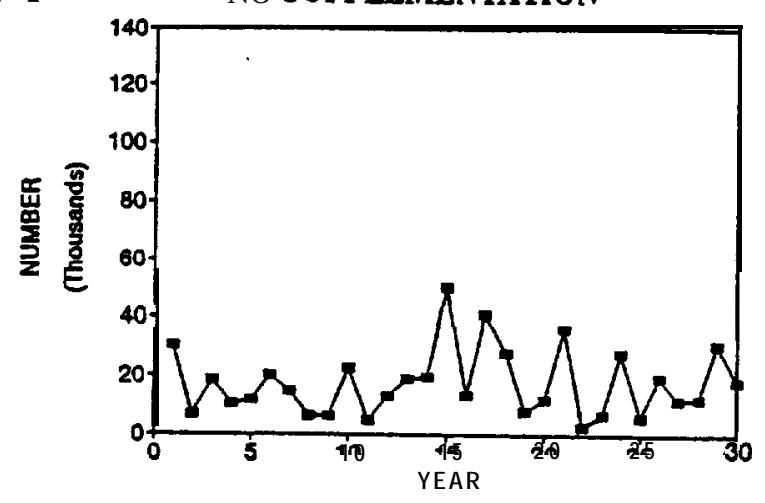

RECTS. TO COLUMBIA PLUS HARVEST - RUN 3 LOCAL BRDSTK - INNOVAT. REAR - $<50 \% \mathrm{H}$

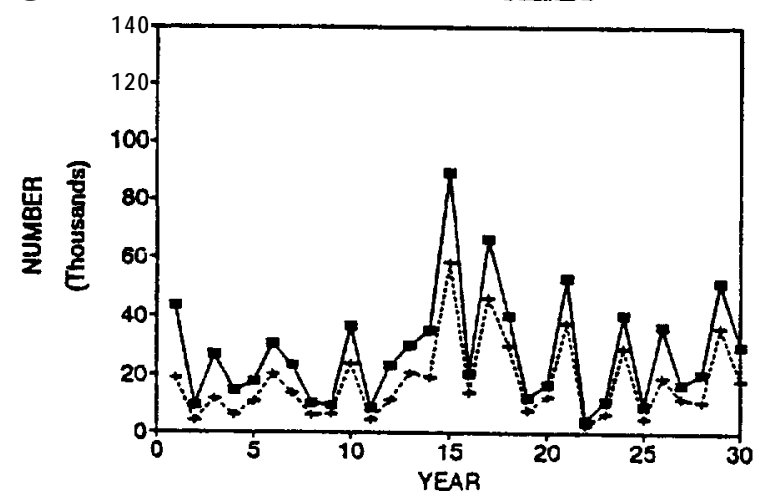

E

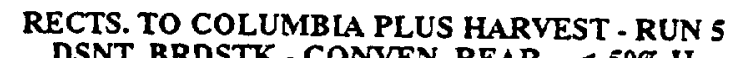
DSNT. BRDSTK - CONVEN. REAR. - <50\% H

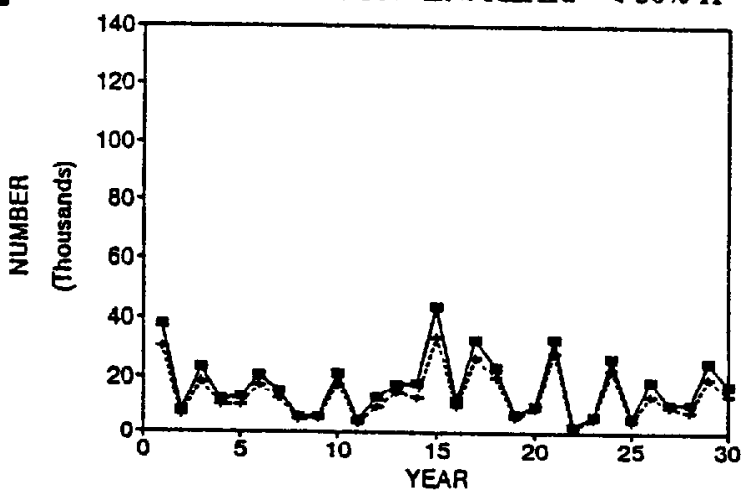

RECTS. TO COLUMBIA PLUS HARVEST - RUN 2 LOCAL BRDSTK - CONVEN. REAR. - <50\% H

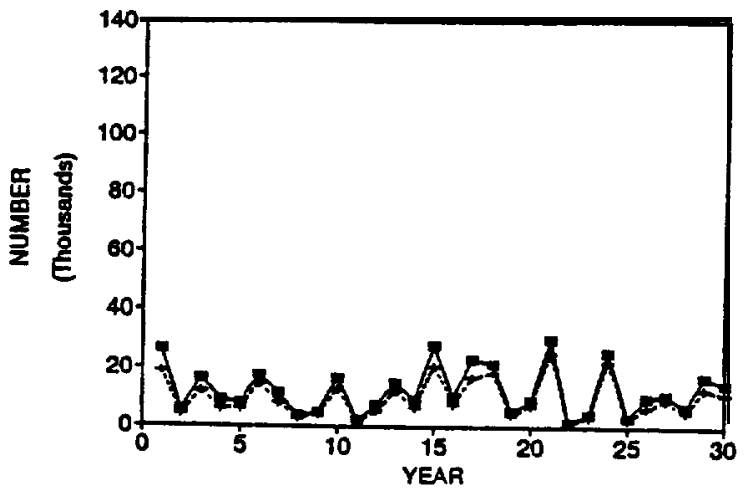

D RECTS. TO COLUMBIA PLUS HARVEST - RUN 4 LOCAL BRDSTK - INNOVAT. REAR - < 10\% H

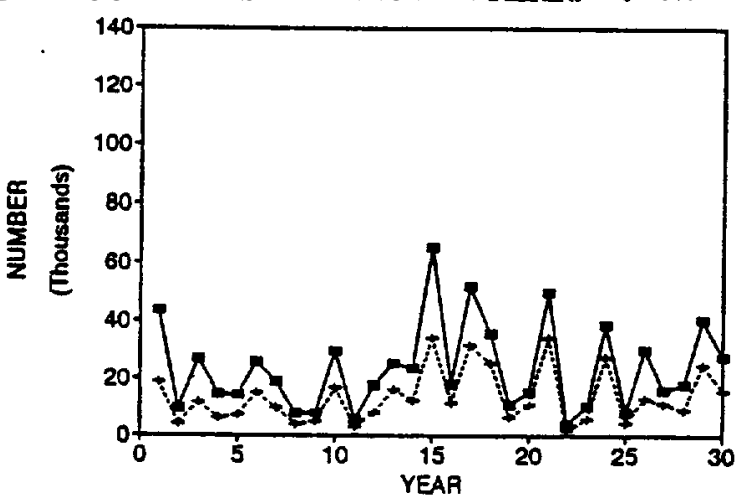

RECTS. TO COLUMBLA PLUS HARVEST - RUN 6 DSNT. BRDSTK - INNOVAT. REAR. - < SO \% H

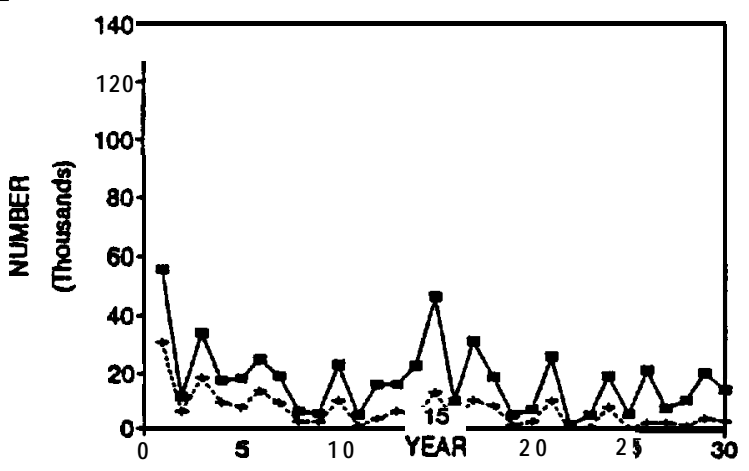

Figure 12. Numbers of adult recruits returning to the Columbia River plus ocean harvest of fish produced in a hypothetical Columbia subbasin without supplementation (A) and with smolt supplementation (B-F). Supplementation strategies shown use either local or distant brood stock, conventional or innovative rearing, and $10 \%$ or $50 \%$ maximum hatchery spawners allowed on spawning grounds. Totals include hatchery produced fish. Smolt release goal was two million fish. Genetic recovery scenario III was used. 

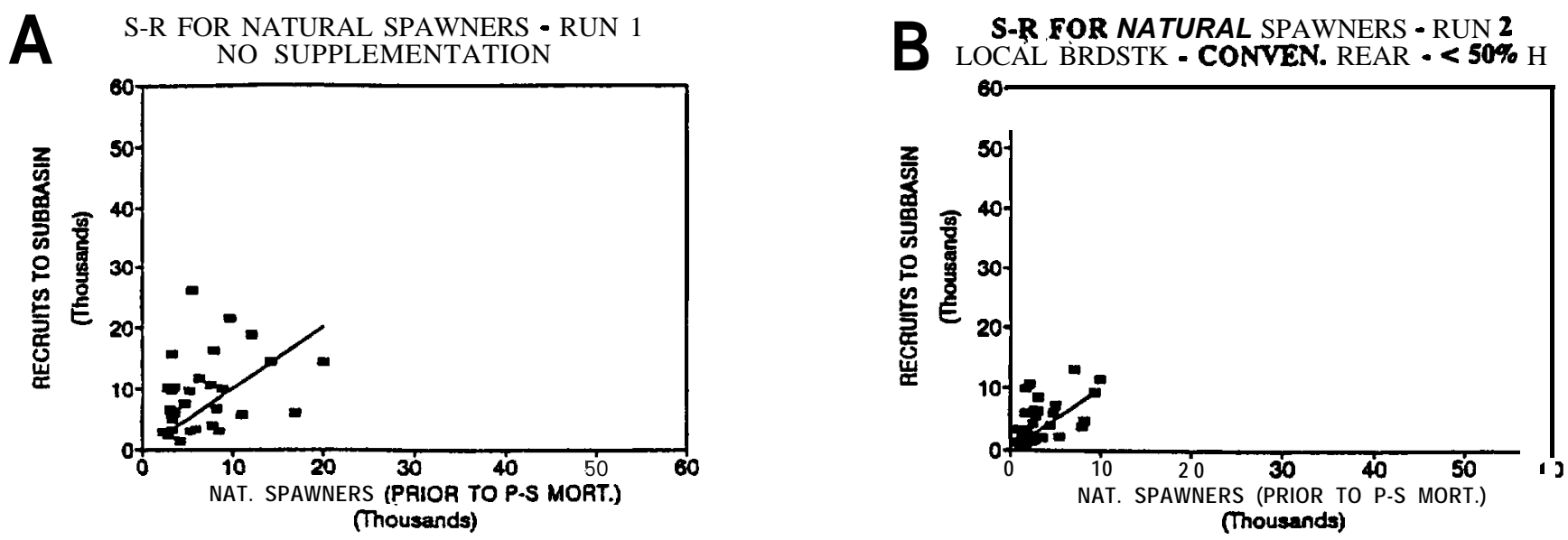

S-R FOR NATURAL SPAWNERS - RUN 3

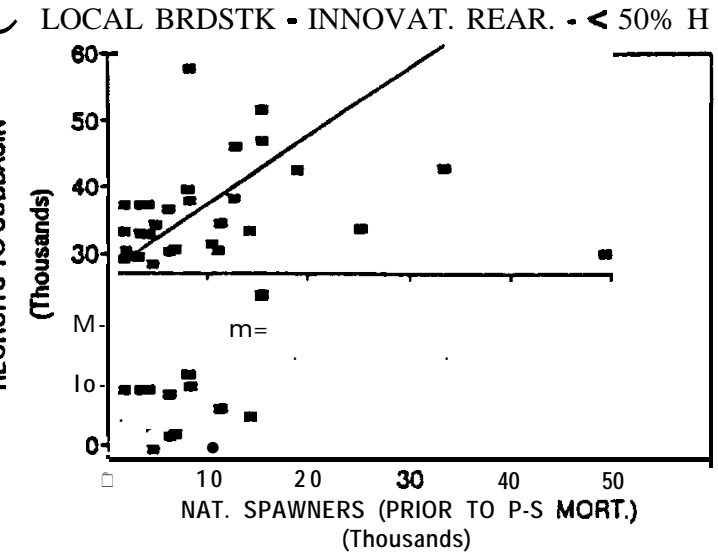

S-R FOR NATURAL SPAWNERS -RUN $\mathbf{5}$

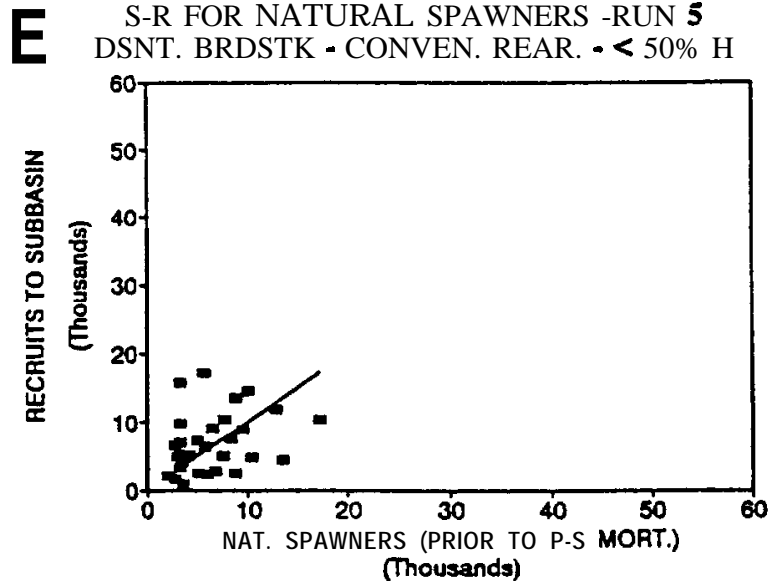

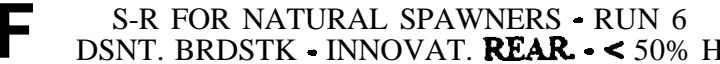
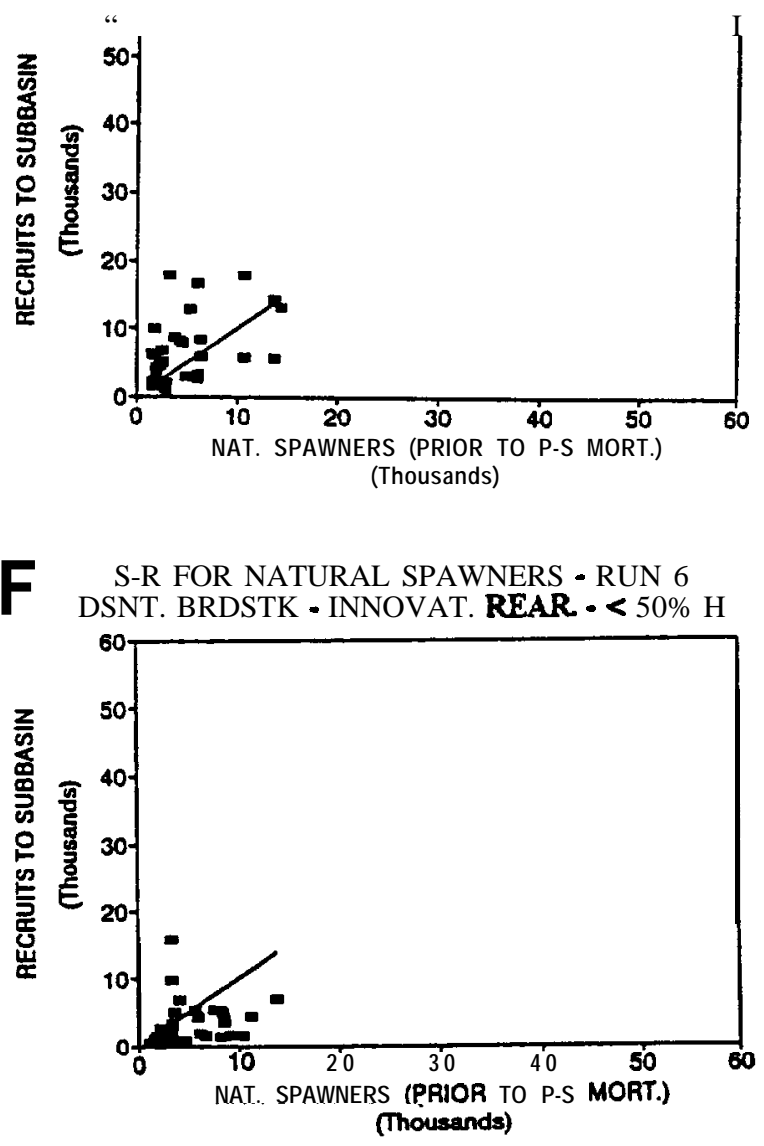

\section{Subbasin recruits - Replacement level ]}

Figure 13. Stock-recruit plots for maturally spawned fish in a hypothetical Columbia R. subbasin without supplementation (A) and with smolt supplementation (B-F). Supplementation strategies shown use either local or distant brood stock, conventional or innovative rearing, and $10 \%$ or $50 \%$ maximum hatchery spawners allowed on spawning grounds. Smolt release goal was two million fish Genetic recovery scenario III was used. 
A R/S FOR NATURAL SPAWNERS - RUN 1

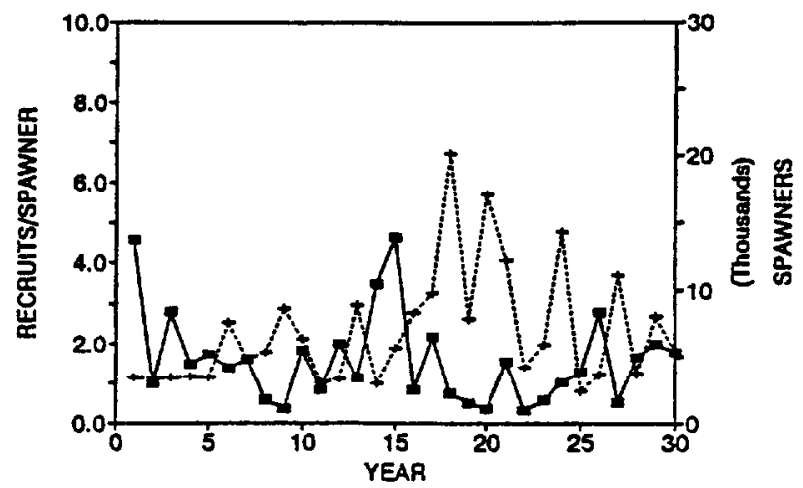

C R/S FOR NATURAL SPAWNERS -RUN 3

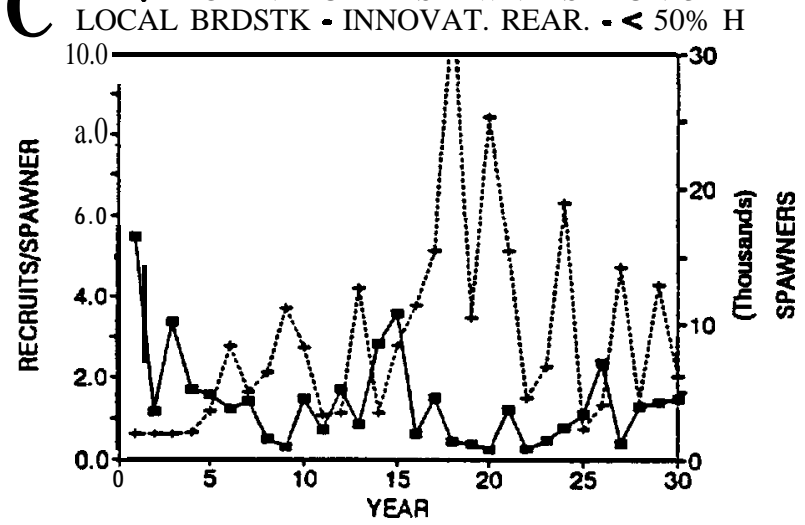

E R/S FOR NATURAL SPAWNERS -RUN 5

E DSNT. BRDSTK - CONVEN. REAR. - < SO\% H

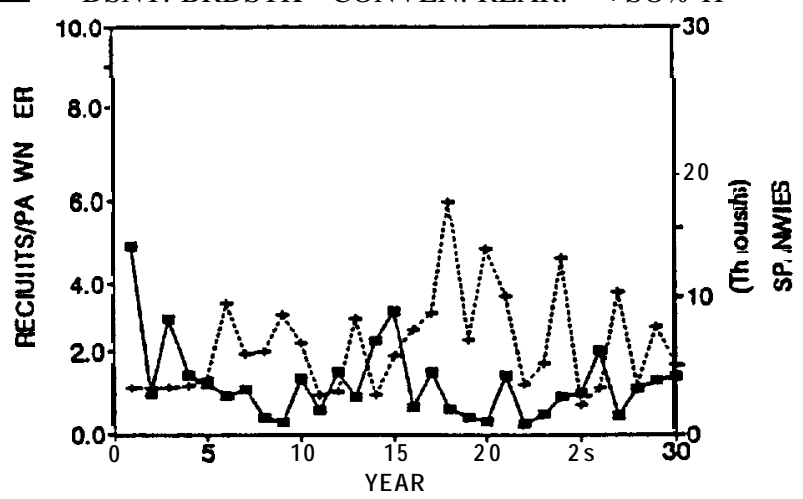

WS FOR NATURAL SPAWNERS • RUN 2

$B$ LOCAL BRDSTK - CONVEN. REAR $-<50 \% \mathrm{H}$

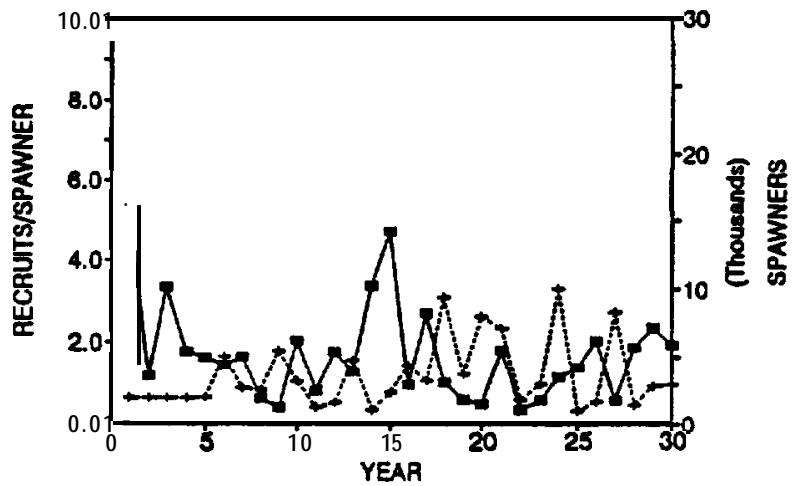

R/S FOR NATURAL SPAWNERS - RUN 4

DOCAL BRDSTK - INNOVAT. REAR - < 10\% H

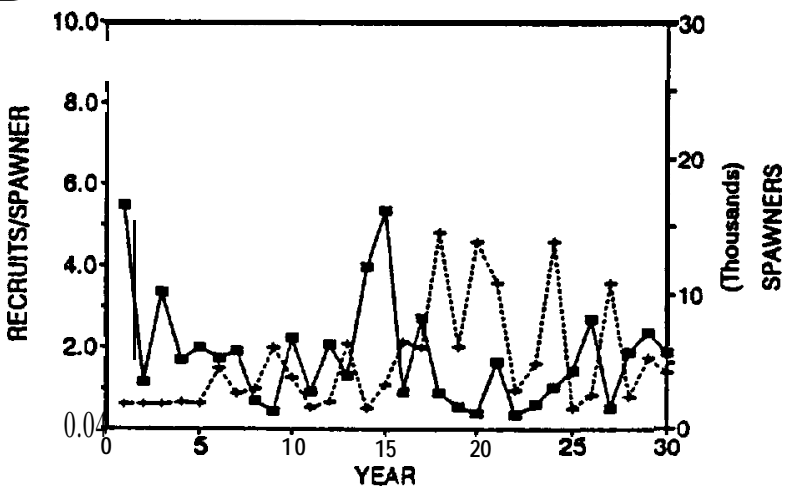

E R/S FOR NATURAL SPAWNERS - RUN 6

- DSNT. BRDSTK - INNOVAT. REAR - $<50 \% \mathrm{H}$

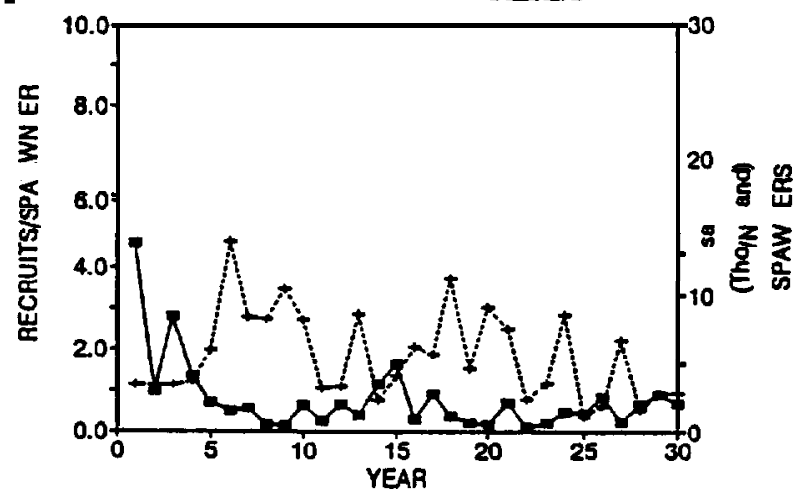

Figure 14. Recruits (back to subbasin) per natural spawner in a hypothetical Columbia R. subbasin without supplementation (A) and with smolt supplementation (B-F). Supplementation strategies shown use either local or distant brood stock, conventional or innovative rearing, and 1096 or $50 \%$ maximum hatchery spawners allowed on spawning grounds. Smolt release goal was two million fish. Genetic recovery scenario III was used. 
propagation. In the latter example, hatchery produced smolts survived and reproduced very poorly, which ultimately had less adverse effect on natural productivity than if more of the hatchery fish had survived and returned to spawn naturally.

However, in Run 6 adverse effects increased. Innovative culture practices in Run 6 improved the survival of hatchery fish, resulting in more hatchery fish returning to spawn naturally in years 6-10 when compared to Run 5. The additional spawners of hatchery origin increased interbreeding between natural and hatchery fish causing a decline in natural productivity over the time period modelled (see Figures 9, 11, 13, and 14).

Changing the genetic recovery scenario from III to either I or II (see Table 5 and Figure 6) for Run 2 (local broodstock, conventional culture practices) resulted in relatively small changes in natural spawner abundance and natural smolt yields (Figure 15). A change from Scenario III to II for Run 6, caused the natural stock to approach extinction at the end of 30 years (Figure 16).

More dramatic changes are produced if smolt survival within the subbasin is assumed to be density-dependent, as would occur if predation is related to the abundance of salmon smolts. If a Type III functional response by predators (see Figure 8) is assumed, for example, natural production is increased significantly by supplementing with local broodstock and conventional culture practices (Figure 17). This result differs markedly from Run 2. The poorer performance by hatchery fish during downstream migration in this case actually helps naturally produced smolts because hatchery smolts are more easily consumed by predators. In that example, the natural population moves from a lower stability domain to a higher one.

\section{REGIONAL COORDINATION OF RESEARCH AND MONITORING}

The concept of a regionally coordinated research and monitoring program in the Columbia Basin has received a great deal of attention. The NPPC formed the Monitoring and Evaluation Group (MEG) to develop the concepts and recent amendments to the FWP call for coordinated implementation, monitoring and evaluation of the program (NPPC 1992). Regional assessment and coordination would increase the efficiency and effectiveness of supplementation M\&E by incorporating sound scientific principles such as strong inference (Platt 1964) uniformly into the design of individual projects, eliminating unnecessary duplication of research, and facilitating the implementation of new information by improving communication of results. In addition, coordination based on a hierarchial organization can address broader and more powerful experiments and resolve uncertainties that individual projects cannot address.

Below we describe the basic elements of a regionally coordinated M\&E program including a proposed program structure, a means of classifying supplementation programs in order to 
NATURAL SPAWNERS - SCN 1

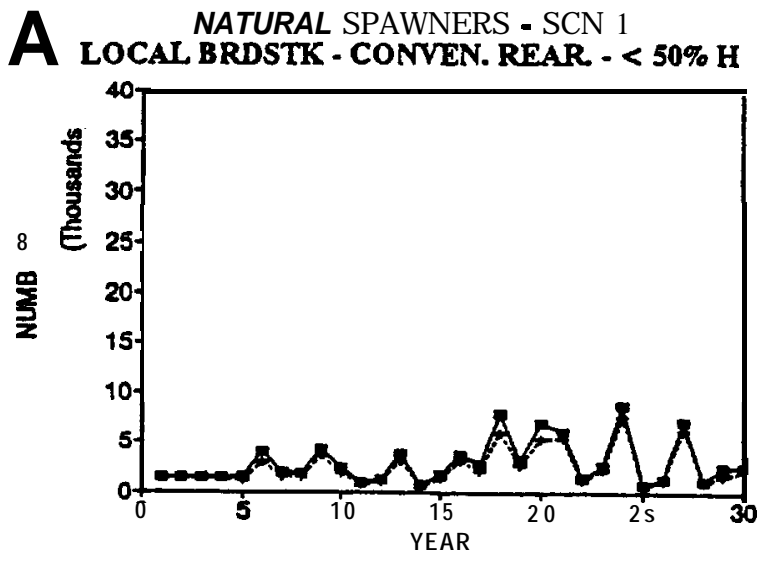

C LOCAL BRDSTK - CONVEN. REAR. $-<50 \%$ H

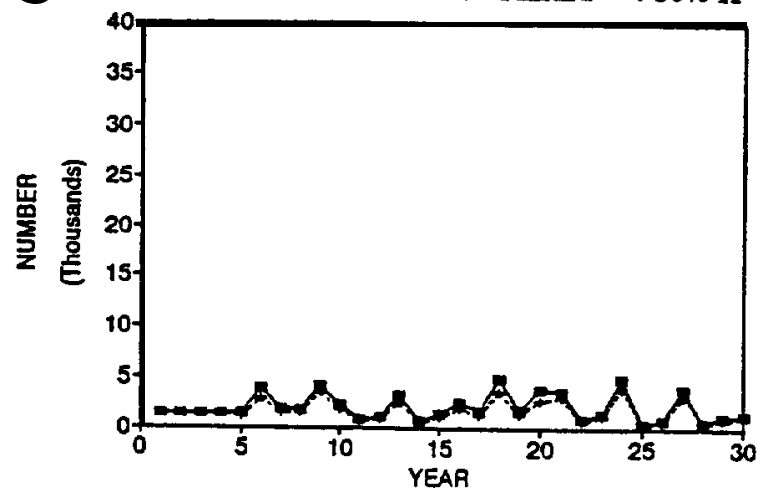

NATURAL SPAWNERS - SCN 3

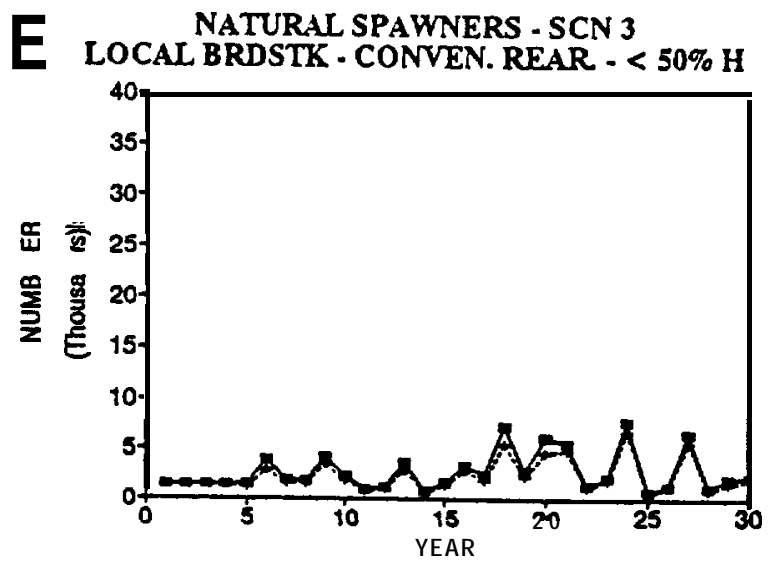

SMOLT YTELD - SCN 1

B LOCAL BRDSTK - CONVEN. REAR - < 50\% H

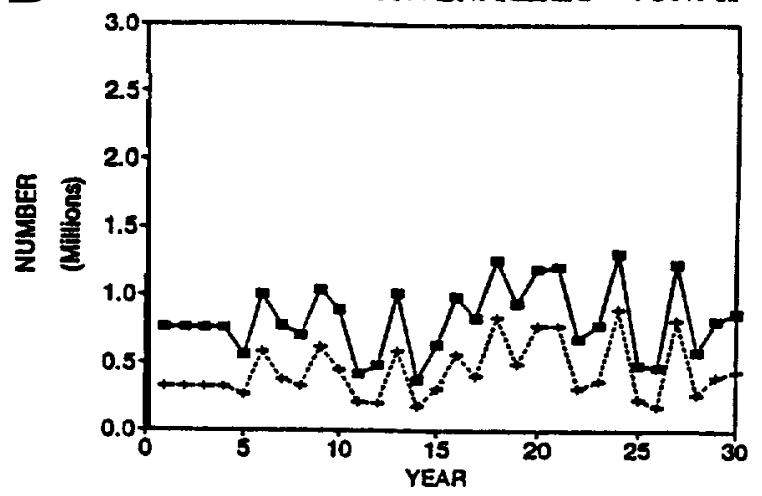

SMOLT YIELD - SCN 2

D LOCAL BRDSTK - CONVEN. REAR - < 50\% H

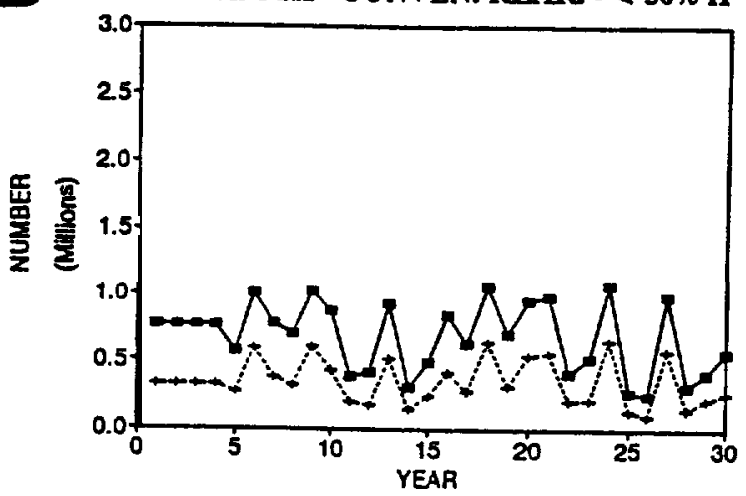

E SMOLT YIELD - SCN 3

LOCAL BRDSTK - CONVEN. REAR - $<50 \% \mathrm{H}$

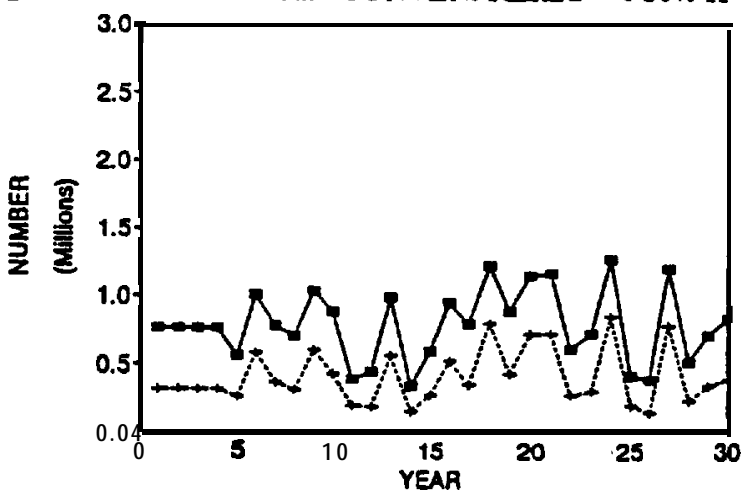

Figure 15. Comparison of the numbers of natural spawners $(\mathbf{A}, \mathbf{C}, \mathbf{E})$ and smolts emigrating from subbasin $(B, D, F)$ under genetic recovery scenarios I, It, and III with smolt supplementation using local brood stock and conventional rearing (Run 2). Smolt release goal was two million fish. Totals include hatchery fish. 
A DSNT. BRDSTK - INNOVAT. REAR. $-<50 \% \mathrm{H}$

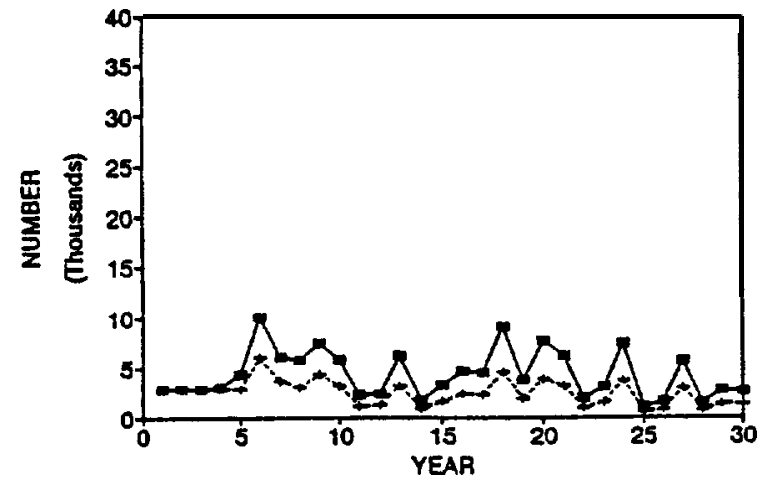

$C$ NATURAL SPAWNERS - SCN 2

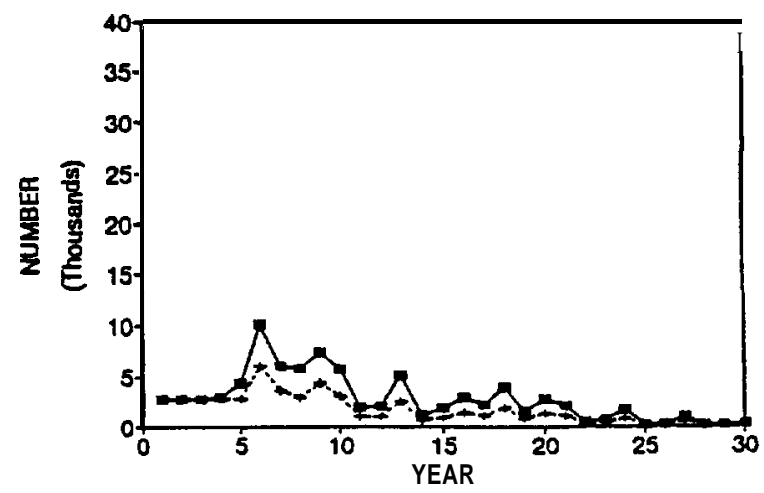

E DSNT. BRDSTK - INNOVAT. REAR. $-<\mathbf{5 0 \%} \mathrm{H}$

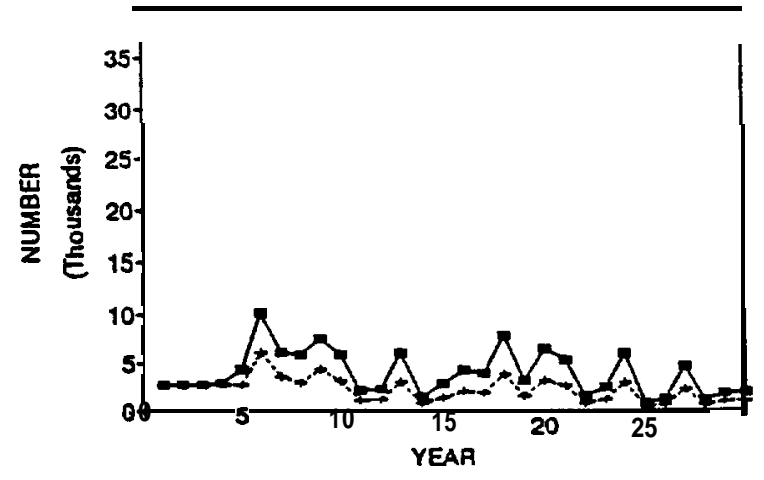

SMOLT YIELD - SCN 1

B DSNT. BRDSTK - INNOVAT. REAR - < 50\% H

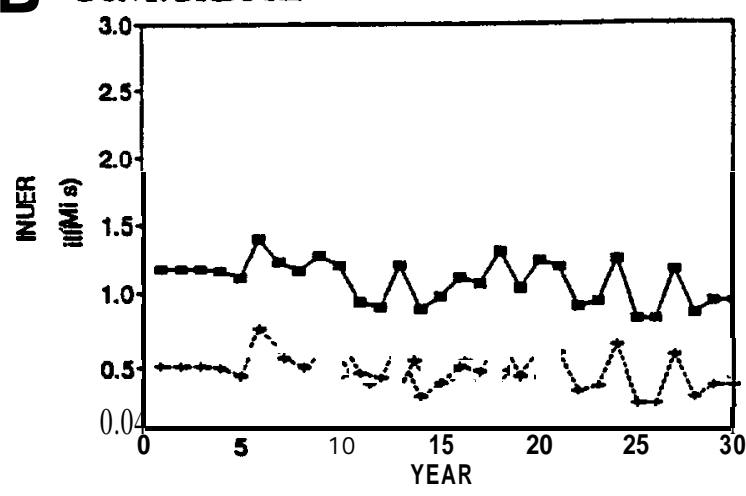

SMOLT YIELD - SCN 2
DSNT. BRDSTK - INNOVAT. REAR - $<50 \% \mathrm{H}$ 3.0

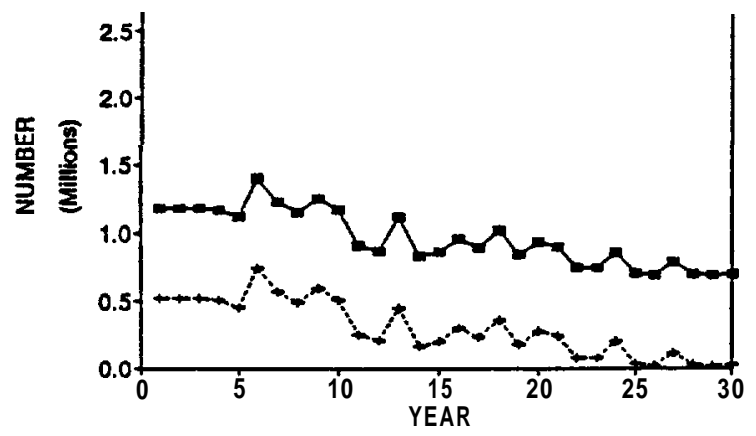

E SMOLT YIELD - SCN 3

- DSNT. BRDSTK - INNOVAT. REAR - $<50 \% \mathrm{H}$

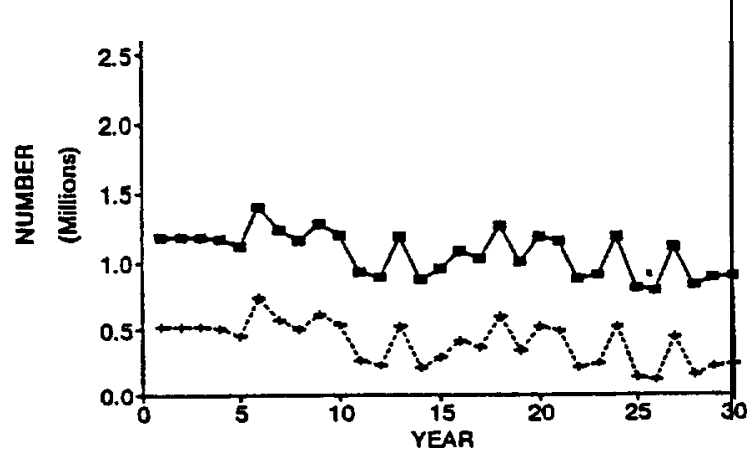

Figure 16. Comparison of the numbers of natural spawners (A,C,E) and smolts emigrating from subbasin $(\mathrm{B}, \mathrm{D}, \mathrm{F})$ under genetic recovery scenarios I, II, and III with smolt supplementation using distant brood stock and innovative rearing (Run 6). Smolt release goal was two million fish. Totals include hatchery fish. 


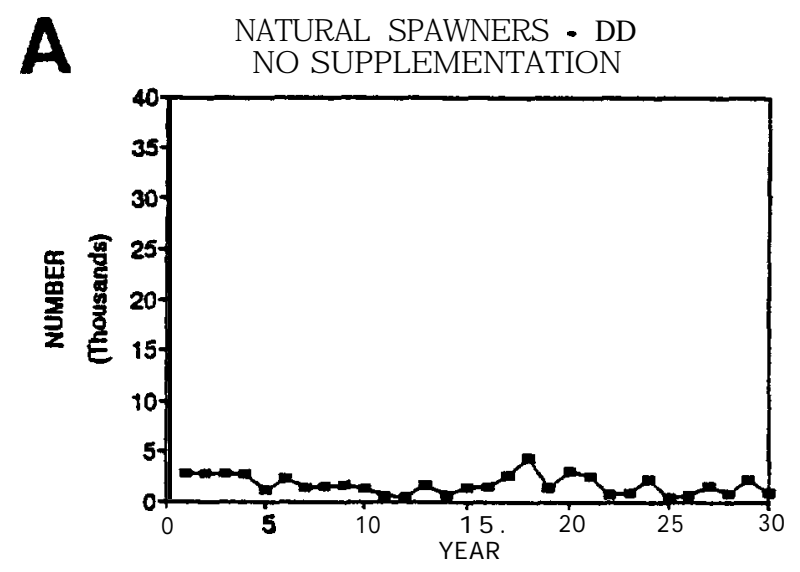

NATURAL SPAWNERS - DD

LOCAL BRDSTK - CONVEN. REAR - $<50 \% \mathrm{H}$
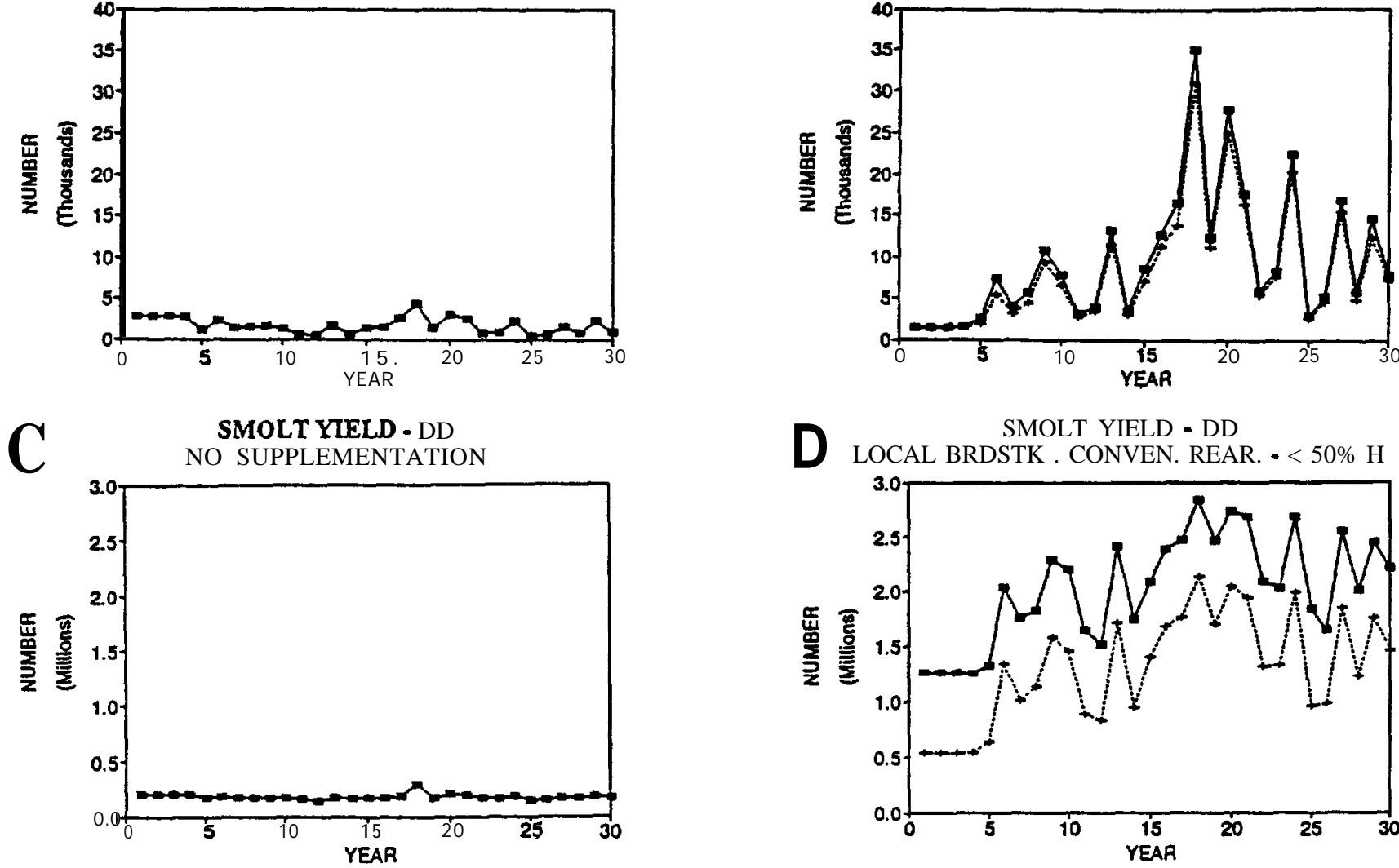

SMOLT YIELD - DD

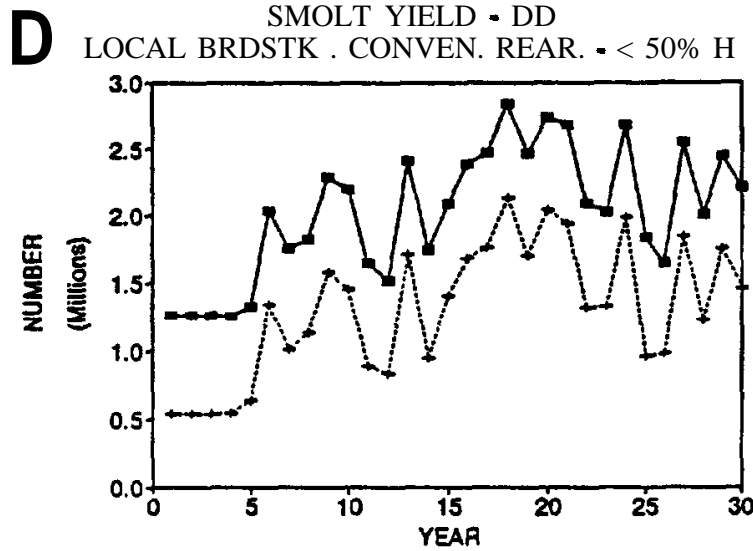

\section{$\rightarrow$ Total $\quad+\cdots$ T0+T1+T2 fish}

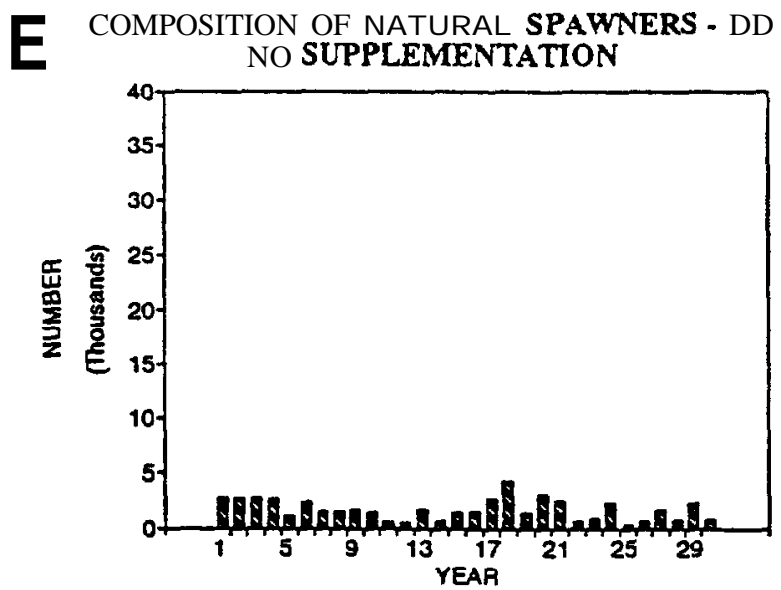

F COMPOSITION OF NATURAL SPAWNERS - DD

\section{T0 fish T1 fish}

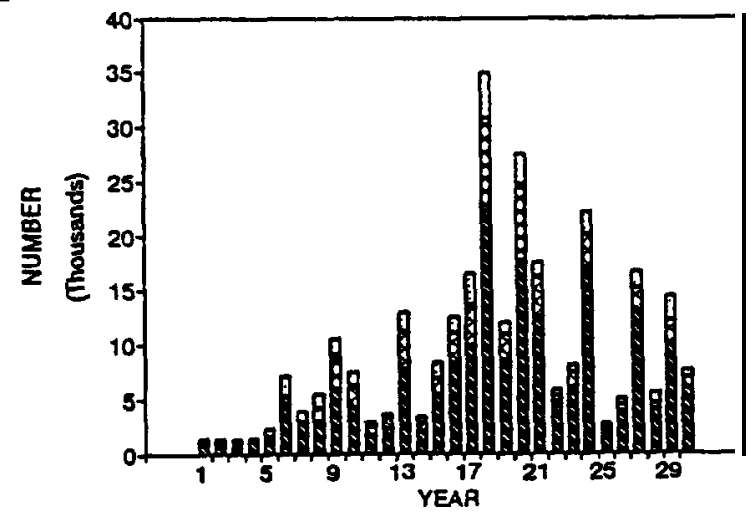

Figure 17. Numbers of natural spawners (A,B), smolts emigrating from subbasin (C,D), and composition of natural spawners (E,F) assuming a Type III functional response of predators during the smolt migration out of the subbasin. Results without supplementation $(A, C, E)$ are compared to those with supplemenation $(\mathbf{B}, \mathbf{D}, \mathbf{F})$ using local broodstock and conventional rearing. The smolt release goal was two million. 
permit similar programs to be grouped, and basic design considerations for an $\mathrm{M} \& \mathrm{E}$ program.

\section{Program structure}

In its simplest form, a regionally coordinated supplementation "program" might consist of a hierarchical arrangement of questions or uncertainties. At the lowest levels, uncertainties apply to and are addressed at individual projects, such as experiments to maximize smolt-toadult survival through manipulation of the size and time of release, experiments to minimize the effects of post-release competition between hatchery and wild fish, and the development of hatchery-release practices that circumvent specific habitat problems such as passage of hatchery-reared fish at irrigation diversions.

Some experiments cannot be conducted at a single project, but require the analysis of information obtained from several different projects, for example, production testing of new disease treatments and new feed formulations. In addition, the answer to some questions requires information collected from the entire basin or from the entire supplementation program. Some of those questions are: Is there a different response to supplementation in subbasins subjected to different levels or types of development or habitat degradation? Does natural production in the subbasins with different levels of habitat degradation respond differently to different supplementation strategies? To what degree are the responses to supplementation determined by survival at low density $\left(\mathbf{S}_{0}\right)$, the productivity parameter in the SPM?

A hierarchical organization of research and monitoring operates most efficiently if each level's activities are organized so they contribute to the resolution of questions at the next level. In this framework, experiments at one level in the hierarchy become experimental units (treatment and control) in the experimental design of the next-higher level. This kind of multiple use of information requires a high degree of integration. A program organized around a hierarchical set of questions implies a central administrative function with responsibility to coordinate project design and compile, analyze, and disseminate new information. In fact, the broader questions, those that require information from several different projects, will not be addressed or resolved without central coordination.

Any regional organization of an $M \& E$ program, even a simple, hierarchical ordering of the questions requires internal consistency, i.e., a common framework for the project and $M \& E$ planning at each level in the program. For the supplementation program, internal consistency can be achieved through a modification of the Patient-Template Analysis (PTA). PTA, as described in Part III of this series, is the basic framework for supplementation planning at the project level. It is a procedure for comparing the historic and current life history and habitat relationships in a stock targeted for supplementation. This comparison leads to a diagnosis of production bottlenecks and a recommended treatment. The PTA focuses on the subbasin as

RASP Summary Report Series, Part IV: Supplementation Model and Regional Coordination 
the physical unit and life histories within a stock as the biological unit. However the concepts embodied in the PTA could be extended to address questions at higher or lower levels in a hierarchy.

Table 8 illustrates a framework for a regionally coordinated supplementation program based on a hierarchial PTA analysis. The three levels of organization are: 1) the entire supplementation program within the Columbia Basin, 2) a specific hatchery program within a subbasin, and 3) specific lots of fish and supplemented stream reaches. Table 9 lists examples of questions, the basic elements of a PTA analysis, and M\&E activities for each of the levels.

In Part III, RASP presented tables that identified information needed to complete a PTA analysis at the hatchery/subbasin level. Table 9 extends the PTA analysis to the basin/supplementation program level. The basin level PTA analysis is comprised of three life stages: juvenile migration, estuarine and ocean rearing, and adult migration.

\section{Classification}

An important first step in the organization of projects within a regional framework is their classification into clusters with similar attributes. This is essentially an inventory of the resources (project level M\&E activities) available to address questions with broad application. RASP designed an M\&E survey of planned and ongoing supplementation projects to complement the earlier survey of projects, streams and strategies (SUPQUEST). The complete survey will provide the basic information needed to organize the regionally coordinated M\&E.

\section{Design Considerations}

Part III gives a detailed discussion of experimental design for project level M\&E. The basic principles are applicable to the design of $M \& E$ at other levels. One way to illustrate a regionally coordinated $\mathrm{M} \& \mathrm{E}$ is through a series of matrices where each level is folded into the matrix at the next higher level (Figure 18 ). Each matrix is defined by the experimental controls and treatments needed to test a hypothesis or address a specific question. Specific sampling units, which are the internal elements of the matrices are not shown, but they consist of variables and replicates. 
Table 8. Hierarchical organization of questions, components of PTA analysis, and M\&E activities in a regionally coordinated supplementation program. The entries under each category are examples and not intended to represent a complete list.

\begin{tabular}{|c|c|c|}
\hline Questions & PTA Analysis & M \& E Activities \\
\hline $\begin{array}{l}\text { Basin/Hatchery Program } \\
\text { 1. What level of increased benefits of } \\
\text { supplementation can we expect from various } \\
\text { levels of improved down stream migration? } \\
\text { 2. How many sanctuaries should be maintained } \\
\text { in the basin i.e., What is the ideal ratio of } \\
\text { supplemented to non-supplemented population } \\
\text { in the basin. } \\
\text { 3. What are realistic expectations for } \\
\text { supplementation: } \\
\text { A) In the upper VS lower basin; } \\
\text { B) In subbasins with different levels } \\
\text { of habitat degradation; and } \\
\text { C) In subbasins with different } \\
\text { geologic and biotic composition. } \\
\text { 4. Does ocean migration, upwelling, or } \\
\text { configuration of the Columbia River plume } \\
\text { influence supplementation expectations? }\end{array}$ & $\begin{array}{l}\text { Basin/HatchervProgram } \\
\text { Juvenile Migration } \\
\text { 1. Timing in relation to hydrograph } \\
\text { 2. Survival at dams } \\
\text { 3. Relationship between flow and } \\
\text { migration rate and survival } \\
\text { Estuarine and ocean rearing } \\
\text { 1. Timing of ocean entry } \\
\text { 2. Ocean distribution } \\
\text { 3. Influence of ocean conditions on } \\
\text { stock productivity } \\
\text { 4. Ocean harvest } \\
\text { 5. Predation } \\
\text { Adult migration } \\
\text { 1. Timing } \\
\text { 2. River harvest } \\
\text { 3. Survival/passage at dams } \\
\text { 4. Factors influencing entry into } \\
\text { subbasin }\end{array}$ & $\begin{array}{l}\text { Basin/Hatcherv Program } \\
\text { 1. Survival of juveniles or adults between } \\
\text { mainstem reaches. } \\
\text { 2. Rate of migration vs flow. } \\
\text { 3. Basin-wide inventory of the quality and } \\
\text { quantity of spawning and rearing habitat. } \\
\text { 4. Monitor critical ocean/estuarine } \\
\text { environmental variables. } \\
\text { 5. Monitor contribution from individual } \\
\text { supplementation projects throughout the } \\
\text { basin. } \\
\text { 6. Classify habitat in supplemented } \\
\text { subbasins. }\end{array}$ \\
\hline
\end{tabular}


Table 8 , contd.

\section{Subbasin/Hatchery.}

1. What changes in conventional hatchery facilities and practices are required to convert them to supplementation?

2. Within a target stream, what ratio of hatchery to natural fish (juveniles and adults) in natural production areas is optimal?

3. What minimal return per hatchery spawner is needed to make supplementation an acceptable management strategy?

4. What supplementation strategies/practices minimize effects on non-target populations?

5. Is there a way to supplement specific life history types within a subbasin?

6. Can supplementation increase natural production without a cost to natural productivity?

7. What hatchery practices, such as size and time of release, achieve the natural production goals of supplementation?

\section{Subbasin/Hatchery}

Spawning and Incubation

1. Habitat quality and quantity

2. Spawning timing

3. Prespawning mortality

4. Age structure and sex ratio of the spawning population

\section{Spring/Summer Rearing}

1. Habitat quality and quantity

2. Density, growth, and survival

3. Species interaction

\section{Fall/Winter Rearing}

1. Habitat quality and quantity

2. Density, growth, and survival

3. Species interaction

\section{Presmolt migration}

1. Timing

2. Survival and blockages

Smolt Migration

1. Timing

2. Species interaction

\section{Subbasin/Hatchery}

1. Monitor seeding level of supplemented habitat.

2. Monitor distribution and abundance of natural- and hatchery-origin spawners,

3. Monitor timing of juvenile migration (hatchery and natural fish).

4. Monitor production of non-target species.

5. Test planning assumptions regarding the effect of alternative hatchery practices on post-release survival and reproductive success of supplemented fish.

6. Monitor life history-habitat relationships to contain risks and to complete the PTA analysis. 
Table 8, contd.

\section{Reach/hatchery pond}

1. Do hatchery reared fish undergo behavior modification that decreases smolt-adult survival? If yes can it be reversed?

2. How can release densities and methods reduce negative interaction with target and non-target fish in stream reaches?

3. What are the effects of specific waterdevelopment practices such as irrigation diversions on migration and survival and how can they be reduced?

4. What is the optimal distribution of habitat types for summer and winter rearing in stream reaches?

5. How does the distribution of habitat types effect supplementation expectations and strategies?

\section{Reach/Hatcherv Pond}

$\underline{\text { Habitat }}$

1. Pool/riffle ratio

2. Bank stability

3. Cover

Fish Aggregates

1. Density

2. Growth

3. Survival

Hatchery Pond

1. Experimental units for testing alternative rearing and release practices.

\section{Reach/Hatcherv Pond}

1. Monitor reproductive success of spawning aggregates in stream reaches.

2. Monitor habitat utilization, density, and growth of tagged juveniles in supplemented stream reaches.

3. Monitor survival and passage efficiency at irrigation diversions. 
Table 9. Basin level patient - template analysis.

\begin{tabular}{|c|c|c|c|c|c|c|c|c|}
\hline \multirow{2}{*}{$\begin{array}{l}\text { Supplemented } \\
\text { Stock/ } \\
\text { Sub Basins }\end{array}$} & \multicolumn{8}{|c|}{ ADULT MIGRATION (Mainstem) } \\
\hline & & $\begin{array}{c}\text { Mainstem } \\
\text { Migmtion } \\
\text { Timing } \\
\end{array}$ & Hydrograph & $\begin{array}{l}\text { Survivall } \\
\text { Passage } \\
\text { at Dams }\end{array}$ & $\begin{array}{c}\text { River } \\
\text { Harvest }\end{array}$ & $\begin{array}{l}\text { Timing of } \\
\text { sub basin } \\
\text { Entry }\end{array}$ & Hydrograph & $\begin{array}{c}\text { In River } \\
\text { Abundance/ } \\
\text { Dam counts }\end{array}$ \\
\hline$\frac{\text { UPPER BASIN }}{\text { Columbia River }}$ & Patient & & & & & & & \\
\hline Stock A & Template & & & & & & & \\
\hline \multirow[b]{2}{*}{ Stock B } & Patient & & & & & & & \\
\hline & Template & & & & & & & \\
\hline Snake Rive & - Patient & & & & & & & \\
\hline Stock C & Template & & & & & & & \\
\hline \multirow[b]{2}{*}{ Stock D } & Patient & & & & & & & \\
\hline & Template & & & & & & & \\
\hline \multirow[t]{2}{*}{ MIDDLEBASIN } & Patient & & & & & & & \\
\hline & Template & & & & & & & \\
\hline \multirow[b]{2}{*}{ Stock $\mathbf{F}$} & Patient & & & & & & & \\
\hline & Template & & & & & & & \\
\hline \multirow[t]{2}{*}{ LOWER BASIN } & Patient & & & & & & & \\
\hline & Template & & & & & & & \\
\hline \multirow{2}{*}{ Stock G } & Patient & & & & & & & \\
\hline & Template & & & & & & & \\
\hline
\end{tabular}


Table 9 cont'd.

\begin{tabular}{|c|c|c|c|c|c|c|c|c|}
\hline \multirow{2}{*}{$\begin{array}{l}\text { Supplemented } \\
\text { Stocks/ } \\
\text { Sub Basins }\end{array}$} & \multicolumn{8}{|c|}{ ESTUARY AND OCEAN REARING } \\
\hline & & $\begin{array}{l}\text { Timing of } \\
\text { Entry to } \\
\text { Estuary }\end{array}$ & $\begin{array}{c}\text { Duration } \\
\text { of Estuarine } \\
\text { Rearing }\end{array}$ & $\begin{array}{c}\text { species } \\
\text { Interaction } \\
\text { Density }\end{array}$ & $\begin{array}{c}0 \text { cean } \\
\text { Distribution }\end{array}$ & $\begin{array}{l}\text { Influence of } \\
\text { Upwelling or } \\
\text { other Indices } \\
\text { of Productivity }\end{array}$ & $\begin{array}{c}\text { Species } \\
\text { Interaction } \\
\text { Marine } \\
\text { Manuals }\end{array}$ & $\begin{array}{l}0 \text { cean } \\
\text { Harvest }\end{array}$ \\
\hline \multirow{2}{*}{$\begin{array}{r}\text { UPPER BASIN } \\
\text { Columbia River } \\
\text { Stock A } \\
\end{array}$} & Patient & & & & & & & \\
\hline & Template & & & & & & & \\
\hline \multirow[b]{2}{*}{ Stock B } & Patient & & & & & & & \\
\hline & Template & & & & & & & \\
\hline \multirow{2}{*}{$\begin{array}{r}\text { Snake Rive } \\
\text { Stock c }\end{array}$} & Patient & & & & & & & \\
\hline & Template & & & & & & & \\
\hline \multirow[b]{2}{*}{ Stock $\mathbf{D}$} & Patient. & & & & & & & \\
\hline & Template & & & & & & & \\
\hline \multirow[t]{2}{*}{ MIDDLE BASIN } & Patient & & & & & & & \\
\hline & Template & & & & & & & \\
\hline \multirow[b]{2}{*}{ Stock $\mathrm{F}$} & Patient & & & -.- & ...-- & .... & & .------v---w-- \\
\hline & Template & & & & & & & \\
\hline \multirow[t]{2}{*}{ LOWER BASIN } & patient & & & & & & & \\
\hline & Template & & & & & & & \\
\hline \multirow[b]{2}{*}{ stock $\mathbf{H}$} & Patient & & & & & & & \\
\hline & Template & & & & & & & \\
\hline
\end{tabular}


Table 9 cont'd.

\begin{tabular}{|c|c|c|c|c|c|c|c|c|}
\hline \multirow{2}{*}{$\begin{array}{l}\text { Supplemented } \\
\text { Stock }\end{array}$} & \multicolumn{8}{|c|}{ JUVENILE MIGRATION } \\
\hline & & $\begin{array}{l}\text { Timing of } \\
\text { Downstream } \\
\text { Migmtion }\end{array}$ & Hydrograph & $\begin{array}{l}\text { Survival/ } \\
\text { Passage } \\
\text { at Dams }\end{array}$ & $\begin{array}{l}\text { Relationship } \\
\text { Betw een } \\
\text { Flow and } \\
\text { Migmtion } \\
\text { Rate }\end{array}$ & $\begin{array}{c}\text { Species } \\
\text { Interaction } \\
\text { (Density } \\
\text { Predation, } \\
\text { etc.) }\end{array}$ & $\begin{array}{l}\text { Obstacles to } \\
\text { Mainstem } \\
\text { Entry - } \\
\text { From } \\
\text { Sub Basin }\end{array}$ & $\begin{array}{l}\text { Reservoir } \\
\text { Rearing }\end{array}$ \\
\hline \multicolumn{9}{|c|}{$\frac{\text { UPPER BASIN }}{\text { Columbia Rive }}$} \\
\hline \multicolumn{9}{|c|}{ Stock A Template } \\
\hline \multirow[b]{2}{*}{ Stock B } & Patient & & & & & & & \\
\hline & Template & & & & & & & \\
\hline \multirow{2}{*}{$\begin{array}{r}\text { Snake River } \\
\text { Stock C }\end{array}$} & Patient & & & & & & & \\
\hline & Template & & & & & & & \\
\hline \multirow[b]{2}{*}{ Stock D } & Patient & & & & & & & \\
\hline & Template & & & & & & & \\
\hline$\underline{\text { MIDDLE BASIN }}$ & Patient & & & & & & & \\
\hline \multicolumn{9}{|c|}{ Stock E Template } \\
\hline \multirow[b]{2}{*}{ Stock F } & Patient & & & & & & & \\
\hline & Template & & & & & & & \\
\hline$\underline{\text { LOWERBASIN }}$ & Patient & & & & & & & \\
\hline \multirow[t]{2}{*}{ Stock G } & Template & & & & & & & \\
\hline & Patient & & & & & & & \\
\hline \multicolumn{2}{|c|}{ Stock $\mathbf{H}$ Template } & & & & & & & \\
\hline
\end{tabular}




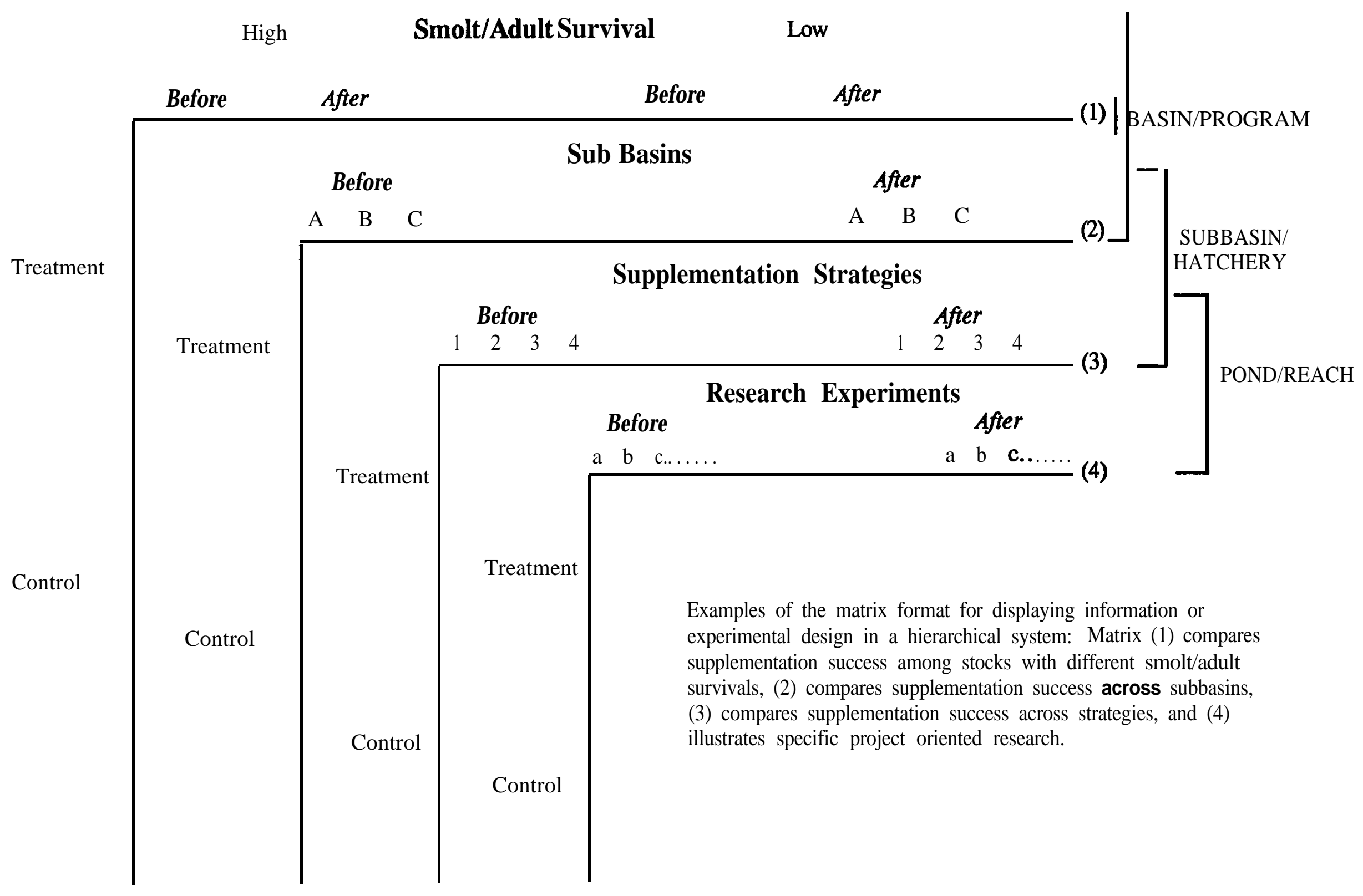

Figure 18. Matrices illustrating the concept of a hierarchical program of global research. Spatial and temporal controls are indicated as well as the relationship between matrices illustrating the three levels discussed in the text. 
Bjomn, T-C., and D.W. Reiser. 1991. Habitat requirements of salmonids in streams. Am. Fish. Soc. Special Publication 19:83-138.

Bjomn, T.C., and C.R. Steward. 1990. Concepts for a model to evaluate supplementation of natural salmon and steelhead stocks with hatchery fish. Technical Report 90-2, Bonneville Power Administration, Portland, OR. 30 p.

Busack, C. 1990. Yakima/Klickitat production project genetic risk assessment. Manuscript. Genetics Unit, Washington Department of Fisheries, Olympia, WA. 21 p.

Byrne, A., T.C. Bjomn, and J.D. McIntyre. 1992. Modeling the response of native steelhead to hatchery supplementation programs in an Idaho River. N. Am. J. Fish. M gt. 12: 62-78.

Columbia Basin Fish and Wildlife Authority. 1991. Integrated system plan. Portland, OR. 527 p.

Falconer, D.S. 1970. Introduction to Q uantitative Genetics. Robert MacLehose and Co. Limited, Glasgow, 365 p.

Fresh, K.L., and S.L. Schroder. 1987. Influence of the abundance, size, and yolk reserves of juvenile chum salmon (O ncorhynchus keta) on predation by freshwater fishes in a small coastal stream. Can. J. Fish. Aquat. Sci. 44: 236-243.

Hilbom, R., and C.J. Walters. 1992. Q uantitative Fisheries Stock Assessment: Choice, Dynamics and Uncertainty. Chapman and Hall, New York, London, 570 p.

Hilbom, R. 1992. Can fisheries agencies learn from experience? Fisheries, 17(4): 6-14.

Hilbom, R. 1987. Living with uncertainty in resource management. N. Am. J. of Fish. M gt. 7(1): $1-5$.

Holling, C.S. 1959. Some characteristics of simple types of predation and parasitism. Can. Entom. 91: $385-398$ 
Hutchings, J.A. 1991. The threat of extinction to native populations experiencing spawning intrusions by cultured Atlantic salmon. Aquaculture, 98:119-132.

Larkin, P.A. 1973. Some observations on models of stock and recruitment relationships for fishes. B.B. Parrish (ed.), in Fish Stocks and Recruitment, Proceedings of a Symposium held in Aarhus, July 7-10, 1970, Denmark, July 7-10, 1970, pp.316324.

Lee, D.C., and J.B. Hyman. 1991. Stochastic life-cycle model (SLCM): A tool for simulating the population dynamics of anadromous salmonids. Resources for the Future, Washington, D.C. 22 p.

Mace, P.M. 1983. Bird predation on juvenile salmonids in the Big Qualicum estuary, Vancouver Island. Can. Tech. Rept. Fish. Aquat. Sci. 1176.

Moussalli, E.I., and R. Hilbom. 1986. Optimal stock size and harvest rate in multistage life history models. Can. J. Fish. Aquat. Sci. 43: 135141.

Northwest Power Planning Council. 1987. Columbia River Basin Fish and Wildlife Program (A mended). 851 SW Sixth Avenue, Suite 1100, Portland, OR.

Northwest Power Planning Council. 1989. Salmon and steelhead systems planning and documentation. Monitoring and Evaluation Group. Northwest Power Planning Council. 851 SW Sixth Avenue, Suite 1100, Portland, OR.

Northwest Power Planning Council. 1992. Strategy for Salmon, Volume II. 851 SW Sixth Avenue, Suite 1100, Portland, OR, 98 p.

Peterman, R.M. 1987. Review of the components of recruitment of Pacific salmon. Am. Fish. Soc. Symposium,1:417-429.

Peterman, R.M. 1977. A simple mechanism that causes collapsing stability regions in exploited salmonid populations. J. Fish. Res. Board of Canada, 34: 1134-1142.

Platt, J.R. 1964. Strong inference. Science, 146(3642): 347-352.

Regional Assessment of Supplementation Project. 1992a. Supplementation in the Columbia Basin: RASP summary report series: Part I - Background, description, performance measures, uncertainty and theory. Bonneville Power Administration, Portland, OR, May 1, 1992, 39 p.

Regional Assessment of Supplementation Project. 1992b. Supplementation in the Columbia Basin: RASP summary report series: Part III - planning guidelines. Bonneville Power Administration, Portland, OR, August 17, 1992, 44 p.

RASP Summary Report Series, Part IV: Supplementation Model and Regional Coordination December, 1992 / Page 53 
Ricker, W.E. 1981. Changes in the average size and average age of Pacific salmon. Can J. Fish. Aquat. Sci. 38: 16361656.

Steward, C. R., and T. C. Bjomn. 1990. Supplementation of salmon and steelhead stocks with hatchery fish: A synthesis of published literature. U.S. Department of Energy, Bonneville Power Administration. Project $88-100$. Portland, OR.

Thompson, W. F. 1959. An approach to population dynamics of the Pacific red salmon. Trans. Am. Fish. Soc. 88(3): 206-209.

Waples, R.S. 1991. Genetic interactions between hatchery and wild salmonids: Lessons from the Pacific Northwest. Can. J. Fish. Aquat. Sci. 48(Suppl. 1): 124-133.

Wood, C.C. 1984. Foraging behavior of common mergansers (Mergus merganser) and their dispersion in relation to the availability of juvenile Pacific salmon. Doctoral dissertation. University of British Columbia, Vancouver, Canada. 


\section{RASP SUMMARY REPORT SERIES \\ PART V}

APPENDICES

December, 1992 


\section{TABLE OF CONTENTS}

APPENDIX A: SUPPLEMENTATION BIBLIOGRAPHY

Introduction

Bibliographic Database.

APPENDIX B: SUPPLEMENTATION QUESTIONNAIRE.

Supquest

APPENDIX C: PATIENT-TEMPLATE ANALYSIS

Analysis

Data Tables.....

APPENDIX D: RASP MODEL 


\section{APPENDIX A}

SUPPLEMENTATION BIBLIOGRAPEIY 


\section{SUPPLEMENTATION BIBLIOGRAPHY}

Information on species translocations in general and supplementation in particular has accumulated in published and unpublished documents over the past five decades. References to supplementation in the fisheries literature have increased steadily due to advances in supplementation theory and a growing body of data obtained through laboratory and field studies. Summaries and bibliographies of this work have begun to appear with more regularity; some of the more recent compendia include: Stroud (editor, 1986), Kelly et al. (1990), Steward and Bjornn (1990); Cuenco (1990); Volume 98, published in 1991, of the journal Aquaculture; and Hindar et al.(1991). Important biological and regulatory aspects of artificial propagation as they relate to the protection and recovery of threatened and endangered salmonid populations under the Endangered Species Act (1973, as amended [16 U.S.C. 1531 et seq.], Sec. 2[a]) are discussed by Hard et al. (1992).

This Appendix provides a supplementation bibliography that was compiled from the aforementioned documents and, additionally, from a systematic survey of literature published in peer-reviewed and report (i.e., "gray literature") formats. Special attention was given to information pertaining to the behavior, genetics, life history patterns, survival, reproductive success, long-term fitness, and ecological interactions of Columbia River Basin salmonids.

The approach used to compile the supplementation bibliography involved searching the literature for material related to supplementation, reviewing the material for relevancy, incorporating bibliographic descriptions of the selected material into a computerized database, formatting computer-stored records for printing, and printing the bibliography on computer storage media and in hardcopy form. Literature survey methods followed those described in Steward and Bjomn (1990); sources included commercially available and privately held literature databases.

The supplementation bibliography contains over 900 records. Of these, the majority are articles from 60 different scientific journals (598 records). The others are reports and bulletins (158); conference and symposia proceedings (77); dissertations (11); books (67); and manuscripts (13).

The supplementation bibliographic database was compiled on a personal computer using ProCite' software running under MS-DOS 5.1. Pro-Cite is a specialized database management program that enables users to create, download, store, organize, and access bibliographic information. It contains most of the capabilities required for managing large computer databases, yet allows for user-defined features that enable customized use of the product. In addition to enabling literature searches guided by user-specified keywords, Pro-Cite can output bibliographies to computer screen, disk file, or printer, The format of the output may be

'Pro-Cite is a registered trademark of Personal Bibliographic Software, Inc. WordPerfect is a registered trademark of WordPerfect Corporation. MS-DOS is a trademark of Microsoft Corporation. 
controlled through the application of default or user-defined style sheets. Output to computer screen allows rapid review of selected records, whereas output routed to disk files can be formatted for input to popular word processing programs. 


\section{SUPPLEMENTATION BIBLIOGRAPHY}

Adelman, H.M., and J.L. Bingham. 1955. Winter survival of hatchery-reared and native brook trout. Progressive Fish-Culturist 17: 177-180.

Aho, R.S., G.L. Concannon, J.S. Ziller, S. Pribyl, R.K. Schroeder, K. Anderson, R. Hill, and D. Ratliff. 1979. An ecological and fish cultural study of Deschutes River salmonids. Fish Research Project F-88-R-9. Oregon Department Fish and Wildlife, Annual Progress Report.

Allee, B.A. 1982. The role of interspecific competition in the distribution of salmonids in streams. Pages 111-122 in E.L. Brannon and E.O. Salo, editors. Proceedings of the salmon and trout migratory behavior symposium. University of Washington Press, Seattle.

Allendorf, F.W., J.E. Lannan, and L.A. Riggs. Unpubl. Clarification of wild/natural production issues in the production principles. Submitted to the Northwest Power Planning Council, September 18, 1990.

Allendorf, F.W., and R.F. Leary. 1988. Conservation and distribution of genetic variation in a polytypic species, the cutthroat trout. Conservation Biology 2: 170-184.

Allendorf, F.W., and S.R. Phelps. 1981. Isozymes and the preservation of genetic variation in salmonid fishes. Pages 37- 52 in N. Ryman, editor. Fish gene pools: preservation of genetic resources in relation to wild fish stocks. Ecological Bulletin 34. Sweden Commission for Research on Natural Resouces, Swedish Council for Planning and Coordination of Research, Stockholm.

Allendorf, F.W., and S.R. Phelps. 1980. Loss of genetic variation in a hatchery stock of cutthroat trout. Transactions of the American Fisheries Society 109:537-543.

Allendorf, F.W., and N. Ryman. 1987. Genetic management of hatchery stocks. Pages 141-160 in N. Ryman and F. Utter, editors. Population Genetics and Fishery Management. University of Washington Press, Seattle.

Allendorf, F.W., N. Ryman, and F. Utter. 1987. Genetics and fishery management. Pages I-20 in N. R yman and F. Utter, editors. Population Genetics and Fishery M anagement. University of Washington Press, Seattle.

Allendorf, F.W., and F.M. Utter. 1979. Population genetics. Pages 407-454 in W.S. Hoar, D.J. R andall, and J .R. B rett, editors. Fish Physiology, Vol. 8. Academic Press, N ew York. 
Allison, L.N. 1961. The fate of kidney disease among hatchery brook trout stocked in natural waters. Progressive Fish-Cult\&t 23:76-78.

Altukhov, Y .P. 1981. The stock concept from the viewpoint of population genetics. Canadian Journal of Fisheries and Aquatic Sciences 38:1523-1538.

Altukhov, Y.P. 1983. Genetic Processes in Populations. Nauka, Moscow.

Altukhov, Y.P., and E.A. Salmenkova. 1987. Stock transfer relative to natural organization, management, and conservation of fish populations. Pages 333-343 in N. Ryman and F. Utter, editors. Population Genetics and Fishery Management. University of Washington Press, Seattle.

Altukhov, Y.P., and E.A. Salmenkova. 1991. The genetic structure of salmon populations. Aquaculture 98: 1 1-40.

Altukhov, Y.P., E.A. Salmenkova, V.T. Omel'chenko, and V.N. Efanov. 1983. Genetic differentiation and population structure in the pink salmon of Sakhalin-Kuril region. Biologiya Morya (Vladivostok) 2:46-5 1.

Altukhov, Y.P., E.A. Salmenkova, G.D. Ryabova, and N.I. Kulikova. 1980. Genetic differentiation of chum salmon $\mathbf{O}$ ncorhynchus keta populations and effectiveness of some acclimatization measures. Biologiya Morya (Vladivostok) 3:23-28.

American Institute of Fishery Research Biologists (Alaska District). 1975. Genetic considerations in artificial propagation of salmon. Alaska Seas and Coasts 3:8-10.

Ames, J. 1980. Salmon stock interactions in Puget Sound: a preliminary look. M.A. Miller, rapporteur. Southeast Alaska coho salmon research and management review and planning workshop. Alaska Department of Fish and Game.

Anderson, A.D., and D.D. Bailey. 1974. The return of chum salmon stocks to the Johnstone Strait-Frasier River study area, and prospects for 1974. Canada Fisheries and Marine Service, Technical Report Series.

Anderson, J.L., and J.E. Wilen. 1985. Estimating the population dynamics of coho salmon (O ncorhynchus kisutch) using pooled time- series and cross-sectional data. Canadian Journal of Fisheries and Aquatic Sciences 42:459-467.

Anderson, R.B. 1962. Comparison of returns from fall and spring stocked hatchery-reared lake trout in Maine. Transactions of the American Fisheries Society 91:425-427. 
Anonymous. 1990. 1989 annual report of the U.S. Atlantic salmon assessment committee. U.S. Atlantic Salmon Assessment Committee.

Anonymous. 1989. Annual fish passage report - 1988. North Pacific Division Corps of Engineers.

Anonymous. 1982. Comprehensive plan for production and management of Oregon's anadromous salmon and trout: Part I, General considerations. Oregon Department of Fish and Wildlife.

Anonymous. 1982. Comprehensive plan for production and management of Oregon's anadromous salmon and trout: Part II, Coho salmon plan. Oregon Department of Fish and Wildlife.

Anonymous. 1985. Fisheries 1986-1990 management plan . Idaho Department of Fish and Game.

Anonymous. 1987. The impact of Oregon Aqua-Foods operation on the wild coho salmon in the Yaquina River. Staff Report. Oregon Department of Fish and Wildlife, Fish Division, Portland, Oregon.

Anonymous. 1990. Natural production and wild fish management rules. Oregon Department of Fish and Wildlife.

Anonymous. 1987. The New England Atlantic salmon program annual progress report. U.S. Fish and Wildlife Service, Region 5.

Anonymous. 1988. The New England Atlantic salmon program annual progress report. U.S. Fish and Wildlife Service, region 5.

Anonymous. 1989. Salmonid enhancement program 1989 update. Department of Fisheries and Oceans, Vancouver, British Columbia.

Anonymous. 1987. Supplementation overview - does it work? Washington Department of Fisheries.

Aspinwall, N. 1974. Genetic analysis of North American populations of the pink salmon (Oncorhynchus gorbwcha): Possible evidence for the neutral mutation-random drift hypothesis. Evolution 28:295-305. 
Aulstad, D., T. Gjedrem, and H. Skjervold. 1972. Genetic and environmental sources of variation in length and weight of rainbow trout (SaImo gairdneri). Journal of the Fisheries Research Board of Canada 29:237-241.

Aulstad, D., and A. Kittelsen. 1971. Abnormal body curvatures of rainbow trout (Sabno gairdneri) in inbred fry. Journal of the Fisheries Research Board of Canada 28:1918-1920.

Ayerst, J.D. 1977. The role of hatcheries in rebuilding steelhead runs of the Columbia River system. Pages 84-88 in E. Schwiebert, editor. Columbia River salmon and steelhead. American Fisheries Society, Bethesda, Maryland.

Ayles, G.B. 1975. Influence of the genotype and the environment on growth and survival of rainbow trout (Sabno gairdneri) in central Canadian aquaculture lakes. Aquaculture 6:181-188.

Ayles, G.B., and R.F. Baker. 1983. Genetic differences in growth and survival between strains and hybrids of rainbow trout (Salmo gairdneri) stocked in aquaculture lakes in the Canadian prairies. Aquaculture 33:269-280.

Babey, G.J., and C.R. Berry. 1989. Post-stocking performance of three strains of rainbow trout in a reservoir. North American Journal of Fisheries Management 9:309-315.

Bachman, R.A. 1984. Foraging behavior of free ranging wild and hatchery brown trout, Salmo trutta, in a stream. Transactions of the American Fisheries Society 113: 1-32.

Bailey, J.K. 1987. Canadian sea ranching program (east coast). Pages 443-448 in K. Tiews, editor. Proceedings of the World Symposium on Selection, Hybridization and Genetic Engineering in Aquaculture, Volume II. Heeneman, Berlin.

Bailey, J.K., and E.J. Loudenslager. 1986. Genetic and environmental components of variation for growth of juvenile Atlantic salmon (Sabno salar). Aquaculture 57:125-132.

Baily, J.E., B.L. Wing, and C.R. Mattson. 1975. Zooplankton abundance and feeding habits of fry of pink salmon, $\mathbf{O}$ ncorhynchus gorbuscha, and chum salmon, $\mathbf{O}$ ncorhynchus keta, in Traitors Cove, Alaska, with speculations on the carrying capacity of the area. Fishery Bulletin 73:846-861.

Bakke, T.A., P.A. Jansen, and L.P. Hansen. 1990. Differences in the host resistance of Atlantic salmon, Salmo salar L., stocks to the monogenean Gyrodactylus salaris Malmberg, 1957. Journal of Fish Biology 37:577-587. 
Bams, R.A. 1967. Differences in performance of naturally and artificially propagated sockeye salmon migrant fry, as measured with swimming and predator tests. Journal of the Fisheries Research Board of Canada 24: 1117-1 153.

Bams, R.A. 1970. Evaluation of a revised hatchery method tested on pink and chum salmon fry. Journal of the Fisheries Research Board of Canada 27:1429-1452.

Barns, R.A. 1972. A quantitative evaluation of survival to the adult stage and other characteristics of pink salmon (O ncorhynchus gorbuscha) produced by a revised hatchery method which simulates optimal natural conditions. Journal of the Fisheries Research Board of Canada 29:1151-1167.

Bams, R.A. 1974. Gravel incubators: a second evaluation on pink salmon, O ncorhynchw gorbuscha, including adult returns. Journal of the Fisheries Research Board of Canada 31: $1379-1385$.

Bams, R.A. 1976. Reflections on salmon enhancement. Pages 191- 196 in D.H. Rosenberg, editor. Proceedings of the Conference on Salmon Aquaculture and the Alaskan Fishing Community. University of Alaska, Fairbanks, Sea Grant Report 76-2.

Bams, R.A. 1976. Results of pink salmon transplant using males native to the recipient stream. Fisheries and Marine Service Technical Report 642.

Bams, R.A. 1976. Survival and propensity for homing as affected by presence or absence of locally adapted paternal genes in two transplanted populations of pink salmon (Oncorhynchus gorbushca). Journal of the Fisheries Research Board of Canada 33:2716-2725.

Bams, R.A. 1990. Outplanting normal and sterilized hatchery coho fall fingerlings into two small British Columbia lakes: an evaluation. Canadian Technical Report of Fisheries and Aquatic Sciences 1765.

Banks, J.L. 1989. A review of rearing density experiments: can hatchery effectiveness be improved? Proceedings from a paper presented at the spring chinook salmon workshop, Pasco, Washington.

Banks, J.L. 1992. Effects of density and loading on coho salmon during hatchery rearing and after release. Progressive Fish- Culturist 54:137-147.

Banks, J.W. 1969. A review of the literature on the upstream migration of adult salmonids. Journal of Fish Biology 1:85-136. 
Banner, C.R., J.S. Rohovec, and J.L. Fryer. 1983. Reinibacterium salmoninarum as a cause of mortality among chinook salmon in salt water. Journal of World Mariculture Society 14:236-239.

Banner, CR., J. J. Long, J.L. Fryer, and J.S. Rohovec. 1986. Ckcurrence of salmonid fish infected with Renibacteriurn salmoninamm in the Pacific Ocean Journal of Fish Disease 9:273- 275 .

Barbehenn, K.R. 1969. Host-parasite relationships and species diversity in mammals: an hypothesis. Biotropica 1: 29-35.

Bartley, D.M., and G.A.E. Gall. 1990. Genetic structure and gene flow in chinook salmon populations of California. Transactions of the American Fisheries Society 11955-71.

Barton, B.A., R.E. Peter, and C.R. Paulencu. 1980. Plasma cortisol levels of fmgerling rainbow trout (Salmo gairdnmi) at rest, and subjected to handling, confinement, transport, and stocking. Canadian Journal of Fisheries and Aquatic Sciences 37: 805-811.

Barton, B.A., C.B. Schreck, and L.A. Sigismondi. 1986. Multiple acute disturbances evoke cumulative physiological stress responses in juvenile chinook salmon. Transactions of the American Fisheries Society 115:245-25 1.

Baum, E.T. 1983. Atlantic salmon research and management report. Pages 34-37 in 1982 Northeast Atlantic salmon workshop. Maine Atlantic Salmon Federation Publication Series.

Beacham, T.D. 1988. A genetic analysis of early development in pink (O ncorhynchus gorbuscha) and chum salmon (O ncorhynchus keta) at three different temperatures. Genome 30: 89-96.

Beacham, T.D., and C.B. Murray. 1986. Comparative developmental biology of pink salmon, O ncorhynchus gorbuscha in southern British Columbia. Journal of Fish Biology 28:233-246.

Beacham, T.D., and C.B. Murray. 1987. Adaptive variation in body size, age, morphology, egg size, and developmental biology of chum salmon (O ncorhynchw keta) in British Columbia. Canadian Journal of Fisheries and Aquatic Sciences 44:244-261.

Beacham, T.D., and C.B. Murray. 1988. Genetic analysis of growth and maturity in pink salmon (O ncorhynchw gorbuscha). Genome 30: 529-535. 
Beacham, T.D., and C.B. Murray. 1989. Variation in developmental biology of sockeye salmon (Oncorhynchus nerka) and chinook salmon (O. tshawytscha) in British Columbia. Canadian Journal of Zoology 67:2081-2089.

Beacham, T.D., C.B. Murray, and R.E. Withler. 1988. Age, morphology, developmental biology, and biochemical genetic variation of Yukon River fall chum salmon, Oncorhynchus kefa, and comparisons with British Columbia populations. Fishery Bulletin 86(4).

Beacham, T.D., A.P. Gould, R.E. Withler, C.B. Murray, and L.W. Bamer. 1987. Biochemical genetic survey and stock identification of chum salmon (O ncorhynchus keta) in British Columbia. Canadian Journal of Fisheries and Aquatic Sciences 44: 1702-1713.

Beacham, T.D., R.E. Withler, and A.P. Gould. 1985. Biochemical genetic stock identification of pink salmon (O ncorhynchus gorbuscha) in southern British Columbia and Puget Sound. Canadian Journal of Fisheries and Aquatic Sciences 42:1474-1483.

Beacham, T.D., R.E. Withler, and A.P. Gould. 1985. Biochemical genetic stock identification of chum salmon (O ncorhynchus keta) in southern British Columbia. Canadian Journal of Fisheries and Aquatic Sciences 42:437-448.

Beck, R.W. 1987. Review of hatchery supplementation methods and effects. Yakima and Klickitat River central outplanting facility proposed master plan (Appendix IV). Northwest Power Planning Council, Portland, Oregon.

Behnke, R.J. 1972. The systematics of salmonid fishes of recently glaciated lakes. Journal of the Fisheries Research Board of Canada 29:639-671.

Bella, D.A., and W.S. Over-ton. 1972. Environmental planning and ecological possibilities. Proceedings of the American Society of Civil Engineers 98579-592.

Bentsen, H.B. 1991. Quantitative genetics and management of wild populations. Aquaculture 98:263-266.

Berg, M. 1977. Pink salmon, O ncorhynchus gorbuscha (Walbaum) in Norway. Institute of Freshwater Research 56.

Berg, W.J., and S.O. Ferris. 1984. Restriction endonuclease analysis of salmonid mitochondrial DNA. Canadian Journal of Fisheries and Aquatic Sciences 41: 1041-1047.

RASP Summary Report Series, Part V: Appendix A: Supplementation Literature

December, 1992 /Page 9 
Berg, W.J., and G.A.E. Gall. 1988. Gene flow and genetic differentiation among California coastal rainbow trout populations. Canadian Journal of Fisheries and Aquatic Sciences 45: $122-131$.

Bergan, P.I., D. Gausen, and L.P. Hansen. 1991. Attempts to reduce the impact of reared Atlantic salmon on wild in Norway. Aquaculture 98:319-324.

Berghe (van den), E.P. 1984. Natural selection and reproductive success of female coho salmon (O ncorhynchus kisutch): a study in female competition. M.Sc. thesis. Simon Fraser University, Bumaby, British Columbia.

Berst, A.H., and R.C. Simon. 1981. Introduction to the proceedings of the 1980 stock concept international symposium. . Canadian Journal of Fisheries and Aquatic Sciences 38: $1457-1458$.

Bilby, R.E., and P.A. Bisson. 1987. Emigration and production of hatchery coho salmon (O ncorhynchus kisutch) stocked in streams draining an old-growth and a clear-cut watershed. Canadian Journal of Fisheries and Aquatic Sciences 44: 1397-1407.

Bilton, H.T. 1984. Returns of chinook salmon in relation to juvenile size at release. Canadian Technical Report of Fisheries and Aquatic Sciences 1245.

Bilton, H.T., D.F. Alderdice, and J.T. Schnute. 1982. Influence of time and size at release of juvenile coho salmon (O ncorhynchus kisutch) on returns at maturity. Canadian Journal of Fisheries and Aquatic Sciences 39:426-447.

Bilton, H.T., and D.W. Jenkinson. 1980. Returns to the fishery and escapement of adult coho salmon from accelerated and normally reared juveniles. Canadian Technical Report of Fisheries and Aquatic Sciences 925.

Bilton, H.T., R.B. Morley, A.S. Cobum, and J. Van Tine. 1984. The influence of time and size at release of juvenile coho salmon (O ncorhynchus kisutch) on returns at maturity; results of releases from Quinsam River Hatchery, B.C. Canadian Technical Report of Fisheries and Aquatic Sciences 1306.

Birt, T.P., J.M. Green, and W.S. Davidson. 1986. Analysis of mitochondrial DNA in allopatric anadromous and nonanadromous Atlantic salmon, Salmon salar. Canadian Journal of Zoology 64: 118- 120.

Bjornn, T.C. 1977. Wild fish production and management. Transactions of the American Fisheries Society, Vol. 10.

RASP Summary Report Series, Part V: Appendix A: Supplementation Literature

December, 1992 /Page 10 
Bjomn, T.C. 1977. Mixed stocks of wild and hatchery steelhead trout, a management problem in Idaho. Pages 77-81 in Genetic Implications of Steelhead Management.

Bjomn, T.C. 1978. Survival, production, and yield of trout and chinook salmon in the Lemhi River, Idaho. Forest, Wildlife and Range Experiment Station, University of Idaho Bulletin 27.

Bjomn, T.C. 1986. Important parameters for assessing anadromous fish stocking programs. Pages 315-322 in R.H. Stroud, editor. Fish culture in fisheries management. American Fisheries Society, Bethesda, Maryland.

Bjomn, T.C., and C.R. Steward. 1990. Concepts for a model to evaluate supplementation of natural salmon and steelhead stocks with hatchery fish. Bonneville Power Administration Project 88-100. U.S. Department of Energy.

Bjomn, T.C., and J. Mallet. 1964. Movements of planted and wild trout in an Idaho river system. Transactions of the American Fisheries Society 93:70-76.

Blackett, R.F. 1979. Establishment of sockeye (Oncorhynchus nerka) and chinook (0. tshawytscha) salmon runs at Frazer Lake, Kodiak Island, Alaska. Journal of the Fisheries Research Board of Canada 36:1265-1277.

Bley, P.W., and J.R. Moring. 1988. Freshwater and ocean survival of Atlantic salmon and steelhead: a synopsis. U.S. Fish and Wildlife Service, Biological Report 88(9).

Backing, R.C., J.R. Irvine, K.K. English, and M. Labelle. 1988. Evaluation of random and indexing sampling designs for estimating coho salmon (O ncorhynchus kisutch) escapement to three Vancouver Island streams. Canadian Technical Report on Fisheries and Aquatic Sciences, 1639.

Boles, H.D. 1960. Experimental stocking of brown trout in a California Lake. Pages 334-339 in Proceedings of the annual conference of the Western Association Game and Fish Commission.

Bolgova, O.M., V.S. Sidorov, Y.A. Smimov, and K.F. Sorvachev. 1977. The fatty acid composition of the cavity fat of juvenile salmon, Salmo salar, under natural conditions and in hatchery rearing. Journal of Ichthyology 17:918-923.

Bouck, G-R., and R.C. Ball. 1966. Influence of capture methods on blood characteristics and mortality in the rainbow trout (Salmo gairdneri). Transactions of the American Fisheries Society 95: 170-176. 
Bowler, B. 1975. Factors influencing genetic control in lakeward migrations of cutthroat trout fry. Transactions of the American Fisheries Society 104:474-482.

Bowles, E., and E. L\&zinger. 1991. Salmon supplementation studies in Idaho rivers. Idaho supplementation studies. Bonneville Power Administration, Portland, Oregon.

Boyce, R.R. 1986. Comprehensive plan for rehabilitation of anadromous fish stocks in the Umatilla River basin. Oregon Department of Fish and Wildlife Final Report 1985.

Boyle, L., and N. Dudiak. 1986. Tutka Lagoon hatchery 1981 adult return evaluation. Alaska Department of Fish and Game, FRED Division, No. 61. Alaska Department of Fish and Game.

Brannon, E.L. 1967. Genetic control of migrating behavior of newly emerged salmon fry. International Pacific Salmon Fisheries Commission Bulletin.

Brannon, E.L. 1982. Orientation mechanisms of homing salmonids. Pages 219-228 in E.L. Brannon and E.O. Salo, editors. Proceedings of the salmon and trout migratory behavior symposium. University of Washington Press, Seattle.

Bristow, G.A., and B. Berland. 1991. A report on some metazoan parasites of wild marine salmon (Salmo salar L.) from the west coast of Norway with comments on their interactions with farmed salmon. Aquaculture 98:311-318.

Bryan, J.E. 1973. Feeding history, parental stock and food selection in rainbow trout. Behaviour 45: 123-153.

Brynildson, O.M., and L.M. Christenson. 1961. Survival, yield, growth and coefficient of condition of hatchery-reared trout in Wisconsin waters. Wisconsin Conservation Department, Misc. Report 3.

Brynildson, O.M. 1967. Dispersal of stocked trout in five Wisconsin streams. Wisconsin Conservation Department, Research and Planning Division, Research Report 26.

Buchanan, D.V., R.M. Hooton, and J.R. Morin. 1981. Northern squawfish (ptychochelius oregonensis) predation on juvenile salmonids in sections of the Willamette River basin, Oregon. Canadian Journal of Fisheries and Aquatic Sciences 38:360-364.

Buchanan, D.V., J.E. Sanders, J.L. Zinn, and J.L. Fryer. 1983. Relative susceptibility of four strains of summer steelhead to infection by Ceratomyxa shasta Transactions of the American Fisheries Society 112:541-543.

RASP Summary Report Series, Part V: Appendix A: Supplementation Literature

December, 1992 /Page 12 
Buchanan, D.V., and J.R. Moring. 1986. Management problems with recycling of adult summer steelhead trout at Foster Reservoir, Oregon. Pages 191-200 in R.H. Stroud, editor. Fish culture in fisheries management. American Fisheries Society, Bethesda, Maryland.

Bullock, G.L., D. Conroy, and S.F. Snieszko. 1971. Bacterial diseases of fishes: Book 2A. 151 pages in SF. Snieszko and H.R. Axelrod, editors. Diseases of Fishes. T.F.H. Publications, Inc., Neptune, New Jersey.

Burrows, R.E. 1969. The influence of fingerling quality on adult salmon survivals. Transactions of the American Fisheries Society 98:777-784.

Busack, C. 1990. YakimaKlickitat Production Project Genetic Risk Assessment. Yakima/Klickitat Production Project Preliminary Design Report, Appendix A. Washington Department of Fisheries and Bonneville Power Administration, Portland, Oregon.

Busack, C., and G.A.E. Gall. 1980. Ancestry of artificially propagated California rainbow trout strains. California Fish and Game 66:17-24.

Busack, C., R. Halliburton, and G.A.E. Gall. 1979. Electrophoretic variation and differentiation in four strains of domesticated rainbow trout (Salmo gairdneri). Canadian Journal of Genetics and Cytology 21:81-94.

Butler, R.L. 1975. Some thoughts on the effects of stocking hatchery trout on wild trout populations. Pages 83-87 in W. Ring, editor. Proceedings of the wild trout management symposium. Trout Unlimited.

Butler, R.L., and D.P. Borgeson. 1965. California "catchable" trout fisheries. California Department of Fish and Game Bulletin 127.

Byrne, A., and T.C. Bjomn. 1988. An evaluation of supplementing wild stocks of steelhead with hatchery fish using a life history model. Technical Report 88-3. Idaho Cooperative Fish and Wildlife Research Unit, University of Idaho.

Cade, T.J. 1988. Using science and technology to reestablish species lost in nature. Pages 279-288 in E.O. Wilson and F.J. Peter, editors. Biodiversity. National Academy Press, Washington, D.C.

Caillouet, C.W. 1968. Lactic acidosis in channel catfish Journal of the Fisheries Research Board of Canada 25:15-23. 
CaIaprice, J.R. 1969. Production and genetic factors in managed salmonid populations. Pages 377-388 in Symposium on salmon and trout streams. H.R. MacMillan Lectures in Fisheries. University of British Columbia, Vancouver.

Calhoun, A. 1966. Inland fisheries management. California Department of Fish and Game, Sacramento.

Campton, D.E., and J.M. Johnston. 1985. Electrophoretic evidence for a genetic admixture of native and nonnative rainbow trout in the Yakima River, Washington. Transactions of the American Fisheries Society 114:782-793.

Campton, D.E., and F.M. Utter. 1985. Natural hybridization between steelhead trout (Salmo gairdneri) and coastal cutthroat trout (Salmo clarki clarki) in two Puget Sound streams. Canadian Journal of Fisheries and Aquatic Sciences 42: 110-1 19.

Campton, D.E., and F.M. Utter. 1987. Genetic structure of anadromous cutthroat trout (Salmo clarki clarki) populations in the Puget Sound area: evidence for restricted gene flow. Canadian Journal of Fisheries and Aquatic Sciences 44:573-582.

Campton, D.E., F. W. Allendorf, R.J. Behnke, F.M. Utter, M.W. Chilcote, S.A. Leider, and J.J. Loch. 1991. Reproductive success of hatchery and wild steelhead. Transactions of the American Fisheries Society 120: 816-827.

Carl, L.M., and M.C. Healey. 1984. Differences in enzyme frequency and body morphology among three juvenile life history types of chinook salmon (O ncorhynchus tshawytscha) in the Nanaimo River, British Columbia. Canadian Journal of Fisheries and Aquatic Sciences 41: 1070-1077.

Cederholm, C.J. 1984. Clearwater River wild steelhead spawning timing. Pages 257-268 in J.M. Walton and D.B. Houston, editors. Proceedings of the Olympic wild fish conference. Peninsula College, Fisheries Technology Program, Port Angeles, Washington.

Chadwick, E.M.P. 1987. Causes of variable recruitment in a small Atlantic salmon stock. M.J. Dodswell, R.J. Klauda, C.M. Moffitt, and R.L. Saunders, editors. Common strategies of anadromous and catadromous fishes: Symposium I. American Fisheries Society, Bethesda, Maryland.

Chakraborty, R., and 0. Leimar. 1987. Genetic variation within a subdivided population. Pages 89-120 in N. Ryman and F. Utter, editors. Population Genetics and Fisheries Management. University of Washington Press, Seattle. 
Chandler, G.L., and T.C. Bjomn. 1988. Abundance, growth, and interactions of juvenile steelhead relative to time of emergence. Transactions of the American Fisheries Society 117:432-443.

Chandler, G.L., and T.C. Bjornn. 1989. Survival and growth of subyearling steelhead homozygous for alternative alleles at the dipeptidase locus. Transactions of the American Fisheries Society 118:74-77.

Chapman, D.W. 1962. Aggressive behavior in juvenile coho salmon as a cause of emigration. Journal of the Fisheries Research Board of Canada 19:1047-1080.

Chapman, D.W. 1966. Food and space as regulators of salmonid populations in streams. American Naturalist 100:345-357.

Chilcote, M.W., B.A. Crawford, and S.A. Leider. 1980. A genetic comparison of sympatric populations of summer and winter steelhead. Transactions of the American Fisheries Society 109: 203-206.

Chilcote, M.W., S.A. Leider, and J.L. Loch. 1986. Differential reproductive success of hatchery and wild summer-run steelhead under natural conditions. Transactions of the American Fisheries Society 115:726-735.

Child, A.R., A.M. Fumell, and N.P. Wilkens. 1976. The existence of two races of Atlantic salmon (Salmo salar L.) in the British Isles. Journal of Fish Biology 8:35-43.

Chourrout, D. 1987. Genetic manipulations in fish: review of methods. Pages 111-126 in K. Tiews, editor. Proceedings of the World Symposium on Selection, Hybridization, and Genetic Engineering in Aquaculture, Volume II. Heeneman, Berlin.

Clady, M.D. 1973. Catchable trout: a literature survey and recommendations for use. Oregon State Game Commission, Federal Aid Progress Report, Project F-94-R-1.

Clark, J., and B. McCarl. 1983. An investigation of the relationship between Oregon coho salmon (Oncorhynchus kisurch) hatchery releases and adult production utilizing law of the minimum regression. Canadian Journal of Fisheries and Aquatic Sciences 40:516-523.

Clarke, L.A., and A.M. Sutterlin. 1985. Associative learning, short-term memory, and colour preference during first feeding by juvenile Atlantic salmon. Canadian Journal of Zoology 63:9-14.

RASP Summary Report Series, Part V: Appendix A: Supplementation Literature

December, 1992 /Page 15 
Clarke, W.C., J.E. Shelboum, and J.R. Brett. 1981. Effects of artificial photoperiod cycles, temperature and salinity on growth and smolting in underyearling coho (Oncorhynchus kisutch), chinook (0. tshawyrscha), and sockeye (0. nerka) salmon. Aquaculture 22:105-116.

Clothier, W.D. 1963. Fish loss and movement in irrigation diversions from the West Gallatin River, Montana. Journal of Wildlife Management 17:144-158.

Colby, P.J., G.R. Spangler, D.A. Hurley, and A.M. McCombie. 1972. J ournal of the Fisheries Research Report of Canada 29:975- 983.

Congelton, J.L., T.C. Bjomn, B.H. Burton, B.D. Watson, J.I. Irving, and R.R. Ringe. 1985. Effects of handling and crowding on the stress response and viability of chinook salmon parr and smolts. Bonneville Power Administration, Division of Fish and Wildlife, Project 82-5. Portland, Oregon.

Conlin, K., and B.D. Tutty. 1979. Juvenile salmonid field trapping manual. Fish. Mar. Serv. MS Rep. 1530.

Conway, W.G. 1989. The prospects for sustaining species and their evolution. Pages 199-209 in D. Western and M. Pearl, editors. Conservation for the Twenty-first Century. Oxford University Press, New York, New York.

Cooper, A.C. 1977. Evaluation of the production of sockeye and pink salmon at spawning and incubation channels in the Fraser River system. International Pacific Salmon Fisheries Commission Canadian Progress Report 36.

Cooper, E.L. 1952. Returns from plantings of legal-sized brook, brown, and rainbow trout in the Pigeon River, otsego County, Michigan. Transactions of the American Fisheries Society $82: 265-280$.

Cordone, A.J., and T.C. Frantz. 1968. An evaluation of trout planting in Lake Tahoe. California Fish and Game 54:68-69.

Cote, Y., and C. Pomerleau. 1985. Survie et dispersion d' alevins de saumon atlantique (Salmo salar) ensemences en milieu natural. Naturaliste Can. (Rev. Ecol. Syst.) 112:549-557.

Craig, P.C. 1985. Identification of sockeye salmon (O ncorhynchus nerka) stocks in the Stikine River based on egg size measurements. Canadian Journal of Fisheries and Aquatic Sciences 42:1696-1701. 
Cramer, D.P. 1981. Effect of smelt release location and displacement of adults on distribution of summer steelhead trout. Progressive Fish-Culturist 43:8-1 1.

Cresswell, R.C. 1981. Post-stocking movements and recapture of hatchery-reared trout released into flowing waters--a review. Journal of Fish Biology 429442.

Cresswell, R.C., and R. Williams. 1982. Post-stocking movements and recapture of hatchery-reared trout released into flowing waters: effect of time and method of stocking. Fisheries Management 13:97-103.

Cresswell, R.C., and R. Williams. 1983. Post-stocking movements and recapture of hatchery-reared trout released into flowing water: effect of prior acclimation to flow. Journal of Fish Biology 23:265-276.

Cresswell, R.C., and R. Williams. 1984. Post-stocking movements and recapture of hatchery-reared trout released into flowing waters: effect of a resident wild population. Fisheries Management 15:9-14.

Cross, T.F. 1989. To what extent are farmed and wild salmon genetically distinct? Pages 7-8 in M. Windsor, editor. Joint NASCO/ICES Meeting, The Genetic Threats to Wild Salmon Posed by Salmon Aquaculture. NASCO, Edinburgh, England.

Cross, T.F., and D.N. Challanain 1991. Genetic characterization of potential farmed escaped salmon (Salmo salar) in Ireland using enzyme electrophoresis. Aquaculture 98:209-216.

Cross, T.F., and J. King. 1983. Genetic effects of hatchery rearing in Atlantic salmon. Aquaculture 33:33-40.

Cunjak, R.A., and J.M. Green. 1984. Species dominance by brook trout and rainbow trout in a simulated stream environment. Transactions of the American Fisheries Society 1131737-743.

Currens, K.P., C.A. Busack, G.K. Meffe, D.P. Philipp, E.P. Pister, F.M. Utter, and S. Yundt. A hierarchal approach to conservation genetics and production of anadromous salmonids in the Columbia river basin. Northwest Power Planning Council.

Daly, J.G., and R.M.W. Stevenson. 1985. Importance of culturing several organs to detect Aeromonas salmonicida in salmonid fish. Transactions of the American Fisheries Society 114:909-910.

Davidson, F.A. 1934. The homing instinct and age at maturity of the pink salmon. Bulletin of the U.S.. Bureau of Fisheries 48.

RASP Summary Report Series, Part V: Appendix A: Supplementation Literature

December, 1992 /Page 17 
Davidson, F.A., E. Vaughan, S.J. Hutchinson, and A.L. Pritchard. 1943. Factors affecting the upstream migration of pink salmon. Ecology 24:149-168.

Davidson, W.W., T.P. Birt, and J.M. Green. 1989. A review of genetic variation in Atlantic salmon, Salmo salar L., and its importance for stock identification, enhancement programmes and aquaculture. Journal of Fish Biology 34:547-560.

Denniston, C.D. 1978. Small population size and genetic diversity: implications for endangered species. Pages 281-289 in S.A. Temple, editor. Endangered birds: management techniques for preserving threatened species. University of Wisconsin Press, Madison.

Denton, C. 1988. Marine survival of chinook salmon, O ncorhynchus tshawytscha, reared at three densities. Alaska Department of Fish and Game FRED Report No. 88. Juneau.

Dickson, T.A., and H.R. MacCrimmon. 1982. Influence of hatchery experience on growth and behavior of juvenile Atlantic salmon (Salmo salar) within allopatric and sympathetic stream populations. Canadian Journal of Fisheries and Aquatic Sciences 39: 1453-1458.

Diggs, D.H. 1984. A "Delphi" survey into the methods and practices of spring chinook salmon culture. U.S. Fish and Wildlife Service, Dworshak Fisheries Assistance Office.

Donaldson, E.M. 1986. The integrated development and application of controlled reproduction techniques in Pacific salmonid aquaculture. Fish. Physiol. and Biochem 2:9-24.

Doyle, R.W. 1983. An approach to the quantitative analysis of domestication selection in aquaculture. Aquaculture 33: 167-186.

Doyle, R.W., and A.J. Talbot. 1986. Artificial selection on growth and correlated selection on competitive behaviour in fish. Canadian Journal of Fisheries and Aquatic Sciences 43: 1059-1064.

Dudiak, N., and L. Boyle. 1988. Homer area sport fisheries enhancement, Vol. 3, No. 6.

Dwyer, W.P., and R.G. Piper. 1984. Three-year hatchery and field evaluations of four strains of rainbow trout. North American Journal of Fisheries Management 4:216-221.

Ebel, W.J. 1970. Effect of release location on survival of juvenile fall chinook salmon, Oncorhynchus tshawytschu. Transaction of the American Fisheries Society 99:672-676. 
Eggers, D.M., L.R. Peltz, B.G. Bue, and T.M. Willette. Trends in abundance of hatchery and wild stocks of pink salmon in Kodiak Island, Cook Inlet and Prince William Sound, Alaska.

Egglishaw, H. J. 1984. Salmon smolt stock enhancement in the River Tummel, Scotland. Manuscript.

Egglishaw, H.J., and P.E. Shackley. 1977. Growth, survival and production of juvenile salmon and trout in a Scottish stream, 19661975. Journal of Fish Biology 11:647-672.

Egglishaw, J.H., and P.E. Shackley. 1980. Survival and growth of salmon, Salmo salar (L.), planted in a Scottish stream. Journal of Fish Biology 16:565-584.

Egidius, E. 1987. Import of furunculosis to Norway with Atlantic salmon smolts from Scotland. International Council for the Exploration of the Sea.

Egidius, E., L.P. Hansen, B. Jonsson, and G. Naevdal. 1991. Mutual impact of wild and cultured Atlantic salmon in Norway. J. Cons. Int. Explor. Mer 47:404-410.

Ejike, C., and C.B. Schreck. 1980. Stress and social hierarchy rank in coho salmon. Transactions of the American Fisheries Society 109:423-426.

Elliot, J.M. 1989. The critical-period concept for juvenile survival and its relevance for population regulation in young sea trout, Salmo trutta. Journal of Fish Biology 35:91-98.

Elliot, J.M. 1987. The distances travelled by downstream-moving trout fry, Salmo trutta, in a Lake District stream. Freshwater Biology 17:491-499.

Elliot, J.M. 1975. Weight of food and time to satiate brown trout (Salmo trutta). Freshwater Biology 5:51-64.

Elliott, D.G., R.J. Pascho, and G.L. Bullock. 1989. Developments in the control of bacterial kidney disease of salmonid fishes. Diseases of Aquatic Organisms 6:201-215.

Ellis, R.J. 1969. Return and behavior of adults of the first filial generation of transplanted pink salmon, and survival of their progeny, Sashin Creek, Baranof Island, Alaska. U.S. Fish and Wildlife Service Special Scientific Report, Fisheries, 589.

Elrod, J.H., and C.P. Schneider. 1992. Effect of stocking season and technique on survival of lake trout in Lake Ontario. North American Journal of Fisheries Management 12: $131-138$. 
Elson, P.F. 1957. Predator-prey relationships between fish- eating birds and Atlantic salmon. Canadian Fish Culturist 21:7- 17.

Elson, P.F. 1957. Using hatchery-reared Atlantic salmon to best advantage. Canadian Fish Culturist 21:7-17.

Elson, P.F. 1975. Atlantic Salmon rivers, smolt production and optimal spawning: an overview of natural production. New England Atlantic Salmon Restoration Conference. Special Publication Series Number 6.

Emlen, J. 199 1. Heterosis and outbreeding depression: a multi- locus model and an application to salmon production. Fish. Res. 12:187-212.

Emlen, J., and R. Reisenbacher. 1988. A re-evaluation of models predicting density-dependent survival at sea for coho salmon. Pages 197-200 in B.G. Shepherd, rapporteur. Proceedings of the 1988 Northeast Pacific chinook and salmon workshop. North Pacific International Chapter American Fisheries Society, Bellingham, Washington.

English, K.K., W.J. Gazey, M. Labelle, T.M. Webb, and E.A. Perry. 1991. Assessment of the methods and data used to determine hatchery and chinook production for the Big Qualicum, Capilano, Robertson Creek, Puntledge and Quinsam hatcheries. DFO/SEP Intern. Rep.

Eriksson, C. , S. Hallgren, and S. Uppman. 1981. Spawning migration of hatchery reared salmon (Salmo salar) released as smolts in River Ljusnan and its estuary. Swedish Salmon Research Institute Report 3: 1-16.

Eriksson, T., and L.O. Eriksson. 1991. Spawning migratory behaviour of coastal-released Baltic salmon (Salmo salar). Effects on straying frequency and time of river ascent. Aquaculture 98:79-87.

Ersbak, K., and B.L. Haase. 1983. Nutritional deprivation after stocking as a possible mechanism leading to mortality in stream- stocked brook trout. North American Journal of Fisheries Management 3: 142-15 1.

Evans, D.R., and R.Z. Smith. 1986. Considerations in reprogramming hatchery production to improve harvest management: a case study in the Pacific Northwest. Pages 109-118 in R.H. Stroud, editor. Fish culture in fisheries management. American Fisheries Society, Bethesda, Maryland. 
Evelyn, T.P., J.E. Ketcheson, and L. Prosperi-Porta. 1988. Trials with anti-bacterial kidney disease vaccines in two species of Pacific salmon. Page 38 in Conference Handbook, International Fish Health Conference. Fish Health Section, American Fisheries Society, Washington D.C.

Everest, F.H., and D.W. Chapman. 1972. Habitat selection and spatial interaction by juvenile chinook salmon and steelhead trout in two Idaho streams. Journal of the Fisheries Research Board of Canada 29:91-100.

Fagen, R., and W.W. Smoker. 1989. How large-capacity hatcheries can alter interannual variability of salmon production. Fish. Res. 8: 1- 11.

Faler, M.P. 1988. Effects of variation in flow on distributions of northern squawfish in the Columbia River below McNary Dam. North American Journal of Fisheries Management 8:30-35.

Fast, D.A., J.D. Hubble, and M.S. Kohn. 1988. Yakima River spring chinook enhancement study. 1988 Annual Report to Bonneville Power Administration, Contract No. 82-16.

Fausch, K.D. 1988. Tests of competition between native and introduced salmonids in streams: what have we learned? Canadian Journal of Fisheries and Aquatic Sciences 45:2238-2246.

Favorite, F., and T. Laevastu. 1979. A study of the ocean migrations of sockeye salmon and estimation of the carrying capacity of the North Pacific using a dynamical salmon ecosystem model (NOPASA). National Marine Fisheries Service, NWAFC Processed Report 79-16.

Favro, L.D., P.K. Kuo, and J.F. McDonald. 1979. Population- genetic study of the effects of selective fishing on the growth rate of trout. Journal of the Fisheries Research Board of Canada 36:552-561.

Felton, S.P., J. Wenjuan, and S.B. Mathews. 1990. Selenium concentrations in coho salmon outmigrant smolts and returning adults: a comparison of wild versus hatchery-reared fish. Diseases of Aquatic Organisms 9:157-161.

Fenderson, O.C., and M.R. Carpenter. 1971. Effects of crowding on the behaviour of juvenile hatchery and wild landlocked Atlantic salmon (Salmo salar L.). Animal Behavior 19:439-447. 
Fenderson, O.C., W.H. Everhart, and K.M. Muth. 1968. Comparative agonistic and feeding behavior of hatchery-reared and wild salmon in aquaria. Journal of the Fisheries Research Board of Canada 25:1-14.

Ferguson, A. 1989. Genetic differences among brown trout, Salmo trutta, stocks and their importance for the conservation and management of the species. Freshwater Biology $21: 35-46$.

Ferris, S.D., and W.J. Berg. 1987. The utility of mitochondrial DNA in fish genetics and fishery management. Pages 277-299 in N. Ryman and F. Utter, Population genetics and fishery management. University of Washington Press, Seattle.

Fisher, J.P., and W.G. Pearcy. 1988. Growth of juvenile coho salmon (O ncorhynchus kisutch) off Oregon and Washington, USA, in years of differing coastal upwelling. Canadian Journal of Fisheries and Aquatic Sciences 45:1036-1044.

Fleming, I.A., and M.A., Gross. 1988. Evolution of adult female life history and morphology in a Pacific salmon (coho: O ncorhynchus kisutch). Evolution 43: 141-157.

Fleming, I.A., and M.R. Gross. 1989. Evolution of adult female life history and morphology in a Pacific salmon (Coho: O ncorhynchus kisutch). Evolution 43:141-157.

Fleming, I.A., and M.R. Gross. 1992. Reproductive behavior of hatchery and wild coho salmon (O ncorhynchus kisutch): does it differ? Aquaculture 103:101-121.

Flick, W.A., and D.A. Webster. 1962. Problems in sampling wild and domestic stocks of brook trout. Transactions of the American Fisheries Society 91:240-144.

Flick, W.A., and D.A. Webster. 1964. Comparative first year survival and production in wild and domestic strains of brook trout. Transactions of the American Fisheries Society 93:58-69.

Foerster, R.E. 1983. An investigation of the relative efficiencies of natural and artificial propagation of sockeye salmon (Oncorhynchus nerka) at Cultus Lake, British Columbia. Journal of the Fisheries Research Board of Canada 4:151-161.

Foerster, R.E. 1968. The sockey salmon (O ncorhynchus nerka). Fisheries Research Board of Canada, Bulletin 162.

Foote, C.J. 1987. Male mate choice dependent on male size in salmon. Behavior 106:63-80.

RASP Summary Report Series, Part V: Appendix A: Supplementation Literature

December, 1992 /Page 22 
Foote, C.J., C.C. Wood, and R.E. Withler. 1989. Biochemical genetic comparison of sockeye salmon and kokanee, the anadromous and nonanadromous forms of Oncorhynchus nerka. Canadian Journal of Fisheries and Aquatic Sciences 46:149-158.

Frantsi, C., J.A. Ritter, and P.F. Elson. 1977. Effect of corynebacterial kidney disease on ocean survival and return of Atlantic salmon (Salmo salar). Conservation and International Exploration of the Sea 1979:29.

Fraser, F.J. 1969. Population density effects on survival and growth of juvenile coho salmon and steelhead trout in experimental stream channels. Pages in 253-265 T.G. Northcote, editor. Symposium on salmon and trout in streams. H.R. MacMillan Lectures in Fisheries, University of British Columbia, Vancouver.

Fraser, J.M. 1974. An attempt to tram hatchery-reared brook trout to avoid predation by the common loon. Transactions of the American Fisheries Society 103:815-818.

Fraser, J.M. 1981. Comparative survival and growth of planted wild, hybrid, and domestic strains of brook trout (Salvelinus fontinalis) in Ontario lakes. Canadian Journal of Fisheries and Aquatic Science 38: 1672-1684.

Fraser, J.M. 1968. Differential recovery of brook trout planted by hand and by airdrop. Transactions of the American Fisheries Society 97:32-36.

Fraser, J.M. 1978. The effect of competition with yellow perch on the survival and growth of planted brook trout, splake, and rainbow trout in a small Ontario lake. Transactions of the American Fisheries Society 107:505-517.

Fraser, J.M. 1972. Recovery of planted brook trout, splake, and rainbow trout from selected Ontario lakes. Journal of the Fisheries Research Board of Canada 29:129-142.

Fraser, J.M. 1978. Recovery of planted brook trout, splake, and rainbow trout from selected Ontario lakes. Journal of the Fisheries Research Board of Canada 35:391-396.

Fried, S.M., J.D. McCleave, and G.W. LaBar. 1978. Seaward migration of hatchery-reared Atlantic salmon, Salmo salar, smolts in the Penobscot River estuary, Maine: riverine movements. Journal of the Fisheries Research Board of Canada 35:76-87.

Fryer, J.L., and J.E. Sanders. 1981. Bacterial kidney disease of salmonid fish. Annual Review of Microbiology 35:273-298. 
Fulton, L.A. 1968. Spawning area and abundance of chinook salmon (O ncorhynchw tshuw ytscha) in the Columbia River Basin - past and present. U.S. Fish and Wildlife Service Scientific Report, Fisheries No. 571.

Fulton, L.A., and R.E. Pearson. 1981. Transplanting and homing experiments on salmon and steelhead trout in the Columbia River system: fish of the 193944 broods. U.S. Department of Commerce, NOAA Technical Memorandum, NMFS F/NWC-12.

Fuss, H.J., and C. Johnson. 1988. Effects of artificial substrate and covering on growth and survival of hatchery-reared coho salmon. Progressive Fish-Culturist 50:232-237.

Gall, G.A.E. 1983. Genetics of fish: a summary of discussion. Aquaculture 33:383-394.

Gall, G.A.E. Inbreeding. Pages 47-88 in N. Ryman and F. Utter, editors. Population genetics and fisheries management. University of Washington, Washington Sea Grant Program, Seattle.

Garcia De Leaniz, C., E. Verspoor, and A.D. Hawkins. 1989. Genetic determination of the contribution of stocked and wild Atlantic salmon, Salmo salar L., to the angling fisheries in two Spanish rivers. Journal of Fish Biology 35:261-270.

Garcia De Leaniz, C., and E. Verspoor. 1989. Natural hybridization between Atlantic salmon, Salmo salar, and brown trout, Salmo trutta, in northern Spain. Journal of Fish Biology 34:41-46.

Garman, G.C., and L.A. Nielsen. 1982. Piscivority by stocked brown trout (Salmo trutta) and its impact on the nongame fish community of Bottom Creek, Virginia. Canadian Journal of Fisheries and Aquatic Sciences 39:862-869.

Gauldie, R.W. 1984. Allelic variation and fisheries management. New Zealand Ministry of Agriculture and Fisheries Bulletin 26.

Gausen, D., and V. Moen. 1991. Large-scale escapes of farmed Atlantic salmon (Salmo salar) into Norwegian rivers threaten natural populations. Canadian Journal of Fisheries and Aquatic Sciences 48:426-428.

Gee, A.S., N.J. Milner, and R.J. Hemsworth. 1978. The effect of density on mortality in juvenile Atlantic salmon (Salmo salar). Journal of Animal Ecology 47:497-505.

Genetics Committee of the Alaska District of the American Institute of Fishery Research Biologists. 1975. Salmon hatcheries- moving too fast? Alaska Seas and Coasts $3(2): 8-10$. 
Gerstung, E.R. 1981. Status and management of the coast cutthroat trout, Salmo clarki clarki. Cal-Nev Wildlife Transactions.

Gharrett, A.J., and M.A. Thomason. 1987. Genetic changes in pink salmon (O ncorhynchus gorbuscha) following their introduction into the Great Lakes. Canadian Journal of Fisheries and Aquatic Sciences 44:787-792.

Gharrett, A.J., and S.M. Shirley. 1985. A genetic examination of spawning methodology in a salmon hatchery. Aquaculture 47:245- 256.

Gharrett, A.J., S.M. Shirley, and G.R. Tromble. 1987. Genetic relationships among populations of Alaskan chinook salmon (O ncorhynchus tshuw ytschu). Canadian Journal of Fisheries and Aquatic Sciences 44:765-744.

Gharrett, S.C., A.J. McGregor, and P.B. Holmes. 1988. Genetic relationships of even-year northwestern Alaskan pink salmon. Transactions of the American Fisheries Society 117:536-545.

Gibson, M.R. 1989. Atlantic salmon restoration studies: January 1, 1988 to December 31, 1988. Performance Report. Job No. 111-4. Rhode Island Division of Fish and Wildlife.

Gibson, R.J. 1981. Interactions of juvenile Atlantic salmon (Salmo salar L.) and brook trout (Salvelinus fontinalis Mitchell). Pages 181-202 in International Atlantic salmon symposium.

Gilbert, C.H. 1913. Age at maturity of Pacific coast salmon of the genus $\mathbf{O}$ ncorhynchw. Bulletin of the U.S. Bureau of Fisheries 32:57-70.

Ginetz, R., and P.A. Larkin. 1976. Factors affecting rainbow trout (Salmo gaordneri) predation on migrant fry of sockey salmon (O ncorhynchus nerka). Journal of the Fisheries Research Board of Canada 33: 19-24.

Gjedrem, T. 1981. Conservation of fish populations in Norway. Pages 33-36 in N. Ryman, editor. Fish gene pools. Ecological Bulletins, Stockholm.

Gjedrem, T. 1983. Possibilities of genetic changees in the salmonids. Roczniki Nauk Rolniczych, Seria H. 100:65-78. 
Gjerset, F. 1989. Salmon farming in Norway: present status and outlook into the 1990s. Pages 33-40 in W.J. McNeil, editor. Salmon production, management, and allocation: biological, economic, and policy issues. Oregon State University Press, Corvallis, Oregon.

Glova, G.J. 1986. Interaction for food and space between experimental populations of juvenile coho salmon (O ncorhynchus kisutch) and coastal cutthroat trout (Salmo clarki) in a laboratory stream. Hydrobiologia 131: 155-168.

Godin, J.G.J. 1981. Migration of salmonid fishes during early life history phases: daily and annual timing. Pages 22-50 in E.L. Brannon and E.O. Salo, editors. Proceedings of the salmon and trout migratory behavior symposium. University of Washington Press, Seattle.

Goede, R.W. 1986. Management considerations in the stocking of diseased or carrier fish. Pages 349-356 in R.H. Stroud, editor. Fish culture in fisheries management. American Fisheries Society, Bethesda, Maryland.

Goodman, M.L. 1990. Preserving the genetic diversity of salmonid stocks: a call for federal regulation of hatchery programs. Environmental Law 120: 111-166.

Gowing, H. 1978. Survival, growth, and production of domestic and Assinica strain brook trout in four Michigan lakes. Michigan Department of Natural Resources, Project F-035-R-04.

Grant, W.S., G.B. Milner, P. Krasnowski, and F.M. Utter. 1980. Use of biochemical genetic variants for identification of sockeye salmon (O ncorhynchus nerka) stocks in Cook Inlet, Alaska. Canadian Journal of Fisheries and Aquatic Sciences 37:1236-1247.

Grau, E.G. 1981. Is the lunar cycle a factor timing the onset of salmon migration? Pages 184-189 in E.L. Brannon and E.O. Salo, editors. Proceedings of the salmon and trout migratory behavior symposium. University of Washington Press, Seattle.

Gray, G.A., G.M. Sonnevil, H.C. Hansel, C.W. Huntington, and D.E. Palmer. 1982. Feeding activity, rate of consumption, daily ration and prey selection of major predators in the John Day Pool. Annual Report to the Bonneville Power Administration. U.S. Fish and Wildlife Service, National Fisheries Research Center, Cook, Washington. 
Gray, G.A., G.M. Sonnevil, H.C. Hansel, C.W. Huntington, and D.E. Palmer. 1983. Feeding activity, rate of consumption, daily ration and prey selection of major predators in the John Day Reservoir. Annual Report to the Bonneville Power Administration. U.S. Fish and Wildlife Service, National Fisheries Research Center, Cook, Washington.

Gray, G.A., and D.W. Rondorf. 1986. Predation on juvenile salmonids in Columbia basin reservoirs. Pages 178-185 in G.E. Hall, editor. Reservoir fisheries management: strategies for the 80's. American Fisheries Society, Bethesda, Maryland.

Gray, R.W., and J.D. Cameron. 1987. A deep-substrate streamside incubation box for Atlantic salmon eggs. Progressive Fish- Culturist 49:124-129.

Green, C.W. 1952. Results from stocking brook trout of wild and hatchery strains at Stillwater Pond. Transactions of the American Fisheries Society 81:43-52.

Green, D.M. 1964. A comparison of stamina of brook trout from wild and domestic parents. Transactions of the American Fisheries Society 93:96-100.

Griffith, B., J.M. Scott, J.W. Carpenter, and C. Reed. 1989. Translocation as a species conservation tool: status and strategy. Science 245:177-180.

Griffith, J.S. 1972. Comparative behavior and habitat utilization of brook trout and cutthroat trout in small streams in northern Idaho. Journal of the Fisheries Research Board of Canada 29:265-273.

Griffiths, R.H. 1983. Stocking practices and disease control. Special Publication 83-2. Great Lakes Fishery Commission, Ann Arbor, Michigan.

Groberg, W.J., and J.L. Fryer. 1983. Increased occurences of infectious hematopoietic necrosis virus in fish at Columbia river basin hatcheries. Oregon Agricultural Experiment Station, Technical Paper No. 6620, Corvallis.

Groot, C., P. Quinn, and T. Hara. 1986. Responses of migrating sockeye salmon (Oncorhynchus nerka) to population-specific odours. Canadian Journal of Zoology 64:926-932.

Gross, M.R. 1985. Disruptive selection for alternative life histories in salmon. Nature (London) 313:47-48.

Gross, M.R. (in press). Maladaptive evolution of fish in hatcheries. Canadian Journal of Fisheries and Aquatic Sciences.

RASP Summary Report Series, Part V: Appendix A: Supplementation Literature December, 1992 /Page 27 
Gudjonsson, S . 1991. Interaction of farmed salmon and wild salmon stocks in the rivers of Iceland. Aquaculture 98: 133-142.

Gunnerod, T.B., N.A. Hvidsten, and T.G. Heggberget. 1988. Open sea releases of Atlantic salmon smolts, Salmo salar, in central Norway, 1973-1983. Canadian Journal of Fisheries and Aquatic Sciences 45: 1340-1345.

Gunsolus, R.T. 1978. The status of Oregon coho and recommendations for managing the production, harvest, and escapement of wild and hatchery-reared stocks. Oregon Department of Fish and Wildlife Proceedings Report, Portland.

Guyomard, R. 1989. Gestion genetique des populations naturelles 1, example de la truite commune. Bull. Fr. Peche Piscicult. 314: 136-145.

Gyllensten, U., and A.C. Wilson. 1987. Mitochondrial DNA of salmonids: Inter- and intraspecific variability detected with restriction enzymes. Pages 301-317 in N. Ryman and F. Utter, editors. Population Genetics and Fishery Management.

Hager, R.C., and R.E. Noble. 1976. Relation of size at release of hatchery-reared salmon at age, size, and sex composition of returning adults. Progressive Fish-Culturist 38: $144-147$.

Hallerman, E.M., and J.S. Beckmann. 1988. DNA-level polymorphism as a tool in fisheries science. Canadian Journal of Fisheries and Aquatic Sciences 45:1075-1087.

Hankin, D.G. 1982. Estimating escapement of Pacific salmon (Oncorhynchus spp) using marking practices to discriminate wild and hatchery fish. Transactions of the American Fisheries Society 111:286-298.

Hankin, D.G. 1981. Salmon enhancement strategies and wild stocks: evaluation of enhancement success and wild stock impacts. Pages 52-61 in T.J. Hassler, editor. Proceedings: propagation, enhancement, and rehabilitation of anadromous salmonid populations and habitat in the Pacific Northwest. Humboldt State University, Arcata, California.

Hansen, L.P. 1990. Behavior of escaped farmed Atlantic salmon and the impact on wild salmon. Pages 50-52 in P. Oliver and E. Colleran, editors. Proceedings of the Symposium on Interactions between Aquaculture and the Environment. An Taisce, The National Trust of Ireland.

Hansen, L.P., and B. Jonsson. 1985. Downstream migration of hatchery-reared smolts of Atlantic salmon (Salmo salar L.) in the River Imsa, Norway. Aquaculture 45:237-248. 
Hansen, L.P., and B. Jonsson. 1991. Effect of smolt age on migratory behaviour of Baltic salmon, Salmo salar L., transplanted to the east Atlantic. Aquaculture and Fisheries Management 22:357-362.

Hansen, L.P., and B. Jonsson. 1991. The effect of timing of Atlantic salmon smolt and post-smolt release on the distribution of adult return. Aquaculture 98:61-71.

Hansen, L.P., and B. Jonsson. 1991. Evidence of a genetic component in the seasonal return pattern of Atlantic salmon, Salmo salar L. Journal of Fish Biology 38:251-258.

Hansen, L.P., B. Jonsson, and K.B. Doving. 1984. Migration of wild and hatchery reared smolts of Atlantic salmon,Salmo salar L., through lakes. Journal of Fish Biology 251617-623.

Hansen, L.P., and B. Jonsson. 1991. Ranching of Atlantic Salmon in the River Imsa, Norway. International Council for the Exploration of the Sea.

Hansen, L.P., and B. Jonsson. 1986. Salmon ranching experiments in the River Imsa: effects of day and night release and of seawater adaptation on recapture rate of adults. Report of the Institute of Freshwater Resources, Drottingholm 63:47-51.

Hansen, L.P., and B. Jonsson. 1989. Salmon ranching experiments in the River Imsa: effect of timing on Atlantic salmon (Salmo salar) smolt migration on survival to adults. Aquaculture 82: 367- 373.

Hansen, L.P., B. Jonsson, and R. Andersen. 1989. Salmon ranching experiments in the River Imsa: is homing dependent on sequential imprinting of the smolts? Pages 19-29 in E. Brannon and B. Jonsson, editors. Proceedings of the salmonid migration and distribution symposium. School of Fisheries, University of Washington, Seattle.

Hansen, L.P., K.B. Doving, and B. Jonsson. 1987. Migration of farmed adult Atlantic salmon with and without olfactory sense, released on the Norwegian coast. Journal of Fish Biology 30:713- 721.

Hansen, L.P., R.A. Lund, and K. Hindar. 1987. Possible interaction between wild and reared Atlantic salmon in Norway. International Council for the Exploration of the Sea.

Hansen, L.P., T. Hastein, G. Naevdal, R.L. Saunders, and J.E. Thorpe. 1990. Interactions between cultured and wild Atlantic salmon. Aquaculture 98:1-324. 
Harris, G.S. 1973. Rearing smolts in mountain lakes to supplement salmon stocks. Pages 237-252 in International Atlantic Salmon Foundation Special Publication Volume 4.

Hartman, G.F. 1965. The role of behavior in the ecology and interaction of underyearling coho salmon (O ncorhynchus kisutch) and steelhead trout (Salmo gairdneri). Journal of the Fisheries Research Board of Canada 22:1035-1081.

Hartman, J.L., J.S. Holland, M. Kaill, and J.L. Madden. 1988. Enhancement and rehabilitation, a successful investment in Alaska's fisheries. Alaska Fish and Game 21:4-8.

Hasler, A.D. 1971. Orientation and fish migration. Pages 429- 500 in Chapter VI. Academic Press, London.

Hasler, A.D., and A.T. Scholz. 1983. Olfactory imprinting and homing in salmon. Springer-Verlag, New York, New York.

Hastein, T., and T. Lindstad. 1991. Diseases in wild and cultured salmon: possible interaction. Aquaculture 98:277-288.

Havey, K.A. 1974. Population dynamics of landlocked salmon, Salmo salar, in Love Lake, Maine. Transactions of the American Fisheries Society 103:448-456.

Hazzard, A.S. 1941. Results from plantings of marked trout of legal size in streams and lakes of Michigan. Transactions of the American Fisheries Society 70:446-468.

Hazzard, A.S., and D.S. Shetter. 1938. Results from experimental plantings of legal-sized brook trout (Salvelinus fontinalis) and rainbow trout (Salmo irideus). Transactions of the American Fisheries Society 68: 196-210.

Healey, M.C. 1979. Detritus and juvenile salmon production in the Nanaimo estuary: I. Production and feeding rates of juvenile chum salmon (0 ncorhynchus keta). Journal of the Fisheries Research Board of Canada 36:488-496.

Healey, M.C. 1986. Optimum size and age at maturity in Pacific salmon and effects of size-selective fisheries. Canadian Special Publication of Fisheries and Aquatic Sciences $89: 39-52$.

Healey, M.C. 1986. Regional and seasonal attributes of catch in the British Columbia troll fishery. Canadian Technical Report of Fisheries and Aquatic Sciences 1494. 
Healey, M.C. 1982. Timing and relative intensity of size- selective mortality of juvenile chum salmon (Oncorhynchw keta) during early sea life. Canadian Journal of Fisheries and Aquatic Sciences 39:952-957.

Healey, M.C., and C. Groot. 1987. Marine migration and orientation of ocean-type chinook and sockeye salmon. Pages 298- 312 in M. J. Dadswell, R. J. Klauda, C.M. Moffitt, R.L. Saunders, R.A. Rulifson, and J.E. Cooper, editors. Common strategies of anadromous and catadromous fishes: Symposium 1. American Fisheries Society, Bethesda, Maryland.

Heard, W.R., and R.A. Crone. 1976. Raising coho salmon from fry to smolts in estuarine pens, and returns of adults from two smolt releases. Progressive Fish-Culturist 38: $171-174$.

Hearn, W.E. 1987. Interspecific competition and habitat segregation among stream-dwelling trout and salmon: a review. Fisheries 12:24-31.

Hearn, W.E., and B.E. Kynard. 1986. Habitat utilization and behavioral interaction of juvenile Atlantic salmon (Salmo salar) and rainbow trout (Salmo gairdneri) in tributaries of the White River of Vermont. Canadian Journal of Fisheries and Aquatic Sciences 43: $1988-1998$.

Hedrick, P.W., and P.S. Miller. 1992. Conservation genetics: techniques and fundamentals. Ecol. Appl. 2:30-46.

Heggberget, T.G., and B.O. Johnsen. 1982. Infestations by Gyrodactylus sp. of Atlantic salmon, Salmo salar L., in Norwegian rivers. Journal of Fish Biology 21: 15-26.

Heggberget, T.G., L.P. Hansen, and T.F. Naesje. 1988. Within- river spawning migration of Atlantic salmon (Salmo salar). Canadian Journal of Fisheries and Aquatic Sciences 45: $1691-1698$.

Heggberget, T.G., N.A. Hvidsten, T.B. Gunnerod, and P.I. Mokkelgjerd. 1991. Distribution of adult recaptures from hatchery-reared Atlantic salmon (Salmo salar) smolts released in and off-shore of the River Surna, western Norway. Aquaculture 98: 89-96.

Heggberget, T.G., N. Ryman, and G. Stahl. 1986. Growth and genetic variation of Atlantic salmon (Salmo salar) from different sections of the River Alta, north Norway. Canadian Journal of Fisheries and Aquatic Sciences 43:1828-1835.

Heggenes, J. 1988. Effects of short-term flow fluctuations on displacement of, and habitat use by, brown trout in a small stream. Transactions of the American Fisheries Society 117:336- 344.

RASP Summary Report Series, Part V: Appendix A: Supplementation Literature

December, 1992 /Page 31 
Heggenes, J., and T. Traaen. 1988. Downstream migration and critical water velocities in stream channels for fry of four salmonid species. Journal of Fish Biology 32:717-727.

Heimer, J.T., W.M. Frazier, and J.S. Griffith. 1985. Post- stocking performance of catchable-size hatchery rainbow trout with and without pectoral fins. North American Journal of Fisheries Management 5:21-25.

Heland, M. 1980. The downstream migration of the brown trout, Salmo trutta L. fry: 2. Activity of downstream migrants compared with that of non-migrants. Annales de Limnologie 16:247-254.

Heland, M. 1980. La devalaison des alevins de truite commune Salmo trutta L.: I. Caracterisation en milieu artificiel. Annales de Limnologie 16:233-245.

Helfrich, L.A., and W.T. Kendall. 1982. Movements of hatchery reared rainbow trout (Salmo gairdneri) brook trout (Salvelinus fontinalis) and brown trout (Salmo trutta) stocked in Virginia, USA, mountain stream. Progressive Fish-Culturist 44:3-7.

Helle, J.H. 1981. Significance of the stock concept in artificial propagation of salmonids in Alaska. Canadian Journal of Fisheries and Aquatic Sciences 38:1665-1671.

Hemmingsen, A.R., R.A. Holt, R.D. Ewing, and J.D. McIntyre. 1986. Susceptibility of progeny from crosses among three stocks of coho salmon to infection by Ceratomyxa Shasta. Transactions of the American Fisheries Society 115:492-495.

Herrig, D.M. 1990. Lower Snake River compensation plan - a review of the compensation program. U.S. Fish and Wildlife Service, Lower Snake River Compensation Plan Office.

Hershberger, W.K. 1989. Directed and "inadvertent" genetic selection in salmonid culture: results and implications for the resource, and regulatory approaches. Pages 177-186 in W.J. McNeil, editor. Salmon production, management, and allocation: biological, economic, and policy issues. University of Oregon Press, Corvallis, Oregon.

Hershberger, W.K., and R.N. Iwamoto. 1984. Systematic genetic selection and breeding in salmonid culture and enhancement programs. Pages 29-32 in C.J. Sindermann, editor. Proceedings of the Eleventh U.S.-Japan Meeting on Aquaculture, Salmon Enhancement. NOAA Technical Report, NMFS 27, Tokyo, Japan. 
Hesthagen, T. 1988. Movements of brown trout, Sabm trutta, and juvenile Atlantic salmon, Salmo salar, in a coastal stream in northern Norway. Journal of Fish Biology 32: 639-653.

Hilbom, R. 1992. Hatcheries and the future of salmon in the Northwest. Fisheries 17(1):5-8.

Hillman, T.W., and D.W. Chapman. 1989. Abundance, growth, and movement of juvenile chinook salmon (O ncorhynchus tshawytscha) and steelbead (0. mykiss) in an eastern-Cascades River. Canadian Journal of Zoology.

Hillman, T.W., and J.W. Mullan. 1989. Effect of hatchery releases on the abundance and behavior of wild juvenile salmonids. Pages 266-281 in Summer and winter ecology of juvenile chinook salmon and steelhead trout in the Wenatchee River, Washington. Don Chapman, Inc., Boise, Idaho.

Hindar, K., N. Ryman, and F. Utter. (submitted: in press). Genetic effects of aquaculture on natural fish populations. Canadian Journal of Fisheries and Aquatic Sciences.

Hindar, K., N. Ryman, and F. Utter. 1991. Genetic effects of cultured fish on natural fish populations. Canadian Journal of Fisheries and Aquatic Sciences 48:945-957.

Hjort, R.C., and.C.B. Schreck 1982. Phenotypic differences among stocks of hatchery and wild coho salmon (O ncorhynchus kisutch) in Oregon, Washington, and California, USA. Fisheries Bulletin 80: 105-120.

Hoffman, G.L. 1970. Intercontinental and transcontinental dissemination and transfaunation of fish parasites with emphasis on whirling disease (M yxosoma cerebralis). Pages 69-81 in D.F. Snieszko, editor. A Symposium on Diseases of Fishes and Shellfishes. American Fisheries Society (Special Publication No. 5), Washington, D.C.

Holland, J.S. 1989. FRED 1988 annual report to the Alaska State Legislature. Alaska Department of Fish and Game, FRED Division, Juneau.

Holling, C.S. 1973. Resilience and stability of ecological systems. Annual Review of Ecology and Systematics 4: 1-23.

Holm, J.C., T. Refstie, and S. Bo. 1990. The effect of fish density and feeding regimes on individual growth rate and mortality in rainbow trout (O ncorhynchus mykiss). Aquaculture 89: 225-232. 
Holtby, L.B. 1988. The importance of smolt size to marine survival of coho salmon. Pages 211-219 in B.G. Shepherd, rapporteur. Proceedings of the 1988 Northeast Pacific chinook and coho salmon workshop. North Pacific International Chapter American Fisheries Society, Bellingham, Washington,

Holtby, L.B., and M.C. Healey. 1990. Sex-specific life history tactics and risk-taking in coho salmon. Ecology 71:678-690.

Holtby, L.B., T.E. McMahon, and J.C. Scrivener 1989. Stream temperatures and inter-annual variability in the emigration timing of coho salmon (Oncorhynchus kisutch) smolts and fry and chum salmon (0. keta) fry from Carnation Creek, British Columbia. Canadian Journal of Fisheries and Aquatic Sciences 46: 13961405.

Horak, D.L. 1972. Survival of hatchery-reared rainbow trout, Salmo gairdneri, in relation to stamina tunnel ratings. Journal of Fisheries Research Board of Canada 29:1005-1009.

Homer, N.J. 1978. Survival, densities and behavior of salmonid fry in streams in relation to fish predation. Masters thesis. University of Idaho, Moscow.

Horton, H.F. 1956. An evaluation of some physical and mechanical factors important in reducing delayed mortality of hatchery-reared rainbow trout. Progressive Fish-Culturist 18:3- 14 .

Hosmer, M.J., J.G. Stanley, and R.W. Hatch. 1979. Effects of hatchery procedures on later returns of Atlantic salmon to rivers in Maine. Progressive Fish-Culturist 41: 115-1 18.

Howell, P., K. Jones, D. Scamecchia, L. Lavoy, W. Kendra, and D. Ortmann. 1985. Stock assessment of Columbia River anadromous salmonids, Volume 1: chinook, coho, chum, and sockeye salmon stock summaries. Final Report, Project No. 83-335. Bonneville Power Administration, Portland, Oregon.

Hulett, P.L., and S.A. Leider. 1989. Genetic interactions of hatchery and wild steelhead trout: findings and implications of research on the Kalama River, Washington.

Hume, J.M.B., and E.A. Parkinson. 1987. Effect of stocking density on the survival, growth, and dispersal of steelhead trout fry (Salmo gairdmeri). Canadian Journal of Fisheries and Aquatic Sciences 44:271-281.

Hume, J.M.B., and E.A. Parkinson. 1988. Effects of size at and time of release on the survival and growth of steelhead fry stocked in streams. North American Journal of Fisheries Management 8:50-57.

RASP Summary Report Series, Part V: Appendix A: Supplementation Literature

December, 1992 /Page 34 
Hunt, R.L. 1979. Removal of woody streambank vegetation to improve trout habitat. Wisconsin Department of Natural Resources Technical Bulletin No. 115. Madison, Wisconsin.

Hunter, J.G. 1959. Survival and production of pink and chum salmon in a coastal stream. Journal of the Fisheries Research Board of Canada 28:1921.

Huntsman, A.G. 1941. Cyclical abundance and birds versus salmon. Journal of the Fisheries Research Board of Canada 5:227- 235.

Hurst, R.E., and B.G. Blackman. 1988. Coho colonization program: juvenile studies 1984 to 1986. Canadian Manuscript Report of Fisheries and Aquatic Sciences, 1968.

Hutchings, J.A. 1991. The threat of extinction to native populations experiencing spawning intrusions by cultured Atlantic salmon. Aquaculture 98: 119-132.

Hvidsten, N.A., and L.P. Hansen. 1988. Increased recapture rate of adult Atlantic salmon, SaZmo salar L., stocked as smolts at high water discharge. Journal of Fish Biology 32: $153-154$.

Hvidsten, N.A., and P.I. Mokkelgjerd. 1987. Predation on salmon smolts (Salmo salar L.) in the estuary of the River Surna, Norway. Journal of Fish Biology 30:273-280.

Hvidsten, N.A., and R.A. Lund. 1988. Predation on hatchery- reared and wild smolts of Atlantic salmon, SaZmo salar L., in the estuary of River Orkla, Norway. Journal of Fish Biology 33: 121- 126.

Hynes, J.D., E.H. Brown, J.H. Helle, N. Ryman, and D.A. Webster. 1981. Guidelines for the culture of fish stocks for resource management. Canadian Journal of Fisheries and, Aquatic Sciences 38: 1867-1876.

Hynes, R.A., E.J. Duke, and P. Joyce. 1989. Mitochondrial DNA as a genetic marker for brown trout, SaZmo trutta L., populations. Journal of Fish Biology 35:687-701.

Ihssen, P.E., H.E. Booke, J.M. Casselman, J.M. McGlade, N.R. Payne, and F. M. Utter. 1981. Stock identification: materials and methods. Canadian Journal of Fisheries and Aquatic Sciences 38: 1838-1855.

Ihssen, P.E., and J.S. Tait. 1974. Genetic differentiation in retention of swimbladder gas between two populations of lake trout (Salvelinus namaycush). Journal of the Fisheries Research Board of Canada 31: 1351-1354.

RASP Summary Report Series, Part V: Appendix A: Supplementation Literature

December, 1992 /Page 35 
Irvine J.R., and B.R. Ward. 1989. Patterns of timing and size of wild coho salmon (O ncorhynchus kisutch smolts migrating from the Keogh River watershed on northern Vancouver Island. Canadian Journal of Fisheries and Aquatic Sciences 46: 10861094.

Irvine, J.R. 1986. Effects of varying discharge on the downstream movement of salmon fry, Oncorhynchus tshaw ytscha Walbaum. Journal of Fish Biology 28:17-28.

Irvine, J.R., and R.E. Bailey. 1992. Some effects of stocking coho salmon fry and supplemental instream feeding on wild and hatchery-origin salmon. North American Journal of Fisheries Management 12:125-130.

Isaksson, A. 1979. Salmon ranching in Iceland. Pages 131-156 in J.E. Thorpe, editor. Salmon ranching. Academic Press, London.

Isaksson, A. 1988. Salmon ranching: a world review. Aquaculture 29:233-241.

Iwamoto, R.N., and E.O. Salo. 1977. Estuarine survival of juvenile salmonids: a review of the literature. Report to Washington Department of Fisheries. Seattle.

Iwamoto, R.N., J.M. Myers, and W.K. Hershberger. 1986. Genotype-environment interactions for growth of rainbow trout, Salmo gairdneri. Aquaculture 57:153-161.

Iwata, M., and S. Komatsu. 1984. Importance of estuarine residence for adaptation of chum salmon (O ncorhynchus keta) fry to seawater. Canadian Journal of Fisheries and Aquatic Sciences 41.

Jacobs, S.E. 1985. Straying in Oregon by adult salmon of hatchery origin. Oregon Department of Fish and Wildlife Informational Report 88-5.

Jenkins, T.M. 1971. Role of social behaviour in dispersal of introduced rainbow trout. Journal of the Fisheries Research Board of Canada 28:1019-1027.

Jenkins, T.M. 1969. Social structure, position choice and microdistribution of two trout species (Salmo trutta and S. gairdneri) resident in mountain streams. Animal Behaviour Monograph 2:57-123.

Jenkins, T.M., C.R. Feldmeth, and G.V. Elliott. 1970. Feeding of rainbow trout (Salmo gairdneri) in relation to abundance of drifting invertebrates in a mountain stream. Journal of the Fisheries Research Board of Canada 27:2356-2361.

RASP Summary Report Series, Part V: Appendix A: Supplementation Literature

December, 1992 /Page 36 
Jensen, A.J., and B.O. Johnsen. 1986. Different adaptation strategies of Atlantic salmon (Salmo salar) populations to extreme climates with special reference to some cold Norwegian rivers. Canadian Journal of Fisheries and Aquatic Sciences 42: 980-984.

Jensen, A.L., and R.N. Duncan. 1971. Homing of transplanted coho salmon. Progressive Fish-Culturist 33:216-218.

Johannes, R.E., and P.A. Larkin. 1961. Competition for food between redside shiners (Richardsonius balteatus) and rainbow trout (Salmo gairdneri) in two British Columbia lakes. Journal of the Fisheries Research Board of Canada 18:203-220.

Johnels, A.G. 1984. Masken som hotar laxen (Gyrodactylus salaris), a parasite threatening the Atlantic salmon. Svenskt Fiske 9:42-44 (in Swedish).

Johnsen, B.O., and A.J. Jensen. 1991. The Gyrodactylus story in Norway. Aquaculture 98:289-302.

Johnsen, B.O., and A.J. Jensen. 1986. Infestations of Atlantic salmon, Salmo salar, by Gyrodactylus salaris in Norwegian rivers. Journal of Fish Biology 29:233-241.

Johnson, J.H. 1981. Food interrelationships of coexisting brook trout and yearling rainbow trout in tributaries of the Salmon River, New York. New York Fish and Game Journal 28:88-99.

Johnson, O.W., T.A. Flagg, D.J. Maynard, G.B. Milner, and F.W. Waknitz. 1991. Status review for lower Columbia River coho salmon. U.S. Department of Commerce, NOAA Technical Memo. NMFS F/ NWC-202, 94 p.

Johnson, R.C. 1974. Effects of hatchery coho on native Puget Sound stocks of chum salmon fry. Pages 102-109 in D.R. Harding, editor. Proceedings of the 1974 northeast Pacific pink and chum salmon workshop. Department of Environmental Fisheries, Vancouver.

Johnson, S.L. 1982. A review and evaluation of release strategies for hatchery reared coho salmon. Oregon Department of Fish and Wildlife Information Reports (Fish) 82-5. Portland, Oregon.

Johnsson, J.I., and M.V. Abrahams. 1991. Interbreeding with domestic strain increases foraging under threat of predation in juvenile steelhead trout (Oncorhynchus mykiss): an experimental study. Canadian Journal of Fisheries and Aquatic Sciences 48:243- 247. 
Johnsson, J.I., and W.C. Clarke. 1988. Development of seawater adaptation in juvenile steel head trout (Salmo gairdneri) and domesticated rainbow trout (Salmo gairdneri) effects of size, temperature and photoperiod. Aquaculture 71:247-263.

Jonsson, B., N. Jonsson, and L.P. Hansen. 1991. Differences in life history and migratory behaviour between wild and hatchery- reared Atlantic salmon in nature. Aquaculture 98:69-78.

Jonsson, B., N. Jonsson, and L.P. Hansen. 1990. Does juvenile experience affect migration and spawning of adult Atlantic salmon? Behavioral Ecology and Sociobiology 26:225-230.

Jonsson, N., L.P. Hansen, and B. Jonsson. 1991. Variation in age, size and repeat spawning of adult Atlantic salmon in relation to river discharge. Journal of Animal Ecology 60:937- 947.

Joyner, T. 1973. Salmon for New England fisheries, Part III: Developing a coastal fishery for Pacific salmon. Marine Fisheries Review 35:9-13.

Kaczynski, V.W., and J.F. Palmisano. 1992. A review of management and environmental factors responsible for the decline and lack of recovery of Oregon's wild anadromous salmonids. Technical report prepared for the Oregon Forest Industries Council. Oregon Forest Industries Council, Salem, Oregon.

Kaeriyama, M. 1989. Aspects of salmon ranching in Japan. Physiol. Ecol. Spec. Vol. 1:625-638.

Kaeriyama, M. 1989. Current situation and future prospects of salmon aquaculture in Japan, Pages 118-123 in P.A. Knudsen, editor. 14th Northeast Pacific Pink and Chum Workshop. Washington Department of Fisheries, Habitat Management, Olympia, Washington.

Kanid'yev, A.N. 1966. Tolerance of hatchery-reared juvenile chum (Oncorhynchus keta) to rate of flow and to predaceous fishes. Tr Murmansk Morsk Biology Institute 12: 101-1 11.

Kapuscinski, A.R. 1991. Genetic analysis of policies and guidelines for salmon and steelhead hatchery production in the Columbia River Basin. Northwest Power Planning Council, Agreement No. 90-037. Portland, Oregon. 
Kapuscinski, A.R., C.R. Steward, M.L. Goodman, C.C. Krueger, J.H. Williamson, E. Bowles, and R. Carmichael. (In review). Genetic conservation guidelines for salmon and steelhead supplementation. Fishery Bulletin: in preparation. Synthesis paper from Northwest Power Planning Council workshop, 1991, Portland, Oregon.

Kapuscinski, A.R., and D.R. Philipp. 1988. Fisheries genetics: issues and priorities for research and policy development. Fisheries 13:4-10.

Kapuscinski, A.R., and E.M. Hallerman. 1990. Transgenic fish and public policy: anticipating environmental impacts of transgenic fish. Fisheries 15:2-11.

Kapuscinski, A.R., and J.E. Lannan. 1986. A conceptual genetic fitness model for fisheries management. Canadian Journal of Fisheries and Aquatic Sciences 43:1606-1616.

Kapuscinski, A.R., and L.D. Jacobson. 1987. Genetic guide for fisheries management. Minnesota Sea Grant Research Report 17. Department of Fisheries and Wildlife, University of Minnesota, St. Paul.

Kapuscinski, A.R., and L.M. Miller. 1992. Is counter-selection an appropriate tool for rebuilding salmon and steelhead populations in the Columbia River Basin?

Kelly, M.D., P.O. McMillan, and W.J. Wilson. 1990. North Pacific salmonid enhancement programs and genetic resources: issues and concerns. Technical Report NPS/NRARO/NRTR-90103. National Park Service, U.S. Department of the Interior, Washington, D.C.

Kelly, M.D., W.J. Wilson, and P.O. McMillan. 1989. Interactions between wild and hatchery-reared produced salmon in Northwest North America, and issues and concerns over Sikusuilaq Springs Hatchery on the Noatak River, Alaska. Arctic Environmental Information and Data Center, University of Alaska, Anchorage.

Kennedy, G.J.A., and C.D. Strange. 1981. Comparative survival from salmon (Salmo salar L.) stocking with eyed and green ova in an upland stream. Fisheries Management $12: 43-48$.

Kennedy, G.J.A., and C.D. Strange. 1986. The effects of intra- and inter-specific competition on the survival and growth of stocked juvenile Atlantic salmon Salmo salar L., and resident trout, Salmo trutta L., in an upland stream. Journal of Fish Biology 28:479-490.

RASP Summary Report Series, Part V: Appendix A: Supplementation Literature

December, 1992 /Page 39 
Kennedy, G.J.A., C.D. Strange, R.J.D. Anderson, and P.M. Johnston. 1984. Experiments on the descent and feeding of hatchery-reared salmon smolts (Salmo salar L.) in the River Bush. Fisheries Management 15: 15-25.

KeMedy, G.J.A., and CD. Strange. 1980. Population changes after two years of salmon (Salmo salar L.) stocking in upland trout (Salmo trutta L.) streams. Journal of Fish Biology 17:577- 586.

Kennedy, G.J.A., and C.D. Strange. 1978. Seven years on -- A continuing investigation of salmonid stocks in Lough Eme tributaries. Journal of Fish Biology 12:325-330.

Kennedy, G.J.A., and C.D. Strange. 1986. The effects of intra- and inter-specific competition on the survival and growth of stocked juvenile Atlantic salmon, Salmo salar L., and resident trout, Salmo trutta L., in an upland stream. Journal of Fish Biology 28:479-489.

Kijima, A., and Y. Fujio. 1984. Relationship between average heterozygosity and river population size in chum salmon. Bull. Jap. Soc. Sci. Fish. 50603 608.

Kincaid, H.L. 1983. Inbreeding in fish populations used for aquaculture. Aquaculture 33 215-227.

Kincaid, H.L., and C.R. Berry. 1986. Trout broodstocks used in management of national fisheries. Pages 211-222 in R.H. Stroud, editor. Fish culture in fisheries management. American Fisheries Society, Bethesda, Maryland.

Kitchell, J.F. 1991. Salmonid carrying capacity: estimates and experiences in the Great Lakes of North America. R.S. Svrjcek, editor. Marine Ranching: Proceedings of the Seventeenth U.S.- Japan Meeting on Aquaculture. NOAA Technical Report, NMFS 102, Ise, Mie Prefecture, Japan.

Klak, G.E. 1941. The condition of brook trout and rainbow trout from four eastern streams. Transactions of the American Fisheries Society 70:282-289.

Kohler, T. 1984. Pink and chum salmon adult returns from releases at Cannery Creek and Main Bay hatcheries: 1983 field season. Alaska Department of Fish and Game, FRED Division, No. 34.

Kristiansson, A.C., and J.D. McIntyre. 1976. Genetic variation in chinook salmon (Oncorhynchus tshawyrscha) from the Columbia River and three Oregon coastal rivers. Transactions of the American Fisheries Society 105:620-623. 
Krueger, C.C., and B. May. In press. Ecological and genetic effects of salmonid introductions in North America. Canadian Journal of Fisheries and Aquatic Sciences.

Krueger, C.C., and B.W. Menzel. 1979. Effects of stocking on genetics of wild brook trout (Salvelinus fontinalis) populations. Transactions of the American Fisheries Society 108:277-287.

Krueger, C.C., and B. May. 1987. Genetic comparison of naturalized rainbow trout populations among Lake Superior tributaries: differentiation based on allozyme data. Transactions of the American Fisheries Society 116:795-806.

Krueger, C.C., and B. May. 1987. Stock identification of natural\&d brown trout in Lake Superior tributaries: differentiation based on allozyme data. Transactions of the American Fisheries Society 116:785-794.

Krueger, C.C., A.J. Gharrett, T.R. Dehring, and F.W. Allendorf. 1981. Genetic aspects of fisheries rehabilitation programs. Canadian Journal of Fisheries and Aquatic Sciences 38: $1877-1881$.

Kuehn, J.H., and R.E. Schumacher. 1957. Preliminary report on a two-year census on four southeastern Minnesota streams. Investigational Report 186. Minnesota Department of Conservation, Division of Game Fisheries.

Kyle, G.B., and D.S. Litchfield. 1989. Enhancement of Crooked River chinook salmon (O ncorhynchus tshuwytscha) and development of a sport fishery on the Kasilof River. Alaska Department of Fish and Game, FRED Division, No. 97.

Kyle, G.B., J.P. Koenings, and B.M. Barrett. 1988. Density- dependent, trophic level responses to an introduced run of sockeye salmon (Oncorhynchus nerka) at Fraser Lake, Kodiak Island, Alaska. Canadian Journal of Fisheries and Aquatic Sciences 45:856-867.

Labelle, M. 1990. A comparative study of coho salmon populations of southeast Vancouver Island, British Columbia: juvenile outmigration, coded wire tagging and recovery, escapement enumeration, and stock composition at Black Creek, Trent River, and French Creek, 1984-1988. Canadian Technical Report on Fisheries and Aquatic Sciences, 1722.

Labelle, M. 1992. Straying patterns of coho salmon (O ncorhynchus kisutch) stocks from southeast Vancouver Island, British Columbia. Canadian Journal of Fisheries and Aquatic Sciences 49: 1843-1855. 
Labellle, M. 1990. A comparative study of the demographic traits and exploitation patterns of coho salmon stocks from southeast Vancouver Island, British Columbia. Ph.D. thesis. Department of Zoology, University of British Columbia, Vancouver, B.C.

Lachance, S., and P. Magnan. 1990. Comparative ecology and behavior of domestic, hybrid, and wild strains of brook trout, salvelinus fontinalis after stocking. Canadian Journal of Fisheries and Aquatic Sciences 47:2285-2292.

Lachance, S., and P. Magnan. 1990. Performance of domestic, hybrid, and wild strains of brook trout, salvelinus fontinalis, after stocking: the impact of intra- and interspecific competition. Canadian Journal of Fisheries and Aquatic Sciences 47:2278-2284.

Lannan, J.E., and A.R. Kapuscinski. 1984. Genetic guidelines for evaluation and selection of enhancement projects under the Salmon and Steelhead Conservation and Enhancement Act. Department of Fisheries and Wildlife, Oregon State University Report for the Enhancement Planning Team. Pacific Marine Fisheries Commission, Newport, Oregon.

LaPatra, S.E., W.J. Groberg, J.S. Rohovec, and J.L. Fryer. 1990. Size-related susceptibility to two strains of infectious hematopoetic necrosis virus. Transactions of the American Fisheries Society 119:25-30.

Larkin, P.A. 1956. Interspecific competition and population control in freshwater fish. Journal of the Fisheries Research Board of Canada 13:327-342.

Larkin, P.A. 1963. Interspecific competition and exploitation. Journal of the Fisheries Research Board of Canada 20:647-678.

Larkin, P.A., and S.B. Smith. 1954. Some effects of the introduction of the redside shiner on the Kamloops trout in Paul Lake, British Columbia. Transactions of the American Fisheries Society 83: 161-175.

Larson, R.W., and J.M. Ward. 1955. Management of steelhead in the State of Washington. Transactions of the American Fisheries Society 84:261-274.

Larsson, P.O. 1977. The importance of time and place of release of salmon and sea trout on the results of stockings. International Council for the Exploration of the Sea.

Larsson, P.O. 1985. Predation on migrating smolts as a regulating factor in Baltic salmon, Salmo salar L., populations. Journal of Fish Biology 26:391-397.

Larsson, P.O. 1980. Smolt rearing and the Baltic salmon fishery. Pages 157-186 in J.E. Thorpe, editor. Salmon ranching. Academic Press, London. 
Leary, R.F., F.W. Allendorf, and K.L. Knudsen. 1985. Developmental instability as an indicator of reduced genetic variation in hatchery trout. Transactions of the American Fisheries Society 114:230-235.

Leary, R.F., F.W. Allendorf, and K.L. Knudsen. 1987. Genetic divergence and identification of seven cutthroat trout subspecies and rainbow trout. Transactions of the American Fisheries Society 116 580-587.

Leary, R.F., F.W. Allendorf, and K.L. Knudsen. 1989. Genetic differences among rainbow trout spawned on different days within a single season. Progressive Fish-Culturist 51: $10-19$.

Leary, R.F., F.W. Allendorf, S.R. Phelps, and L. Knudsen. 1984. Jntrogression between westslope cutthroat and rainbow trout in the Clark Fork River drainage. Proceedings of the Montana Academy of Sciences 43:1-18.

LeCren, E.D. 1972. Fish production in freshwaters. Pages 115- 133 in Symposium of the Zoological Society of London: Volume 29.

LeCren, E.D. 1965. Some factors regulating the sire of populations of freshwater fish. International Association of Theoretical and Applied Limnology 13:88-105.

Lee, K.N. 1989. The Columbia River Basin: experimenting with sustainability. Environment 31:6.

Legault, M., and L.M. Lalancette. 1985. Time of adjustment of buoyancy of Atlantic salmon (Salmo salar) compared with buoyancy of hatchery-reared and wild salmon. Canadian Journal of Fisheries and Aquatic Sciences 42:619-623.

Leggett, W.C. 1977. The ecology of fish migrations. Annual Review of Ecological Systems 8:285-308.

Leider, S.A., M.W. Chilcote, and J.L. Loch. 1986. Comparative life history characteristics of hatchery and wild steelhead trout (Salmo gairdneri) of summer and winter races in the Kalama River, Washington. Canadian Journal of Fisheries and Aquatic Sciences 43: $1398-1409$.

Leider, S.A., M.W. Chilcote, and J.L. Loch. 1984. Spawning characteristics of sympatric populations of steelhead trout (Salmo gairdneri): evidence for partial reproductive isolation. Canadian Journal of Fisheries and Aquatic Sciences 41: 1454-1462.

RASP Summany Report Series, Part V: Appendix A: Supplementation Literature

December, 1992 /Page 43 
Leider, S.A., J.J. Loch, and P.L. Hulett. 1986. Studies of hatchery and wild steelhead in the lower Columbia region. Washington State Game Department, Report 86-14. Washington State Game Department, Olympia.

Leider, S.A., J.J. Loch, and P.L. Hulett. 1989. Studies of hatchery and wild steelhead in the lower Columbia region. 1989 Progress Report. Washington Department of Wildlife Report 89-5.

Leider, S.A., P.L. Hulett, J.J. Loch, and M.W. Chilcote. 1990. Electrophoretic comparison of the reproductive success of naturally spawning transplanted and wild steelhead trout through the returning adult stage. Aquaculture 88:239-252.

Lemmien, W.A., PI. Tack, and W.F. Morofsky. 1957. Results from planting brown trout and rainbow trout in August Creek, Kalamazoo County, Michigan. Quarterly Bulletin of the Michigan State University Agricultural Experimentation Station 40:242-249.

Levings, CD., C.D. McAllister, and B.D. Chang. 1986. Differential use of the Campbell River estuary, British Columbia, by wild and hatchery-reared juvenile chinook salmon (Oncorhynchus tshawytscha). Canadian Journal of Fisheries and Aquatic Sciences 43: 13861397.

Levings, C., and R. Lauzier. 1988. Migration patterns of wild and hatchery-reared juvenile chinook salmon in the Nicola River, British Columbia. Pages 267-275 in B.G. Shepherd, rapporteur. Proceedings of the 1988 Northeast Pacific chinook and coho salmon workshop. North Pacific International Chapter American Fisheries Society, Bellingham, Washington.

Levy, D.A., and C.D. Levings. 1978. A description of the fish community of the Squamish River estuary, British Columbia: relative abundance, seasonal changes, and feeding habits of salmonids. Canadian Fisheries and Marine Service Manuscript Report No.1475.

Levy, D.A., and T.G. Northcote. 1982. Juvenile salmon residency in a marsh area of the Fraser River estuary. Canadian Journal of Fisheries and Aquatic Sciences 393270-276.

Lewynsky, V.A., and T.C. Bjomn. Response of cutthroat and rainbow trout to experimental catch-and-release fishing. Pages 16-32 in R.A. Bamhart and T.D. Roelofs, editors. Proceedings of a national sport fishing symposium on catch-and-release fishing, a decade of experience. Humboldt State University, Arcata, California.

Li, H.W., and R.W. Brocksen. 1977. Approaches to the analysis of energetic costs of intraspecific competition for space by rainbow trout (Salmo gairdneri). Journal of Fish Biology 11:329- 341. 
Lichatowich, J.A., and J.D. McIntyre. 1987. Use of hatcheries in the management of Pacific anadromous salmonids. Pages 131-136 in M.J. Dadswell, R.J. Klauda, C.M. Moffitt, R.L. Saunders, R.A. Rulifson, and R.A. Cooper, editors. Common strategies of anadromous and catadromous fishes: Symposium 1. American Fisheries Society, Bethesda, Maryland.

Lichatowich, J.A., and J.W. Nicholas. 1992. Oregon's first century of hatchery intervention in salmon production: evolution of the hatchery program, legacy of a utilitarian philosophy and management recommendations.

Light, J.T. 1989. The magnitude of artificial production of steelhead trout along the Pacific Coast of North America (document submitted to the International North Pacific Fisheries Commission).

Lister, D.B., D.G. Hickey, and I. Wallace. 1981. Review of the effects of enhancement strategies on the homing, straying and survival of Pacific salmonids. Report prepared for the Canadian Department of Fisheries and Oceans: Volumes I \& II. D.B. Lister \& Associates, Ltd., Vancouver, BC.

Lister, D.B., and H.S. Genoe. 1970. Stream habitat utilization by cohabitating underyearlings of chinook (Oncorhynchus tshawytscha) and coho (0. kisutch) salmon in the Big Qualicum River, British Columbia. Journal of the Fisheries Research Board of Canada 27: $1215-1224$.

Litchfield, D.S., and L.B. Flagg. 1988. Hidden Lake sockeye salmon investigations, 1983-1984. Alaska Department of Fish and Game, FRED Division, No. 86.

Loftus, K.H. 1976. Science for Canada's fisheries rehabilitation needs. Journal of the Fisheries Research Board of Canada 33:1822-1857.

Lord, R.F. 1934. Hatchery trout as foragers and game fish. Transactions of the American Fisheries Society 70:282-289.

Lovejoy, T.E. 1977. Genetic aspects of dwindling populations: a review. Pages 275-279 in The University of Wisconsin Press, Madison, Wisconsin.

Lund, R.A., F. Okland, and L.P. Hansen. 1991. Farmed Atlantic salmon (Salmo salar) in fisheries and rivers in Norway. Aquaculture 98:143-150.

RASP Summruy Report Series, Part V: Appendix A: Supplementation Literature

December, 1992 /Page 45 
Lund, R.A., L.P. Hansen, and T. J\&vi. 1989. Identification of reared and wild salmon by external morphology, size of fins and scale characteristics. Norwegian Institute for Nature Research, Trondheim.

Lund, R.A., and T.G. Heggberget. 1992. Migration of Atlantic salmon, Salmo salar L., parr through a Norwegian fjord: potential infection path of Gyrodactylus saluris. Aquaculture and Fisheries Management 23:367-372.

Lura, H., and H. Saegrov. 1991. Documentation of successful spawning of escaped farmed female Atlantic salmon, Salmo salar in Norwegian rivers. Aquaculture 98: 151-159.

Lura, H., and H. Saegrov. 1991. A method of separating offspring from farmed and wild Atlantic salmon (Salmo salar) based on different ratios of optical isomers of astaxanthin. Canadian Journal of Fisheries and Aquatic Sciences 48:429-433.

Lynch, M. 1991. The genetic interpretation of inbreeding depression and outbreeding depression. Evolution 45(3):622-629.

MacCrimmon, H.R. 1954. Stream studies on planted Atlantic salmon. Journal of the Fisheries Research Board of Canada 11:362- 403.

MacDonald, J.S., I.K. Birtwell, and G.M. Kruzynski. 1987. Food and habitat utilization by juvenile salmonids in the Campbell River estuary. Canadian Journal of Fisheries and Aquatic Sciences 44: 1233-1246.

Macdonald, S.J., C.D. Levings, C.D. McAllister, U.H.M. Fagerlund, and J.R. McBride. 1988. A field experiment to test the importance of estuaries for chinook salmon (Oncorhynchus tshawytscha) survival: short-term results. Canadian Journal of Fisheries and Aquatic Sciences 45:1366-1377.

Mace, P.M. 1983. Bird predation on juvenile salmonids in the Big Qualicum River, Vancouver Island, Canada. Canadian Technical Report of Fisheries and Aquatic Sciences 1176.

MacLean, J.A., and D.O. Evans. 1981. The stock concept, discreteness of fish stocks, and fisheries management. Canadian Journal of Fisheries and Aquatic Sciences 38: 1889-1898.

Mahnken, C.V.W., D.M. Damkaer, and V.G. Wespestad. 1983. Perspectives of North Pacific salmon sea ranching. Proceedings of the International Fish Farming Conference 2: $186-216$. 
Mahnken, C., E. Prentice, W. Waknitz, G. Monan, C. Sims, and J. Williams. 1982. The application of recent smoltification research to public hatchery releases: an assessment of size/time requirements for Columbia River hatchery coho salmon (O ncorhynchw kisutch). Aquaculture 28:251-268.

Maitland, P.S. 1989. The genetic impact of farmed Atlantic salmon on wild populations. Nature Conservancy Council, Edinburgh, Scotland.

Maitland, P.S. The potential impact of fish culture on wild stocks of Atlantic salmon in Scotland. Pages 73-78 in D. Jenkins and W.M. Shearer, editors. The Status of the Atlantic Salmon in Scotland, I.T.E. Symposium No. 15. Abbots Ripton, Huntingdon.

Marnell, L.F. 1986. Impacts of hatchery stocks on wild fish populations. Pages 339-347 in R.H. Stroud, editor. Fish culture in fisheries management. American Fisheries Society, Bethesda, Maryland.

Marnell, L.F., R.J. Behnke, and F. W. Allendorf. 1987. Genetic identification of cutthroat trout, Salmo clarki, in Glacier National Park, Montana. Canadian Journal of Fisheries and Aquatic Sciences 44: 1830-1 839.

Marsden, J.E., and C.C. Krueger. 1989. Identification of parental origins of naturally produced lake trout in Lake Ontario: application of mixed-stock analysis to a second generation. North American Journal of Fisheries Management 9:257- 268.

Martin, J.T. 1984. Social value of wild fish. Pages 297-301 in J.M. Walton and D.B. Houston, editors. Proceedings of the Olympic wild fish conference. Peninsula College, Fisheries Technology Program, Port Angeles, Washington.

Martin, R.M., and A. Wertheimer. 1989. Adult production of chinook salmon reared at different densities and released as two smolt sires. Progressive Fish-Culturist 51: 194-200.

Mason, J.D. 1974. Behavioral ecology of chum salmon fry (O ncorhynchw keta) in a small estuary. Journal of the Fisheries Research Board of Canada 41:70-92.

Mason, J.C., and D.W. Chapman. 1965. Significance of early emergence, environmental rearing capacity, and behavioral ecology of juvenile coho salmon in stream channels. Journal of the Fisheries Research Board of Canada 22:173-190.

Mason, J.W., O.M. Brynildson, and P.E. Degarse. 1967. Comparative survival of wild and domestic strains of brook trout in streams. Transactions of the American Fisheries Society 96: 313-319.

RASP Summary Report Series, Part V: Appendix A: Supplementation Literature

December, 1992 / Page 47 
Mathews, S.B. 1983. Variability of marine survival of Pacific salmonids: a review. Pages 161-182 in W.G. Pearcy, editor. The influence of ocean conditions on production of salmonids in the North Pacific: a workshop. Oregon State University, Oregon Sea Grant Program ORESU-W-83-001, Corvallis.

Mathews, S.B., and Y. Ishida. 1989. Survival, ocean growth, and ocean distribution of differentially timed releases of hatchery coho salmon (O ncorhynchus kisutch). Canadian Journal of Fisheries and Aquatic Sciences 46:1216-1226.

Matthews, G.M., and R.S. Waples. 1991. Status review for Snake River spring and summer chinook salmon. U.S. Department of Commerce, NOAA Technical Memo. NMFS F/NWC-200, 75 p.

Maule, A.G., and H.F. Horton. 1984. Feeding ecology of walleye, Stiw stedion vitrew, in the mid-Columbia River, with emphasis on the interactions between walleye and juvenile anadromous fishes. Fishery Bulletin 82:411-418.

Mayama, H., T. Nomura, and K. Ohkuma. 1989. Reciprocal transplantation experiment of masu salmon (O ncorhynchus masou) population. 2. Comparision of seaward migrations and adult returns of local stock and transplanted stock of masu salmon. Scientific Report of the Hokkaido Salmon Hatchery 43:99-113.

Mazeaud, M.M., F. Mazeaud, and E.M. Donaldson. 1977. Primary and secondary effects of stress in fish, some new data with a general review. Transactions of the American Fisheries Society 106:201-212.

McCarl, B.A., and R.B. R ettig. 1983. Influence of hatchery smolt releases on adult salmon production and its variability. Canadian Journal of Fisheries and Aquatic Sciences 40: $1880-1886$.

McCleave, J.D. 1978. Rhythmic aspects of estuarine migration of hatchery-reared Atlantic salmon (Salmo salar) smolts. Journal of Fish Biology 12:559-570.

McCraren, J.P., and J.L. Millard. 1978. Transportation of warmwater fishes. Pages 43-88 in Manual of fish culture, Section G: Fish transportation. U.S. Fish and Wildlife Service.

McDaniel, T.R., T. Kohler, and D.M. Dougherty. 1984. Results of pink salmon (O ncorhynchus gorbuscha) fry transplants to Ho10 Creek, Prince William Sound, Alaska. Alaska Department of Fish and Game, FRED Division, No. 33. 
McDermott, L.A., and A.H. Berst. 1968. Experimental plantings of brook trout from furunculosis-infected stock. Journal of the Fisheries Research Board of Canada 25:2643-2649.

McDonald, J., and J.M. Hume. 1984. Babine Lake sockeye salmon (O ncorhynchw nerka) enhancement program: testing some major assumptions. Journal of the Fisheries Research Board of Canada 41:70-92.

McFadden, J.T. 1969. Dynamics and regulation of salmonid populations in streams. Pages 313-329 in T.G. Northcote, editor. Symposium on salmon and trout in streams. H.R. MacMillan Lectures in Fisheries, University of British Columbia, Vancouver.

McGie, A.M. 1984. Commentary: evidence for density dependence among coho salmon stocks in the Oregon Production Index Area. Pages 37-49 in W.G. Pearcy, editor. The influence of ocean conditions on the production of salmonids in the North Pacific: a workshop. Oregon State University, Oregon Sea Grant Program ORESU-W-83-001, Corvallis.

McGie, A.M. 1981. Trends in escapement and production of fall chinook and coho salmon in Oregon. Fish Division Information Report 81-7. Population Dynamics Statistical Service Section, Oregon Department of Fish and Wildlife, Portland.

McIntyre, J.D. (in press). Pacific salmon culture for stocking.

McIntyre, J.D., and D.F. Amend. 1978. Heritability of tolerance for infectious hematopoietic necrosis in sockeye salmon (O ncorhynchw nerka). Transactions of the American Fisheries Society 107:305-308.

McIntyre, J.D., R.R. Reisenbichler, J.M. Emlen, R.L. Wilmot, and J.E. Finn. 1989. Predation of Karluk River sockeye salmon by coho salmon and char. Fishery Bulletin 86:611-616.

McIntyre, J.D., A.R. Hemmingsen, and R.C. Simon. 1988. Selection to increase survival of smolts in four successive broods of coho salmon. Transactions of the American Fisheries Society 117:90-92.

McIntyre, J.D., and R.R. Reisenbichier. 1986. A model for selecting harvest fraction for aggregate populations of hatchery and wild anadromous salmonids. Pages 179-189 in R.H. Stroud, editor. Fish culture in fisheries management. American Fisheries Society, Bethesda, Maryland. 
McIsaac, D.O., and T.P. Quinn. 1988. Evidence of a hereditary component in homing behavior of chinook salmon (Oncorhynchus tshuwytscha). Canadian Journal of Fisheries and Aquatic Sciences 45:2201-2205.

McLaren, J.B. 1979. Comparative behavior of hatchery-reared and wild brown trout and its relation to intergroup competition in a stream. Doctoral dissertation. Pennsylvania State University, University Park.

McLaren, J., and R.L. Butler. 1970. The Spruce Creek catch-and- release study. Trout Unlimited.

McMullin, S.L. 1982. Inventory and survey of the waters of the Bighole and Beaverhead drainage. DJ Job Completion Report F-9-R- 30. Montana Department of Fish, Wildlife and Parks, Helena.

McNeil, W.J. 1989. Salmon production, management, and allocation: biological, economic, and policy issues. Oregon State University Press, Corvallis, Oregon.

McNeil, W.J., S.C. Smedley, and R.J. Ellis. 1969. Transplanting adult pink salmon to Sashin Creek, Baranof Island, Alaska, and survival of their progeny. U.S. Fish Wildl. Serv. Spec. Sci. Rep. Fish. 587:9.

Mead, R.W., and W. Woodall. 1968. Comparison of sockeye salmon fry produced by hatcheries, artificial channels, and natural spawning areas. Progress Report No. 20. International Pacific Salmon Fisheries Commission.

Meffe, G. 1986. Conservation genetics and the management of endangered fishes. Fisheries 11: $14-23$.

Meffe, G. 1987. Conserving fish genomes: philosophies and practices. Environmental Biology of Fishes 18:3-9.

Meister, A.J. 1962. Atlantic salmon production in Cove Brook, Maine. Transactions of the American Fisheries Society 91:208-212.

Millard, T.J., and H.R. MacCrimmon. 1972. Evaluation of the contribution of supplemental plantings of brown trout, Salmo trutta L., to a self-sustaining fishery in the Sydenham River, Ontario, Canada. Journal of Fish Biology 4:369-384.

Millenbach, C. 1973. Genetic selection of steelhead trout for management purposes. Washington State Department of Game, Olympia. 
Miller, R.B. 1954. Comparative survival of wild and hatchery- reared cutthroat trout in a stream. Transactions of the American Fisheries Society 83:120-130.

Miller, R.B. 1958. The role of competition in the mortality of hatchery trout. Journal of the Fisheries Board of Canada 15:27- 45.

Miller, R.B. 1952. Survival of hatchery-reared cutthroat trout in an Alberta stream. Transactions of the American Fisheries Society 81:35-42

Miller, R.B. 1955. Trout management research in Alberta. Transactions of the 20th North American Wildlife Conference 242- 252.

Miller, W.H. 1990. Analysis of salmon and steelhead supplementation. Report to Bonneville Power Administration, Project 88-100. Bonneville Power Administration, Portland, Oregon.

Miller, W.H., T.C. Coley, H.L. Burge, and T.T. Kisanuki. 1990. Analysis of salmon and steelhead supplementation: emphasis on unpublished reports and present programs. Part 1 in W.H. Miller, editor. Analysis of salmon and steelhead supplementation, Parts 1-3. Technical Report 88-100. Bonneville Power Authority, U.S. Department of Energy, Portland, Oregon.

Mills, D.H. 1964. The ecology of young stages of the Atlantic salmon in the River Bran, Rosshire. Department of Agriculture Fisheries of Scotland, Freshwater Salmon Fisheries Research 32.

Mills, D.H. 1969. The survival of hatchery-reared salmon fry in some Scottish streams. Freshwater and Salmon Fisheries Research 39.

Minta, P., S. Gephard, and R. Van Nostrand. 1987. Anadromous fish enhancement restoration. 1987 Annual Performance Report, F- 50-D-8. Connecticutt Department of Marine Fisheries, Waterford.

Mitans, A.R. 1973. Dwarf males and the sex structure of a Baltic salmon (Salmo salar L.) population. Journal of Icthyology 13: 192-197.

Mitans, A.R. 1977. Investigations on wild and hatchery salmon of the river Daugava. Ann. Biol. Copenh. 32: 156-157. 
Mitchum, D.L., L.E. Sherman, and G.T. Baxter. 1979. Bacterial kidney disease in feral populations of brook trout (Salvelinus fontinalis), brown trout (Salmo trutta), and rainbow trout (Salmo gairdneri). Journal of the Fisheries Research Board of Canada 36: $1370-1376$.

Mitchum, D.L., and L.E. Sherman. 1981. Transmission of bacterial kidney disease from wild to stocked hatchery trout. Canadian Journal of Fisheries and Aquatic Sciences 38:547-551.

Moav, R., T. Brody, and G. Hulata. 1978. Genetic improvement of wild fish populations. Science 201: 1090-1094.

Moller, D. Atlantic salmon aquaculture: Past, present, and future.

Moller, D. 1970. Transferrin polymorphism in Atlantic salmon (Salmo salar). Journal of the Fisheries Research Board of Canada 27:1617-1625.

Monitoring and Evaluation Group. 1989. System planning model documentation. Northwest Power Planning Council, Portland, Oregon.

Moring, J.R. Stocking anadromous species to restore or enhance fisheries. Pages 75-80 in R.H. Stroud, editor. Fish culture in fisheries management. American Fisheries Society, Bethesda, Maryland.

Moring, J.R., and D.V. Buchanan. 1978. Downstream movements and catches of two strains of stocked trout. Journal of Wildlife Management 42(2):329-333.

Mortensen, E. 1977. Density dependent mortality of trout fiy (Salmo trutta L.) and its relationship to the management of small streams. Journal of Fish Biology 11:613-617.

Mortensen, E. 1977. The population dynamics of young trout (Salmo trutta L.) in a Danish brook. Journal of Fish Biology 10: 23-33.

Moyle, P.B. 1969. Comparative behavior of young brook trout of domestic and wild origin. Progressive Fish-Culturist 3 1:5 1-56.

Mulcahy, D., R.J. Pascho, and C.K. Jenes. 1983. Titre distribution patterns of infectious hematopoietic necrosis virus in ovarian fluids of hatchery and feral salmon populations. Journal of Fish Diseases 6:321-330.

Mullan, J. 1987. Status and propagation of chinook salmon in the mid-Columbia river through 1985. U.S. Fish and Wildlife Service Biol. Rep. 87(3):1-111. 
Mullan, J.W., and J.D. McIntyre. Growth and survival of salmon and steelhead in a controlled section of Icicle Creek. U.S. Fish and Wildlife Service Information Report FRI/FAO-86-14. Seattle, Washington.

Murphy, B.R., and W.E. Kelso. 1986. Strategies for evaluating fresh-water stocking programs: past practices and future needs. Pages 303-314 in R.H. Stroud, editor. Fish culture in fisheries management. American Fisheries Society, Bethesda, Maryland.

Myers, K. 1978. Comparative analysis of stomach contents of cultured and wild juvenile salmonids in Yaquina Bay, Oregon. S.J. Lipovsky and C.A. Simensted, editors. Fish food habit studies. Proceedings of the second Pacific Northwest technical workshop. Washington Sea Grant Publications, University of Washington, Seattle.

Myers, K., and H. Horton. 1982. Temporal use of an Oregon estuary by hatchery and wild juvenile salmon. Pages 377-392 in V. Kennedy, editor. Estuarine comparisons. Academic Press, New York.

Narver, D.W. 1973. Hatcheries, channels are not panaceas. Western Fisheries, April:38-46.

National Council on Gene Resources. Anadromous salmonid genetic resources: an assessment and plan for California. Report for California Department of Food and Agriculture. California Gene Resources Program, Berkeley, California.

Neave, F. 1953. Principles affecting the sire of pink and chum salmon populations in British Columbia. Journal of the Fisheries Research Board of Canada 9:450-491.

Needham, P.R., and D.W. Slater. 1945. Seasonal changes in growth, mortality, and condition of rainbow trout following planting. Transactions of the American Fisheries Society 73: 117- 124.

Needham, P.R., and D.W. Slater. 1944. Survival of hatchery- reared brown and rainbow trout as affected by wild trout populations. Journal of Wildlife Management 8:22-36.

Nehlsen, W., J.E. Williams, and J.A. Lichatowich. 1991. Pacific salmon at the crossroads: stocks at risk from California, Oregon, Idaho, and Washington. Fisheries 16(2):4-21.

Neilson, J.D., G.H. Geen, and D. Bottom. 1985. Estuarine growth of juvenile chinook salmon (O ncorhynchus tshaw ytscha) as inferred from otolith microstructure. Canadian Journal of Fisheries and Aquatic Sciences 42:899-908. 
Neitzel, D.A., and D.H. Fickeisen. 1990. Proceedings of the anadromous fish release strategies workshop: December 11-14, 1989. Project No. 86-118 Bonneville Power Administration, U.S. Department of Energy.

Nelson, K., and M. Soule. 1987. Genetical conservation of exploited fishes. Pages 345-368 in N. Ryman and F. Utter, editors. Population genetics and fishery management. University of Washington Press, Seattle.

Newell, A.E. 1957. Two-year study of movements of stocked brook trout and rainbow trout in a mountain trout stream. Progressive Fish-Culturist 19:76-80.

Ney, J.J., and D.J. Orth. 1986. Coping with future shock: matching predator stocking programs to prey abundance. Pages 81- 92 in R.H. Stroud, editor. Fish culture in fisheries management. American Fisheries Society, Bethesda, Maryland.

Nicholas, J.W., and D.G. Hankin. 1989. Chinook salmon populations in Oregon coastal river basins. Oregon Department of Fish and Wildlife Information Report 88-1. Portland, Oregon.

Nicholas, J.W., and T.W. Downey. 1989. Looking back on two decades of work at Elk River Hatchery: has there been harmony between the natural and artificial production systems? And has Elk River been a prototype conservation hatchery? Oregon Department of Fish and Wildlife.

Nickelson, T.E. 1981. Coho pre-smolt program for Oregon coastal streams. Oregon Department of Fish and Wildlife Report (Fish) 81- 1. Portland, Oregon.

Nickelson, T.E. 1986. Influences of upwelling, ocean temperature, and smolt abundance on marine survival of coho salmon (0 ncorhynchus kisutch) in the Oregon Production Area. Canadian Journal of Fisheries and Aquatic Sciences 43:527-535.

Nickelson, T.E., M.F. Solazzi, and S.L. Johnson. 1986. Use of hatchery coho salmon (Oncorhynchus kisutch) presmolts to rebuild wild populations in Oregon coastal streams. Canadian Journal of Fisheries and Aquatic Sciences 43:2443-2449.

Nielson, R.S., N. Reimers, and H.D. Kennedy. 1956. A six-year study of the survival and vitality of hatchery-reared rainbow trout of catchable size in Convict Creek, California. California Fish and Game 43:1-42.

Nikinmaa, J , A. Soivio, T. Nakari, and S. Lindgren. 1983. H auling stress in brown trout (Salmo trutta): physiological responses to transport in fresh water or salt water, and recovery in natural brackish water. Aquaculture 34:93-99.

RASP Sunmary Report Series. Part V: Appendix A: Supplementation Literature

December, 1992 /Page 54 
Nilsson, N.A. 1967. Interactive segregation between fish species. Pages 293-313 in S.D. Gerking, editor. The biological basis of freshwater fish production. Blackwell Scientific Publications, Oxford, England.

Norman, L. 1987. Stream aquarium observations of territorial behaviour in young salmon (Salmo salar L.) of wild and hatchery origin. Salmon Research Institute, Alvkarlby, Report 1987-2.

North Atlantic Salmon Conservation Organization. 1987. Report of the activities of the Bilateral Scientific Working Group of the North American Commission on Salmonid Introductions and Transfers. Miami, Florida.

Northcote, T.G., and B.W. Kelso. 1981. Differential response to water current by two homozygous LDH phenotypes of young rainbow trout (Salmo gairdneri). Canadian Journal of Fisheries and Aquatic Sciences 38:348-352.

Northcote, T.G., S.N. Williscroft, and H. Tsuyuki. 1970. Meristic and lactate dehydrogenase genotype differences in stream populations of rainbow trout below and above a waterfall. Journal of the Fisheries Research Board of Canada 273: 1987-1995.

Northwest Power Planning Council. 1987. Columbia River basin fish and wildlife program. Portland, Oregon.

Olla, B.L., and M.W. Davis. 1989. The role of learning and stress in predator avoidance of hatchery-reared coho salmon (O ncorhynchus kisutch) juveniles. Aquaculture 76:209-214.

Onodera, K., and T. Ueno. 1961. On the survival of trout fingerlings stocked in a mountain brook. II. Survival rate measured and scouring effect of flood as a cause of mortality. Freshwater Fisheries Research Laboratory No. 107.

Oregon Department of Fish and Wildlife. 1981. Comprehensive plan for production and management of Oregon's anadromous salmon and trout: Part III, Coho Salmon Plan.

Osterdahl, L. 1968. The smolt run of a small Swedish river. Pages 205-215 in T.G. Northcote, editor. Symposium on salmon and trout in streams. H.R. MacMillan Lectures in Fisheries, University of British Columbia, Vancouver, Vancouver.

Palmer, D.E., H.C. Hansel, J.M. Beyer, S.C. Vigg, W.T. Yasutake, P.T. Lofy, S.D. Duke, M.J. Parsley, M.G. Mesa, L.A. Prendergast, R. Burkhart, C. Burley, D.W . Eib, and T.P. Poe. 1986. Feeding activity, rate of consumption, daily ration and prey selection 
of major predators in John Day Reservoir, 1985. Bonneville Power Administration, Division of Fish and Wildlife Project No. 82-3. Portland, Oregon.

Parker, N.C. 1986. Physical and biological factors influencing growth and survival of stocked fish, Pages 235-242 in R.H. Stroud, editor. Fish culture in fisheries management. American Fisheries Society, Bethesda, Maryland.

Parkinson, E.A. 1984. Genetic variation in populations of steelhead trout (Salmo gairdneri) in British Columbia. Canadian Journal of Fisheries and Aquatic Sciences 41: 1412-1420.

Parsons, J.E., and G.H. Thorgard. 1985. Production of androgenetic diploid rainbow trout. Journal of Heredity 76: 177- 181.

Paszkowski, C.A., and B.L. Olla. 1985. Foraging behavior of hatchery-produced coho salmon (O ncorhynchus kisutch) smolts on life prey. Canadian Journal of Fisheries and Aquatic Sciences 42: 1915-1921.

Paulik, G.J., A.S. Hourston, and P.A. Larkin. 1967. Exploitation of multiple stocks by a common fishery. Journal of the Fisheries Research Board of Canada 24:2527-2537.

Pearcy, W.G. 1984. The influence of ocean conditions on the production of salmonids in the North Pacific: proceedings of a workshop. Sea Grant Publication ORESU-W-0001, Oregon State University, Corvallis, Oregon.

Pearcy, W.G. 1984. Where do all the coho go? The biology of juvenile coho salmon off the coasts of Oregon and Washington. Pages 50-60 in W.G. Pearcy, editor. The influence of ocean conditions on the production of salmonids in the North Pacific: a workshop. Oregon State University, Oregon Sea Grant Program ORESU-W-83-001, Corvallis.

Pearcy, W.G., and J.P. Fisher. 1988. Migrations of coho salmon (O ncorhynchus kisutch) during their first summer in the ocean. Fisheries Bulletin.

Peck, J.W. 1974. Migration, food habits, and predation on yearling coho salmon in a Lake Michigan tributary and bay. Transactions of the American Fisheries Society 103: 10-14.

Peterman, R.M. 1989. Application of statistical power analysis to the Oregon coho salmon (O ncorhynchus kisutch) problem. Canadian Journal of Fisheries and Aquatic Sciences 46:1183-1187.

Peterman, R.M. 1981. Form of random variation in salmon smolt- to-adult relations and its influence on production estimates. Canadian Journal of Fisheries and Aquatic Sciences 38:1113-1119. 
Peterman, R.M. 1982. Nonlinear relation between smolts and adults in Babine Lake sockeye salmon (Oncorhynchus nerka) and implications for other salmon populations. Canadian Journal of Fisheries and Aquatic Sciences 39904-913.

Peterman, R.M. 1987. Review of the components of recruitment of Pacific salmon. Pages 417-429 in M. J. Dadswell, R.J. Klauda, C.M. Moffitt, R.L. Saunders, R.A. Rulifson, and J.E. Cooper, editors. Common strategies of anadromous and catadromous fishes. American Fisheries Society Symposium 1. American Fisheries Society, Bethesda, Maryland.

Peterman, R.M. 1977. A simple mechanism that causes collapsing stability regions in exploited salmonid populations. Journal of the Fisheries Research Board of Canada 34: 1130-1 142.

Peterman, R.M. 1978. Testing for density-dependent marine survival in Pacific marine salmonids. Journal of the Fisheries Research Board of Canada 35:1434-1450.

Peterman, R.M., and M. Gatto. 1978. Estimation of functional responses of predators on juvenile salmon. Journal of the Fisheries Research Board of Canada 35:797-808.

Peter-man, R., and R.D. Routledge. 1983. Experimental management of Oregon coho salmon (Oncorhynchus kisutch): designing for yield of information. Canadian Journal of Fisheries and Aquatic Sciences 40: 1212-1223.

Peterson, H.H. 1973. Smolt rearing methods, equipment and techniques used successfully in Sweden. International Atlantic Salmon Foundation Special Publication Series 2.

Petrosky, C.E. 1984. Competitive effects from stocked catchable-size rainbow trout on wild trout population dynamics. Doctoral dissertation. University of Idaho, Moscow.

Petrosky, C.E., and T.C. Bjomn. 1988. Response of wild rainbow (Salmo gairdneri) and cutthroat trout (S. clarki) to stocked rainbow trout in fertile and infertile streams. Canadian Journal of Fisheries and Aquatic Sciences 45:2087-2105.

Pettit, S.W. 1977. Comparative reproductive success of caught- and-released and unplayed hatchery female steelhead trout (Salmon gairdneroi) from the Clearwater River, Idaho. Transactions of the American Fisheries Society 106:431-436.

Phillips, A.M., D.R. Brockway, F.E. Lovelace, and H.A. Podoliak. 1957. A chemical comparison of hatchery and wild brook trout. Progressive Fish-Culturist 19:19-25. 
Phillip, D.P., C.C. Krueger, G.H. Thorgaard, E.T. Wattendorf, and J.E. Claussen. 1986. Fisheries genetics: where should we be going? Fisheries 11:14-17.

Pickering, A.D., and J. Duston 1983. Administration of cortisol to brown trout, Salmo trutta $L_{\text {., }}$ and its effects on the susceptability to Saprolegnia infection and furunculosis. Journal of Fish Biology 23:163-175.

Piggins, D.J. 1959. Investigation on predators of salmon smolts and parr. Salmon Research Trust Ireland 5, Appendix 1.

Piggins, D.J., and C.P.R. Mills. 1985. Comparative aspects of the biology or naturally produced and hatchery-reared Atlantic salmon smolts, Salmo salar. Aquaculture 45:321-334.

Piper, D., B.L. Nicholson, and J. DUM. 1973. Immunoflourescent study of the replication of infectious pancreatic necrosis virus in trout and Atlantic salmon cell cultures. Infectious Immunology 8:249-254.

Piper, R.G., I.B. McElwain, L.E. Orme, J.P. McCraren, L.G. Fowler, and J.R. Leonard. 1982. Fish Hatchery Management. U.S. Department of Agriculture, U.S. Fish and Wildlife Service, Washington, D.C.

Pippy, J.H.C. 1969. Kidney disease in juvenile Atlantic salmon (Salmo salar) in the Margaree River. Journal of the Fisheries Research Board of Canada 26:2535-2537.

Pollard, H.A., and T.C. Bjornn. 1973. The effects of angling and hatchery trout on the abundance of juvenile steelhead trout. Transactions of the Amererican Fisheries Society 102:745-752.

Potter, B.A., B.R. Zalewski, B.A. Barton, and N.C. Fraser. 1982. Summary and annotated bibliography of salmonine stocking investigations, stocking assessment methodology and stocking policies in North America. Fisheries Branch, Ontario Ministry of Natural Resources, Canada.

Potter, B.A., and B.A. Barton. 1986. Stocking goals and criteria for restoration and enhancement of cold-water fisheries. Pages 147-160 in R.H. Stroud, editor. Fish culture in fisheries management. American Fisheries Society, Bethesda, Maryland.

Povilitis, T. 1990. Is captive breeding an appropriate strategy for endangered species conservation? Endangered Species Update 8: 20-23. 
Power, J.H., and J.D. McCleave 1980. Riverine movements of hatchery-reared Atlantic salmon (Salmo salar) upon return as adults. Environmental Biology of Fishes 5:3-13.

Pritchard, A.L. 1947. Efficiency of natural propagation of Pacific salmon. Canadian Fish Culturist 1:22-26.

Pritchard, A.L. 1936. Stomach contents analysis of fishes preying upon the young of Pacific salmon during the fry migration at McClinton Creek, Masset Inlet, British Columbia. Canadian Field-Naturalist 50: 104-105.

Ptolemy, R.A. 1986. Assessment of highway construction impacts and fisheries mitigation in the Coquihalla River near Hope, British Columbia: progress in 1985. BC Fisheries Project Report No. FIU-04.

Quinn, T.P., and G.M. Tolson. 1986. Evidence of chemically mediated population recognition in coho salmon (O ncorhynchus kisutch), Canadian Journal of Zoology 64:84-87.

Quinn, T.P., and K. Fresh. 1984. Homing and straying in chinook salmon (Oncorhynchus tshaw ytscha) from Cowliitz River Hatchery, Washington. Canadian Journal of Fisheries and Aquatic Sciences 41: 1078-1082.

Quinn, T.P., and W.C. Leggett. 1987. Perspectives on the marine migrations of diadromous fishes. Pages 377-388 in M.J. Dadswell, R. J. Klauda, C. M. Moffitt, R. L. Saunders, R. A. Rulifson, and J. E. Cooper, editors. Common strategies of anadromous and catadromous fishes. American Fisheries Society Symposium 1. American Fisheries Society, Bethesda, Maryland.

Raleigh, R.F. 1971. Innate control of migration of salmon and trout fry from natal gravels to rearing areas. Ecology 52:291- 297.

Raleigh, R.F., and D.W. Chapman. 1971. Genetic control in lakeward migration in cutthroat trout fry. Transactions of the American Fisheries Society 100:33-40.

Raney, E.C., and E.A. Lachner. 1942. Autumn food of recently planted young brown trout in small streams of central New York. Transactions of the American Fisheries Society 71:106-111.

Ratliff, D.E. 1981. Ceratomyxa shasta: epizootiology in chinook salmon of central Oregon. Transactions of the American Fisheries Society 110:507-513.

Rawstrom, R.R. 1972. Harvest, survival, and cost of two domestic strains of tagged rainbow trout stocked in Lake Berryassa, California. California Fish and Game 58:44-49.

RASP Summary Report Series, Part V: Appendix A: Supplementation Literature

December, 1992 /Page 59 
Raymond, H.L. 1988. Effects of hydroelectric development and fisheries enhancement on spring and summer chinook salmon and steelhead in the Columbia River Basin. North American Journal of Fisheries Management 8:1-24.

Raymond, J.A. 1986. Growth of wild and hatchery juvenile coho salmon in an interior Alaska stream. Alaska Department of Fish and Game, FRED Division, No. 60.

Redding, J.M., and C.B. Schreck. 1983. Influence of ambient salinity on osmoregulation and cortisol concentration in yearling coho salmon during stress. Transactions of the American Fisheries Society. 112:800-807.

Reimers, N. 1963. Body condition, water temperature, and over- winter survival of hatchery-reared trout in Convict Creek, California. Transactions of the American Fisheries Society 92:39- 46.

Reimers, N. 1957. Some aspects of the relation between stream foods and trout survival. California Fish and Game 43:43-69.

Reimers, P.E. 1973. The length of residence of juvenile fall chinook salmon in Sixes River, Oregon. Fisheries Commission of Oregon, Report 4.

Reimers, P.E. 1979. Success in a hatchery program with fall chinook salmon by simulating the natural life history of the stock. Progressive Fish-Culturist 41:192-195.

Reingold, M. 1975. Effects of displacing, hooking, and releasing on migrating adult steelhead trout. Transactions of the American Fisheries Society 104:458-460.

Reisenbichler, R.R. 1987. Basis for managing the harvest of chinook salmon. North American Journal of Fisheries Management 7: 589-591.

Reisenbichler, R.R. 198 1. Columbia River salmonid broodstock management - annual progress report (unpublished). National Fishery Research Center, U.S. Fish and Wildlife Service, Seattle, Washington.

Reisenbichler, R.R. 1977. Effects of artificial propagation of anadromous salmonids on wild populations. Pages 2-3 in T.J. Hassler and R.R. VanKirk, editors. Proceedings of the genetic implications of steelhead management symposium: Special Report 77-1. Humboldt State University, Arcata, California. 
Reisenbichler, R.R. 1984. Outplanting: potential for harmful genetic change in naturally spawning salmonids. Pages 33-39 in J.M. Walton and D.B. Houston, editors. Proceedings of the Olympic wild fish conference. Peninsula College, Fisheries Technology Program, Port Angeles, Washington.

Reisenbichler, R.R. 1988. Relation between distance transferred from natal stream and recovery rate for hatchery coho salmon. North American Journal of Fisheries Management 8: 172-174.

Reisenbichler, R.R. 1985. Use of hatcheries in management of anadromous fish. Pages in 124-137 Proceedings of the Soviet- American Symposium.

Reisenbichler, R.R. 1986. Use of hatcheries in management of anadromous fish. Pages 124-136 in Y.P. Yakovleva, editor. Aquaculture in USSR and USA. Proceedings of the Soviet-American symposium on aquaculture. National Fisheries Research Center, U.S. Fish and Wildlife Service, Seattle, Washington.

Reisenbichler, R.R., and J.D. McIntyre. 1977. Genetic differences in growth and survival of juvenile hatchery and wild steelhead trout, Salmo gairdneri. Journal of the Fisheries Research Board of Canada 34:123-128.

Reisenbichler, R.R., J.D. McIntyre, and R.J. Hallock 1982. Relation between size of chinook salmon (O ncorhynchus tshawytscha) released at hatcheries and returns to hatcheries and ocean fisheries. California Fish and Game 68:57-59.

Reisenbichler, R.R., and J.D. McIntyre. 1986. Requirements for integrating natural and artificial production of anadromous salmonids in the Pacific Northwest. Pages 365-374 in R.H. Stroud, editor. Fish culture in fisheries management. American Fisheries Society, Bethesda, Maryland.

Reisenbichler, R.R., and S.R. Phelps. 1987. Genetic variation in chinook, O ncorhynchus tshaw ytscha, and coho, 0. kisutch, salmon from the north coast of Washington. Fishery Bulletin 85: 681-701.

Reisenbichler, R.R., and S.R. Phelps. 1989. Genetic variation in steelhead (SaZ mo gairdneri) from the north coast of Washington. Canadian Journal of Fisheries and Aquatic Sciences 4655-73.

Reitan, O., N.A. Hvidsten, and L.P. Hansen. 1987. Bird predation on hatchery reared Atlantic salmon smolts SaZmo salar L., released in the River Eira, Norway. Fauna Norv. Ser. A. $8: 35-38$. 
Rensel, J.E., R.P. Harris, and T.J. Tynan. 1988. Fishery contribution and spawning escapement of coho salmon reared in net-pens in southern Puget Sound, Washington. North American Journal of Fisheries Management 8:359-366.

Richards, C., and P.J. Cemera. 1989. Dispersal and abundance of hatchery-reared and naturally spawned juvenile chinook salmon in an Idaho stream. North American Journal of Fisheries Management 9:345-35 1.

Richards, C., and P.J. Cemera. 1988. Movement and abundance of hatchery-reared and naturally-spawned juvenile chinook salmon in an Idaho stream. (submitted to North American Journal of Fisheries Management.)

Ricker, W.E. 1981. Changes in the average size and average age of Pacific salmon. Canadian Journal of Fisheries and Aquatic Sciences 38:1636-1656.

Ricker, W.E. 1941. The consumption of young sockeye salmon by predaceous fish. Journal of the Fisheries Research Board of Canada 5:293-313.

Ricker, W.E. 1972. Hereditary and environmental factors affecting certain salmonid populations. Pages 19-160 in R.C. Simon and P.A. Larkin, editors. The stock concept in Pacific salmon. H.R. MacMillan Lectures in Fisheries,

Ricker, W.E. 1958. Maximum sustained yield from fluctuating environments and mixed stocks. Journal of the Fisheries Research Board of Canada 15:559-623.

Ricker, W.E. 1976. Review of the rate of growth and mortality of Pacific salmon in saltwater and non-catch mortality caused by fishing. Journal of the Fisheries Research Board of Canada 33: 1483-1524.

Ricker, W.E. 1982. Size and age of sockeye salmon (O ncorhynchus nerka) in relation to environmental factors and the fishery. Canadian Technical Report of Fisheries and Aquatic Sciences 1115.

Ricker, W.E. 1954. Stock and recruitment. Journal of the Fisheries Board of Canada 11:559-623. 
Riddell, B.E., and W.C. Leggett. 1981. Evidence of an adaptive bases for geographic variation in body morphology and time of downstream migration of juvenile Atlantic salmon (Salmo salar). Canadian Journal of Fisheries and Aquatic Sciences 38:308-320.

Riddell, B.E., W.C. Leggett, and R.L. Saunders. 1981. Evidence of adaptive polygenic variation between two populations of Atlantic salmon (Salmo salar) native to tributaries of the S.W. Miramichi River, New Brunswick. Canadian Journal of Fisheries and Aquatic Sciences 38:321-333.

Riggs, L.A. 1986. Genetic considerations in salmon and steelhead planning. Final Report for the Northwest Power Planning Council. GENREC/ Genetic Resource Consulting, Berkeley, California.

Riggs, L.A. 1990. Principles for genetic conservation and production quality: results of a scientific and technical clarification and revision. Northwest Power Planning Council, Contract No. C90-005. Portland, Oregon.

Riley, G.F. 1953. Theory of growth and competition in natural populations. Journal of the Fisheries Research Board of Canada 10:211-223.

Ringler, N.H. 1979. Selective predation by drift feeding brown trout (Salmo trutta). Journal of the Fisheries Research Board of Canada 36:392-403.

Ritter, J.A. 1975. Lower ocean survival rates for hatchery- reared Atlantic salmon (Salmo salar) stocks released in rivers other than their native streams. International Council for the Exploration of the Sea Publications, 26.

Roadhouse, S., M.J. Saari, and D. Roadhouse. 1986. Behavioral and biochemical correlates of hatchery rearing methods on lake trout. Progressive Fish-Culturist 48:38-42.

Robinette, R.H., J. Hynes, N.C. Parker, R. Putz, R.E. Stevens, and R.R. Stickney. 1991. Commercial aquaculture. Fisheries 16(1): 18-22.

Rogers, D.E. 1980. Density-dependent growth of Bristol Bay sockeye salmon. Pages 267-283 in W.J. McNeil and D.C. Himsworth, editors. Salmonid ecosystems of the North Pacific. Oregon State University, Oregon Sea Grant Program, Corvallis. 
Rogers, D.E. 1984. Trends in abundance of northeastern Pacific stocks of salmon. Pages 100-127 in W.G. Pearcy, editor. The influence of ocean conditions on the production of salmonids in the north Pacific. Oregon State University, Oregon Sea Grant Program ORESU-W-83-001, Corvallis.

Rohovec, J.S. 1983. Development of policies to avoid the introduction of infectious disease among populations of fish and shellfish. Pages 371-373 in P.M. Arana, editor. Proceedings of the International Conference on Marine Resources of the Pacific. Vina del mar, Chile.

Rohovec, J.S., J.R. Winton, and J.L. Fryer. 1989. Potential hazard for spread of infectious disease by transplantation of fish. Pages 171-176 in W.J. McNeil, editor. Salmon production, management, and allocation: biological, economic, and policy issues. University of Oregon Press, Corvallis, Oregon.

Rosberg, G.E., K.J. Scott, and R. Rithaler. 1986. Review of the international pacific salmon fisheries commision's sockeye and pink salmon enhancement facilities on the Fraser River. Salmonid Enhancement Program, Department of Fisheries and Oceans, Canada.

Rosenau, M.L., and J.D. McPhail. 1987. Jnherited differences in agonistic behavior between two populations of coho salmon. Transactions of the American Fisheries Society 116646-654.

Rosentreter, N. 1977. Characteristics of hatchery fish: angling, biology, and genetics. Pages 79-83 in E. Schwiebert, editor. Columbia River salmon and steelhead. American Fisheries Society, Special Publication No. 10, Bethesda, Maryland.

Royal, L.A. 1972. An examination of the anadromous trout program of the Washington State Game Department. Unpublished manuscript.

Ruggerone, G.T. 1986. Consumption of migrating juvenile salmonids by gulls foraging below a Columbia River dam. Transactions of the American Fisheries Society 115:736-742.

Ruggerone, G.T., and D.E. Rogers. 1984. Arctic charr predation on sockeye salmon smolts at Little Togiak River, Alaska. Fishery Bulletin 82:401-409.

Ruggles, C.P. 1980. A review of the downstream migration of Atlantic salmon. Canadian Technical Report of Fisheries and Aquatic Sciences 9852.

Ruggles, P.F. 1966. Depth and velocity as a factor in stream rearing and production of juvenile coho salmon. Canadian Fish Culturist 38:37-53.

RASP Summary Report Series, Part V: Appendix A: Supplementation Literature

December, 1992 /Page 64 
Ruzzante, D.E. 1991. Variation in agonistic behaviour between hatchery and wild populations of fish: a comment on Swain and Riddell (1990). Canadian Journal of Fisheries and Aquatic Sciences 48:519-520.

Ryder, R.A., S.R. Kerr, W.W. Taylor, and P.A. Larkin. 1981. Community consequences of fish stock diversity. Canadian Journal of Fisheries and Aquatic Sciences 38: 1856-1866.

Ryman, N. 1981. Conservation of genetic resources: experiences from the brown trout (Salmo trutta). Pages 61-74 in N. Ryman, editor. Fish gene pools. Ecological Bulletin 34, Stockholm.

Ryman, N. 1983. Patterns of distribution of biochemical genetic variation in salmonids: differences between species. Aquaculture 33:1-21.

Ryman, N., and F. Utter. 1987. Population genetics and fishery management. Washington Sea Grant Publications. University of Washington Press, Seattle, Washington, and London, England.

Ryman, N., and G. Stahl. 1980. Genetic changes in hatchery stocks of brown trout (Salmo trutta). Canadian Journal of Fisheries and Aquatic Sciences 37:82-87.

Ryman, N., and G. Stahl. 1981. Genetic perspectives of identification and preservation of Scandinavian stocks of fish. Canadian Journal of Fisheries and Aquatic Sciences 38: 1562-1575.

Ryman, N., and L. Laikre. 1991. Effects of supportive breeding on the genetically effective population size. Conservation Biology 5:3.

Salo, E.O., and W.H. Bayliff. 1958. Artificial and natural production of silver salmon (Oncorhynchus kisutch) at Minter Creek, Washington. Washington Department of Fisheries Research Bulletin 4, Olympia.

Sanders, J.E., J.L. Fryer, D.A. Leith, and K.D. Moore. 1972. Control of the infectious protozoan Ceratomyxa shasta by treating hatchery water supplies. Progressive Fish-Culturist 34: 13-16.

Sanders, J.E., J.L. Fryer, and R.W. Gould. 1970. Occurrence of the myxosporidan parasite Ceratomyxa Shasta in salmonid fish from the Columbia River basin and Oregon coastal streams. Pages 133- 141 in American Fisheries Society,Special Scientific Publication 5, Bethesda, Maryland. 
Sanders, J.E., K.S. Pitcher and J.L. Fryer. 1978. Relation of water temperature to bacterial kidney ddisease in coho salmon (O ncorhynchus kisutch), sockeye salmon (0. nerka), and steelhead trout (Selmo gairdneri). Journal of the Fisheries Research Board of Canada 35:8-11.

Sankovich, P. 1990. Distribution and spawning behavior of adults and survival of offspring of wild and hatchery chinook salmon. Summary Annual Report to Idaho Department of Fish and Game. Boise, Idaho.

Sattaur, 0. 1989. The threat of the well-bred salmon. New Scientist 29:54-58.

Saunders, R.L. 1991. Potential interaction between cultured and wild Atlantic salmon. Aquaculture 98:51-60.

Scamecchia, D.L. 1983. Age at sexual maturity in Icelandic stocks of Atlantic salmon (Salmo salar). Canadian Journal of Fisheries and Aquatic Sciences 40:1456-1468.

Scamecchia, D.L. 1984. Climatic and oceanic variations affecting yield of Icelandic stocks of Atlantic salmon (Salmo salar). Canadian Journal of Fisheries and Aquatic Sciences 41: 917-935.

Scamecchia, D.L. 1984. Forecasting yields of two-sea-winter Atlantic salmon (Salmo salar) from Icelandic rivers. Canadian Journal of Fisheries and Aquatic Sciences 41: 1234-1240.

Scarnecchia, D.L. 1989. The history and development of Atlantic salmon management in Iceland. Fisheries 14(2): 14-21.

Scarnecchia, D.L., and H.H. Wagner. 1980. Contribution of wild and hatchery-reared coho salmon, Oncorhynchus kisutch, to the Oregon ocean sport fishery. Fishery Bulletin 77(3):617.

Scamecchia, D.L., A. Isaksson, and S.E. White. 1989. Effects of oceanic variations and the west Greenland fishery on age at maturity of Icelandic west coast stocks of Atlantic salmon (Salmo salar). Canadian Journal of Fisheries and Aquatic Sciences 46: 1627.

Scheer, B.T. 1939. Homing instinct in salmon. Quarterly Review of Biology 14:408-420.

Schoz, A.T., C.K. Gosse, J.C. Cooper, R.M. Horrall, A.D. Hasler, RI. Daly, and R.J. Poff. 1978. Homing of rainbow trout transplanted in Lake Michigan: a comparison of three procedures used for imprinting and stocking. Transactions of the American Fisheries Society 107:439-443. 
Schreck, C.B., R. Patino, C.K. Pring, J.R. Winton, and J.E. Holway. 1985. Effects of rearing density on indices of smoltification and performance of coho salmon, Oncorhynchus kisutch. Aquaculture 45 345-358.

Schroder, S.L. 1981. The role of sexual selection in determining overall mating patterns and mate choice in chum salmon. Doctoral dissertation. University of Washington, Seattle.

Schuck, H.A. 1948. Survival of hatchery trout in streams and possible methods of improving the quality of hatchery trout. Progressive Fish-Culturist 10:3-14.

Seeb, L., J.E. Seeb, R.L. Allen, and W.K. Hershberger. 1990. Evaluation of adult returns of genetically marked chum salmon, with suggested future applications. American Fisheries Society Symposium 7: 4 18-425.

Seelbach, P.W. 1987. Effect of winter severity on steelhead smolt yield in Michigan: an example of the importance of environmental factors in determining smolt yield. Pages 441-450 in M. J. Dadswell, R. J. Klauda, C.M. Moffitt, R.L. Saunders, R. A. Rulifson, and J.E. Cooper, editors. Common strategies of anadromous and catadromous fishes. American Fisheries Society Symposium 1. American Fisheries Society, Bethesda, Maryland.

Seelbach, P.W. 1987. Smolting success of hatchery-raised steelhead planted in a Michigan tributary of Lake Michigan. North American Journal of Fisheries Management 7:223-231.

Seelbach, P.W., and G.W. Whelan. 1988. Identification and contribution of wild and hatchery steelhead stocks in Lake Michigan tributaries. Transactions of the American Fisheries Society 117:444-45 1.

Seidel, P., P. Appleby, H. Fuss, and M. Kimbel. 1988. Washington Department of Fisheries Columbia River fall chinook salmon studies. Pages 240-246 in B.G. Shepherd, rapporteur. Proceedings of the 1988 Northeast Pacific chinook and coho salmon workshop. North Pacific International Chapter American Fisheries Society, Bellingham, Washington,

Sekulich, P.T. 1980. The carrying capacity of infertile forest streams for rearing juvenile chinook salmon. Doctoral dissertation. University of Idaho, Moscow.

Selye, H. 1973. The evolution of the stress concept. American Scientist 61:692-699. 
Semko, R.S. 1945. A method for determinin the consumption of predators of the young Pacific salmon during early stages of development. Fisheries Research Board of Canada 215: $124-134$.

Senn, H., J. Mack, and L. Rothfus. 1984. Compendium of low-cost Pacific salmon and steelhead trout production facilities in the Pacific Northwest. Report prepared by Fish Management Consultants for the U.S. Department of Energy, Bonneville Power Administration. Project No. 83-353, Contract No. DE-AC79- 83BP12745. Portland, Oregon.

Shearer, W.M. 1961. Survival rate of young salmonids in streams stocked with green ova. International Council for the Exploration of the Sea, 98.

Shetter, D.S. 1947. Further results from spring and fall planting of legalized, hatchery-reared trout in streams and lakes of Michigan. Transactions of the American Fisheries Society 74: $35-58$.

Shetter, D.S., and A.S. Hazard. 1941. Results from plantings of marked trout of legal size in streams and lakes of Michigan. Transactions of the American Fisheries Society 70:446-468.

Sholes, W.H., and R.J. Hallock. 1979. An evaluation of rearing fall-run chinook salmon, Oncorhynchus tshaw ytscha, to yearlings at Feather River Hatchery, with a comparison of returns from hatchery and downstream releases. California Fish and Game 64: 239-255.

Shustov, Y.A., I.L. Shchurov, and Y.A. Smirnov. 1980. Adaption times of hatchery salmon, Salmo salar, to river conditions. Journal of Icthyology 20:156-159.

Sigler, J.W., T.C. Bjomn, and F.H. Everest. 1984. Effects of chronic turbidity on density and growth of steelhead and coho salmon. Transactions of the American Fisheries Society 113:142- 150 .

Silby, R.M., and P. Calow. 1986. Physiological ecology of animals. Blackwell, Oxford, England.

Simenstad, C.A., B.S. Miller, C.F. Nyblade, K. Thomburgh, and L.J. Bledsoe. 1979. Food web relationships of northern Puget Sound and the Strait of Juan de Fuca: a synthesis of the available knowledge. MESA Puget Sound Project, Marine Ecosystems Analysis Program, Environmental Research Laboratories, DOC/EPA Interagency Energy/Environmental Research and Development Program Report EPA-600-7-79-259. 
Simenstad, C.A., K.L. Fresh, and E.O. Salo. 1982. The role of Puget Sound and Washington coastal estuaries in the life history of Pacific salmon: an unappreciated function. Pages 343-364 in V. Kennedy, editor. Estuarine comparisons. Academic Press, New York.

Simon, R.C. 1970. Genetics and marine aquaculture. Pages 53-63 in W.J. McNeil, editor. Marine aquaculture. Oregon State University Press, Corvallis.

Simon, R.C. 1986. Improving strains and species genetically for higher production, faster growth, and increased survival. Pages 223-227 in R.H. Stroud, editor. Fish culture in fisheries management. American Fisheries Society, Bethesda, Maryland.

Simon, R.C. 1991. Management techniques to minimize the loss of genetic variability in hatchery fish populations. American Fisheries Society Special Symposium 10:487-494.

Skaala, O., and G. Nevdal. 1989. Genetic differentiation between freshwater resident and anadromous brown trout, Salmo trutta, within watercourses. Journal of Fish Biology 34597405 .

Skala, O., G. Dahle, K.E. Jorstad, and G. Naevdal. 1990. Interactions between natural and farmed fish populations: information from genetic markers. Journal of Fish Biology 36:449- 460.

Slaney, P.A., S.J. Billings, and H.A. Smith. 1980. Experimental stocking of steelhead fry above barriers in a high gradient tributary of the Keogh River: Progress 1978 and 1979. Ministry of the Environment, Fisheries Technical Circular, Victoria, Canada.

Slaney, P.A., and T.G. Northcote. 1974. Effects of prey abundance on density and territorial behavior of young rainbow trout (Salmo gairdneri) in laboratory stream channels. Journal of the Fisheries Research Board of Canada 31:1201-1209.

Smith, E.M. 1987. Outplanting experience in Oregon. Oregon Department of Fish and Wildlife.

Smith, E.M., B.A. Miller, J.D. Rodgers, and M.A. Buckman. 1985. Outplanting anadromous salmonids - a literature survey. Bonneville Power Administration Project No. 85-68. U.S. Department of Energy.

Smith, H.D., and L. Margolis. 1970. Some effects of Eubothrium salvenlini (Schrank 1790) on sockeye salmon, Oncorhynchyus nerka (Walbaum), in Babine Lake, British Columbia. Journal of Parasitology Section II 56:321-322. 
Smoker, W.W. 1985. Review of literature on impacts of salmon hatcheries in Alaska. Final report for University of Alaska- Juneau Research Council. University of Alaska, Juneau.

Snieszko, S.F. 1974. The effects of environmental stress on outbreaks of infectious diseases of fishes. Journal of Fish Biology 6: 197-208.

Snow, H.E. 1974. Effects of stocking northern pike in Murphy's Flowage. Wisconsin Department of Natural Resources Technical Bulletin No. 79.

Solazzi, M.F., S.L. Johnson, and T.E. Nickelson. 1983. The effectiveness of stocking hatchery coho pre-smolts to increase the rearing density of juvenile coho salmon in Oregon coastal streams. Information Report 83-4. Oregon Department of Fish and Wildlife.

Solomon, D.J. 1981. Migration and dispersion of juvenile brown and sea trout. Pages 136-145 in E.L. Brannon and E.O. Salo, editors. Proceedings of the salmon and trout migratory behavior symposium. University of Washington Press, Seattle.

Solomon, D.J., and R.G. Templeton. 1976. Movements of brown trout, Salmo trutta L., in a chalk stream. Journal of Fish Biology 9:411-423.

Sosiak, A.J. 1982. Buoyancy comparisons between juvenile Atlantic salmon and brown trout of wild and hatchery origin. Transactions of the American Fisheries Society 111:307-3 11.

Sosiak, A.J. 1978. The comparative behaviour of wild and hatchery-reared juvenile Atlantic salmon (Salmo salar L.). Masters thesis. University of New Brunswick, Fredericton, Canada.

Sosiak, A.J., R.G. Randall, and J.A. McKenzie. 1979. Feeding by hatchery-reared and wild Atlantic salmon (Salmo salar) parr in streams. Journal of the Fisheries Research Board of Canada 36: 1408-1412.

Soule, M.E. Viable populations for conservation. Cambridge University Press, Cambridge, England.

Specker, J.L., and C.B. Schreck. 1980. Stress responses to transportation and fitness for marine survival in coho salmon (Oncorhynchus kisutch) smolts. Canadian Journal of Fisheries and Aquatic Sciences 37:765-769. 
Stabell, O.B. 1981. Homing of Atlantic salmon in relation to olfaction and genetics. Pages 238-246 in E.L. Brannon and E.O. Salo, editors. proceedings of the salmon and trout migratory behavior symposium. University of Washington Press, Seattle.

Stabell, O.B. 1984. Homing and olfaction in salmonids: a critical review with special reference to the Atlantic salmon. Biological Review 59:333-388.

Stahl, G. 1983. Differences in the amount and distribution of genetic variation between natural populations and hatchery stock of Atlantic salmon. Aquaculture 33:23-32.

Stahl, G. 1981. Genetic differentiation among natural populations of Atlantic salmon (Salmo salar) in northern Sweden. Pages 95-105 in N. Ryman, editor. Fish gene pools. Ecological Bulletins 34, Stockholm, Sweden.

Stahl, G. 1987. Genetic population structure of Atlantic salmon. Pages 121-140 in N. Ryman and F. Utter, editors. Population genetics and fisheries management. University of Washington Press, Seattle.

Stein, R.A., P.E. Reimers, and J.D. Hall. 1972. Social interaction between juvenile coho salmon (O ncorhynchus kisutch) and fall chinook salmon (0. tshawytscha) in Sixes River, Oregon. Journal of the Fisheries Research Board of Canada 29:1737-1748.

Steward, C.R., and T.C. Bjomn. 1990. Supplementation of salmon and steelhead stocks with hatchery fish: a synthesis of published literature. Part 2. In W.H. Miller, editor. Analysis of Salmon and Steelhead Supplementation, Parts 1-3. Technical Report 90-1, Bonneville Power Authority. U.S. Department of Energy, Portland, Oregon.

Stewart, L. 1963. Investigations into migratory fish propagation in the area of the Lancashire River Board. Lancaster, Barber, United Kingdom.

Strange, C.D., and G.J.A. Kennedy. 1979. Yield to annglers of spring and autumn stocked, hatchery-reared and wild brown trout. Fisheries Management 10:45-52.

Strange, R.J., C.B. Schreck, and J.T. Golden. 1977. Corticoid stress responses to handling and temperature in salmonids. Transactions of the Amererican Fisheries Society 106:213-217.

Strange, R.J., C.B. Schreck, and R.D. Ewing. 1978. Cortisol concentrations in confined juvenile chinook salmon (Oncorhynchus tshawytscha). Transactions of the American Fisheries Society 107: 812-819.

Strickberger, M.W. 1976. Genetics. Macmillan, New York, New York. 
Stringer, G.E. 1967. Comparative hooking mortality using three types of terminal gear on rainbow trout from Pennask Lake, British Columbia. Canadian Fish Culture 39: 17-21.

Stringer, G.F. 1952. An experimental study of some visually released behaviour patterns in young coho salmon and Kamloops trout. Department of Zoology, University of British Columbia.

Stroud, R.H. 1986. Fish Culture in Fisheries Management. Proceedings of a Symposium on the Role of Fish Culture in Fisheries Management at Lake Ozark, Missouri, March 31-April 3, 1985. Fish Culture Section; Fisheries Mangagement Section; American Fisheries Society, Bethesda, Maryland.

Suboski, M.D., and J.J. Templeton. 1989. Life skills training for hatchery fish: social learning and survival. Fisheries Research 7:343-352.

Supplementation Technical Work Group. 1988. Supplementation research - proposed five-year work plan. Northwest Power Planning Council, Portland, Oregon.

Suzumoto, B.K., C.B. Schreck, and J.D. McIntyre. 1977. Relative resistances of three transferrin genotypes of coho salmon (O ncorhynchus kisurch) and their hematological responses to bacterial kidney disease. Journal of the Fisheries Research Board of Canada 34: $1-8$.

Suzumoto, B.K., and L. Peltz. 1989. The value of hatcheries to the Prince William Sound commercial fisheries. Pages 140-143 in P.A. Knudsen, editor. 14th North Pacific Pink and Chum Salmon Workshop. Port Ludlow, Washington.

Swain, D.P., B.E. Riddell, and C.B. Murray. 199 1. Morphological differences between hatchery and wild populations of coho salmon (O ncorhynchus kisutch): environmental versus genetic origin. Canadian Journal of Fisheries and Aquatic Sciences 48: 1783-1791.

Swam, D.P., and B.L. Holtby. 1989. Differences in morphology and behavior between juvenile coho salmon (O ncorhynchus kisutch) rearing in a lake and its tributary stream. Canadian Journal of Fisheries and Aquatic Sciences 46:1406-1414.

Swartzberg, M., and J. Fryer. 1989. Experiments in identifying hatchery and naturally spawning stocks of Columbia Basin spring chinook salmon using scale pattern analysis. Columbia River Inter-Tribal Fish Commission, Technical Report 89-3. Portland, Oregon.

Swartzman, G.L. 1991. Equilibrium abundance of salmon stocks in a life cycle model with interacting hatchery and natural substocks. Natural Resource Modeling 5( 1): 1-17.

RASP Summary Report Series, Part V: Appendix A: Supplementation Literature

December, 1992 /Page 72 
Sylvester, J.R. 1973. Effect of light on vulnerability of heat- stressed sockeye salmon to predation by coho salmon. Transactions of the American Fisheries Society 102: 139-142.

Symons, P.E.K. 1969. Greater dispersal of wild compared with hatchery-reared juvenile Atlantic salmon released in streams. Journal of the Fisheries Research Board of Canada 26: 1867-1876.

Symons, P.E.K., and M. Heland. 1978. Stream habitats and behavioral interactions of under-yearling and yearling Atlantic salmon (Salmo salar) Journal of the Fisheries Research Board of Canada 35:175-183.

Taggart, J.B., and A. Ferguson. 1986. Electrophoretic evaluation of a supplemental stocking program for brown trout (Salmo trutta). Aquaculture Fish Managment 17: 155-162.

Tagmaz'yan, Z.I. 1971. Relationship between the density of the downstream migration and predation of young pink salmon (O ncorhynchus gorbuscha). Journal of Icthyology 11:984-987.

Tallman, R.F. 1986. Genetic differentiation among seasonally distinct spawning populations of chum salmon, Oncorhynchus keta. Aquaculture 57:211-217.

Tave, D. 1986. Genetics for fish hatchery managers. AVI Publishing Company, Westport, Connecticut.

Taylor, E.B. 1988. Adaptive variation in rheotactic and agonistic behavior in newly emerged fry of chinook salmon, O ncorhynchus tshawytscha, from stream- and ocean-type populations. Canadian Journal of Fisheries and Aquatic Sciences 45:237-243.

Taylor, E.B. 1986. Experimental evidence for geomagnetic orientation in juvenile salmon, O ncorhynchus tshawytscha. Journal of Fish Biology 28607623.

Taylor, E.B., and J.D. McPhail. 1985. Variation in body morphology among British Columbia populations of coho salmon, Oncorhynchus kisutch. Canadian Journal of Fisheries and Aquatic Sciences 42:2020-2028.

Taylor, E.B., and J.D. McPhail. 1985. Variation in burst and prolonged swimming performance among British Columbiapopulations of coho salmon, O ncorhynchus kisutch. Canadian Journal of Fisheries and Aquatic Sciences 42:2029-2033.

Taylor, E.B., and P.A. Larkin. 1986. Current response and agonistic behavior in newly emerged fry of chinook salmon, Oncorhynchus tshawytschta, from stream- and ocean-type populations. Canadian Journal of Fisheries and Aquatic Sciences 43:565-573.

RASP Summary Report Series, Part V: Appendix A: Supplementation Literature

December, 1992 /Page 73 
Taylor, E.B. 1986. Differences in morphology between wild and hatchery populations of juvenile coho salmon. Progressive Fish- Culturist 48:171-176.

Thomas, A.E. 1975. Effect of egg concentration in an incubation channel on survival of chinook salmon fry. Transactions of the American Fisheries Society 104:335-337.

Thompson, D. 1985. Genetic identification of trout strains. Aquaculture 46:341-351.

Thompson, G.G. 1991. Determining minimum viable populations under the Endangered Species Act. U.S. Department of Commerce, NOAA Technical Memo. NMFS F/NWC-198, 78 p.

Thompson, R.B. 1959. Food of the squawfish ptychocheilus oregonensis (Richardson) of the lower Columbia River. U.S. Fish and Wildlife Bulletin 158:42-58.

Thompson, R.B., and D.F. Tufts. 1964. Predation by Dolly Varden and Northern squawfish on hatchery-reared sockeye salmon in Lake Wenatchee, Washington. Transactions of the American Fisheries Society 96:424-427.

Thorpe, J.E. 1991. Acceleration and deceleration effects of hatchery rearing on salmonid development, and their consequences for wild stock. Aquaculture 98:111-118.

Thorpe, J.E. 1982. Migration in salmonids, with special reference to juvenile movements in freshwater. Pages 86-97 in E.L. Brannon and E.O.Salo, editors. Proceedings of the salmon and trout migratory behavior symposium. University of Washington Press, Seattle.

Thorpe, J.E. 1980. Salmon ranching. Academic Press, London, England.

Thorpe, J.E., J.F. Koonce, D. Borgeson, B. Henderson, A. Lamsa, P.S. Maitland, M.A. Ross, R.C. Simon, and C.J. Walters. 1981. Assessing and managing man's impact on fish genetic resources. Canadian Journal of Fisheries and Aquatic Sciences 38:1899-1907.

Thuember, T. 1975. Fish and the blue ribbon streams. Wisconsin Conservation Bulletin No. 40.

Tiedje, J.M., R.K. Colwell, Y.L. Grossman, R.E. Hodson, R.E. Lenski, R.N. Mack, and P.J. Regal. 1989. The planned introduction of genetically engineered organisms: ecological considerations and recommendations. Ecology 70:298-315. 
Tilseth, S., T. Hansen, and D. Moller. 1991. Historical development of salmon culture. Aquaculture 98: 1-9.

Tsuyuki, H., and S.N. Williscroft. 1977. Swimming stamina differences between genotypically distinct forms of rainbow (Salmo gaordmei) and steelhead trout. Journal of the Fisheries Research Board of Canada 34:996-1003.

Utter, F.M., D. Campton, S. Grant, G.B. Milner, J. Seeb, and L. Wishard. 1980. Population structures of indigenous salmonid species of the Pacific Northwest. Pages 285-304 in W.J. McNeil and D.C. Himsworth, editors. Sahnonid ecosystems of the North Pacific. Oregon State University, Oregon Sea Grant Program, Corvallis.

Utter, F.M., G.B. Milner, G. Stahl, and D.J. Teel. 1989. Genetic population structure of chinook salmon in the Pacific Northwest. Fishery Bulletin 85: 13-23.

Verspoor, E. 1986. Reduced genetic variability in hatchery stocks of Atlantic salmon in eastern Canada. Mini-symposium on population genetics in regard to fisheries and mariculture. International Council for the Exploration of the Sea, Copenhagen, Denmark.

Verspoor, E. 1988. Reduced genetic variability in first- generation hatchery populations of Atlantic salmon (Salmo salar). Canadian Journal of Fisheries and Aquatic Sciences 45: 16861690.

Verspoor, E. 1988. Widespread hybridization between native Atlantic salmon, Salmo salar, and introduced brown trout, S. trutta, in eastern Newfoundland. Journal of Fish Biology 32:327- 334.

Verspoor, E., and L. J. Cole. 1988. Genetically distinct sympatric populations of resident and anadromous Atlantic salmon, Salmo salar. Canadian Journal of Zoology 67: 1686-1690.

Verspoor, E., and W.C. Jordan. 1989. Genetic variation at the Me-2 locus in the Atlantic salmon within and between rivers: evidence for its selective maintenance. Journal of Fisheries Biology 35:205-213.

Vijayan, M.M., and J.F. Leatherland. 1988. Effect of stocking density on the growtb and stress-response in brook charr, Salvelinus fontinalis. Aquaculture 75: 159-170.

Vincent, E.R. 1960. Some influences of domestication upon three stocks of brook trout. Transactions of the American Fisheries Society 89:35-32. 
Vincent, E.R. 1972. Effect of stocking catchable trout on wild trout populations. Pages 602-608 in Proceedings of the annual conference of the Western Association of State Game and Fish Commissioners 51.

Vincent, E.R. 1975. Effects of stocking catchable trout on wild trout populations. Pages 88-91 in W. King, editor. Proceedings of the wild trout management symposium. Trout Unlimited.

Vincent, E.R. 1987. Effects of stocking catchable-size hatchery rainbow trout on two wild trout species in the Madison River and O'Dell Creek, Montana. North American Journal of Fisheries Management 7:91-105.

Vinyard, G.L., R.W. Drenner, and D.A. Hanzel. 1982. Feeding success of hatchery reared kokanee salmon when presented with zooplankton prey. Progressive Fish-Culturist 44:37-39.

Vreeland, R.R. 1986. Evaluation of the contribution of chinook salmon reared at Columbia River hatcheries to the Pacific salmon fisheries. Final Report to Bonneville Power Administration. Portland, Oregon.

Vuorinen, J. 1984. Biochemical genetic studies on salmonid populations. Joensuun Yliiopiston Luonnontieteellisia Julk 2: 1- 11.

Vuorinen, J., and O.K. Berg. 1989. Genetic divergence of anadromous and nonanadromous Atlantic salmon (Salmo salar in the River Namsen, Norway. Canadian Journal of Fisheries and Aquatic Sciences 46:406-409.

Wagner, E., and P. Ingram. 1973. Evaluation of fish facilities and passage at Foster and Green Peter dams on the South Santiam River drainage in Oregon. Final Report to U.S. Army Corps of Engineers, Contract No. DACW57-68-C-0013. Fisheries Commission of Oregon.

Wagner, H.H. 1968. Effect of stocking time on survival of steelhead trout, Salmo gairdneri, in Oregon. Transactions of the American Fisheries Society 97:374-379.

Wagner, H.H. 1969. Effect of stocking location of juvenile steelhead trout, Salmo gairdneri, on adult catch. Transactions of the American Fisheries Society 98:27-34.

Wagner, H.H. 1967. A summary of investigations of the use of hatchery-reared steelhead in the management of a sport fishery. Oregon Stage Game Commission Fisheries Report 5 . 
Wagner, H.H. 1979. Why wild coho? Oregon Wildlife 34:3-7.

Wagner, H.H., R.L. Wallace, and H.J. Campbell. 1963. The seaward migration and return of hatchery-reared steelhead trout, Salmo gairdneri Richardson, in the Alsea river, Oregon. Transactions of the American Fisheries Society 92:202-210.

Wagner, W.C., and T.M. Stauffer. 1978. Survival of rainbow trout stocked in a Lake Superior tributary, 1971- 1973. Michigan Department of Natural Resources Fisheries Research Report 1859. Ann Arbor.

Walters, C.J. 1988. Mixed-stock fisheries and the sustainability of enhancement production for chinook and coho salmon. Pages 109-115 in W.J. McNeil, editor. Salmon production, management, and allocation. Oregon State University Press, Corvallis, Oregon,

Walters, C.J., R. Hilbom, R.M. Peterman, and M.J. Staley. 1978. Model for examining early ocean limitation of Pacific salmon production. Journal of the Fisheries Research Board of Canada 35: 1303-1315.

Waples, R.S. 1991. Genetic interactions between hatchery and wild salmonids: lessons from the Pacific Northwest. Canadian Journal of Fisheries and Aquatic Sciences 48: 124-133.

Waples, R.S. (In press). Pacific salmon and the definition of "species" under the Endangered Species Act. Marine Fisheries Review.

Waples, R.S., G.A. Winans, F.M. Utter, and C. Mahnken. 1990. Genetic monitoring of Pacific salmon hatcheries. Pages 33-37 in R.S. Svrjcek, editor. Genetics in Aquaculture: Proceedings of the 16th U.S.-Japan Meeting on Aquaculture. U.S. Department of Commerce, NOAA Technical Report NMFS 92.

Ware, D.M. 1971. Predation by rainbow trout (Salmo gairdneri): the effect of experience. Journal of the Fisheries Research Board of Canada 28:1847-1852.

Warner, K. 1972. Further studies of fish predation on salmon stocked in Maine lakes. Progressive Fish-Culturist 34:217-221.

Washington, P.J. 1985. Survey of artificial production of anadromous salmonids in the Columbia River basin. Final report to the Bonneville Power Administration. Bonneville Power Administration, Portland, Oregon.

Webster, D.A., and W.A. Flick. 1981. Performance of indigenous, exotic and hybrid strains of brook trout (Salvelinus fontinalis) in waters of the Adironback Mountains, New York. Canadian Journal of Fisheries and Aquatic Sciences 38:1701-1707. 
Wedemeyer, G. 1972. Some physiological consequences of handling stress in the juvenile coho salmon (O ncorhynchus kisutch) and steelhead trout (Salmo gairdnen]. Journal of the Fisheries Research Board of Canada 29:1780-1783.

Wedemeyer, G. 1970. Stress of anesthesia with MS-222 and benzocaine in rainbow trout (Salmo gaordmeri). Journal of the Fisheries Research Board of Canada 27:909-914.

Wedemeyer, G., and J. Wood. 1974. Stress as a predisposing factor in fish diseases. U.S. Fish and Wildlife Service Fish Disease Leaflet 38.

Wedemeyer, G.A., R.L. Saunders, and W.C. Clarke. 1980. Environmental factors affecting smoltification and early marine survival of anadromous salmonids. Marine Fisheries Review 42:1- 14.

Wehrhahn, C.F., and R. Powell. 1987. Electrophoretic variation, regional differences, and gene flow in the coho salmon (O ncorhynchus kisutch) of southern British Columbia. Canadian Journal of Fisheries and Aquatic Sciences 44:822-831.

Wentworth, R.S., and G.W. LaBar 1984. First-year survival and growth of steelhead stocked as fry in Lewis Creek, Vermont. North American Journal of Fisheries Management 4: 103-1 10 .

White, L.E. 1986. Sockeye salmon rehabilitation at upper Thumb River, Karluk Lake, Alaska 1978-1984. Alaska Department of Fish and Game, FRED Division, No. 69.

White, R.J. 1992. Why wild fish matter: balancing ecological and aquacultural fishery management. Trout 33(4): 17-48.

Wilkins, N.P. 1981. The rationale and relevance of genetics in aquaculture: an overview. Aquaculture 22: 209-228,

Williams, J.G. 1990. Effects of hatchery broodstock weirs on natural production. Pages 62-24

in D.L. Park, convener. Status and future of spring chinook salmon in the Columbia River Basin-- conservation and enhancement. U.S. Department of Commerce NOAA Technical Memo. NMFS F/NWC-187.

Williams, J.G. 1989. Snake River spring and summer chinook salmon: can they be saved? Regulated Rivers; Research and Management 4:17-26.

Wilmot, R.L., and C.V. Burger. 1984. Genetic differences among populations of Alaskan sockeye salmon. 
Wilson, G.M., W.K. Thomas, and A.T. Beckenbach. 1985. Intra- and interspecific mitochonddrial DNA sequence divergence in Salmo: rainbow, steelhead, and cutthroat trouts. Canadian Journal of Zoology 63:2088-2094.

Wilson, G.M., W.K. Thomas, and A.T. Beckenbach. 1987. Mitochondrial DNA analysis of Pacific Northwest populations of Oncorhynchus tshawytscha. Canadian Journal of Fisheries and Aquatic Sciences 44: 1301-1305.

Winans, G.A. 1989. Genetic variability in chinook salmon stocks from the Columbia River Basin. North American Journal of Fisheries Management 9:47-52.

Winans, G.A. 1984. Multivariate morphometric variability in Pacific salmon: technical demonstration. Canadian Journal of Fisheries and Aquatic Sciences 41: 1150-1 159.

Winter, G.W., C.B. Schreck, and J.D. McIntyre. 1980. Resistance of different stocks and transferrin genotypes of coho salmon, Oncorhynchus kisutch, and steelhead trout, Salmo gairdneri, to bacterial kidney disease and vibriosis. Fishery Bulletin 77:795- 802.

Wishard, L.N., J.E. Seeb, F.M. Utter, and D. Stefan. 1984. A genetic investigation of suspected redband trout populations. Copeia 120-132.

Withler, F.C. 1982. Transplanting Pacific salmon. Canadian Technical Report on Fisheries and Aquatic Science-s, 1079.

Wohlfarth, G.W. 1986. Decline in natural fisheries - a genetic analysis and suggestion for recovery. Canadian Journal of Fisheries and Aquatic Sciences 43:1298-1306.

Wolf, K. 1972. Advances in fish virology: a review 1966-1971. Pages 305-331 in Diseases of Fish: Symposium of the Zoological Society of London 30.

Wood, C.C. 1984. Foraging behaviour of common mergansers (Mergus merganser) and their dispersion in relation to the availability of juvenile Pacific salmon. Doctoral dissertation. University of British Columbia, Vancouver.

Wood, C.C. 1987. Predation of juvenile Pacific salmon by the common merganser (Mergus merganser) on eastern Vancouver Island. I. Predation during the seaward migration. Canadian Journal of Fisheries and Aquatic Sciences 44:941-949.

Wood, J. 1974. Stress as a predisposing factor in fish diseases. U.S. Fish and Wildlife Service, Fish Disease Leaflet 38. 
Woodward, C.C., and R.J. Strange. 1987. Physiological stress responses in wild and hatchery-reared rainbow trout. Transactions of the American Fisheries Society 116:574-579.

Worlund, D.D., R. J. Wahle, and P.D. Zimmer. 1969. Contributions of Columbia river hatcheries to harvest of fall chinook salmon (0ncorhynchus tshcrwytscha). U.S. Fish and Wildlife Service Fisheries Bulletin 67:361-391.

Wunderlich, R. 1982. A review of literature on the feasibility of outplanting hatchery-reared fry, fingerling, and smolts with emphasis on coho and spring chinook salmon outplanting in the Puget Sound region. Unpublished manuscript.

Wydoski, R.S. 1986. Informational needs to improve stocking as a cold- water fisheries management tool. Pages 41-59 in R.H. Stroud, editor. Fish culture in fisheries management. American Fisheries Society, Bethesda, Maryland.

Wydoski, R.S. 1977. Relation of hooking mortality and sublethal hooking stress to quality fishery management. Pages 43-87 in R.A. Barnhart and T.D. Roelofs, editors. Proceedings of the catch-and-release fishing symposium. Humbolt State University, Arcata, California, USA.

Wydoski, R.S., G.A. Wedemeyer, and N.C. Nelson. 1976. Physiological response to hooking stress in hatchery and wild rainbow trout (Salmo gairdneri). Transactions of the American Fisheries Society 105:601-606.

Yamada, S.B., T.J. Mulligan, and S.J. Fairchild. 1979. Strontium marking of hatchery-reared coho salmon (Oncorhynchus kisutch Walbaum). Journal of Fisheries Biology 14:267-275.

Yamamoto, T. 1975. Frequency of detection and survival of infectious pancreatic necrosis virus in a carrier population of brook trout (Salvelinus fontinalis) in a lake. Journal of the Fisheries Research Board of Canada 32:568-573.

Yamamoto, T. 1974. Infectious pancreatic necrosis virus occurrence at a hatchery in Alberta. Journal of the Fisheries Research Board of Canada 31:397-402.

Yamamoto, T., and J. Killistoff. 1979. Infectious pancreatic necrosis virus: quantification of carriers in lake populations during a 6-year period. Journal of the Fisheries Research Board of Canada 36 562-567.

Youngson, A.F., L.P. Hansen, B. Jonsson, and T.F. Naesje. 1989. Effects of exogenous thyroxine or prior exposure to raise water flow on the downstream movement of hatchery-reared Atlantic salmon smolts. Journal of Fish Biology 34:791-797. 
Zaugg, W.S. Freshwater gill $\mathrm{Na}+-\mathrm{K}+$ ATPase activities and migration of coho and fall chinook salmon from selected hatcheries. Page 32 in Prentice et al., editors. A study to assess status of smoltification and fitness for ocean survival of chinook and coho salmon and steelhead. National Oceanic Atmospheric Administration, National Marine Fisheries Service, Seattle.

Zaugg, W.S. 1982. Some changes in smoltification and seawater adaptability of salmonids resulting from environmental and other factors. Aquaculture 28:143-152.

Zaugg, W.S., E. Wold, J.E. Bodle, and J.E. Manning. 1986. Smolt transformation and seaward migration in O-age progeny of adult spring chinook salmon (O ncorhynchus tshuw ytscha) matured early with photoperiod control. Canadian Journal of Fisheries and Aquatic Sciences 43 885-888.

Zinn, J.L., K.A. Johnson, J.E. Sanders, and J.L. Fryer. 1977. Susceptibility of salmonid species and hatchery strains of chinook salmon (Oncorhynchus tshaw ytscha) to infections by Ceratomyxa Shasta. Journal of the Fisheries Research Board of Canada 34:933-936. 


\section{APPENDIX B}

SUPPLEMENTATION QUESTIONNAIRE SUPQUEST 


\section{Classification of Supplementation}

The following material explains the SUPQUEST database. Supplementation planners were asked questions similar or identical to the questions presented below. The responses of these individuals, supplemented by data excerpted from the Integrated System Planning effort, comprise the database.

Some responses were coded as letters, while others were coded as numbers. Numerical coding was employed for variables which were used to create additional, "composite variables".

1. Program Name [field A]

Common name of the supplementation program.

2. Agency [field B]

The agency or agencies implementing the project.

3. Species [field C]

The species and run targeted by the program.

4. Subbasin [field D]

The abbreviation used in System Planning for the targeted subbasin.

5. 1st Proj. Down [field E]

The first mainstem Snake or Columbia River dam dow nstream of the tributary.

6. Streams [field F]

Specific rivers and tributaries targeted.

7. Outplant Number [field G]

The number of artificially propagated fish released per year. 
8. Info Source [field $\mathrm{H}$ ]

Theindividual that supplied thedata.

9. Input Date [field Ij

The date the data was supplied.

10. Implementation Status [field J]

A. ongoing

Ongoing projects have completed construction of all necessary facilities, and are now actually engaged in production: viz., the project is somewhere on the continuum from collecting broodstock to introducing eggs or juveniles to the system.

B. Planned

Planned projects are not currently engaged in production. Rather, they are somew here on a continuum ranging from initiation of a formal planning process to the final stages of conmuction.

11. Longevity [field K]

1. Fiite Duration

The program has a limited life-span, and will be discontinued after accomplishment of a specific goal, such as reestablishing natural production or filly seeding available habitat.

\section{Continuous}

12. Targeted Life Stage [field L]

A. Adults

In this scheme, the adults referred to should be returning hatchery adults used, for example, to colonize previously barren habitat. Conceptually, the release of wild adults in upper reaches or tributaries of the river in which they were trapped is much closer to a passage project than supplementation. Similarly, the release of wild adults in a "non-ancestral" subbasin is strictly a relocation project. In neither case is there a significant element of artificial propagation. 
B. Fertilized Eggs

The distribution of fertilized eggs, in artificial redds or low-tech incubation boxes, in a targeted drainage is a clear attempt to use artificial propagation to increase natural production.

c. Fry and Parr

Fry are defined as juvenile fish that have been free-swimming for no more than several weeks. Parr are defined as juveniles in the late summer or fall of their first year. Fry and purr releases are lumped because both occur in the same general time period, spring and summer.

D. Pre-smolt

Presmolts are juveniles in the late fall and winter preceding their normal spring of outmigration. For species that smolt as I+ 's, pre-smolts will be "late young-of-the-year" or very early yearlings. For species characterized by older smolts, such as steel head or sockeye, pre-smolts may refer to II+ (or conceivably II+) juveniles. All pre-smolt releases occur in the fall and winter.

E. Smolt (continuously reared, conventional conditions)

Smolt are conceived of as being behaviorally and physiologically prepared for outmigration. Arguably, the use of this strategy implies nothing about production bottlenecks in the targeted system; survival of outmigrating smolts is widely believed to be independent of the productive capacity of the natal stream. This category is reserved for "continuously reared "smolts: fish reared artificially from fertilized egg to junctional smolt. This category is also reserved for smolts reared under "conventional" conditions - i.e., in standard raceways or ponds, at standard densities, and without the incorporation of various "naturalistic" features, such as the provision of cover in the rearing vessel, the provision of complex flow patterns, subsurface feeding, predator avoidance conditioning, etc.

F. Smolt (partial rearing conventional conditions)

This category covers both fry and purr trapped in the wild and transferred to a hatchery for rearing to the smolt stage. This strategy applies equally well to drainages with limited summer-rearing or overwintering carrying capacity, and might circumvent the genetic risk associated with incubation and early rearing in an articficial environment.

G. Smolt (continuously reared, natura;istic conditions)

This category covers fish reared from egg to smolt under conditions intended to simulate nature. Naturalistic features can be expected to include one or more of the following: reduced rearing densities: incorporation of natural substrate in rearing vessels; provision of overhead cover and structure in rearing vessels: subsurface 
feeding; exposure to predators and/or predator avoidance conditioning; and prerelease acclimation in a naturalistic vessel.

4. Brood Stock Strategy

a) Origin [field $\mathbf{M}$ ]

A. Local

The broodstock source is a natural population inhabiting the target stream. Note that *target stream " includes specification of stream or\& r: major tributaries are excluded if a mainstem river is the target. This distinction is based on the assumption that a "local stock" is in fact a single genetic entity and not, as is the case within a number of subbasins, a mixture of substocks.

B. Adjacent

The broodstock source originated from a natural population inhabiting a stream within the same subbasin as he targeted stock, but from the targeted stream itself The "default" list of subbasins are the 31 subbasins listed in the Integrated System Plan (ISP). Like the previous category, this level of stock discrimination is primarily intended to reflect relative genetic similarity. However, dissimilarities of habitat and intra-specific life histories within some of the larger subbasins in the region, like Idaho's Salmon River Subbasin, may well require more resolution that the ISP provides. In such cases regional biologists, with the advice of geneticists familiar with Columbia Basin stocks, should subdivide ISP Subbasins to reflect known or suspected genetic similarities more closely.

\section{Distant}

The broodstock source originated from a natural population inhabiting a different subbasin. Again, the \& fault list of subbasins are those cataloged in the ISP. Subdividing larger "geographic subbasins" on the basis of genetic and ecological similarities is an option in this category as well.

b) Annual Stock Selection Criteria [field N]

A. Substock-specific

If the existence and geographic distribution of genetically distinct substocks of a targeted species/run have been determined, it is possible to supplement on a substockspecific basis: viz., to collect broodstock and release progeny only in ancestral tributaries. This category refers to such a policy.

B. Wild/Natural

Only fish spawned and reared naturally within the target subbasin are selected. 
C. Mixed - \% Natural Stock Unknown

Both natural and hatchery-reared individuals from the target subbasin are selected, but the percentage of natural stock used is unknown.

0. Mixed - <33\% Natural Stock

Both natural and hatchery-reared individuals from the target subbasin are selected, with the percentage of natural stock used being less than $33 \%$.

E. Mixed - 34-67\% Natural Stock

Both natural and hatchery-reared individuals from the target subbasin are selected, with the percentage of natural stock used being between 34 and $67 \%$.

F. Mixed - > 67\% Natural Stock

Both natural and hatchery-reared individuals from the target subbasin are selected, with the percentage of natural stock being $>67 \%$.

G. Hatchery

O nly hatchery-reared individuals are selected. The hatchery must be within the subbasin.

H. Hatchery Importation

Individuals are selected from returns to a hatchery in an adjacent or distant subbasin.

I. Wild Stock Importation

Individuals are selected from wild stocks in adjacent or distant subbasins.

c) Run Timing Criteria [field O]

1. Representative

This category and the one that follows describe the relationship between the timing of broodstock collection and the timing of adult returns in the donor population. In representative collection, the proportion of total broodstock collected at any time is equal to the proportion of adult returns in the donor stock expected at that time. This strategy may have genetic implications for species/runs that return over long periods, such as summer steelhead.

3. Selective

Individuals are selected only from a specofic temporal stratum of the return of the donor population.

d) Adult Transportation [field P]

A. Transported

Adults are transported from the collection site to the spawning site. 
B. Not Transported

Adults are spawned at collection site.

e) Adult Holding Conditions [field Q]

1. High survival-(uniform)

Broodstock survival to spawning is uniformly high: survival is high and there is no difference in survival among any subdivision of fish collected for broodstock (e.g., early vs. late).

3. Low or Group-specific Survival

Broodstock survival to spawning is sometimes rather low, with mortalities distributed uniformly through the "take" or concentrated in some portion of it.

f) Maturation treatment [field R]

A. None

Individuals collected for broodstock are not treated (e.g., with hormones) to accelerate or \&lay reproductive maturation.

B. Yes-(delay)

Individuals are treated in some manner to \& lay reproductive maturation.

C. Yes-(accel)

Individuals are treated in some manner to accelerate reproductive maturation.

g) Age Distribution [field S]

A. Age at maturity of broodstock is similar to target stock.

B. Age at maturity of broodstock differs from target stock.

h) Sex Ratio [field T]

1. Sex ratio is similar to target stock.

2. Sex ratio is different from target stock.

i) Domestication [field U]

1. None

No generations, or at most a single generation, within the donor stock has been reared in a hatchery.

$2.2-\mathrm{s}$

Tw 0 to five generations within the donor stock have been reared in a hatchery. 
3. $>5$

More than five generations within the donor stock have been reared in a hatchery.

5, Mating

a) Number of Spawners [field V]

This category is intended to assess the risk of genetic drift in hatchery populations generally know as the 'tandkeffect The minimum number of founders necessary to eliminate risk of the founder effect has not yet been decided on. Thus the numeric categories that follow should be viewed as provisional. Specific numerical categories are, how ever, necessary for the classification survey.

\section{Less than 200}

2. From 200 to 500

1. Above 500

b) Mating Strategies [field W]

This category refers to rules governing the ratio of males to females in artificial spaw ning operations, and largely determines effective population size.

3. No strategy or $>1$ male per female.

2. 1:1 males to females

1. Less than 1:1 (split crosses).

6. Incubation Strategy

a) Containers [field $\mathbf{X}$ ]

A. Stream side

B. Spawning Channels

C. Hatchery Heath Trays

D. Hatchery Baskets

E. Hatchery Gravel Incubators 
b) Health Management [field Y]

1. Extensive

\section{Minimal}

c) Hatching Programming [field Z]

1. Mimics Natural

Incubation water temperatures are manipulated to cause hatching at

approximately the same time as hatching occurs in the target stream.

3. Retarded or accelerated

Incubation water temperatures are manipulated to cause hatching to occur at a time different from the time of natural hatching.

7. Rearing Strategy

a) Ponding-Lot Management [field AA]

3. Mixed

Progeny of fish from direrent stocks or streams are indiscriminately reared together in the same vessels.

1. Separate

Progeny of fish from different stocks or streams are always reared in separate vessels.

b) Grading [field AB]

1. None

2. Yes - Save all

3. Yes - Discard culls

c) Pond Loading [field AC]

The degree to which fish are "crowded" during hatchery rearing is generally expressed by two concepts, "pond loading" and "pond density ". Pond loading denotes the ability of the cultural system to accommodate physiological needs, such as oxygen \& livery and waste removal and is customarily expressed in terms of lb/gpm/in: "pounds of fish per gallons per minute (of water inflow) per inch of fish length. " Respondents are asked to enter the maximum anticipated loading, in Ib\& pm/in. 


\section{d) Pond Density [field AE]}

The degree to which fish are "crow ded" during hatchery rearing is generally expressed by two concepts, "pond loading" and "pond density ". Pond density refers to the ability of the cultural system to meet "psychological " needs for space and is normally expressed in terms of $l b / f^{3} /$ in: "pounds of fish per cubic foot of rearing space per inch of body length. " Respondents are asked to enter the maximum anticipated the maximum anticipated density, in $l b / f t^{3} / i n$.

e) Programmed Growth Rates [field AG]

1. Mimics

Growth programmed to mimic natural rates in target stream.

3. Retarded or accelerated

Growth programmed to be slower or more rapid than natural rates in target stream.

f) Container Sequence [field $\mathrm{AH}$ ]
A. Raceway-Raceway
B. Raceway-Raceway-Acclimation Pond
C. Raceway-Netpen
D. Semi-natural Earthen Pond
E. Concrete Pond
F. Other

g) Pre-release naturalization [field $\mathrm{A}]$ ]

This category \& notes the degree to which supplementation strategies are likely to produce "hatchery Smolts " that mimic wild smolts behaviorally, and physiologically. Pre-release naturalization status ranges from 0 to 3 , with higher numbers indicating a higher degree of "artificiality ".

0 . Life stage released $=$ adults, fry or pre-smolt

1. Liie stage released = naturalisticallyrearedsmolt or "partially reared" smolt (wild fry or pre-smolt captured and reared in a hatchery to the smolt stage). 
2. Conventionally reared smolts which are acclimated before release (volitional or forced release).

3. Conventionally reared smolts released without acclimation.

h) Transport (between rearing containers) [field AJ]

A. Trucked

B. Not trucked

i) Health Management [field AK]

1. Extensive

3. Minimal

8. Release Strategy

a) Location [field AL]

2. Target Stream - Single point

1. Target Stream - Multiple points

3. On station

b) Transported (to release location) [field AM]
A. No
B. Yes

c) Method of Release [field AN]

3. Direct Release (from truck or rearing vessel)

1. Acclimated Release (forced or volitional)

d) Size at Release (relative to natural in target stream) [field AO]

1. Mimics

3. Differs (larger or smaller) 
e) Time of release [field AP]

1. Mimics wild

3. Does not mimic wild (fixed date or other cues)

f) Age at Release [field AQ]

1. Mimics Natural in Target Stream

3. Differs from Natural in Target Stream

g) Relative Stocking Level [field AR]

This is a very approximate and somewhat subjective category that is nevertheless

important. It \& notes the annual stocking level of hatchery fish in smolt equivalents relative to the estimated smolt carrying capacity of the target stream. An admittedly unsatisfactory \& fault value for existing smolt carrying capacity may be found in the ISP.

1. $\mathrm{O}-20 \% \mathrm{~K}$

2. $20-50 \% \mathrm{~K}$

3. $50-100 \% \mathrm{~K}$

4. $>100 \mathrm{~K}$

9. Quality Control Strategy [field AS]
A. Formal
B. Informal
C. None

\section{Classification of Recipient Stocks/Streams}

(Potential and Actual)

1. Hatchery Location [field AT]
A. In target stream subbasin
B. Not in target stream subbasin 


\section{Limiting Factors}

The two questions that follow identify the single most dominant factor limiting natural production in the target stream.

\section{Habitat Quantity [field AU]}

This category identifies the factor that most limits production because so little of it is available.
A. Adult holding/migration
Natural production is limited primarily by the quantity of holding habitat for pre-spaw ning adults (pools, overhead cover, etc.).
B. Spawning
Natural production is limited primarily by a lack of spawning habitat.
C. Incubation

Natural production is limited primarily by the lack of areas affording good conditions for incubation.

D. Summer rearing

$N$ atural production is limited primarily by the lack of areas providing good rearing for fry and parr during the spring and summer.

E. Overwinter rearing

Natural production is limited primarily by the lack of areas providing good overwinter rearing conditions.

F. Smolt to smolt

Natural production is limited primarily by the fact "outmigration corridors" for most local populations in the subbasin entail high in-basin smolt mortalities.

\section{Habitat Quality [field AV]}

This category identifies the factor that most limits production because of generally poor quality.

\section{A. Adult holding/migration}

Natural production is limited primarily by the poor quality of adult holding habitat and/or by poor conditions (insufficient depth, excessive velocities or temperatures, etc.) in the passage corridor. 


\section{B. Spawning}

Natural production is limited primarily by the poor quality of spawning habitat (inappropriately sized or embedded substrate, inappropriate depths or velocities for spawners, etc.).

C. Incubation

Inappropriate flows (low enough to expose or high enough to scour) and/or sedimentation cause the population to be limited by mortality at the incubation (intra-gravel) stage.

D. Summer rearing Inappropriate flows and/or lack of appropriate cover cause natural production to be limited by mortalities occurring betw een the firy and late-summer parr stages.

\section{E. Overwinter rearing}

Inappropriate flows during the fall/winter period (0 ctober-February) poor overwintering habitat or interactions betw een flows and habitat accessibility cause natural production in the targeted stream to be limited by overwinter mortality.

\section{F. Smolt to Smolt}

Inappropriate flows during the primary smolt outmigration period (betwen rearing areas and the mainstem Columbia), natural or man-made impediments to passage, and/or predation losses exacerbated by poor flow or passage conditions cause natural production to be limited by in-basin smolt mortality.

\section{Hatchery Water Source [field AW] •}
A. Surface water
B. Well water
C. Surface and well water
D. Recirculation system

4. System Planning Model Parameters

The following four items are the primary survival and carrying capacity parameters used in the System Planning Model for the targeted stock/populations.

\section{A. Smolt Carrying Capacity [field AX]}


B. Smolt-Smolt Survival Rate [field AY]

C. Egg-Smolt Survival Rate [field AZ]

D. Pre-Spawning Mortality [field BA]

5. Existing Genetic Risk Status

a) Extinction [field BC]

Extinction is the loss of all genetic material originally contained in a population. The extinction event itself may occur for many reasons other than those stemming from genetic problems. In fact, catastrophic demographic and environmental events are usually much more important than genetics until effective population size drops below about 500.

4. Population Extinct

Risk High

2. Risk Medium

1. Risk Low

b) Genetic Drift [field BD]

The variation of allele frequency from one generation to the next as a result of chance events.

4. Population Extinct

3. Risk High

2. Risk Medium

1. Risk Low

c) Genetic Identity

Interbreeding among populations, including hatchery and wild fish of similar origin, can contribute to the loss of the between-population component of genetic diversity and may result in outbreeding depression. This is know $n$ as loss of genetic identity.

4. Population Extinct

3. Risk High 
2. Risk Medium

1. Risk Low

d) Domestication Selection

D omestication selection may occur if egg take, incubation, hatching, rearing and/or release procedures and conditions result in different survival probabilities for genetically distinct individuals or groups (e.g., families) than would obtain under natural conditions. This might occur either through the relaxation of natural selection on features of egg-to-smolt life history, or through the imposition of artificial management conditions that may have selective effects

The effects of domestication selection are more likely to be expressed as differences in performance measured by quantitative traits than as any detectable change in easilymonitored biochemical markers. Consequently, a concerted monitoring eflort will be necessary if this kind of risk is to be quantified and monitored.

4. Population Extinct

3.Risk HIigh

2. Risk Medium

1. Risk Low

6. Existing Adult Production Level [field BF]

4. Absent or marginal

3. $<20 \%$ Production Capacity

$2.2 \& 50 \%$ Production Capacity

1. $>50 \%$ Production Capacity

7. Stock Status Trends [field BG]

1. Population Increasing

2. Population Stable

3. Population Declining

4. Population Extinct or Marginal 
8. Primary Management Objectives [field $\mathbf{B H}$ ]
A. Unspecified
B. Natural production enhancement
C. Harvest augmentation
D. Restoration

9. Potential Harvest Opportunities [field BD]
A. Targeted mixed stock fishery
B. Targeted terminal fishery
C. Both A and B
D. No target fishery opportunity
E. No harvest expected

10. Stock History [field BJ]

1. Endemic

"Endemic" stocks are naturally reproducing populations which have never been supplemented by hatchery-reared fish.

2. Endemic/Hatchery Maintained

"Endemic/hatchery maintained" stocks are naturally reproducing populations which have been supplemented at one time, or are currently being supplemented.

\section{Introduced/Hatchery Maintained/Successful}

This category denotes stocks which now capable of a considerable amount of natural reproduction, but which were established by hatchery outplants. Outplanting may or may not still be occurring.

\section{Introduced/Hatchery Maintained/Marginal}

This category \& notes "stocks" receiving hatchery outplants, but for which natural reproduction is nil or marginal. 


\section{Artificial Selection Risk [Composite Variable, field BK]}

This "composite variable' integrates a number of features relating to the risk of imposing artificial selection on hatchery-reared fish by the way in which broodstock are selected, the conditions under which they are held, the number of fish spaw ned and the way in which they are spawned, and the duration of the project. All of these factors were assigned "point values' ranging from 1 to 3, with higher values indicating a greater probability of artificial selection. The raw score for "artificial selection risk" was calculated as the sum of the points, and has a possible range of 10 (low est risk) to 30 (highest risk). Point assignments are as indicated in Table 1.

\begin{tabular}{|c|c|c|c|}
\hline$\frac{\text { FACTOR }}{\text { Mating strategy [field } \mathbf{W}]}$ & $\begin{array}{l}\text { 3 POINTS } \\
\text { None, or more than } 1 \text { male per } \\
\text { female. }\end{array}$ & $\begin{array}{l}\text { ROINTS } \\
\text { One male per female. }\end{array}$ & $\begin{array}{l}\qquad 1 \text { POINT } \\
\text { Less than } 1 \text { male per female } \\
\text { (split-croseses). }\end{array}$ \\
\hline Project duration [field $\mathbf{K}$ ] & continuous & & Finite \\
\hline $\begin{array}{l}\text { Annual stock selection criteria } \\
\text { [field } \mathbf{N} \text { ] }\end{array}$ & $\begin{array}{l}\text { Hatchery fish, imported } \\
\text { hatchery fish, or imported wild } \\
\text { fish. }\end{array}$ & $\begin{array}{l}\text { Any mixture of local hatchery } \\
\text { and wild fish. }\end{array}$ & Local wild fish only. \\
\hline $\begin{array}{l}\text { Broodstock run timing [field } \\
\text { O] }\end{array}$ & $\begin{array}{l}\text { Fish not selected uniformly } \\
\text { through run. }\end{array}$ & & $\begin{array}{l}\text { Fish selected representatively } \\
\text { through run. }\end{array}$ \\
\hline $\begin{array}{l}\text { Transport of adults to } \\
\text { spawning site [field } P \text { ] }\end{array}$ & & Transported. & Spawned on site. \\
\hline $\begin{array}{l}\text { Adult holding survival [field } \\
\text { Q] and maturation treatment } \\
\text { [field } R \text { ] }\end{array}$ & Low survival, no treatment. & $\begin{array}{l}\text { Low aurvival but appropriate } \\
\text { treatments applied. }\end{array}$ & High survival. \\
\hline $\begin{array}{l}\text { Age diatribution of broodstock } \\
\text { fish relative to targeted stock } \\
\text { [field S] }\end{array}$ & $\begin{array}{l}\text { Broodstock fish differ from } \\
\text { target. }\end{array}$ & $\begin{array}{l}\text { Age distribution of targeted } \\
\text { stock unknown. }\end{array}$ & $\begin{array}{l}\text { Age distribution of broodstock } \\
\text { fish and targeted stock } \\
\text { identical. }\end{array}$ \\
\hline $\begin{array}{l}\text { Sex ratio, broodstock fish and } \\
\text { targeted stock [field T] }\end{array}$ & Broodstock differs from target. & $\begin{array}{l}\text { Sex ratio of targeted stock } \\
\text { unknown. }\end{array}$ & $\begin{array}{l}\text { Sex ratio of broodstock fish } \\
\text { and targeted stock identical. }\end{array}$ \\
\hline $\begin{array}{l}\text { Domestication of donor stock } \\
\text { [field } \mathbf{U} \text { ] }\end{array}$ & $\begin{array}{l}>5 \text { generations of hatchery } \\
\text { impact. }\end{array}$ & $\begin{array}{l}\text { 2-5 generations of hatchery } \\
\text { impact. }\end{array}$ & $\begin{array}{l}<2 \text { generations of hatchery } \\
\text { impact. }\end{array}$ \\
\hline $\begin{array}{l}\text { Number of spawners in } \\
\text { hatchery mating protocol } \\
\text { Ifield Vl }\end{array}$ & $<200$ & $200-500$ & $>500$ \\
\hline
\end{tabular}

RASP Summary Report Series, Part V: Appendix B: Supplementation Questionnaire-SUPQUEST 


\section{Rearing Risk [Composite Variable, field BL]}

This "composite variable" integrates a number of features assumed to relate to the risk of impairing adaptive behavior, undermining health, putting adverse competitive or predatory pressures on wild conspecifics, and imposing artificial selection pressures by rearing practices. The following rearing practices were considered: health management during incubation and rearing; mixed/separate pond management; hatching and growth programming: and the degree to which fish are reared under natural or "naturalistic" conditions. All of these contributing factors were assigned point values ranging from 0 to 3 , with higher values indicating a greater presumptive risk. The raw score for "rearing risk" was calculated as the sum of the points, and can range from 8 (lowest risk) to 27 (highest risk). Point assignments are as indicated in Table 2.

Table 2. Point values for estimating "rearing risk"

\begin{tabular}{|c|c|c|c|c|}
\hline \begin{tabular}{l}
\multicolumn{1}{c}{ FACTOR } \\
Incubation health \\
management [field $\mathbf{Y}$ ]
\end{tabular} & $\begin{array}{l}\text { POINTS } \\
\text { Minimal. }\end{array}$ & 2 PONTS & $\begin{array}{l}1 \text { POINT } \\
\text { Extensive. }\end{array}$ & O PONT \\
\hline $\begin{array}{l}\text { Rearing health } \\
\text { management [field } \mathbf{A K} \text { ] }\end{array}$ & Minimal & & Extensive. & \\
\hline $\begin{array}{l}\text { Pond lot management } \\
\text { [field AA] }\end{array}$ & Mixed. & & Separate. & \\
\hline $\begin{array}{l}\text { Hatching timing [field } \\
\text { Z] }\end{array}$ & Altered. & & Mimics wild. & \\
\hline Grading [fiold $\mathrm{AB}$ ] & Yes, with culling. & Yer, but U Uaved. & No grading. & \\
\hline $\begin{array}{l}\text { Pond loadii (rank) } \\
\text { [field AD] }\end{array}$ & Higher third of range. & Middle thind of range. & Lower third of range. & \\
\hline $\begin{array}{l}\text { Pond density (rank) } \\
\text { [field AF] }\end{array}$ & Higher third of range. & Middle thind of range. & Lower third of range. & \\
\hline $\begin{array}{l}\text { Growth programming } \\
\text { [field } \mathbf{A} \text { G] }\end{array}$ & Differs from natural. & & Mimics natural. & \\
\hline $\begin{array}{l}\text { Pre-release } \\
\text { naturalization [field } \\
\text { AI] }\end{array}$ & $\begin{array}{l}\text { Conventionally-reared, } \\
\text { unacclimated smolts. }\end{array}$ & $\begin{array}{l}\text { Conventionally-roared, } \\
\text { acclimated smolts. }\end{array}$ & $\begin{array}{l}\text { Acclimated } \\
\text { "naturalistically-reared" } \\
\text { smolts. }\end{array}$ & $\begin{array}{l}\text { Release before molt } \\
\text { stage (i.e., adult, fry } \\
\text { or pre-smolt releases). }\end{array}$ \\
\hline
\end{tabular}

\section{Release Risk [Composite Variable, field BM]}

This "composite variable " integrates a number of features relating to the presumed risks associated with the conditions under which fish are released,,; specifically, the risk of exposing hatchery-reared fish to elevated predatory or environmental mortality by releasing them before they have recovered from the stress of transport; risks of hatchery/wild competition and/or predation associated with releases concentrated in 
space; and the risk of imposing adverse competitive or predatory pressures on wild conspecifics by releasing hatchery fish that differ from wild fish in size or age.

The following release conditions were considered: on-station vs target-stream releases at one or a number of points; direct vs acclimated release; size at release mimics wild vs size at release differs from wild; age at release mimics wild vs age at release differs from wild; and release timing coincident with wild outmigration timing vs release timing not coincident with wild outmigration.

All of these factors were assigned point values ranging from 1 to 3 , with higher values indicating greater presumptive risk. The raw score for "release risk" was calculated as the sum of the points, and can range from 5 (lowest risk) to 15 (highest risk). Point assignments are as indicated in Table 3.

\begin{tabular}{||l|l|l|l||}
\hline \hline \multicolumn{1}{||c||}{ Table 3. Point values for estimating "release risk" } \\
\hline \hline $\begin{array}{l}\text { Release point [field } \\
\text { AL] }\end{array}$ & \multicolumn{1}{|c||}{$\begin{array}{c}\text { 3 POINTS } \\
\text { On station. }\end{array}$} & $\begin{array}{l}\text { 2 POINTS } \\
\text { In target stream, single } \\
\text { point. }\end{array}$ & $\begin{array}{l}\text { 1 POINT } \\
\text { Multiple points in } \\
\text { target stream. }\end{array}$ \\
\hline Acclimation [field AN] & None. & & $\begin{array}{l}\text { Pre-release acclimation } \\
\text { occurs. }\end{array}$ \\
\hline $\begin{array}{l}\text { Size at release [field } \\
\text { AO] }\end{array}$ & Diffem from wild. & & Mimics wild. \\
\hline $\begin{array}{l}\text { Timing of relesse } \\
\text { [field } \text { AP] }\end{array}$ & $\begin{array}{l}\text { Fixed or not coincident } \\
\text { with wild outmigration. }\end{array}$ & & $\begin{array}{l}\text { Coincident with wild } \\
\text { outmigration. }\end{array}$ \\
\hline $\begin{array}{l}\text { Age at release [field } \\
\text { AQ }\end{array}$ & Diffem from wild. & & Same as wild. \\
\hline \hline
\end{tabular}

14. Adult Upstream Dam Survival [field BN]

This parameter, excerpted from the System Planning Model database, estimates the cumulative survival of adults in passing the mainstem Columbia and Snake Dams separating the "home tributary " from the ocean.

\section{Adult Survival in Terminal Fishery [field BO]}

This parameter, excerpted from the System Planning Model database, estimates the survival of adults in passing through the terminal fishery.

16. Pre-spawning Survival [field BP]

This parameter, excerpted from the System Planning Model database, estimates the survival of adult spawners after passing through the terminal fishery. 


\section{Adult Survival Index [field BQ]}

The cumulative survival of adults in moving past mainstem dams, passing through the terminal fishery and "absorbing " pre-spawning mortality... calculated as the product of (D am survival), (terminal fisheries survival) and (pre-spaw ning survival).

18. Mean Fecundity Per Adult [field BR]

This parameter is based on data contained in the System Planning Model database, and represents the mean number of eggs per adult. It is intended to be an index of reproductive capacity, as both the mean fecundity of females and the mean fraction of spawners that are female increase its value. It was calculated as follows:

$$
M F P A=\sum_{i=j}^{i=l}\left(\text { frac }_{i}\right)\left(\text { fracfemales }_{i}\right)\left(\text { Fec }_{i}\right)
$$

where MFPA = mean fecundity per adult;

$\mathrm{i}=$ age, which ranges from the earliest age of sexual maturity, $\mathrm{j}$, to the latest, 1 ;

$\left(\right.$ frac $\left._{j}\right)=$ the mean fraction of spawners age $i$;

(frac females $\left.s_{i}\right)=$ the fraction of females age $i$; and $\left(\mathrm{Fec}_{\mathrm{i}}\right)=$ the mean fecundity of females age i.

19. Limiting Factor, Quantity [field BS]

Respondents to the SUPQUEST questionnaire listed one of the following as the most important factor limiting natural production from the standpoint of habitat quantity: adult holding/passage, spawning habitat, incubation conditions, summer rearing habitat, overwinter rearing habitat, and in-basin smolt passage/survival. $0 \mathrm{n}$ the basis of the factors identified (and not identified), these responses were lumped according to which of the following elementary components of the freshwater life cycle were considered a limiting factor: spaw ning related; summer rearing related; overwinter rearing related. and smolt-to-smolt survival.

1. Spawning related

2. Summer rearing

3. Overwinter rearing

4. Smolt-to-smolt survival 
20. Limiting Factor, Quality [field BT]

Respondents to the SUPQUEST questionnaire listed one of the following as the most important factor limiting natural production from the standpoint of habitat quality: adult holding/passage, spaw ning habitat, incubation conditions, summer rearing habitat, overwinter rearing habitat, and in-basin smolt passage/survival. $0 \mathrm{n}$ the basis of the factors identified (and not identified), these responses were lumped according to which of the following elementary components of the freshwater life cycle were considered a limiting facror: spawning related; summer rearing related; overwinter rearing related; and molt-to-molt survival.

1. Spawning related

2. Summer rearing

3. Overwinter rearing

4. Smolt-to-smolt survival

21. Smolt Survival Through Snake/Columbia [field BU]

This parameter was excerpted from the System Planning M odel database, and represents the estimated survival of smolts from the mouth of their natal river to the Columbia below Bonneville Dam.

22. Smolt Survival Index [field BV]

This parameter estimates the cumulative survival of smolts through their natal subbasin and the Snake/Columbia to a point below Bonneville Dam. It was calculated as the product of smolt-to-smolt survival and smolt survival through the Snake/Columbia.

23. General Stock Status [Composite Variable, field BW]

This *composite variable" integrates a number of features relating to the demographic and genetic "health " of the target population. The factors considered included: extinction risk; genetic drift risk, risk of loss of genetic identity; domestication risk; population trend: and stock status (with respect to adult carrying capacity). All of these factors were assigned "point values" ranging from 1 to 3 , with higher values indicating a "lower" or "more imperiled " target population. The raw score for "artificial selection risk" was calculated as the sum of the points, and has a possible range of 6 (most healthy) to 18 (least healthy). Point assignments are as indicated in Table 4.

RASP Summary Report Series. Part V: A ppendiX B: Supplementation Questionnaire-SUPQUEST

December, 1992 /Page 21 


\begin{tabular}{|c|c|c|c|}
\hline$\frac{\text { F a c tor }}{\text { Extinction risk [field BB] }}$ & $\begin{array}{l}3 \text { Points } \\
\text { High. }\end{array}$ & $\begin{array}{l}2 \text { Points } \\
\text { Medium. }\end{array}$ & 1 Points \\
\hline $\begin{array}{l}\text { Risk of genetic drift [field } \\
\text { BQ }\end{array}$ & High. & Medium. & Low. \\
\hline $\begin{array}{l}\text { Risk of loss of genetic } \\
\text { identity [field BD] }\end{array}$ & High. & Medium. & Low. \\
\hline Domestication risk [field BE] & High. & Medium. & L $0 \mathrm{~W}$. \\
\hline Population trend [field BF] & Declining. & Stable. & Increasing. \\
\hline $\begin{array}{l}\text { Stock status [field BG] and } \\
\text { maturation treatment [field RI }\end{array}$ & $<20 \%$ adult carrying capacity. & $\begin{array}{l}20.50 \% \text { adult carrying } \\
\text { capacity. }\end{array}$ & $\begin{array}{l}>50 \% \text { adult carrying } \\
\text { capacity. }\end{array}$ \\
\hline
\end{tabular}

